\title{
A Healthcare Failure Mode and Effect Analysis on the Safety of Secondary Infusions
}

\author{
by
}

Ying Kwan Yue

\begin{abstract}
A thesis submitted in conformity with the requirements for the degree of Master of Health Sciences

Institute of Biomaterials and Biomedical Engineering University of Toronto
\end{abstract}

(C) Copyright by Ying Kwan Yue 2012 


\title{
A Healthcare Failure Mode and Effect Analysis on the Safety of Secondary Infusions
}

\author{
Ying Kwan Yue \\ Master of Health Sciences \\ Institute of Biomaterials and Biomedical Engineering \\ University of Toronto \\ 2012
}

\begin{abstract}
Secondary infusions are a common and convenient method to administer intermittent infusions unattended through a single IV access using infusion pump technology. Previous studies have indicated that clinicians have a high frequency of committing operation errors while administering secondary infusions, which can cause patient harm. The purpose of this study was to evaluate the safety of secondary infusion practice by identifying and analyzing potential failure modes when delivering secondary infusions on five different smart infusion pumps. Healthcare Failure Mode and Effect Analysis (HFMEA) was used to prioritize potential failure modes that are considered high-risk for each pump. Results showed that four of the five pumps were not able to mitigate physical set-up errors. As well, each pump contributed differently to programming errors due to difference in interface design. Recommendations from this study focused on outlining desired infusion pump features and mitigation strategies to help alleviate high-risk secondary infusion failure modes.
\end{abstract}




\section{Acknowledgments}

I would like to take this opportunity to extend my appreciation to a number of people, more than can be named here, for their support and assistance over the course of this research project.

First and foremost, I would like to extend my gratitude to my co-supervisors, Dr. Tony Easty and Dr. Patricia Trbovich. Your guidance and continuous encouragement not only shaped my work, but also helped me grow as a person and a researcher. The countless hours you spent on reviewing my work and providing valuable feedback has been greatly appreciated. It was a pleasure working with you.

I would also like to thank my thesis committee, Dr. Kim Vicente and Dr. Chris Parshuram, for your expertise and creative ideas that always led to fascinating discussions in our meetings. Thank you, Dr. Birsen Donmez, for your time in serving as my external examiner.

I am deeply indebted to Mark Fan and Andrea Cassano-Piché for all the help on guiding the HFMEA process as well as the HFMEA ratings. It was a pleasure working with such dedicated individuals. As well, I would like to thank the Health Technology Safety Research Team for your commitment and enthusiasm towards patient safety. It has been inspiring to witness your passion in improving healthcare and it has been an honor to be part of your team.

I would also like to acknowledge Health Quality Ontario for funding this research project.

Lastly, my deepest gratitude goes to my friends and family for all the support, motivation, and understanding in the last two years. Special thanks to:

Paulo, for always showing encouragement and being there when I need it the most. You're the one person who I can share anything with, knowing that you'll always understand me and brighten my day.

Vick, for your patience and understanding for the past two years, sharing all my best and worst moments with me. Thanks for giving me a sense of family in this unfamiliar place.

Archana, Emily, and Lata for listening to all my updates and constantly motivating me through this Clinical Engineering journey. I wouldn't have made it without you! 


\section{Table of Contents}

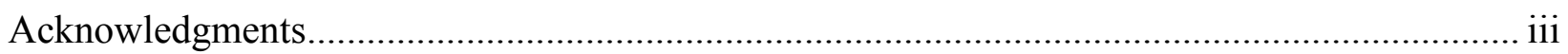

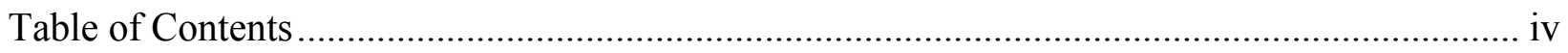

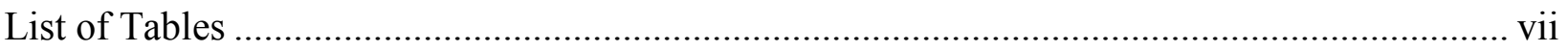

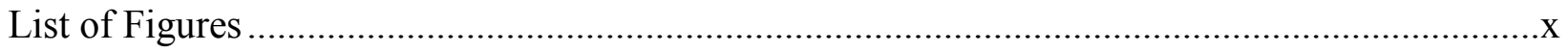

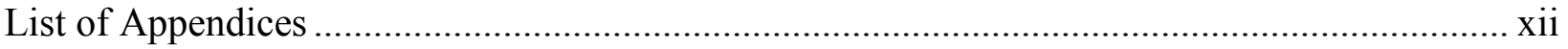

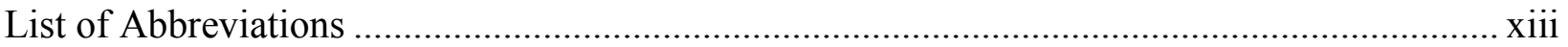

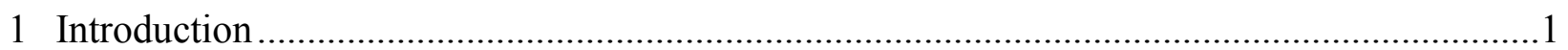

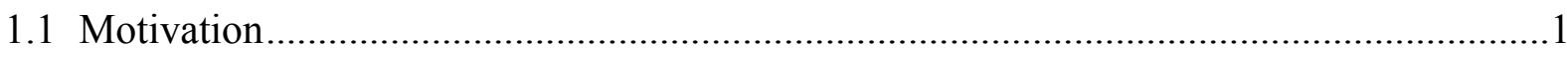

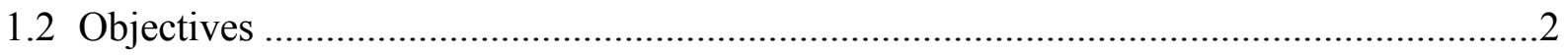

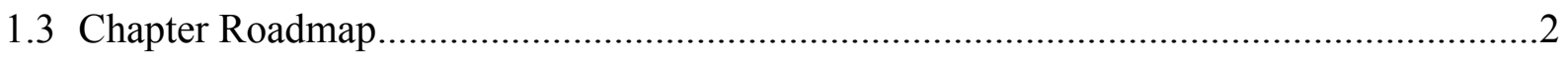

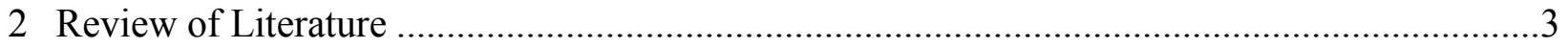

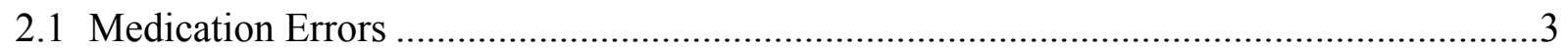

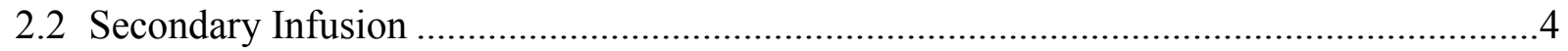

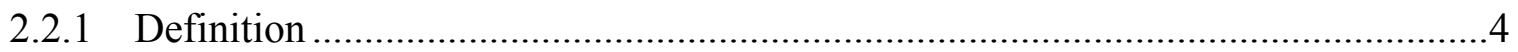

2.2.2 Secondary Infusion Administration Process ……………………..........................

2.2.3 Secondary Infusion Errors ..............................................................................

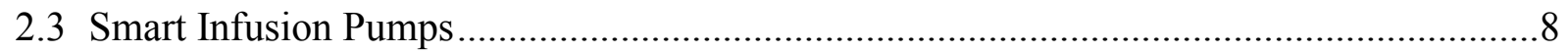

2.4 Failure Mode and Effect Analysis in Healthcare ..............................................................10

2.4.1 Failure Mode and Effect Analysis (FMEA) ..........................................................11

2.4.2 Healthcare Failure Mode and Effect Analysis (HFMEA) …………………….....12

2.4.3 Methods that Help Inform HFMEA ......................................................................13

2.4.4 HFMEA versus Other Risk Assessment Tools in Healthcare ................................15

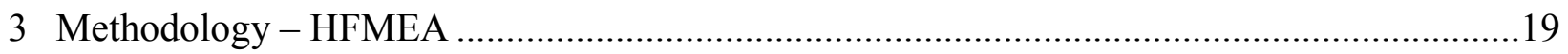

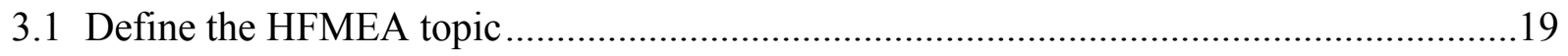


3.1.1 Smart Infusion Pump Selection ................................................................19

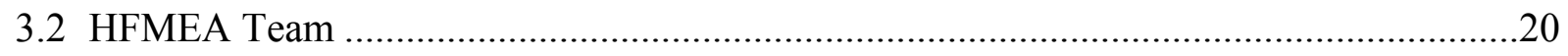

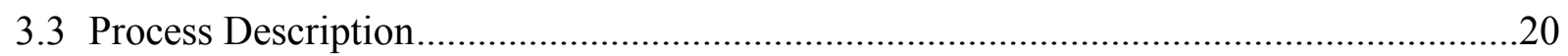

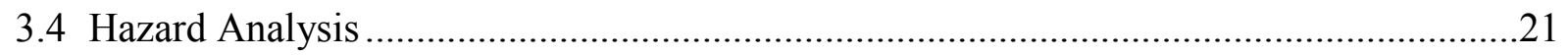

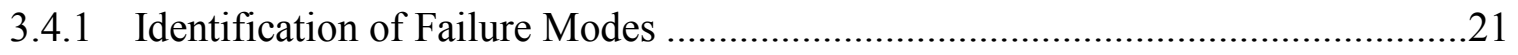

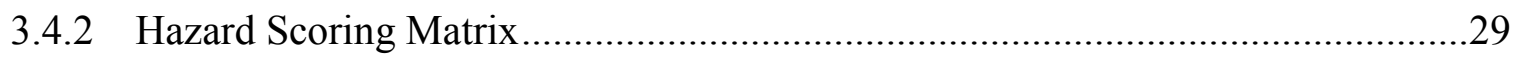

3.4.3 Decision Tree Analysis .....................................................................................

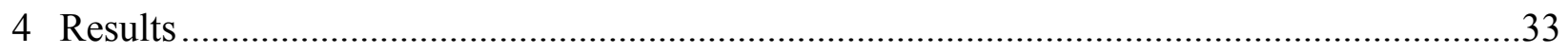

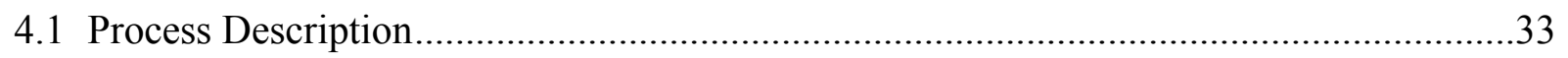

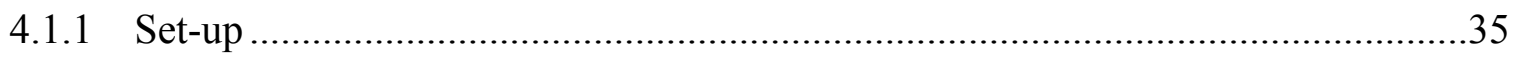

4.1.2 Activation ................................................................................................4

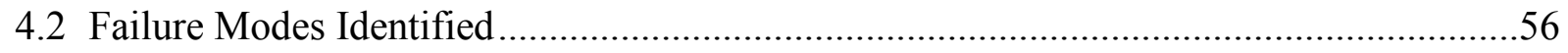

4.2.1 Literature Search ........................................................................................56

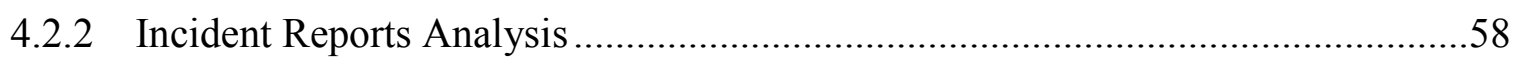

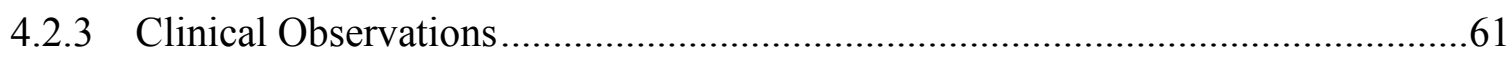

4.2.4 Brainstorming with HFMEA Team ..................................................................63

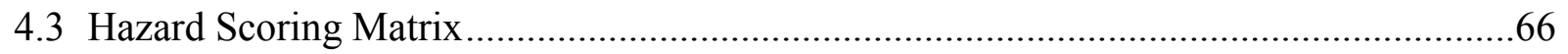

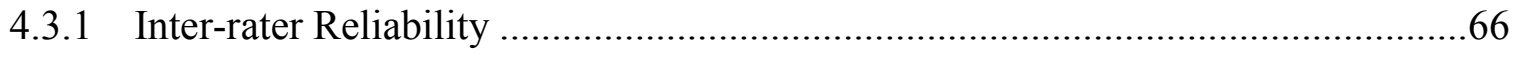

4.4 Decision Tree Analysis ................................................................................................67

4.4.1 Comparison of Smart Infusion Pumps: Set-up Errors .............................................67

4.4.2 Comparison of Smart Infusion Pumps: Activation Errors .......................................71

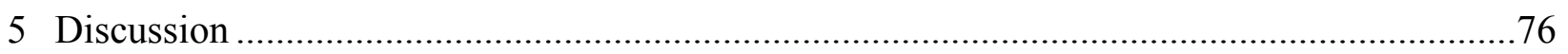

5.1 Comparison of Smart Infusion Pumps ..........................................................................

5.1.1 Set-up Errors ..............................................................................................

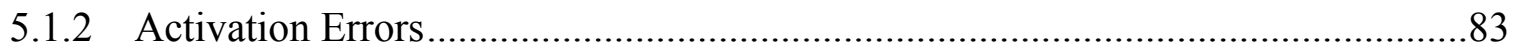

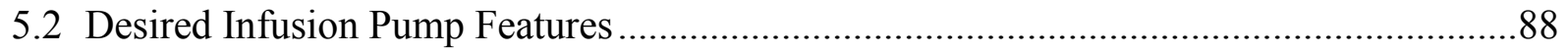




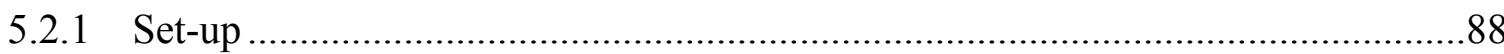

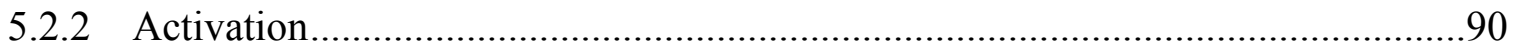

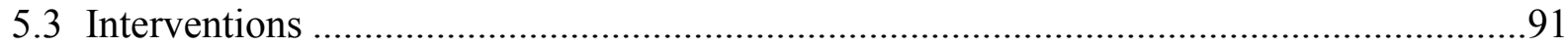

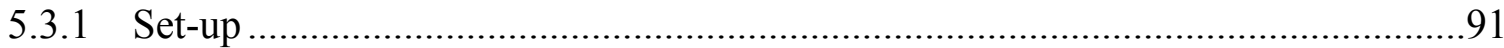

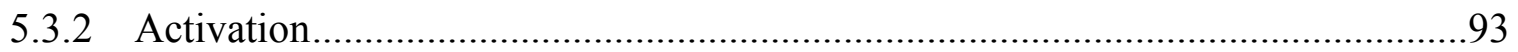

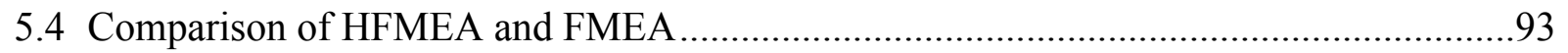

5.5 Relevancy of Methods Used to Identify Failure Modes ....................................................95

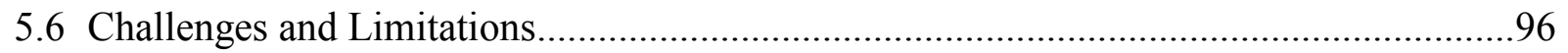

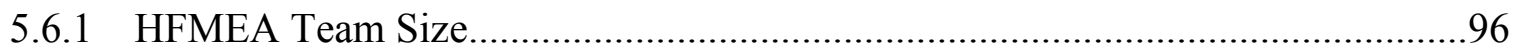

5.6.2 Secondary Infusion Scenario and Assumptions......................................................96

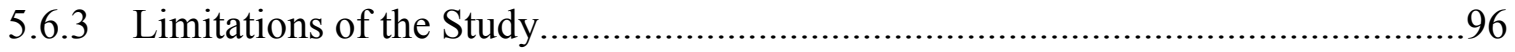

5.6.4 Limitations on Probability Ratings and Severity Ratings of HFMEA ……….......97

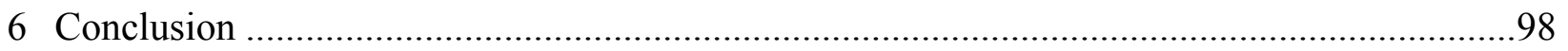

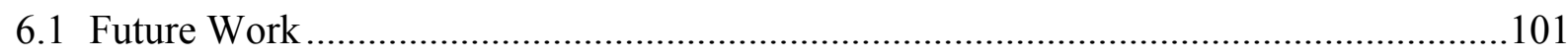

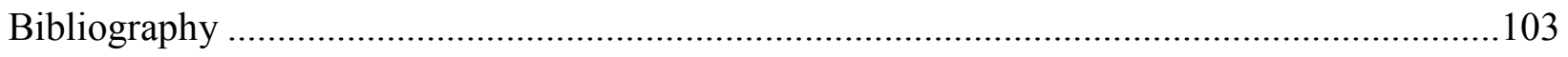

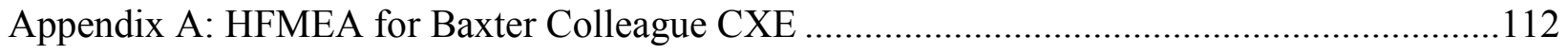

Appendix B: HFMEA for B. Braun Infusomat Space ………...................................................119

Appendix C: HFMEA for Cardinal Health Alaris PC ...............................................................126

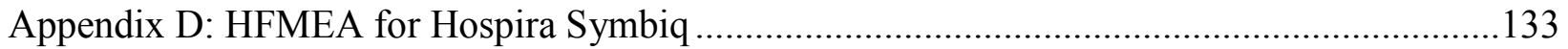

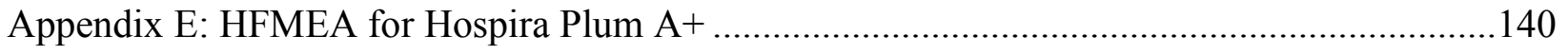

Appendix F: HFMEA for Hospira Plum A+ (Robustness Analysis)..........................................146 


\section{List of Tables}

Table 1: Medication errors at different phases of the medication delivery system (Leape et al., 1995)

Table 2: Smart infusion pumps cost comparison (ECRI Institute, 2007) ................................ 9

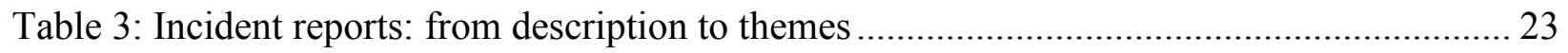

Table 4: Hospitals and units where field observations were conducted .................................. 24

Table 5: Clinical observations data collection sheet example ............................................... 25

Table 6: Hazard Scoring Matrix (DeRosier \& Stalhandske, 2002) .......................................... 29

Table 7: Severity Ratings (DeRosier \& Stalhandske, 2002).............................................. 29

Table 8: Probability Ratings (DeRosier \& Stalhandske, 2002) ............................................ 30

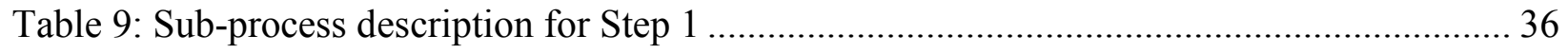

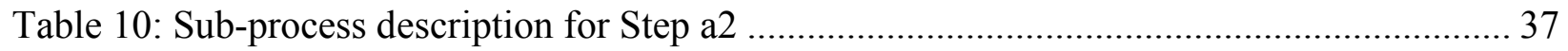

Table 11: Sub-process description for Step a3/b2 - Baxter Colleague CXE, B. Braun Infusomat Space, Cardinal Health Alaris PC, and Hospira Symbiq .................................................... 38

Table 12: Sub-process description for Step a3/b2 - Hospira Plum A+ ................................... 38

Table 13: Sub-process description for Step a4/b3 - Baxter Colleague CXE, B. Braun Infusomat Space, Cardinal Health Alaris PC, and Hospira Symbiq ..................................................... 39

Table 14: Sub-process description for Step a4/b3 - Hospira Plum A+ .................................. 39

Table 15: Sub-process description for Step b4 - Baxter Colleague CXE, B. Braun Infusomat

Space, Cardinal Health Alaris PC, and Hospira Symbiq .................................................. 41

Table 16: Sub-process description for Step b4 - Hospira Plum A+..................................... 42

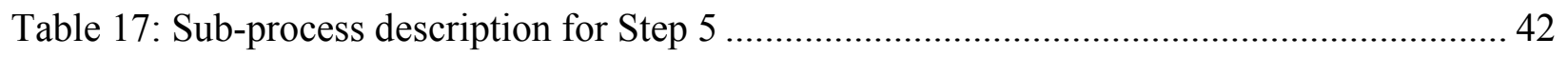


Table 18: Comparison of secondary infusion programming between smart infusion pumps ...... 51

Table 19: Sub-process description for Step 7 - Baxter Colleague CXE, B. Braun Infusomat Space, Cardinal Health Alaris PC, and Hospira Plum A+ ..................................................... 52

Table 20: Sub-process description for Step 7 - Hospira Symbiq............................................. 52

Table 21: Sub-process description for Step 8 - Baxter Colleague, B. Braun Infusomat Space, Cardinal Health Alaris PC 53

Table 22: Sub-process description for Step 8 - Hospira Symbiq ............................................ 53

Table 23: Sub-process description for Step 8 - Hospira Plum A+ ....................................... 53

Table 24: Failure modes identified from the literature - Set-up.......................................... 56

Table 25: Failure modes identified from the literature - Activation ...................................... 57

Table 26: Issues identified from relevant incident reports and numbers of incidents associated with each issue - Set-up.

Table 27: Issues identified from relevant incident reports and numbers of incidents associated with each issue - Activation

Table 28: Potential failure modes identified through clinical observations - Set-up ................ 62

Table 29: Potential failure modes and potential effects identified through clinical observations Activation. 62

Table 30: Potential failure modes and potential effects identified through brainstorming - Set-up

Table 31: Potential failure modes and potential effects identified through brainstorming Activation. 65

Table 32: Kappa values for severity and probability ratings for each smart infusion pump examined 
Table 33: Comparison of total number of failure modes and total number of high-risk failure

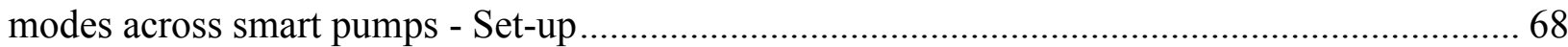

Table 34: List of high-risk failure modes and failure mode types - Set-up .................................. 70

Table 35: Comparison of total number of failure modes and total number of high-risk failure

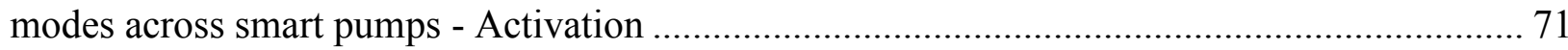

Table 36: List of high-risk failure modes and failure mode types - Activation............................. 73 


\section{List of Figures}

Figure 1: Secondary infusion set-up (Carefusion Corporation, 2011) .................................... 5

Figure 2: Secondary infusion administration process flow diagram .................................. 6

Figure 3: Difference in secondary infusion set-up between most smart infusion pumps and the

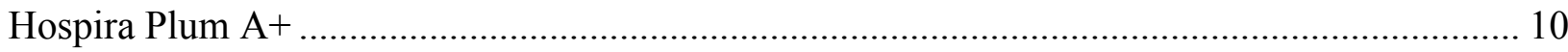

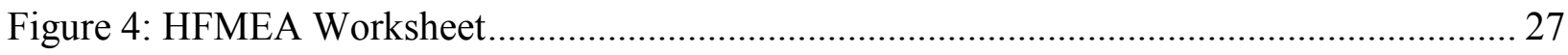

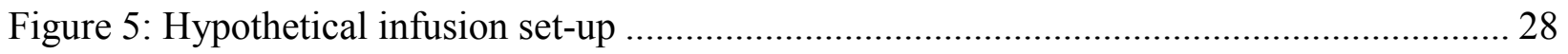

Figure 6: Decision Tree from VA's HFMEA model (DeRosier \& Stalhandske, 2002)............. 32

Figure 7: Secondary infusion administration process flow diagram ................................... 34

Figure 8: Example of conversion calculation when programming secondary infusions ............ 45

Figure 9: Workflow diagram for programming a secondary infusion on the Baxter Colleague

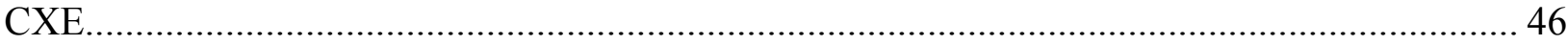

Figure 10: Workflow diagram for programming a secondary infusion on the B. Braun Infusomat

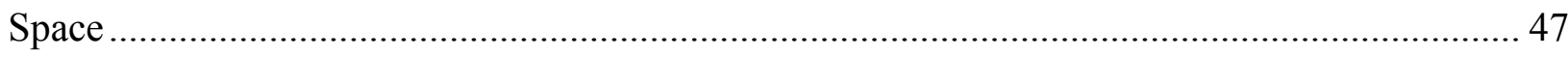

Figure 11: Workflow diagram for programming a secondary infusion on the Cardinal Health

Alaris PC

Figure 12: Workflow diagram for programming a secondary infusion on the Hospira Symbiq.. 49

Figure 13: Workflow diagram for programming a secondary infusion on the Hospira Plum A+ 50

Figure 14: Comparison of total number of high-risk failure modes associated with each smart pump - Set-up.

Figure 15: Comparison of total number of high-risk failure modes associated with each smart

pump - Activation 
Figure 16: Baxter primary infusion set ....................................................................... 77

Figure 17: Example of secondary infusion set from Hospira ................................................ 78

Figure 18: B. Braun Infusomat Space primary infusion set............................................... 78

Figure 19: Cardinal Health Alaris PC primary infusion set.............................................. 78

Figure 20: Hospira Symbiq primary infusion set........................................................... 79

Figure 21: Hospira Plum A+ primary infusion set ........................................................ 79

Figure 22: Comparing secondary infusion screens between Hospira Symbiq (left) and B. Braun

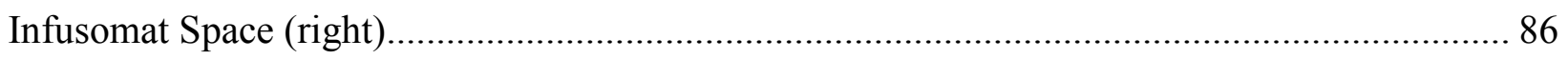




\section{List of Appendices}

Appendix A: HFMEA for Baxter Colleague CXE .......................................................... 112

Appendix B: HFMEA for B. Braun Infusomat Space ….....................................................119

Appendix C: HFMEA for Cardinal Health Alaris PC ........................................................126

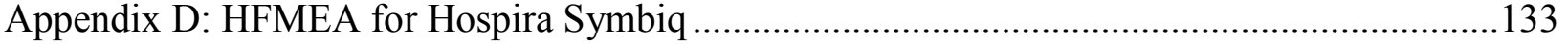

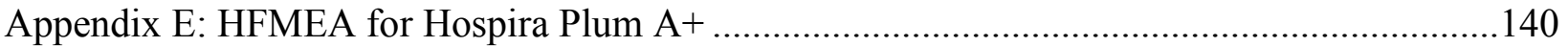

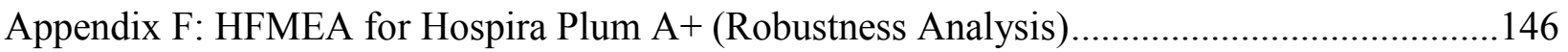




\section{List of Abbreviations}

CCP - Critical Control Point

CPOE - Computerized Physician Order Entry

CVICU - Cardiovascular Intensive Care Unit

D5W $-5 \%$ Dextrose in Water Solution

DEHP - Di(2-ethylhexyl)phthalate

DERS - Dose Error Reduction Systems

EHR - Electronic Health Record

FDA - Food and Drug Administration

FMEA - Failure Mode and Effect Analysis

HACCP - Hazard Analysis and Critical Control Point

HFMEA - Healthcare Failure Mode and Effect Analysis

ICU - Intensive Care Unit

IOM - Institute of Medicine

IV - Intravenous

JCAHO - Joint Commission on Accreditation of Healthcare Organizations

MAUDE - Manufacturer and User Facility Device

MSICU - Medical/Surgery Intensive Care Unit

NASA - National Aeronautics and Space Administration 
NCPS - National Center for Patient Safety

RCA - Root Cause Analysis

RPN - Risk Priority Number

VA - Department of Veterans Affairs 


\section{Chapter 1 Introduction}

\section{Introduction}

\subsection{Motivation}

Research has shown that adverse drug events are a significant cause of medical injuries (Hicks \& Becker, 2006). Thirty-four percent of preventable adverse medication errors have been identified as occurring during drug administration at the point-of-care (Bates, Cullen, \& Laird, 1995). Since an estimated $90 \%$ of hospitalized patients receive medication via intravenous (IV), IV infusions have been identified as the most frequent contributors to administration errors (Husch et al., 2005).

Patients in the hospital, particularly in critical care environments, often require multiple IV infusions (Burdeu et al., 2006). One of the methods to infuse multiple IV drugs is the use of secondary infusions. Secondary infusions, or piggybacks, are a common and convenient method to administer intermittent infusions through a single IV access using infusion pump technology (Nunnally \& Bitan, 2006). This practice allows clinicians to deliver multiple intermittent drugs through an already established access point, limiting the number of needle insertions for patients. As well, clinicians can attend to other responsibilities when delivering secondary infusions and return at their convenience since the secondary infusion automatically reverts back to the primary infusion once the infusion is complete (Nunnally \& Bitan, 2006). To set up a secondary infusion, the secondary tubing is "piggybacked" onto the primary infusion line at the y-site port, upstream from the infusion pump but below the back-check valve. The secondary bag is hung at an elevation higher than the primary bag. As a result, the hydrostatic pressure produced causes the back-check valve to close off the primary infusion while allowing the secondary bag to infuse. Once the secondary infusion is complete, the primary infusion resumes as the back-check valve automatically opens (Nunnally \& Bitan, 2006).

Previous studies have indicated that clinicians have a high frequency of committing operation errors while administering secondary infusions, which have led to adverse events (ISMP Canada, 2003, 2005; Nunnally \& Bitan, 2006; Trbovich et al., 2010). For example, some common errors include bag mis-alignment, forgetting to open the roller clamp on the secondary tubing, and 
programming errors. Although the types of error are frequently reported (ISMP Canada, 2003, 2005; Nunnally \& Bitan, 2006; Trbovich et al., 2010), there is little data on the causes of the errors, as well as how smart infusion pumps may mitigate these errors, if at all.

\subsection{Objectives}

The purpose of this thesis project was to evaluate the safety of secondary infusion practice by identifying and analyzing potential failure modes when delivering secondary infusions, which may include physical set-up and programming of the infusion pump. As well, this project aimed to suggest best practices and outline desired pump features that would help manufacturers design safer systems, and nurses deliver secondary infusions safely.

\subsection{Chapter Roadmap}

In Chapter 2 of this thesis, a review of the literature on the secondary infusion administration process, the types of errors associated with secondary infusions and how the design of smart infusion pumps contribute to the safety of secondary infusions is presented. As well, the use of Healthcare Failure Mode and Effect Analysis (HFMEA) as a risk assessment tool compared to other risk assessment tools is presented. With this background information, Chapter 3 presents the HFMEA methodology used to evaluate the safety of secondary infusions, including various sources used to identify potential failure modes. Chapter 4 then presents the results from the HFMEA, reporting on the high-risk failure modes identified for the secondary infusion administration process. In Chapter 5, high-risk failure modes identified are described in detail and possible interventions or mitigation strategies are proposed. Lastly, Chapter 6 concludes the thesis with the implications that the findings have for the safety of secondary infusion administration, as well as directions for future work. 


\section{Chapter 2 \\ Review of Literature}

\section{Review of Literature}

\subsection{Medication Errors}

In 2000, the Institute of Medicine (IOM) report, To Err is Human: Building a Safer Healthcare System, concluded that between 44,000 to 98,000 people die annually in the United States due to preventable medical errors (Institute of Medicine, 1999). Even when considering the lower estimate, deaths in hospitals due to preventable adverse events exceed the deaths attributable to motor vehicle accidents, breast cancer, or AIDS (Institute of Medicine, 1999). Medicationrelated error was identified to be one of the most common types of error, and was estimated to account for about 7,000 deaths a year. In 2004, Baker et al published a similar adverse events study on Canadian hospitals. The study estimated an annual rate of 9,000 to 24,000 deaths due to preventable adverse events, with medication errors (drug- or fluid-related events) being the second leading cause of error. Furthermore, the IOM estimated that over 1.5 million preventable medication errors occur each year in the United States, with approximately one medication error occurring per patient per day in a hospital (Institute of Medicine, 2007). As a result, these reports have raised awareness of the need to improve patient safety over the last decade, particularly in the context of medication safety.

The medication delivery system can be broken down into four stages: prescribing, transcribing, dispensing, and administering. Table 1 (Leape et al., 1995) shows the percentage of medication errors that occur in each phase of the medication delivery process, with prescribing and administering phases having the highest rate of medication errors. If a medication error occurs in the initial phase of the medication delivery system, there is a greater chance that other healthcare professionals from later phases would intercept the error before reaching the patient. However, if a medication error occurs in the later phases, there is less chance for other healthcare professionals to intercept the error. As shown in Table 1, more than half of the medication errors that occur during the administering phase result in harm, yet only $2 \%$ of the errors are intercepted. Most medications administered in the hospital are administered through the intravenous (IV) route. Therefore, since IV medications have immediate bioavailability, once the 
medication reaches the patient, there is little chance for healthcare professionals to intercept the medication error before it harms the patient (Hicks \& Becker, 2006).

Table 1: Medication errors at different phases of the medication delivery system (Leape et al., 1995)

\begin{tabular}{|l|c|c|c|c|}
\hline & Prescribing & Transcribing & Dispensing & Administering \\
\hline$\%$ of Errors Occurring & $39 \%$ & $12 \%$ & $11 \%$ & $38 \%$ \\
\hline$\%$ of Errors Resulting in Harm & $28 \%$ & $11 \%$ & $10 \%$ & $51 \%$ \\
\hline$\%$ of Errors Intercepted & $48 \%$ & $33 \%$ & $34 \%$ & $2 \%$ \\
\hline
\end{tabular}

\subsection{Secondary Infusion}

IV fluids and medications can be administered in a few different ways. They can be delivered as a primary, continuous infusion where the infusion runs continuously to maintain certain physiological parameters. Alternatively, IV medications can be given intermittently through secondary infusion and IV push when single-dose medications, such as antibiotics, need to be given at a specific time for a specific time interval (Dougherty \& Elliott, 2008).

\subsubsection{Definition}

Secondary infusions, also known as piggybacks, are commonly used to administer single-dose IV medication (e.g. antibiotics, high-alert medications, electrolyte replacements, chemotherapy, blood products) through an established intravenous access. Secondary infusions can be administered using gravity or through an infusion device. The secondary infusion bag is usually hung above the primary infusion bag to generate a difference in hydrostatic pressure, which closes the back-check valve of the primary infusion to prevent the flow of primary fluid (Nunnally \& Bitan, 2006). To set up a basic secondary infusion using an infusion device, the clinician is required to connect the secondary tubing to the y-site port on the primary line upstream of the infusion pump, hang the secondary bag above the primary bag (Figure 1), and program the infusion device using the secondary (or piggyback) feature by entering relevant data such as rate and volume to be infused. Once the secondary infusion is over, the back-check valve re-opens and the primary infusion automatically resumes (Nunnally \& Bitan, 2006). 


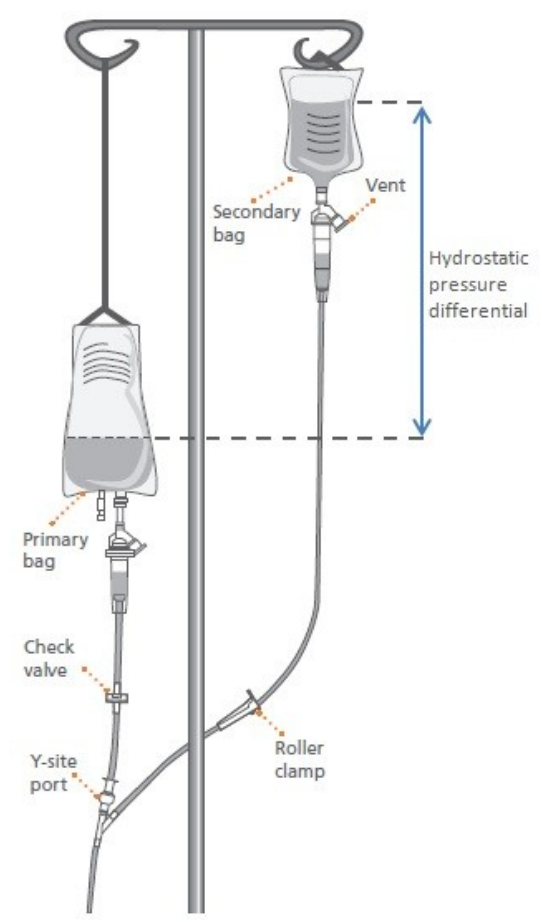

Figure 1: Secondary infusion set-up (Carefusion Corporation, 2011)

\subsubsection{Secondary Infusion Administration Process}

The process of secondary infusion administration is outlined below in Figure 2. The first step is to spike the secondary bag with secondary tubing. The two parallel processes in steps two to four show the different ways to prime the secondary line in preparation for the infusion. Priming means to fill the infusion tubing with fluid to remove all the air in the tubing. The first way is to prime the secondary line with the secondary fluid, hang the secondary bag, and connect the secondary tubing to the primary tubing. The second way is to hang the secondary bag, connect the secondary tubing to the primary tubing, then back-prime the secondary tubing with primary fluid. If the secondary container is glass or semi-rigid, the vent on the secondary tubing should be opened (step 5 in Figure 2) once all the components are connected for the air to displace the fluid in glass containers (Centre for Quality and Productivity Improvement, 2004; Nettina, 2009). These first five steps of the process are referred to as the "Set-up" part of the process as the clinician assembles all the physical components together to prepare for secondary infusion administration. 


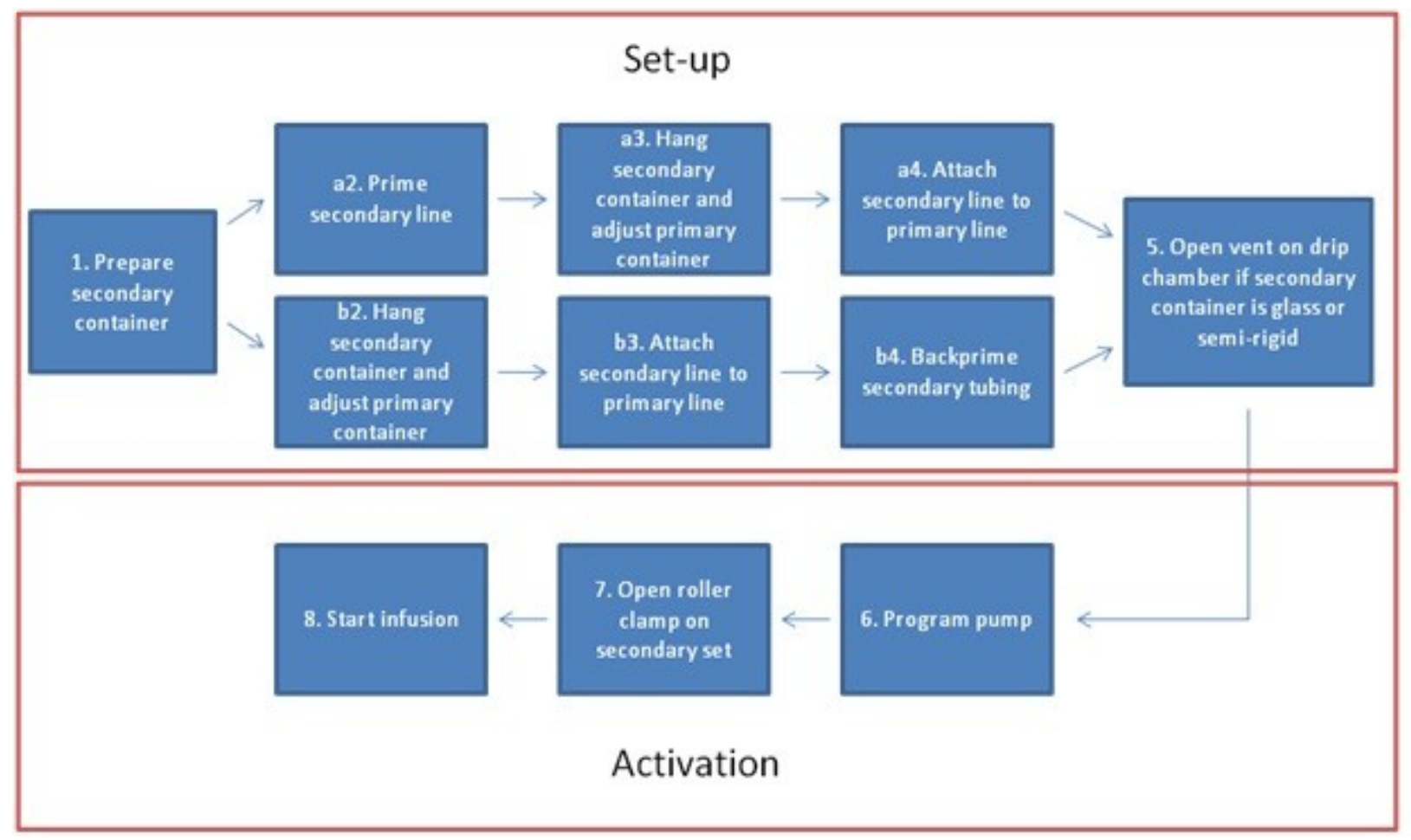

\section{Figure 2: Secondary infusion administration process flow diagram}

Once all the physical components are assembled, the infusion pump is then programmed to monitor the flow of the secondary fluid by manually entering the desired volumetric rate or duration of the infusion for the given infusion bag volume. The roller clamp on the secondary line must be opened to allow for secondary fluid flow before starting the infusion on the infusion pump. This part of the process is referred to as the "Activation" part of the process.

\subsubsection{Secondary Infusion Errors}

Since a number of steps are required to set up and administer secondary infusions properly, there is potential for committing administration errors when delivering secondary infusions. Potential failure modes are described for both the "Set-up" and "Activation" part of the process in the following sections.

\subsubsection{Set-up}

The Set-up part of the secondary infusion process refers to tasks required to prepare and set-up infusion bags and tubing when piggyback infusions are administered. Previous studies have indicated that clinicians have a high frequency of committing use errors related to the set-up and 
administration of secondary infusions, which have led to adverse events (ISMP Canada, 2005; Nunnally \& Bitan, 2006; Trbovich et al., 2010). For example, a study by Nunnally and Bitan (2006) showed that clinicians were unable to complete piggyback tasks in 53\% of cases in a simulated hospital environment while under observation. Common set-up errors observed include failure to adjust bag height and manipulate tubing correctly (i.e. connect the secondary tubing to the correct y-site port on the primary tubing), which may result in concurrent infusion of both primary and secondary fluid and secondary fluid free-flowing into the patient, respectively (Nunnally \& Bitan, 2006).

There was a recent study that compared conventional infusion pump to smart pump infusion systems as well as smart infusion pumps with barcode capability. The difference in these infusion pumps will be described in Section 2.3. The results of the study found that an error rate of $50 \%$ in secondary infusion scenarios was observed with the traditional infusion pump, compared to an error rate of $33 \%$ and $50 \%$ with the smart infusion pump and the barcode infusion pump (Trbovich et al., 2010). However, no significant differences were found in the nurses' ability to successfully program secondary infusions across pump types. Although the purpose of the study was not to determine the error rates of secondary IV infusions, the observations supported the findings of Nunnally and Bitan (2006), including the diversity of error types.

\subsubsection{Activation}

The activation part of the process includes programming the infusion pump and opening the roller clamp on the secondary line to allow the secondary fluid to be delivered in a controlled manner. Since the rate of infusion is controlled by the infusion pump, it is important for clinicians to program the pump correctly for the infusion to be delivered safely and accurately. However, depending on the pump interface design, users may not be able to perform their tasks efficiently when navigating through the menus. Pump programming errors may include: becoming confused between the rate and volume of primary and secondary lines, programming incorrect parameters, and becoming lost in the menu system while programming the infusion pumps (ISMP Canada, 2003; Trbovich et al., 2010). As a result, patients may receive the medication at an undesirable rate or therapy may be delayed. In addition to programming errors, a recent study also identified that roller clamps sometimes remained unclamped in the secondary 
line, forcing primary fluid from the primary line to be infused at an improper rate (Trbovich et al., 2010).

\subsection{Smart Infusion Pumps}

In an attempt to reduce IV medication errors, manufacturers developed smart infusion pumps with dose error reduction systems (DERS). DERS allow hospitals to configure IV infusion drug libraries that contain data on dose range limits, infusion rate limits, and dilution factors for infusion medications. Hospitals can customize these libraries to better fit specific patient populations and patient care areas (Elias \& Moss, 2011). When IV medication is administered, the clinician selects the name and concentration of the medication and enters the dosage parameters. The smart pump will generate either a soft or hard limit alert if the parameters entered do not fall within the recommended dose range for that drug. A soft limit alert can be overridden and will allow the medication to be administered as programmed. Conversely, a hard limit alert will not allow the medication to be administered, resulting in the need to verify the drug and ordered rate of infusion with the medication administration record, pharmacist, or physician (Elias \& Moss, 2011). Although smart infusion pumps contain safeguards against dosing errors, they do not prevent errors related to administering the right drug, to the right patient, by the right route, at the right time. Smart infusion pumps equipped with barcode readers were designed to help prevent these types of errors but are not yet widely implemented (Husch et al., 2005; Trbovich et al., 2010; Vanderveen, 2006).

From a report published in 2009 , the adoption rate of smart infusion pumps in Ontario has been low. Only $19 \%$ of Ontario hospitals have already implemented or in the process of implementing smart infusion pumps (Trbovich, Jeon, \& Easty, 2009). This is possibly due to the high capital cost and time investment associated with the implementation. Smaller hospitals and rural hospitals, for example, would be less likely to have the funds to invest in a smart infusion pump implementation. The following table (Table 2) compares the unit price of five smart infusion pumps that are licensed to be sold in Canada and were examined in the present work. These five smart infusion pumps are: Baxter Colleague CXE (Colleague ${ }^{\circledR}$ CXE Volumetric Infusion System with Guardian Feature, Baxter Corporation, Deerfield, IL), B. Braun Infusomat Space (Infusomat ${ }^{\circledR}$ Space, B. Braun Melsungen AG, Melsungen, Germany), Cardinal Health Alaris PC (Alaris ${ }^{\circledR}$ PC 8015 series and Alaris ${ }^{\circledR}$ Pump 8100 series, CareFusion Corporation, San Diego, 
CA), Hospira Plum A+ (Plum ${ }^{\circledR}$ A+ Infusion System, Hospira Inc, Lake Forest, IL) and Hospira Symbiq (Symbiq ${ }^{\mathrm{TM}}$ Infusion System, Hospira Inc, Lake Forest, IL). The rationale for pump selection will be discussed in Section 3.1.1.

Table 2: Smart infusion pumps cost comparison (ECRI Institute, 2007)

\begin{tabular}{|l|c|c|l|l|c|}
\hline & Alaris PC & $\begin{array}{l}\text { B. Braun } \\
\text { Infusomat Space }\end{array}$ & $\begin{array}{l}\text { Baxter } \\
\text { Colleague } \\
\text { CXE }\end{array}$ & $\begin{array}{l}\text { Hospira } \\
\text { Symbiq }\end{array}$ & $\begin{array}{l}\text { Hospira } \\
\text { Plum A+ }\end{array}$ \\
\hline Unit Cost (USD) & $\$ 4400$ & $\begin{array}{c}\text { Data Not } \\
\text { Available }\end{array}$ & $\$ 7800$ & $\$ 7095$ & $\$ 5095$ \\
\hline $\begin{array}{l}\text { Annual Software } \\
\text { License Fee } \\
\text { (USD) }\end{array}$ & $\$ 1200$ & $\begin{array}{c}\text { Data Not } \\
\text { Available }\end{array}$ & $\begin{array}{c}\text { Not } \\
\text { Applicable }\end{array}$ & $\begin{array}{c}\text { Not } \\
\text { Applicable }\end{array}$ & $\$ 1025$ \\
\hline
\end{tabular}

The use of smart infusion pump to deliver secondary infusions may enhance safety by preventing clinicians from programming a detrimental dose of medication to patients. However, this advance in infusion pump technology seem to focus mainly on reducing activation errors but not set-up errors (ISMP Canada, 2003, 2005; Trbovich et al., 2010). For example, if the piggyback infusion is not set up properly, the infusion pump may still operate, but deliver the piggyback or primary infusion in a way that is not intended. Most smart infusion pumps on the market require the traditional set-up to deliver secondary infusion properly except for the Hospira Plum A+ (Plum ${ }^{\circledR}$ A+ Infusion System, Hospira Inc, Lake Forest, IL). Figure 3 aimed to illustrate the difference between the traditional secondary infusion set-up and the secondary infusion set-up on the Hospira Plum A+. For instance, the Hospira Plum A+ provides a separate port on the cassette (labeled as a black rectangle on the left side of the pump) for the secondary line to be connected onto the cassette. As a result, the pump can pull fluids directly from the primary bag, the secondary bag, or both bags at the same time. Therefore, no back-check valve is needed on the primary tubing when using the Hospira Plum $\mathrm{A}+$, which eliminates the need to establish the difference in hydrostatic pressure between the primary and secondary bags, as shown in the diagram on the right in Figure 3. 


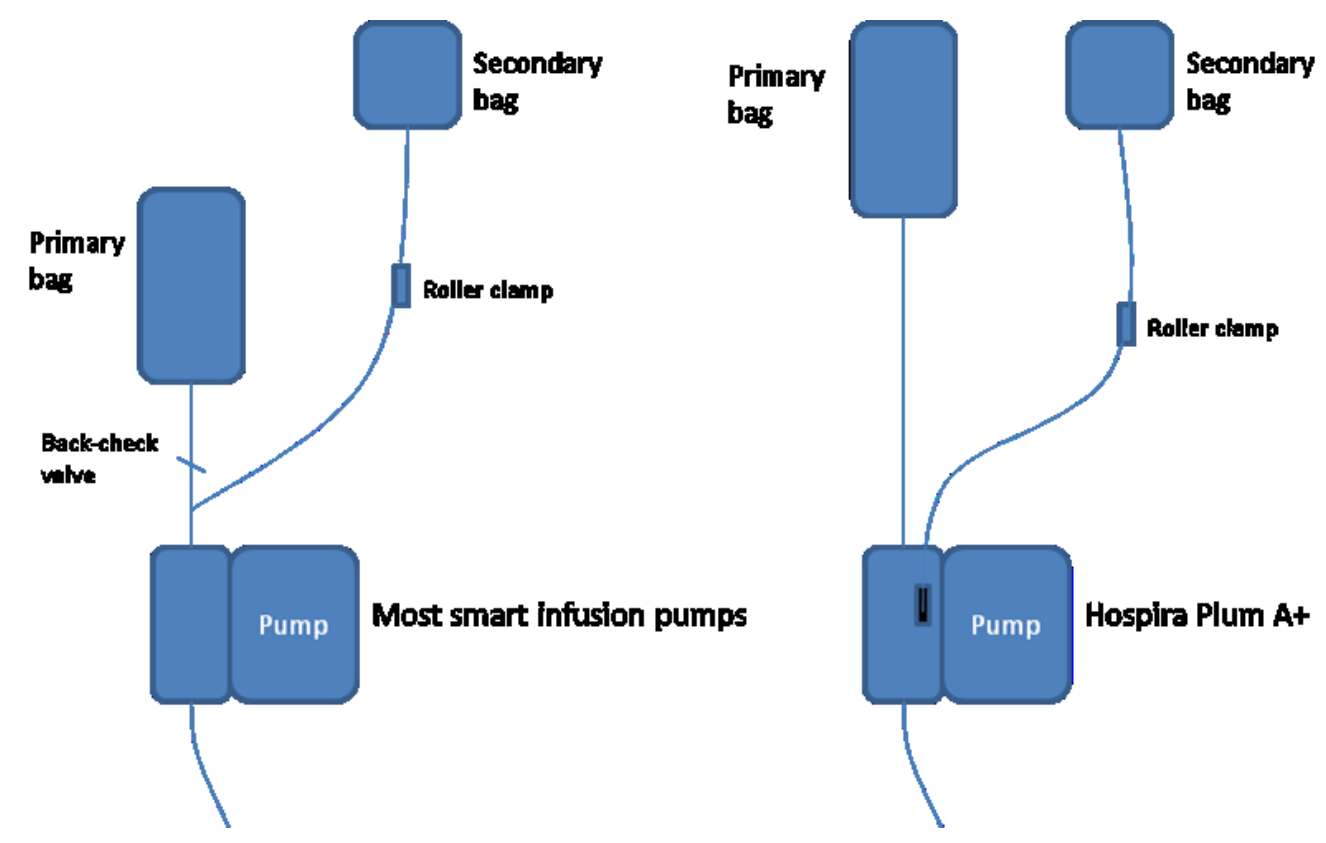

Figure 3: Difference in secondary infusion set-up between most smart infusion pumps and the Hospira Plum A+

With the introduction of smart pump technology, manufacturers have designed different user interfaces for pump programming and DERS, as well as different mechanisms of fluid delivery which affects the set-up of infusion bags and tubing. Therefore, it is of interest to examine the differences between smart infusion pumps and assess the potential risks of secondary infusion administration when using these pumps. Healthcare Failure Mode and Effect Analysis (HFMEA) is one method that can be used to identify and assess those potential risks.

\subsection{Failure Mode and Effect Analysis in Healthcare}

Proactive risk assessment tools have proven to be useful in evaluating the safety of various medication administration processes by forecasting potential failures, revealing process vulnerabilities, and applying control measures before harm occurs (Adachi \& Lodolce, 2005; Burgmeier, 2002; Nickerson et al., 2008). Healthcare Failure Mode and Effect Analysis (HFMEA) was chosen to be the risk assessment tool used in this study. A comparison between HFMEA and some of the other risk assessment tools are detailed in section 2.4.4. 


\subsubsection{Failure Mode and Effect Analysis (FMEA)}

FMEA is a systematic process for identifying potential process failures before they occur.. It is a tool, based on principles of reliability engineering, that is used to identify and assess potential failure modes in products, processes and systems (Habraken et al., 2009; Wetterneck et al., 2006). Failure mode is defined as the different ways that a particular process or sub process step can fail to accomplish its intended purpose. For example, if the sub process step is confirming known drug allergies with patient, then failure modes would include: (1) not recording drug allergies and (2) incompletely capturing drug allergies (DeRosier \& Stalhandske, 2002). FMEA intends to (Crane, 2006; Reid, 2005; Reiling \& Knutzen, 2003):

- Recognize and evaluate the potential failures of a product or process and the effects of those failures

- Identify actions that could eliminate or reduce the chance of the potential failures occurring

\section{- Document the process flow}

The components to an FMEA include: identifying potential failure modes, identifying the possible effects for each failure mode, conducting a root-cause analysis for the most critical effects, testing and implementing risk reduction strategies, and monitoring the effect of actions taken to reduce the risk of failures (Crane, 2006; Reid, 2005; Reiling \& Knutzen, 2003). When analyzing the possible effects for each identified failure mode, scores from one to ten, from low to high-risk, are assigned to each of the three variables: severity, probability, and detectability. Severity refers to the seriousness of the patient outcome as a result of the failure modes. Probability refers to how likely it is that the failure would occur, and detectability refers to how likely it is that the failure would be detected before the completion of task or before harm is done. The product of the three variables would yield a risk priority number (RPN) for a particular failure mode, which can help identify and prioritize potential failures that are most critical or that may need attention immediately by sorting from failure modes with the highest RPN to the lowest RPN (Reiling \& Knutzen, 2003).

FMEA was first developed by the United States military in the 1940s and utilized by the National Aeronautics and Space Administration (NASA) in the 1960s (La Pietra, Calligaris, Molendini, Quattrin, \& Brusaferro, 2005; Reid, 2005). It was later used to assess and improve the safety of high-risk industries such as aviation and nuclear power (Ashley \& Armitage, 2010). 
Recently, FMEA has also been applied in healthcare to improve patient safety (Adachi \& Lodolce, 2005; Burgmeier, 2002; Day et al., 2007; Paparella, 2007; Wetterneck et al., 2006).

In 2001, The Joint Commission on Accreditation of Healthcare Organization (JCAHO) included new proactive patient safety improvement standards for healthcare organizations seeking JCAHO accreditation (Spath, 2003). The Joint Commission requires that accredited organizations now use risk assessment techniques proactively to identify weaknesses in the process, predict outcomes as a result of those weaknesses, and initiate process redesigns that would minimize those risks. Also, accredited organizations are expected to perform at least one proactive risk assessment on a high-risk process or technology every year. Similarly, since 2007, the Canadian Council on Health Services Accreditation Program requires health organizations to conduct at least one proactive risk assessment within the past year of the accreditation process, which occurs on a three-year cycle (Accreditation Canada, 2012). Although the Joint Commission and Accreditation Canada standards do not mandate that a specific risk analysis model be used, the required components of this analysis are very similar to an FMEA. The required components include (van Tilburg et al., 2006):

- Identifying potential failure modes

- Identifying the possible effects for each failure mode

- Conducting a root-cause analysis for the most critical effects

- Testing and implementing risk reduction strategies

- Monitoring the effect of actions taken to reduce the risk of failures

Typical applications for FMEA in healthcare organizations include preventing technology or device defects and improving patient care processes for high-risk procedures (e.g. blood transfusion and MRI) (T. Wetterneck et al., 2004).

\subsubsection{Healthcare Failure Mode and Effect Analysis (HFMEA)}

In 2002, the Department of Veterans Affairs (VA) National Center for Patient Safety (NCPS) developed healthcare failure mode and effect analysis (HFMEA) as a risk assessment tool that healthcare facilities could use to meet the new proactive risk assessment requirement contained in the JCAHO patient safety standard. HFMEA is a hybrid prospective analysis model that combines concepts found in industry's FMEA and the U.S. Food and Drug Administration's 
Hazard Analysis and Critical Control Point (HACCP) with tools and definitions from the VA's root cause analysis (RCA) process (DeRosier \& Stalhandske, 2002). Descriptions of HACCP and RCA will be discussed in Section 2.4.4. HFMEA is a five-step process that uses a multidisciplinary team to proactively evaluate a healthcare process or technology. The team uses process flow diagramming, a hazard scoring matrix, and a decision tree to identify and assess potential vulnerabilities (DeRosier \& Stalhandske, 2002; van Tilburg et al., 2006). The vulnerabilities are evaluated based on the probability of occurrence, the potential severity in patient harm, and the detectability of the failure modes. A worksheet is used to record the team's assessment, proposed actions, and outcome measures. Since 2002, HFMEA has been successfully applied to several healthcare processes, such as drug ordering and administration and sterilization and use of surgical instruments (Esmail et al., 2005; T. Wetterneck et al., 2004; van Tilburg et al., 2006). However, the main constraints often reported when conducting an HFMEA are the significant time commitment and resources needed (Nagpal et al., 2010; T. Wetterneck et al., 2004). Also, the severity and probability is scored on a four-point scale for the HFMEA rather than a ten-point scale for the industry's FMEA. As a result, the rigidity of the hazard scoring had been viewed as a disadvantage since it did not allow for minute differentiation of probability and severity, which made the ability to follow the hazard score over time for improvement difficult (T. Wetterneck et al., 2004).

HFMEA was chosen to be the risk assessment tool used for this study because it was specifically developed to evaluate healthcare processes and has been applied successfully in medication administration processes similar to secondary infusion administration.

\subsubsection{Methods that Help Inform HFMEA}

When performing an HFMEA, the HFMEA team is expected to identify all possible failure modes for the process of interest and evaluate the potential probability, severity, and detectability of the failure modes, as mentioned above. In addition to brainstorming as a team and drawing from individual experiences, there are other methods and sources of information that can be used to help inform these tasks. The following sections describe two methods that were used for this task in the study. 


\subsubsection{Incident Reports}

Incident reporting systems collect data about error events in a structured format for analysis of incidents (Ahluwalia \& Marriott, 2005). These systems serve as tools to allow for learning from adverse events, understanding the nature of the event, and monitoring of trends and patterns to allow early detection of potential future adverse events (Ahluwalia \& Marriott, 2005). As a result, they help provide an understanding of risks and help generate solutions to prevent the occurrence of future incidents (Colvin, 2011).

Since incident report data are collected in a structured format, incident reporting systems allow for extraction of incident reports related to a particular issue (e.g. secondary infusions) in a timely manner. With information on various adverse events that have occurred, incident reporting systems can guide prospective analysis, such as HFMEA, for identifying potential failure modes and identifying factors contributing to system failures (Colvin, 2011). However, incidents are often under-reported with variation in the quality of information obtained (Noble $\&$ Pronovost, 2010); therefore, extracting data from incident reports alone may not be sufficient in identifying all failure modes related to secondary infusions.

\subsubsection{Clinical Observations}

Field observation studies in the clinical setting can be a useful tool during the exploratory phase when studying a work process to gain a realistic view of the full complexity of the process or working environment (Roth et al., 2004). Field observations allow observers to document patterns of interaction between the participant and the technology or environment, complications that arise, and deviations of actual practice from policies and protocols (Roth et al., 2004). There are two types of observation when conducting field studies: structured and unstructured (Mulhall, 2003). The purpose of structured observation is to record physical and verbal behavior. And the data obtained are based on metrics developed from known theory. In contrast, unstructured observation is used to understand and interpret cultural behavior. It is usually used during an early phase of the research to provide insight into interactions between the subject and other people, capture context or process, and inform about the influence of the physical environment (Mulhall, 2003).

The method of unstructured observations was used in this study to understand interactions between nurses and the infusion system (e.g. infusion bags, tubing, and pumps) when delivering 
secondary infusions. Data acquired from field observations can be useful when conducting HFMEA failure mode identification as the observer documents how infusion tasks were performed and complications that arise when performing such tasks (Carayon et al., 2004). However, the Hawthorne Effect (Parsons, 1974), or the idea that participants in research studies may modify their behavior in response to being studied, is a factor for consideration when conducting field observations because nurses' medication administration performance is under investigation. As a result, nurses may try to be on their best behavior, making it difficult to identify practices that may lead to failure in the system.

\subsubsection{HFMEA versus Other Risk Assessment Tools in Healthcare}

\subsubsection{Hazard Analysis and Critical Control Point (HACCP)}

Hazard Analysis and Critical Control Point (HACCP) is a systematic approach to the identification, assessment, and control of hazards. Hazard refers to any part of a process that has the potential to cause a safety problem. Analysis is the identification and assessment of the probability of occurrence and the severity of the consequences of a hazard. Lastly, a Critical Control Point is a point, step, or procedure at which control can be exercised to prevent, eliminate, or minimize a hazard (McDonough, 2002).

HACCP was first developed by the Pillsbury Company in 1959 to help ensure the quality and purity of food at the National Aeronautics and Space Administration (NASA). HACCP was first described publicly in 1971 at the National Conference on Food Protection and the U.S. Food and Drug Administration (FDA) mandated the use of HACCP for all low-acid canned foods in 1973 after the botulism outbreak involving canned soups (McDonough, 2002). The National Research Council produced a report in 1985, recommending widespread use of HACCP in all food groups. Since then, HACCP has been applied to food groups such as meat and poultry products, fruits and vegetables, seafood, and more. Additionally, HACCP is becoming an international requirement as the Codex Alimentarius Commission, the international food standards, now recommends HACCP adoption across the globe (McDonough, 2002).

The HACCP system consist of seven principles (Codex_Alimentarius_Commission, 1997):

1. Conduct a hazard analysis

2. Determine the Critical Control Points (CCPs) 
3. Establish critical limits(s)

4. Establish a system to monitor control of the CCP

5. Establish corrective actions to be taken when monitoring indicates that a particular $\mathrm{CCP}$ is not under control

6. Establish procedures for verification to confirm that the HACCP system is working effectively

7. Establish documentation concerning all procedures and records appropriate to these principles and their application

HFMEA and HACCP have many similarities. Both tools involve selection of process, selection of a team, creation of a process flow diagram, hazard or failure identification, risk assessment, corrective or preventive action, and ongoing monitoring and assessment. As well, both rely on the use of cross-functional teams and a preventive approach to hazard and failure mode identification and elimination or reduction (McDonough, 2002).

Although the process in conducting HFMEA and HACCP are very similar, the two techniques differ in the nature of information identified by the analyst. For instance, both techniques take into consideration the physical contribution of the human and the hardware to the working of the system. But HFMEA also considers the cognitive contribution of the human to the working of the system (Lyons, 2009). Therefore, while both HACCP and HFMEA can be used to identify system failures, HFMEA can also be used to identify human errors. Given this study focuses on human errors related to the secondary infusion administration practice, HFMEA is a more suitable method for this study than HACCP.

\subsubsection{Root Cause Analysis (RCA)}

Root cause analysis (RCA) is a retrospective investigative process with the purpose of identifying underlying causes and contributory factors of a serious adverse event. The goal of RCA is to obtain knowledge and thereby prevent recurrences of the serious adverse event (Jensen, 2004).

RCA was first introduced to the health care community by the US Department of Veterans Affairs (VA) and the Joint Commission in the mid-1990's. By 1997, The Joint Commission 
mandated all health care organizations to perform an RCA for every serious adverse event (Shojania et al., 2001).

VA's root cause analysis consists of eleven steps (Mills, Neily, \& Luan, 2005):

1. Charter a team and gather and analyze data for the event being reviewed

2. Draw a flowchart of the general steps involved in the process

3. Use text to describe how the team reviewed the general process in the system

4. Identify resources such as evidence-based best practices, policies/procedures, and staff

5. Use the data and the flowchart to determine the focus of this review

6. Determine root cause/contributing factors; may use Triage/Triggering Questions and causeand-effect diagram

7. Further develop root cause/contributing factors using the five rules of causation (VA National Centre for Patient Safety Triage Cards)

8. Determine actions to address the root causes

9. Write outcome measures

10. Present analysis and actions to leadership for concurrence

11. Implement actions and evaluate effectiveness; conduct aggregate root cause analysis on a regular basis

Although performing RCA may reveal causal factors of a serious adverse event, the nature of the investigation is very labor-intensive (Shojania et al., 2001). As well it is limited by its hindsight and outcome bias as the issue being investigated has already occurred. Hindsight bias is the tendency for people to falsely believe that the actions that should have been taken to prevent an incident seem obvious, once all the facts become clear (National Patient Safety Agency, 2008). And outcome bias is the tendency to judge a past decision or action by its success or failure, instead of based on the quality of decision made at the time (National Patient Safety Agency, 2008). Both hindsight and outcome bias can result in misinterpretation of findings in a retrospective investigation. As well, since RCA is in essence case studies of highly unpredictable incidents, it is difficult to know if the root cause established by the analysis is indeed the cause of the incident (Shojania et al., 2001). 
HFMEA takes a different approach than RCA as HFMEA is a prospective risk assessment tool and RCA is a retrospective risk analysis tool. HFMEA aims to proactively prevent failure while RCA aims to find root causes to learn and understand how the incident occurred, as well as find ways to prevent similar incidents from occurring again. Compared to RCA, HFMEA focuses on system design rather than on a single incident. As a result, the knowledge obtained and changes implemented are likely to impact a larger number of patients (Nagamine \& Williams, 2005). 


\section{Chapter 3 \\ Methodology}

\section{Methodology - HFMEA}

The HFMEA methodology developed by the Veterans Affairs (VA) National Center for Patient Safety (NCPS) was used for this study (DeRosier \& Stalhandske, 2002). It consists of five steps: define the HFMEA topic, assemble the team, graphically describe the process (i.e. process flow diagrams), conduct a hazard analysis, and develop actions and outcome measures. The last step, develop action and outcome measures, was not completed since this study focused on evaluating the safety of secondary infusion practice rather than implementing changes to the system. However, mitigation strategies for high-risk failure modes will be discussed as possible interventions to improve the safety of secondary infusion practice.

\subsection{Define the HFMEA topic}

The secondary infusion administration process was evaluated using HFMEA in this study. The process began with the task of preparing the secondary container and ended with the task of starting the secondary infusion. The scope of this study included potential failure modes that can occur during the secondary infusion administration process from infusion systems and supplies selection, infusion systems set-up, and infusion pump programming. However, the analysis did not include failure modes or issues that may occur downstream of the infusion pump (e.g. drug transit time, drug interactions when mixing multiple drugs at connection pieces downstream of the infusion pump). The conventional secondary infusion process was examined and compared against five different smart pumps on the Canadian market.

\subsubsection{Smart Infusion Pump Selection}

Since most secondary infusions are administered using infusion pumps, it is of interest to examine the potential risks when delivering secondary infusions with smart infusion pumps from different manufacturers. There are four manufacturers who currently sell smart infusion pumps in Ontario (Trbovich et al., 2009), one of which has two smart infusion pumps on the market. The five smart infusion pumps are: Baxter Colleague CXE (Colleague ${ }^{\circledR}$ CXE Volumetric Infusion System with Guardian Feature, Baxter Corporation, Deerfield, IL), B. Braun Infusomat 
Space (Infusomat® Space, B. Braun Melsungen AG, Melsungen, Germany), Cardinal Health Alaris PC (Alaris ${ }^{\circledR}$ PC 8015 series and Alaris ${ }^{\circledR}$ Pump 8100 series, CareFusion Corporation, San Diego, CA), Hospira Plum A+ (Plum ${ }^{\circledR}$ A+ Infusion System, Hospira Inc, Lake Forest, IL) and Hospira Symbiq (Symbiq ${ }^{\mathrm{TM}}$ Infusion System, Hospira Inc, Lake Forest, IL). The current thesis examined all five infusion pumps and evaluated the safety of the secondary infusion administration process when using these pumps with Healthcare Failure Mode and Effect Analysis (HFMEA).

\subsection{HFMEA Team}

The HFMEA team consisted of the author and two human factors researchers. Ideally, an HFMEA team should include subject matter experts as well as safety or human factors experts (Lyons, 2009). Subject matter experts refer to experts who are familiar with the technical process under evaluation. In the case of the secondary infusion administration process that is being studied, subject matter experts would be nurses, doctors, pharmacists, and all aspects of regulatory, quality or other management roles. Safety or human factors experts are important when conducting HFMEA because they are likely to have a more detailed understanding and experience of FMEA/HFMEA, its purpose, method and expected results, as well as its strength and weaknesses (Lyons, 2009). However, due to time and resources constraints, it was not feasible to assemble a multidisciplinary team. To compensate for the lack of subject matter experts on the HFMEA team, all members of the team shadowed nurses in various clinical environments, which allowed them to have a basic understanding of nursing practice and infusion management in the clinical setting. The details of clinical observations are outlined in Section 4.4.3.

Once the team was assembled, the HFMEA team followed the tutorial outlined in DeRosier et al, 2002 to complete the HFMEA on the secondary infusion administration process.

\subsection{Process Description}

The description of the secondary infusion administration process as well as all the major tasks of the process were mapped based on the literature (Centre for Quality and Productivity Improvement, 2004; Nettina, 2009). All the sub-tasks for each major task were then outlined 
based on clinical observations where nurses were observed when delivering secondary infusions. Since there were variations of practice observed between nurses in terms of the sequence of steps performed when setting up the physical components of the secondary infusion, the process that was most often observed was documented. It should be noted that all nurses had to perform the same sub-tasks in order to complete the set-up part of the secondary infusion administration process regardless of the order of tasks. Therefore, even though there were variations in practice, the HFMEA was able to capture failure modes within those variations since failure modes were identified by focusing on one sub-task at a time.

In addition, the secondary infusion programming sequence for each smart infusion pump was documented by the author through interacting with the infusion pumps and following instructions on the infusion pump manuals developed by the pump manufacturer. Once the process flow diagram was mapped, the author confirmed its accuracy by using the process flow diagram as a guide to program secondary infusions on each of the five smart infusion pumps.

\subsection{Hazard Analysis}

The hazard analysis part of the HFMEA process consists of three main steps: Identification of failure modes, hazard scoring, and decision tree analysis. The following sections describe how each of the steps was conducted.

\subsubsection{Identification of Failure Modes}

All potential failure modes identified for each step of the secondary infusion administration process were listed. Several methods were used to identify these potential failure modes.

\subsubsection{Literature Search}

A thorough literature search was completed to help understand and identify potential failure modes related to secondary infusions, as well as possible mitigation strategies for those failure modes. Electronic databases (i.e. MEDLINE, CINAHL, Google Scholar, and Scopus) were used to conduct the literature search using search terms that reflect the terms used to describe secondary infusions in the literature and in the clinical environment. The search terms used were: "piggyback infusion” OR "secondary infusion” OR "intermittent infusion” AND/OR "infusion pump error". The term "infusion pump error" was included because this study aimed to study the 
safety of secondary infusion when delivered using an infusion pump. Therefore, it is desirable to learn about the types of errors made when using an infusion pump.

\subsubsection{Incident Reports Analysis}

Incident reports were used to help identify potential failures modes as well as patient outcomes as a result of those failure modes. The present thesis was part of a larger project in which incident reports related to multiple infusions from the Food and Drug Administration's (FDA) Manufacturer and User Facility Device (MAUDE) database for the year 2008 have been reviewed and coded based on the method used to deliver multiple infusions (Colvin, 2011; Health Technology Safety Research Team, 2010). A total of 211 incident reports were coded into one of three methods: piggyback, concurrent, and both (i.e. piggyback and concurrent). Piggyback infusions refer to the secondary infusion practice where the intermittent drug and the continuous fluid are delivered in sequence. Concurrent infusions refer to the delivery of multiple drugs at the same time to the patient. Since this study focused on secondary infusions, only incident reports that were related to secondary infusions were analyzed. Therefore, all incident reports that were coded "piggyback" and "both" piggyback and concurrent from the incident reports were extracted and reviewed. Only incidents that occurred in the presence of secondary infusions were then included and were further analyzed using thematic analysis.

Thematic analysis is a method for identifying, analyzing, and reporting patterns or themes within the data (Braun \& Clarke, 2006). A theme is a cluster of incidents that are similar in nature. To conduct thematic analysis, each incident report was reviewed by the author in detail once and a brief description of the incident report was documented. Brief descriptions were then reviewed by the author and were further summarized into underlying issues or adverse events, which evolve into themes. Table 3 provides an example of how a given incident description is summarized into underlying issues and themes. 
Table 3: Incident reports: from description to themes

\begin{tabular}{|c|c|c|}
\hline Incident Description from Incident Report & $\begin{array}{l}\text { Underlying Issue or } \\
\text { Adverse Event }\end{array}$ & Theme \\
\hline $\begin{array}{l}\text { PT WAS RECEIVING MAGNESIUM SULFATE } 2 \\
\text { GM IN NS } 50 \text { ML OVER ONE HOUR VIA } \\
\text { PIGGYBACK. THE SECONDARY LINE WAS } \\
\text { SET AT } 50 \text { ML/HR. HOWEVER, THE PUMP } \\
\text { DELIVERED THE MAGNESIUM WITHIN } 15 \text { TO } \\
20 \text { MINUTES. THE CHARGE NURSE RE- } \\
\text { CHECKED PUMP SETTINGS AND WAS FOUND } \\
\text { TO BE CORRECT. THE PT SUFFERED AN } \\
\text { EPISODE OF BRADYCARDIA BUT QUICKLY } \\
\text { STABILIZED WITHOUT ADDITIONAL } \\
\text { TREATMENT. }\end{array}$ & $\begin{array}{l}\text { Pump infused } \\
\text { medication too } \\
\text { quickly when } \\
\text { programmed } \\
\text { correctly }\end{array}$ & Over-infusion \\
\hline
\end{tabular}

Other information that was extracted from incident reports includes the number of reports associated with the identified themes and patient outcomes reported.

Incident reports usually provide a description of the adverse events that occurred. Therefore, themes identified from the incident reports reflect the consequences or effects of secondary infusion errors. As a result, themes identified from incident reports will be referred to as "issues" rather than "failure modes". For example, the incident report description in Table 3 describes a patient receiving a medication too quickly, which resulted in an overdose or over-infusion. Consequently, the underlying issue or consequence of a secondary infusion error was categorized as “Over-infusion". And since patient outcomes were often reported, data from incident reports were used to inform severity ratings for the potential effects of failure modes in the HFMEA. The most severe cases of the effects were used to inform the severity ratings in the HFMEA such that the greatest potential harm that can be done as a result of the particular failure mode is captured. Using the same incident from Table 3, for example, patients who received an overinfusion died in the most severe case. Therefore, any failure modes that led to the possibility of over-infusion were given a severity rating of 4 (Catastrophic).

\subsubsection{Clinical Observations}

The field observation phase of the thesis was completed as part of a larger study. Field studies were conducted in six different hospitals across Ontario selected based on size, patient 
population, and type of infusion pump to ensure a wide range of practices were represented (Table 4).

Table 4: Hospitals and units where field observations were conducted

\begin{tabular}{|c|c|c|c|c|}
\hline Hospital & Unit & Location & Hospital Type & Infusion Pump \\
\hline $\begin{array}{l}\text { Sudbury } \\
\text { Regional } \\
\text { Hospital }\end{array}$ & $\begin{array}{l}\text { Medical/Surgery } \\
\text { Intensive Care } \\
\text { Unit (MSICU) } \\
\text { Cardiovascular } \\
\text { Intensive Care } \\
\text { Unit (CVICU) }\end{array}$ & Sudbury & Teaching & Hospira Plum A+ \\
\hline $\begin{array}{l}\text { St. Michael's } \\
\text { Hospital }\end{array}$ & MSICU & Toronto & Teaching & Baxter Colleague \\
\hline $\begin{array}{l}\text { Hamilton } \\
\text { General Hospital }\end{array}$ & $\begin{array}{l}\text { Emergency } \\
\text { Department }\end{array}$ & Hamilton & Teaching & Alaris PC \\
\hline $\begin{array}{l}\text { Hospital for Sick } \\
\text { Children } \\
\text { (SickKids) }\end{array}$ & Pediatric ICU & Toronto & Teaching & Alaris PC \\
\hline $\begin{array}{l}\text { Children's } \\
\text { Hospital of } \\
\text { Eastern Ontario }\end{array}$ & $\begin{array}{l}\text { Pediatric } \\
\text { Oncology Unit }\end{array}$ & Ottawa & Teaching & Alaris SE \\
\hline $\begin{array}{l}\text { Juravinski } \\
\text { Cancer Centre }\end{array}$ & $\begin{array}{l}\text { Chemotherapy } \\
\text { Outpatient Unit }\end{array}$ & Hamilton & Teaching & Alaris PC \\
\hline
\end{tabular}

Observations on each unit took place over three consecutive days. Each visit began with a halfday interview with unit administrators and managers conducted by two to three human factors researchers. The purpose of the interviews was to learn about the unit at a higher level, including workflow processes (i.e. medication delivery process from prescribing to administering), education and training provided on the unit, policies that help guide best practices in administering secondary infusions, as well as incidents that have occurred related to secondary infusions. For the remainder of the visit, each human factors researcher shadowed approximately five nurses per unit, one-on-one by the bedside, for no longer than one shift. Depending on the institution, a nursing shift was either eight or twelve hours in length. 
Field observation data were used to understand the current practice of secondary infusion delivery, and to identify environmental factors and behaviours that may contribute to preventable adverse events, such as incidents found in the FDA MAUDE incident report database. Examples of adverse events may include: patient received a secondary drug too quickly, primary fluid and secondary drug were delivered concurrently, and primary infusion was delivered at the rate of the secondary infusion. Tasks observed included setting up of bag and tubing for secondary infusions and programming the infusion pump. Any potential failure modes or challenges observed during the delivery of secondary infusions were documented in a table. The table consists of information such as descriptions of the different potential failure modes, consequences of each failure mode, and incidents described by nurses at each hospital, if any. If the failure modes identified were not applicable to a particular hospital due to certain control measures, the mitigation strategies for the failure modes were documented.

Table 5 shows an example of how the information is recorded for two of the hospitals visited.

Table 5: Clinical observations data collection sheet example

\begin{tabular}{|l|l||l|l|}
\hline \multicolumn{1}{c|}{$\begin{array}{c}\text { Failure Mode } \\
\text { Description }\end{array}$} & \multicolumn{1}{|c|}{ Potential Consequences } & $\begin{array}{l}\text { Hospital for Sick } \\
\text { Children PICU }\end{array}$ & $\begin{array}{c}\text { Sudbury } \\
\text { Regional } \\
\text { Hospital }\end{array}$ \\
\cline { 2 - 3 } $\begin{array}{l}\text { The secondary } \\
\text { bag is not hung } \\
\text { at the correct } \\
\text { height relative to } \\
\text { the primary bag }\end{array}$ & $\begin{array}{l}\text { If the height differential between } \\
\text { the primary and secondary bags is } \\
\text { not large enough, when the } \\
\text { secondary bag volume depletes to } \\
\text { the level of the top of the primary } \\
\text { bag, both fluids will be pulled into } \\
\text { the system at the rate of the } \\
\text { secondary infusion, meaning the } \\
\text { rate of both drugs is not controlled } \\
\text { as specified. }\end{array}$ & $\begin{array}{l}\text { One nurse } \\
\text { mentioned that the } \\
\text { hangers are } \\
\text { sometimes not long } \\
\text { enough, particularly } \\
\text { for "longer" IV } \\
\text { bags. Sometimes } \\
\text { multiple hangers are } \\
\text { used. }\end{array}$ & $\begin{array}{l}\text { Plum A+ pumps } \\
\text { do not require } \\
\text { secondary bags } \\
\text { different height }\end{array}$ \\
\hline
\end{tabular}

The Hawthorne Effect (Parsons, 1974), or the idea that participants in research studies may modify their behavior in response to being studied, is a factor for consideration when conducting field observations because nurses' medication administration performance is under investigation. To avoid influencing nurses' behavior during shadowing (i.e. the Hawthorne Effect (Parsons, 1974)), observers tried to be as unobtrusive as possible while nurses performed their tasks and only ask for clarification when nurses have a brief break in between tasks. Although it is 
impossible to guarantee that nurses' behavior remained unchanged as a result of being observed, it is expected that any change in behavior resulted from the Hawthorne Effect was only likely to decrease the number of errors due to increased vigilance. Thus, errors and behaviours discovered from the field observations can reasonably be considered as best-case outcomes.

\subsubsection{Brainstorming with HFMEA Team}

Additional failure modes were identified through team brainstorming sessions. During brainstorming sessions, the team focused on one sub-task at a time and brainstormed possible failure modes for that particular task. The failure modes identified were then recorded on the HFMEA worksheet (Figure 4). Each HFMEA worksheet records data for one major process step. To complete the HFMEA worksheet, the team first labelled the process step title and number on the top of the worksheet (labelled as "A" on Figure 4). Then, sub-tasks and their step numbers were recorded on the first column on the left (labelled as "B" on Figure 4). Subsequently, the failure modes identified for each sub-task along with the corresponding potential effects were documented in the "Failure Mode" and "Potential Effects" columns (labelled as "C" on Figure 4). Once the identified failure modes were recorded, the HFMEA team assigned hazard scores using the Hazard Scoring Matrix and determined if the potential failure mode was considered high-risk using the Decision Tree Analysis. The steps to completing the Hazard Scoring Matrix and the Decision Tree Analysis parts of the HFMEA worksheet will be explained in sections 3.4.2 and 3.4.3. 


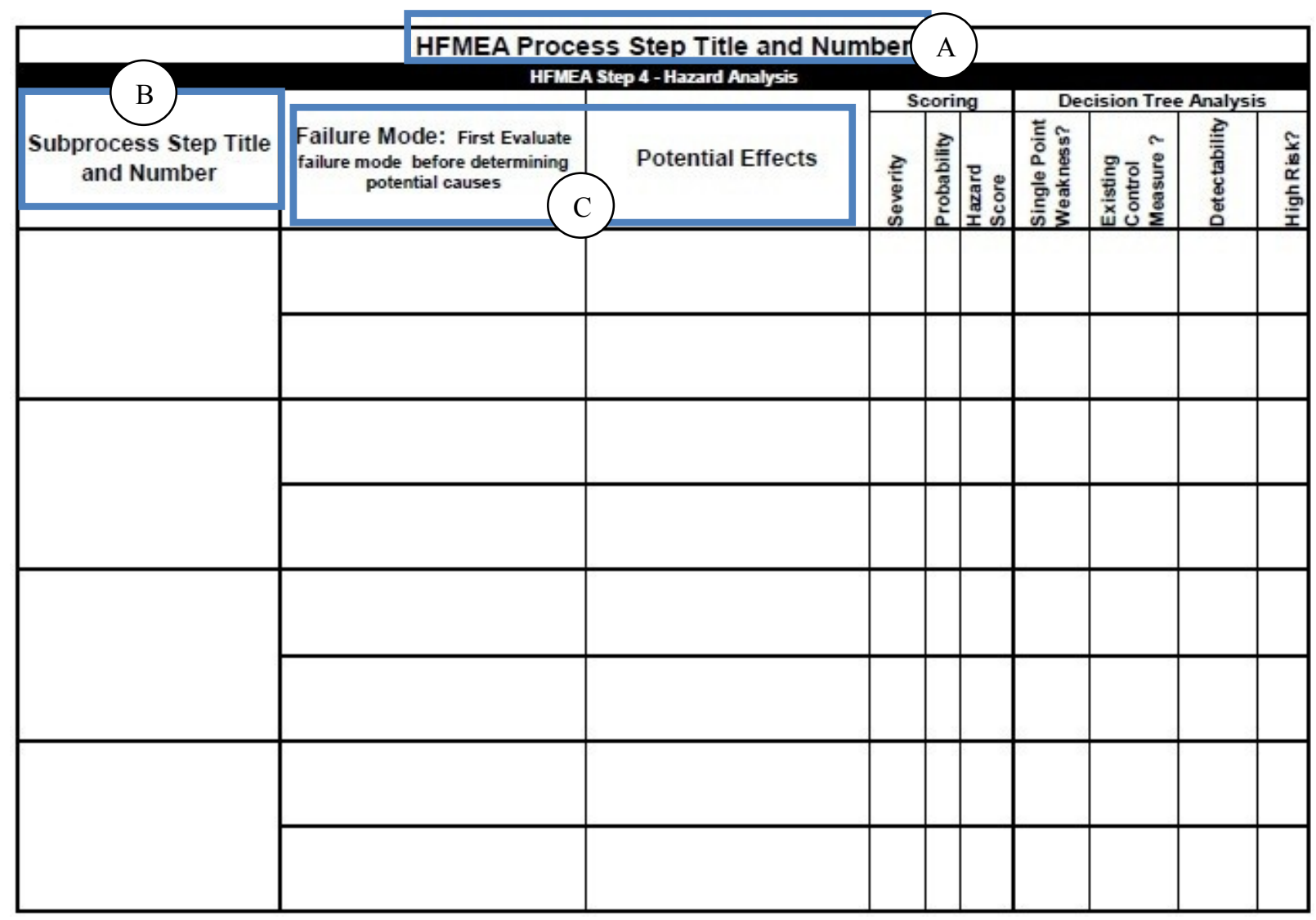

Figure 4: HFMEA Worksheet

\subsubsection{Secondary Infusion Scenario and Assumptions}

When brainstorming as a team in the failure modes identification step of the HFMEA process, it is important to consider the environment where the process takes place in order to be able to identify possible failure modes within the environment. Therefore, the clinical environment where secondary infusions are usually practiced should be described in order for the HFMEA team to be able to identify potential failure modes as well as potential effects as a result of the failure modes. Hence, a hypothetical scenario was developed to reflect a typical clinical setting while incorporating factors that may increase the risk of the delivery of secondary infusions. The hypothetical scenario also outlined common materials and components involved in an infusion system so that the HFMEA team could picture possible interactions between components which may or may not be identified as a failure mode. As well, since the severity of the failure mode partly depends on the drugs involved, the scenario gave a common basis to the potential patient outcome as a result of the failure modes identified. 
The hypothetical infusion set-up involved two primary infusions running at the same time on two separate pump channels, as shown on Figure 5. One of the primary infusions was $5 \%$ dextrose in water solution (D5W) and the other primary infusion was an inotrope which is classified as a high-risk drug. The secondary infusion being prescribed was morphine, which is also considered a high-risk drug and is not chemically compatible with the inotrope, but is compatible with D5W. Therefore, the secondary infusion should be piggybacked onto the D5W primary line. High-risk drugs were chosen for one of the primary infusions as well as the secondary infusion to illustrate the most severe case possible if the drugs were delivered at an inappropriate rate.
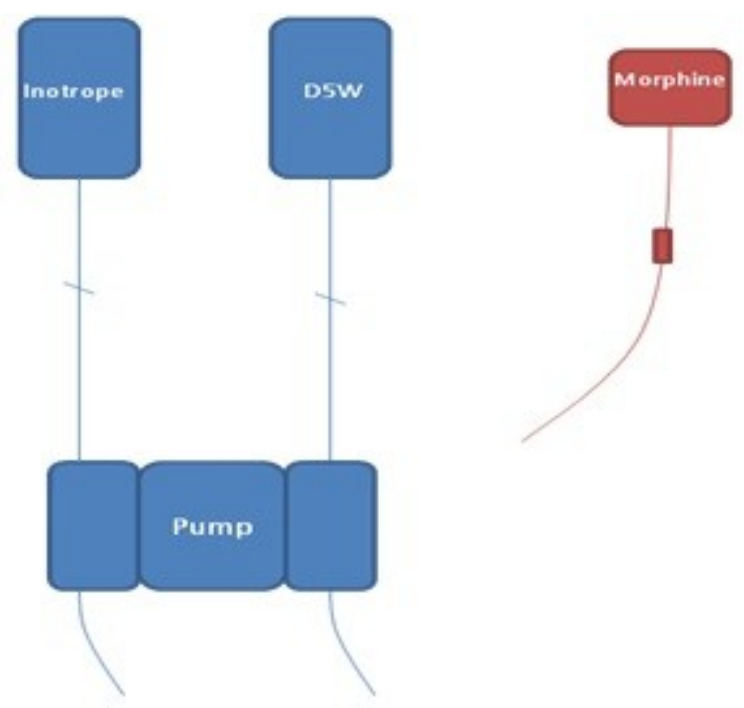

\section{Figure 5: Hypothetical infusion set-up}

Assumptions made in this scenario include:

- Nurses are familiar with the smart infusion pumps being evaluated; therefore, nurses would know how to program secondary infusions on the pump

- All infusions were mixed by pharmacy and were correctly labeled

- Secondary drug orders included the following infusion parameters: drug dose, volume, and duration

- No previous secondary infusion was given to this patient; therefore, requires new secondary set-up (i.e. new tubing)

- All primary tubing have three y-site ports 


\subsubsection{Hazard Scoring Matrix}

Hazard scores for each failure mode were assigned based on severity and probability (Table 6). Severity was rated based on potential patient outcome as a result of the failure modes and probability was rated based on the frequency of occurrence. The descriptions and definitions of the ratings are described below (Table 6, Table 7 and 
Table 8) (DeRosier \& Stalhandske, 2002). Data from clinical observations, incident report databases, and literature review were used to help assess the probability as well as the severity of identified failure modes.

Table 6: Hazard Scoring Matrix (DeRosier \& Stalhandske, 2002)

\begin{tabular}{|c|l|c|c|c|c|}
\hline \multirow{4}{*}{} & \multicolumn{5}{|c|}{ Severity of Effect } \\
\cline { 2 - 7 } & & Catastrophic & Major & Moderate & Minor \\
\cline { 2 - 7 } Probability & Frequent & 16 & 12 & 8 & 4 \\
\cline { 2 - 7 } & Occasional & 12 & 9 & 6 & 3 \\
\cline { 2 - 7 } & Uncommon & 8 & 6 & 4 & 2 \\
\cline { 2 - 7 } & Remote & 4 & 3 & 2 & 1 \\
\hline
\end{tabular}

Table 7: Severity Ratings (DeRosier \& Stalhandske, 2002)

\begin{tabular}{|l|l|}
\hline Severity Rating & Definition \\
\hline Minor & No injury, nor increased length of stay nor increased level of care \\
\hline Moderate & Increased length of stay \\
\hline Major & $\begin{array}{l}\text { Permanent lessening of bodily functioning (sensory, motor, physiologic, or } \\
\text { intellectual) }\end{array}$ \\
\hline Catastrophic & $\begin{array}{l}\text { Death or major permanent loss of function (sensory, motor, physiologic, or } \\
\text { intellectual) }\end{array}$ \\
\hline
\end{tabular}


Table 8: Probability Ratings (DeRosier \& Stalhandske, 2002)

\begin{tabular}{|l|l|}
\hline Probability Rating & Definition \\
\hline Remote & Unlikely to occur (may happen sometime in 5 to 30 years) \\
\hline Uncommon & Possible to occur (may happen sometime in 2 to 5 years) \\
\hline Occasional & Probably will occur (may happen several times in 1 to 2 years) \\
\hline Frequent & $\begin{array}{l}\text { Likely to occur immediately or within a short period (may happen } \\
\text { several times in one year) }\end{array}$ \\
\hline
\end{tabular}

\subsubsection{Inter-rater Reliability}

Hazard scoring was completed by two different raters (the author and a human factors researcher) individually. Since severity was based on patient outcome as a result of the failure modes, the incident reports data acted as a reference for the severity ratings. Before the hazard scores were assigned to the identified failure modes, the two raters reviewed the worst possible patient outcome for each issue from the incident report data and assigned severity ratings accordingly. These scores served as a rubric for the severity scoring process. On the other hand, probability scores were assigned based on literature review and clinical observations data. For example, if a failure mode was observed in the field as well as reported in the literature, the probability rating for that particular failure mode would be frequent. And if a failure mode have never been reported in the literature nor mentioned by nurses in the field, the probability rating would be remote. The draw back with this approach is that this exercise is subjective, since the rating is based on what the raters think the likelihood of occurrences are based on different sources, rather than using statistical data.

To assess the degree of agreement among raters, Kappa values were calculated for each group of ratings (i.e. Kappa values calculated for each of severity rating and probability rating for each failure mode; a total of two Kappa values for each failure mode identified) as it is an appropriate test for the inter-rater reliability of two raters (Posner et al., 1990). According to the literature (Landis \& Koch, 1977), a substantial agreement is reached if the Kappa value calculated is between 0.61 and 0.80 . As well, the degree of agreement is considered as "almost perfect" if the calculated Kappa value falls between 0.81 and 1.00 (Landis \& Koch, 1977). A group discussion 
with the two raters plus another human factors researcher (a total of three people) was held to reach a consensus when a discrepancy in the scoring was found.

\subsubsection{Decision Tree Analysis}

Once hazard scores were assigned, the Decision Tree Analysis was used to determine if the failure modes require further attention. This evaluative method is based on criticality, presence of effective control measure, and detectability, as shown in Figure 6. The purpose of the Decision Tree Analysis is to identify areas where the team needs to mitigate vulnerabilities as well as areas not needing further attention (DeRosier \& Stalhandske, 2002). Identified failure modes were classified as high-risk by the Decision Tree Analysis when they were critical, did not have an effective control measure in place, and were not easily detectable. A failure mode was considered critical if it involves a sufficient likelihood of occurrence and severity to warrant that it be controlled (a hazard score of 8 or higher), or if it was a single point weakness of the process, meaning if the failure mode leads to a failure of the system (DeRosier \& Stalhandske, 2002). Data from clinical observations and literature review acted as references for this part of the HFMEA analysis. 


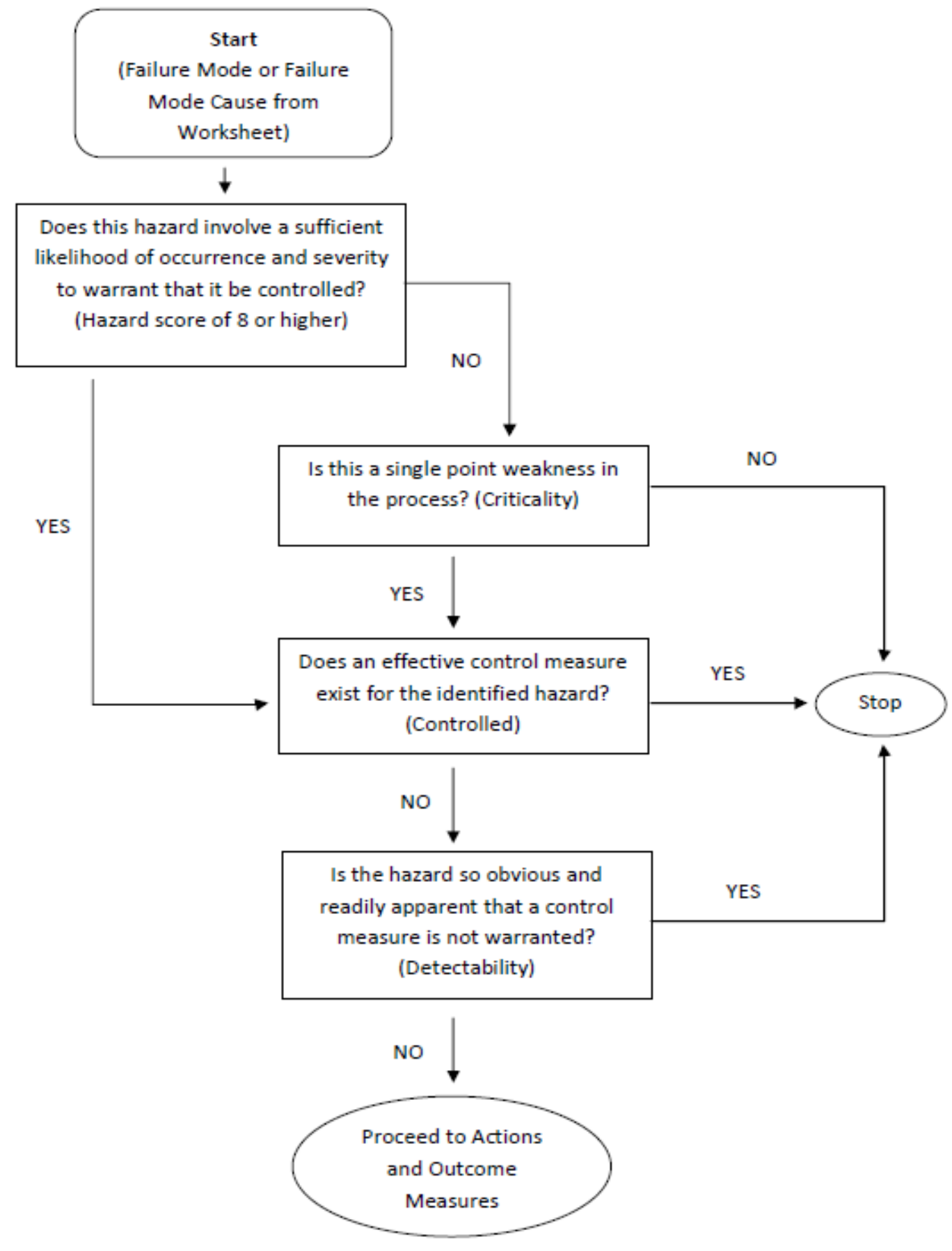

Figure 6: Decision Tree from VA’s HFMEA model (DeRosier \& Stalhandske, 2002) 


\section{Chapter 4 Results}

\section{Results}

This chapter will begin with a description of the model secondary infusion process to outline all the major tasks and sub-tasks required to administer secondary infusions since each process step is a potential event or opportunity for errors to occur, which may cause the system to fail. Once the secondary infusion process is mapped, Section 4.2 will present the different failure modes identified by the four methods described in the previous chapter: literature review, incident reports analysis, clinical observations, and brainstorming with the HFMEA team. This chapter will end by outlining the high-risk failure modes identified from the hazard scoring matrix and decision tree analysis to highlight failure modes that are of most concern and require further attention. The high-risk failure modes will be compared across the five different smart infusion pumps (Alaris PC, Baxter Colleague, B. Braun Infusomat Space, Hospira Symbiq, and Hospira Plum $\mathrm{A}+$ ) to examine the advantages and disadvantages of each smart pump in the delivery of secondary infusions.

\subsection{Process Description}

The description of the model secondary infusion administration process was based on the literature (Centre for Quality and Productivity Improvement, 2004; Nettina, 2009). The process flow diagram is shown below in Figure 7, which consists of eight major tasks. The two parallel processes from steps two to four describe the tasks required for the two different priming techniques. Priming means to fill the infusion tubing with fluid to remove all the air in the tubing. Nurses first connect the appropriate secondary tubing to the secondary container. Then, , nurses can choose to prime the secondary line with the secondary fluid, hang the secondary container, and attach the secondary line to the primary line. Alternatively, they can choose to hang the secondary container after the secondary container is prepared, attach the secondary line to the primary line, and back-prime the primary fluid into the secondary line. To back-prime, nurses would bring the secondary fluid container at an elevation lower than the primary container so that the fluid would flow from higher hydrostatic pressure (primary container) to lower hydrostatic pressure (secondary container). 


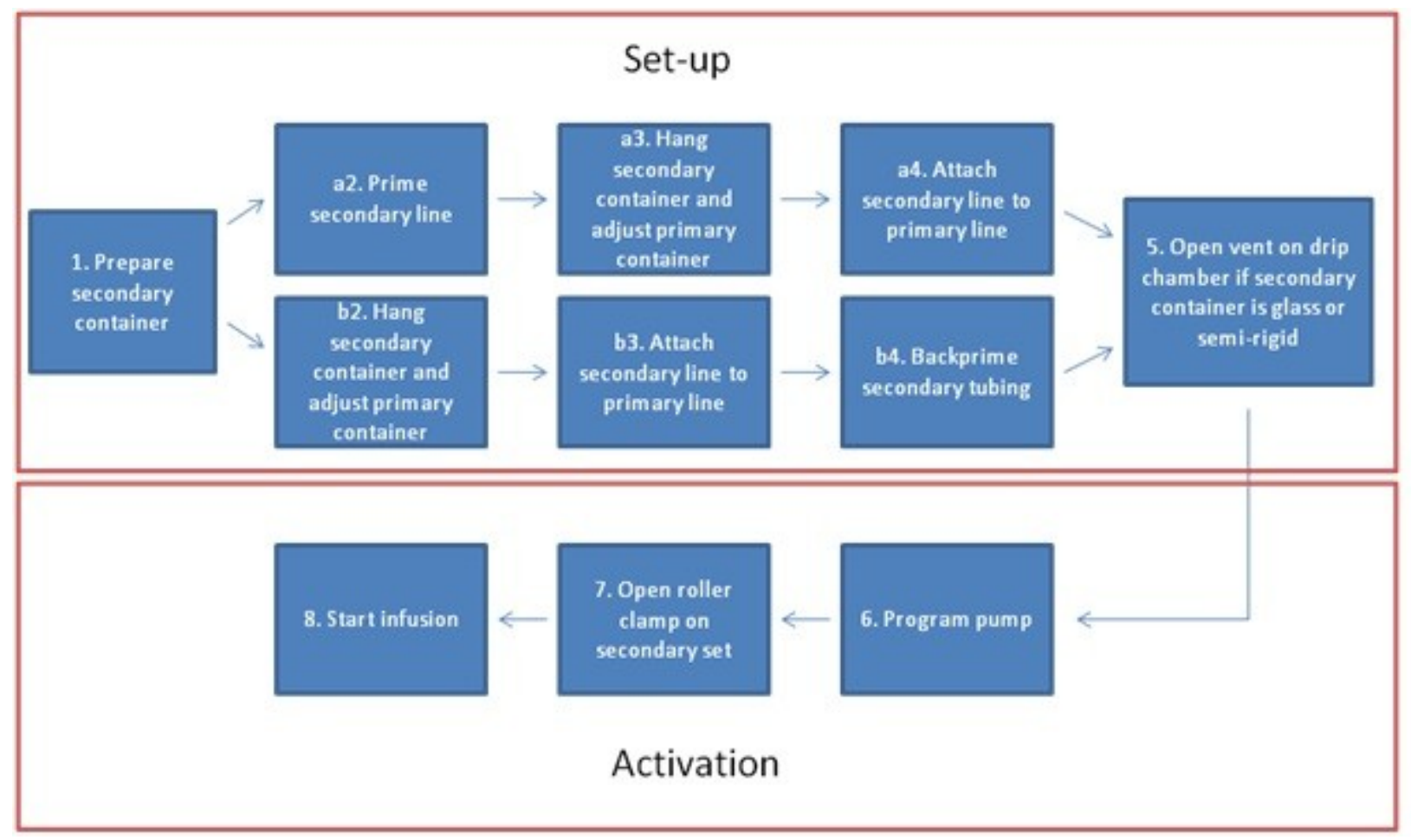

\section{Figure 7: Secondary infusion administration process flow diagram}

The outlined secondary infusion administration process is considered as a model process because in reality, nurses may deviate from this process depending on personal preference or how they were trained by their mentors. However, as observed in clinical observations, deviations only occurred in steps two to four of the "Set-up" part of the process. For instance, nurses may choose to hang the secondary container and adjust the primary container (step a3) prior to priming the secondary line (step a2), or attach the secondary line to the primary line (step a4) prior to hanging the secondary container and lowering the primary container (step a3). The first deviation described (step a3 before step a2) would allow nurses to set-up the secondary container and tubing correctly without consequences. However, when performing the second deviation described (step a4 before step a3) after the secondary tubing is primed (step a2), nurses would have to be careful not to let the secondary container drop below the primary container when hanging the secondary container and lower the primary container (step a3). The reason being, once the secondary line is connected to the primary line, fluid would flow from the container with higher hydrostatic pressure (higher container) to lower hydrostatic pressure (lower container). As a result, if the secondary container is dropped below the primary container after the secondary tubing is primed and connected, primary fluid would flow into the secondary 
tubing, increasing the volume of the secondary container to an unknown value. Therefore, nurses may have to adjust the volume on the secondary infusion program or the patient may not receive the amount of drug intended. On the other hand, a similar deviation can be performed in parallel process " $b$ " where nurses may connect the secondary line to the primary line (step b3), backprime secondary tubing with primary fluid (step b4), and then hang the secondary container and lower the primary container (step b2). In this case, the priming volume is known if primary fluid is used to fill the whole secondary tubing. As a result, no consequences would be observed since the nurses would know the volume of fluid added to the secondary container and would be able to adjust the secondary program accordingly to make sure the patient receives the full volume of the secondary container.

As shown in Figure 7, the first five steps of the process are classified as the "Set-up" part of the process as the nurses have to manipulate the secondary bags and tubing to prepare for the secondary infusion administration. The second part of the process is named the "Activation" part of the process where the nurses activate all the components of the system to start the infusion. "Activation" consists of programming the infusion pump, opening the roller clamp on the secondary set, and starting the infusion on the infusion pump. Each major step of the process is further described in Sections 4.1.1 and 4.1.2 as the detailed task break-down for each major step revealed potential events and opportunities for errors to occur, which may cause the system to fail.

\subsubsection{Set-up}

The following sections describe all the major steps in the "Set-up" part of the process in detail, outlining all the sub-tasks required to complete each step as well as the descriptions for each subtask. The sub-tasks required will also be compared between the five smart infusion pumps examined since there are differences in the set-up of secondary container and tubing between the five smart infusion pumps.

\subsubsection{Step 1: Prepare Secondary Container}

This study assumes all infusion bags are pre-mixed by pharmacy with the correct drug, correct drug concentration, and correct label on the infusion bag. Therefore, the first step of the process is to prepare the secondary container by selecting the appropriate secondary tubing, opening the secondary tubing package, making sure the roller clamp on the tubing is closed, and spike the 
secondary container to connect the infusion bag to the tubing. Table 9 shows the description for each of the sub-tasks required when preparing the secondary container for secondary infusion. This step of the process does not vary across infusion pumps.

Table 9: Sub-process description for Step 1

\begin{tabular}{|l|l|l|}
\hline $\begin{array}{l}\text { Sub-process } \\
\text { Step Number }\end{array}$ & Sub-process Step Title & Description \\
\hline 1A & $\begin{array}{l}\text { Select appropriate secondary } \\
\text { tubing }\end{array}$ & $\begin{array}{l}\text { Select appropriate tubing material (i.e. } \\
\text { secondary tubing with/without Di(2- } \\
\text { ethylhexyl)phthalate (DEHP) depending on } \\
\text { drug and material compatibility) and } \\
\text { appropriate tubing type (i.e. primary versus } \\
\text { secondary tubing) }\end{array}$ \\
\hline 1B & $\begin{array}{l}\text { Open secondary tubing } \\
\text { package and close roller clamp } \\
\text { on secondary tubing }\end{array}$ & $\begin{array}{l}\text { Roller clamp is originally opened when in the } \\
\text { package. Therefore, after opening the } \\
\text { package, nurses need to close the roller clamp } \\
\text { in order to prevent drug leak }\end{array}$ \\
\hline 1C & Spike secondary container & $\begin{array}{l}\text { Connect the secondary tubing to the } \\
\text { secondary bag by inserting the spike into the } \\
\text { secondary bag }\end{array}$ \\
\hline
\end{tabular}

\subsubsection{Step a2: Prime Secondary Line}

Once the secondary container is prepared, nurses can either prime the secondary line with the secondary fluid (process "a") or back-prime with the primary fluid (process "b"). If nurses choose to prime the secondary line with the secondary fluid (process "a"), then the second step of the process would be to prime the line by filling the drip chamber, opening the roller clamp, allow for fluid to flow through the tubing so that the tubing is filled with secondary medication to displace the air in the tubing, and close the clamp on the secondary tubing once the medication reaches the end of the tubing to prevent leakage.

Table 10 shows the description for each of the sub-tasks required to prime the secondary line.

This step of the process does not vary across infusion pumps.

Table 10: Sub-process description for Step a2

\begin{tabular}{|l|l|l|}
\hline $\begin{array}{l}\text { Sub-process } \\
\text { Step Number }\end{array}$ & Sub-process Step Title & Description \\
\hline
\end{tabular}




\begin{tabular}{|l|l|l|}
\hline a2A & Fill drip chamber to 2/3 full & $\begin{array}{l}\text { Squeeze the drip chamber to allow the fluid } \\
\text { from the infusion bag to drip down and collect } \\
\text { in the drip chamber. Drip chamber should be } \\
\text { filled to prevent air from getting into the } \\
\text { tubing while still be able to observe the fluid } \\
\text { dripping from the bag }\end{array}$ \\
\hline a2B & $\begin{array}{l}\text { Open roller clamp on } \\
\text { secondary tubing }\end{array}$ & $\begin{array}{l}\text { Open roller clamp on secondary tubing to } \\
\text { allow fluid to flow }\end{array}$ \\
\hline a2C & $\begin{array}{l}\text { Allow fluid to flow until } \\
\text { tubing is primed }\end{array}$ & $\begin{array}{l}\text { Filling the tubing with fluid to force all the air } \\
\text { out of the tubing }\end{array}$ \\
\hline a2D & $\begin{array}{l}\text { Close roller clamp on } \\
\text { secondary tubing }\end{array}$ & $\begin{array}{l}\text { Close roller clamp on secondary tubing to } \\
\text { prevent drug leakage before the secondary } \\
\text { drug is ready to be infused. }\end{array}$ \\
\hline
\end{tabular}

\subsubsection{Step a3 and b2: Hang Secondary Container and Adjust Primary Container}

The third step in process " $a$ ", or the second step in process " $b$ ", is to hang the secondary container. The sub-tasks involved with this step of the process may vary between infusion pumps. The reason being, some infusion pumps require a difference in hydrostatic pressure to be established in order to close the back-check valve so that the secondary fluid can flow while the primary fluid is stopped temporarily. For most of the smart infusion pumps examined in this study (i.e. Baxter Colleague CXE, B. Braun Infusomat Space, Cardinal Health Alaris PC, and Hospira Symbiq), this step consists of lowering the primary container with the secondary hanger to establish a difference in hydrostatic pressure between the two infusion bags and close the back-check valve on the primary tubing to stop the flow of primary fluid.

Table 11 describes each of the sub-tasks required to hang the secondary container and adjust the primary container when using most of the infusion pumps studied (i.e. Baxter Colleague CXE, B. Braun Infusomat Space, Cardinal Health Alaris PC, and Hospira Symbiq).

Table 11: Sub-process description for Step a3/b2 - Baxter Colleague CXE, B. Braun Infusomat Space, Cardinal Health Alaris PC, and Hospira Symbiq

\begin{tabular}{|l|l|l|}
\hline $\begin{array}{l}\text { Sub-process } \\
\text { Step Number }\end{array}$ & Sub-process Step Title & Description \\
\hline
\end{tabular}




\begin{tabular}{|l|l|l|}
\hline a3A/b2A & $\begin{array}{l}\text { Hang secondary container on } \\
\text { IV pole }\end{array}$ & $\begin{array}{l}\text { Hang secondary container on the hooks on the } \\
\text { IV pole }\end{array}$ \\
\hline a3B/b2B & $\begin{array}{l}\text { Confirm primary set has back- } \\
\text { check valve }\end{array}$ & $\begin{array}{l}\text { Check to make sure the primary tubing has a } \\
\text { back-check valve to stop the flow of primary } \\
\text { fluid while the secondary medication is being } \\
\text { administered }\end{array}$ \\
\hline a3C/b2C & $\begin{array}{l}\text { Hang primary container lower } \\
\text { using secondary hanger }\end{array}$ & $\begin{array}{l}\text { Lower the primary container by hanging the } \\
\text { primary container on the secondary hanger }\end{array}$ \\
\hline
\end{tabular}

For the Hospira Plum A+, the cassette draws fluid directly from either the primary bag or secondary bag. Therefore, the pump does not rely on the back-check valve to control the flow of the primary and secondary fluids. Without the use of the back-check valve, nurses would not have to adjust the height of the primary bag when using the Hospira Plum A+ smart infusion pump. As a result, the only sub-task in this step when using the Hospira Plum A+ is to hang the secondary container on the IV pole (Table 12).

Table 12: Sub-process description for Step a3/b2 - Hospira Plum A+

\begin{tabular}{|l|l|l|}
\hline $\begin{array}{l}\text { Sub-process } \\
\text { Step Number }\end{array}$ & Sub-process Step Title & Description \\
\hline a3A/b2A & $\begin{array}{l}\text { Hang secondary container on } \\
\text { IV pole }\end{array}$ & $\begin{array}{l}\text { Hang secondary container on the hooks on the } \\
\text { IV pole }\end{array}$ \\
\hline
\end{tabular}

Since there are fewer sub-tasks involved when using the Hospira Plum A+ to complete this step, there is potentially less chance for errors to occur in this step of the process with the Hospira Plum A+ compared to the other smart infusion pumps examined in this study (i.e. Baxter Colleague CXE, B. Braun Infusomat Space, Cardinal Health Alaris PC, and Hospira Symbiq)

\subsubsection{Step a4 and b3: Connect Secondary Line to Primary Tubing}

The fourth step in process "a", or third step in process " $b$ ", is to connect the secondary line to the primary tubing. The sub-tasks involved are different between the Hospira Plum A+ and the other smart infusion pumps examined. For most of the smart infusion pumps examined (i.e. Baxter Colleague CXE, B. Braun Infusomat Space, Cardinal Health Alaris PC, and Hospira Symbiq), the secondary tubing is connected to the upper y-site port on the primary tubing, above the infusion pump. On the other hand, the secondary tubing is connected to the secondary port on the 
cassette when using the Hospira Plum A+. Table 13 provides a description for each of the subtasks required to connect the secondary line to primary tubing when using the Baxter Colleague CXE, B. Braun Infusomat Space, Cardinal Health Alaris PC, and Hospira Symbiq.

Table 13: Sub-process description for Step a4/b3 - Baxter Colleague CXE, B. Braun Infusomat Space, Cardinal Health Alaris PC, and Hospira Symbiq

\begin{tabular}{|l|l|l|}
\hline $\begin{array}{l}\text { Sub-process } \\
\text { Step Number }\end{array}$ & Sub-process Step Title & Description \\
\hline a4A/b3A & $\begin{array}{l}\text { Swab upper y-site port on } \\
\text { primary tubing with } \\
\text { appropriate antiseptic }\end{array}$ & $\begin{array}{l}\text { Sterilize the connection site with the } \\
\text { appropriate antiseptic }\end{array}$ \\
\hline a4B/b3B & $\begin{array}{l}\text { Connect secondary line to } \\
\text { upper y-site port on primary } \\
\text { tubing }\end{array}$ & $\begin{array}{l}\text { Connect the secondary tubing to the y-site port } \\
\text { on primary tubing that is upstream of the } \\
\text { infusion pump }\end{array}$ \\
\hline
\end{tabular}

For the Hospira Plum A+, the secondary tubing is connected to the secondary port on the cassette. Table 14 provides a description for each of the sub-tasks performed.

Table 14: Sub-process description for Step a4/b3 - Hospira Plum A+

\begin{tabular}{|l|l|l|}
\hline $\begin{array}{l}\text { Sub-process } \\
\text { Step Number }\end{array}$ & Sub-process Step Title & Description \\
\hline a4A/b3A & $\begin{array}{l}\text { Swab upper y-site port on } \\
\text { infusion pump chamber with } \\
\text { appropriate antiseptic }\end{array}$ & $\begin{array}{l}\text { Sterilize the connection site with the } \\
\text { appropriate antiseptic }\end{array}$ \\
\hline a4B/b3B & $\begin{array}{l}\text { Connect secondary line to } \\
\text { secondary port on cassette }\end{array}$ & $\begin{array}{l}\text { Connect the secondary line to the secondary } \\
\text { port on the cassette }\end{array}$ \\
\hline
\end{tabular}

Thus, the Hospira Plum A+ differs from other smart infusion pumps examined in the location where the secondary tubing is connected.

\subsubsection{Step b4: Back-prime Secondary Tubing}

Once the tubing is connected, the fourth step of process " $b$ " is to back-prime the secondary tubing with the primary fluid. The sub-tasks involved for this step of the process is different between the Hospira Plum A+ and the other smart infusion pumps examined (i.e. Baxter Colleague CXE, B. Braun Infusomat Space, Cardinal Health Alaris PC, and Hospira Symbiq). 
When back-priming most smart infusion pumps examined (i.e. Baxter Colleague CXE, B. Braun Infusomat Space, Cardinal Health Alaris PC, and Hospira Symbiq), nurses are required to open the roller clamp and bring the secondary bag to below the primary bag, lowering the hydrostatic pressure of the secondary bag relative to the primary bag. As a result, primary fluid flows into the secondary tubing and the drip chamber. Once the drip chamber is filled, nurses can close the roller clamp and hang the secondary bag back on the pole. 
Table 15 provides a description for each of the sub-tasks required when back-priming the secondary tubing for most of the smart infusion pumps examined. 
Table 15: Sub-process description for Step b4 - Baxter Colleague CXE, B. Braun Infusomat Space, Cardinal Health Alaris PC, and Hospira Symbiq

\begin{tabular}{|l|l|l|}
\hline $\begin{array}{l}\text { Sub-process } \\
\text { Step Number }\end{array}$ & Sub-process Step Title & Description \\
\hline b4A & Open secondary clamp & $\begin{array}{l}\text { Open roller clamp on secondary tubing to } \\
\text { allow fluid to flow }\end{array}$ \\
\hline b4B & $\begin{array}{l}\text { Lower secondary bag below } \\
\text { primary container }\end{array}$ & $\begin{array}{l}\text { Lower the secondary bag to below the primary } \\
\text { container, which causes the hydrostatic } \\
\text { pressure of the secondary container to be lower } \\
\text { than the primary container, allowing the } \\
\text { primary fluid to flow into the secondary } \\
\text { tubing. }\end{array}$ \\
\hline b4C & $\begin{array}{l}\text { Allow primary fluid to flow } \\
\text { into secondary tubing until drip } \\
\text { chamber } 2 / 3 \text { full }\end{array}$ & $\begin{array}{l}\text { Allow primary fluid to prime the secondary } \\
\text { tubing. Drip chamber should be filled to } \\
\text { prevent air from getting into the tubing while } \\
\text { still be able to observe the fluid dripping from } \\
\text { the bag }\end{array}$ \\
\hline b4D & $\begin{array}{l}\text { Close secondary clamp } \\
\text { b4E }\end{array}$ & $\begin{array}{l}\text { Close roller clamp on secondary tubing to } \\
\text { prevent secondary drug from delivering at an } \\
\text { undesired rate }\end{array}$ \\
\hline
\end{tabular}

On the other hand, the Hospira Plum A+ pump provides a back-prime button to allow nurses to back-prime the secondary tubing without having to adjust the height of the secondary bag. To use this feature, nurses would open the roller clamp on the secondary tubing, hold the backprime button until the drip chamber is filled, then release the back-prime button. Table 16 provides a description for each of the sub-tasks required when back-priming the secondary tubing using the Hospira Plum A+. 
Table 16: Sub-process description for Step b4 - Hospira Plum A+

\begin{tabular}{|l|l|l|}
\hline $\begin{array}{l}\text { Sub-process } \\
\text { Step Number }\end{array}$ & Sub-process Step Title & Description \\
\hline b4A & Open secondary clamp & $\begin{array}{l}\text { Open roller clamp on secondary tubing to } \\
\text { allow fluid to flow }\end{array}$ \\
\hline b4B & $\begin{array}{l}\text { Hold Back-prime button on } \\
\text { pump }\end{array}$ & $\begin{array}{l}\text { Hold Back Prime button to prime the } \\
\text { secondary line with primary fluid }\end{array}$ \\
\hline b4C & $\begin{array}{l}\text { Allow primary fluid to flow } \\
\text { chamber } 2 / 3 \text { full }\end{array}$ & $\begin{array}{l}\text { Allow primary fluid to prime the secondary } \\
\text { tubing. Release the Back Prime button when } \\
\text { the drip chamber is } 2 / 3 \text { full. Drip chamber } \\
\text { should be filled to prevent air from getting into } \\
\text { the tubing while still be able to observe the } \\
\text { fluid dripping from the bag }\end{array}$ \\
\hline
\end{tabular}

Since there are fewer sub-tasks involved when using the Hospira Plum A+ to complete this step, there is potentially less chance for errors to occur in this step of the process with the Hospira Plum A+ compared to the other smart infusion pumps examined in this study (i.e. Baxter Colleague CXE, B. Braun Infusomat Space, Cardinal Health Alaris PC, and Hospira Symbiq)

\subsubsection{Step 5: Open Vent on Drip Chamber if Secondary Container is Glass or Semi-Rigid}

The fifth step of the process is to open the vent near the drip chamber if the secondary container is glass or semi-rigid. Glass and semi-rigid containers are not able to collapse or expand; therefore, the containers must be vented to allow fluid to flow in or out. This step of the process is the same across all infusion pumps. Table 17 provides a description of this step.

Table 17: Sub-process description for Step 5

\begin{tabular}{|l|l|l|}
\hline $\begin{array}{l}\text { Sub-process } \\
\text { Step Number }\end{array}$ & Sub-process Step Title & Description \\
\hline $5 \mathrm{~A}$ & Open vent & $\begin{array}{l}\text { If the secondary container is glass or semi- } \\
\text { rigid, the vent needs to be opened in order for } \\
\text { air to displace the volume of fluid in the glass } \\
\text { container. }\end{array}$ \\
\hline
\end{tabular}

In sum, the tasks required in the set up part of the secondary infusion administration process are similar across most smart infusion pumps examined (i.e. Baxter Colleague CXE, B. Braun 
Infusomat Space, Cardinal Health Alaris PC, and Hospira Symbiq), except for the Hospira Plum A+. For instance, most smart infusion pumps require nurses to establish a difference in hydrostatic pressure between the primary and secondary containers in order to close the backcheck valve on the primary tubing to allow for secondary fluid to flow while temporarily stopping the primary fluid flow. As well, when using most infusion pumps, the secondary tubing is connected to the y-site port on the primary tubing above the smart infusion pump, but below the back-check valve, so that the difference in hydrostatic pressure would close the back-check valve while the flow of the secondary fluid can be controlled by the infusion pump. However, when using the Hospira Plum A+ pump, nurses would not have to hang the primary and secondary bags at different heights and the secondary tubing is connected to the cassette rather than to the y-site port on the primary tubing. This is because the cassette and pumping mechanism on the Hospira Plum A+ is designed in a way that the infusion pump draws the secondary fluid directly from the secondary container rather than relying on a back-check valve to control the flow of the secondary fluid. Lastly, when using the back-prime method to prime the secondary line, the Hospira Plum A+ offers a mechanical mechanism on the infusion pump that can drive the primary fluid to the secondary tubing with the press of a button. However, with most other smart infusion pumps examined (i.e. Baxter Colleague CXE, B. Braun Infusomat Space, Cardinal Health Alaris PC, and Hospira Symbiq), nurses would have to manually lower the height of the secondary container to manipulate the difference in hydrostatic pressure so that fluid would flow from the primary line to the secondary line. Therefore, with the simplified process of setting up secondary infusions when using the Hospira Plum $\mathrm{A}^{+}$, there are potentially less areas for errors to occur.

\subsubsection{Activation}

The activation part of the process refers to the last three steps of the process where nurses program the infusion pump, open the roller clamp to allow for fluid flow, and start the infusion. The following sections describe all the tasks performed in the activation part of the process.

\subsubsection{Step 6: Program Pump}

Step six is to input infusion parameters into the secondary program for the infusion pump in order to control the rate of the secondary infusion. In general, programming a secondary infusion involves selecting the secondary infusion function menu, selecting drug from DERS, selecting 
drug concentration from DERS, and inputting infusion parameters. Some infusion pumps may also require the user to select the appropriate drug library profile when programming a secondary infusion pump. Drug library profile refers to the profile associated with the collection of drugs and drug information available on a particular patient unit type (e.g. critical care, oncology, etc.). Various drug library profiles are usually set-up for the fleet of smart infusion pumps in the hospital because different drugs or different concentration of drugs may be used in different types of patient units. For example, chemotherapy drugs may be included in the oncology unit drug library profile but not in other unit types. By separating the libraries based on unit type, nurses would only be able to select and deliver drugs that are available on their designated unit. When comparing the different smart infusion pumps, the programming sequences differ in the presence of DERS, library profile selection, and mandatory input parameters. Depending on the infusion parameters specified on the physician's order and the mandatory input parameters on the infusion pump, manual calculations may be needed when programming a secondary infusion on the smart infusion pumps. For example, with the physician's order that was used in the secondary infusion scenario described in this study, the infusion parameters specified consisted of drug dose, volume and duration, which reflects the types of information the physicians specify at the majority of the hospitals observed. If an infusion pump requires nurses to input the volumetric rate of the infusion, they would need to perform manual calculations in order to program the secondary infusion because the volumetric rate of the infusion was not specified on the physician's order. An example of the calculation is shown in Figure 8. 


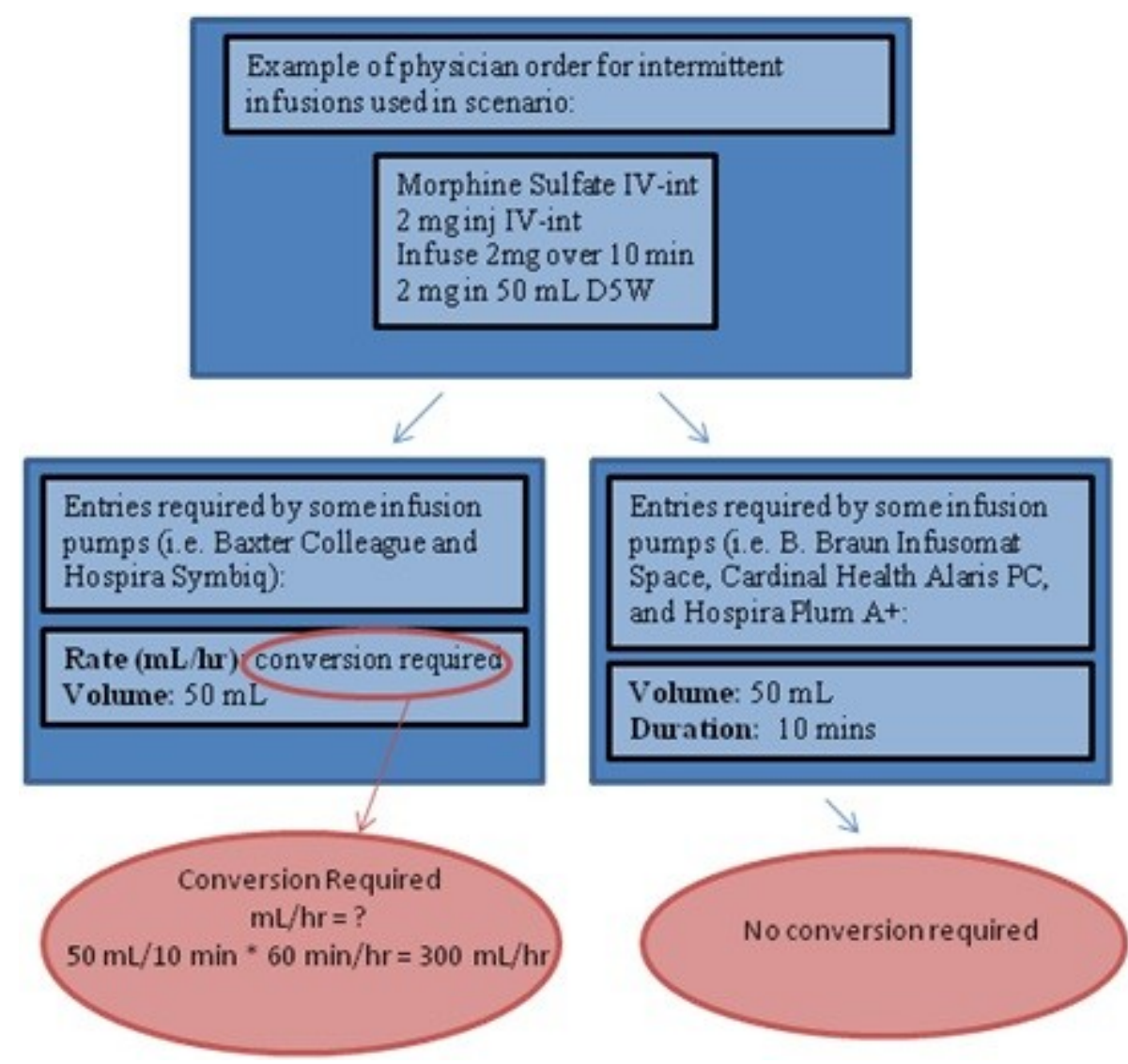

Figure 8: Example of conversion calculation when programming secondary infusions

To understand the difference in programming sequence between each smart infusion pump examined, the workflow process for each smart infusion pump was mapped and described in the following sections.

\subsection{Baxter Colleague CXE}

Figure 9 shows the workflow process of programming a secondary infusion on the Baxter Colleague CXE. When inputting infusion parameters on this infusion pump, the pump requires nurses to enter the volumetric rate and volume of the infusion by default. As a result, manual calculations would be required when programming secondary infusions based on the scenario described in this study when programming in the default menu. However, the nurses can also choose to "Change Mode" and program the secondary infusion using volume and duration so that manual calculations are not required. Based on the scenario described in this study, manual calculations would be required when programming the secondary infusion using the default mode as volumetric rate information was not specified on the physician's order. Manual 
calculations, however, would not be required in the volume-duration mode since those parameters were specified on the physician's order. Compared to other smart infusion pumps included in the study, the Baxter Colleague CXE is the only pump that does not offer DERS for secondary infusions, which means that dosing limits are not applied when programming secondary infusions on this pump. As a result, this infusion pump would not be able to detect any programming errors.

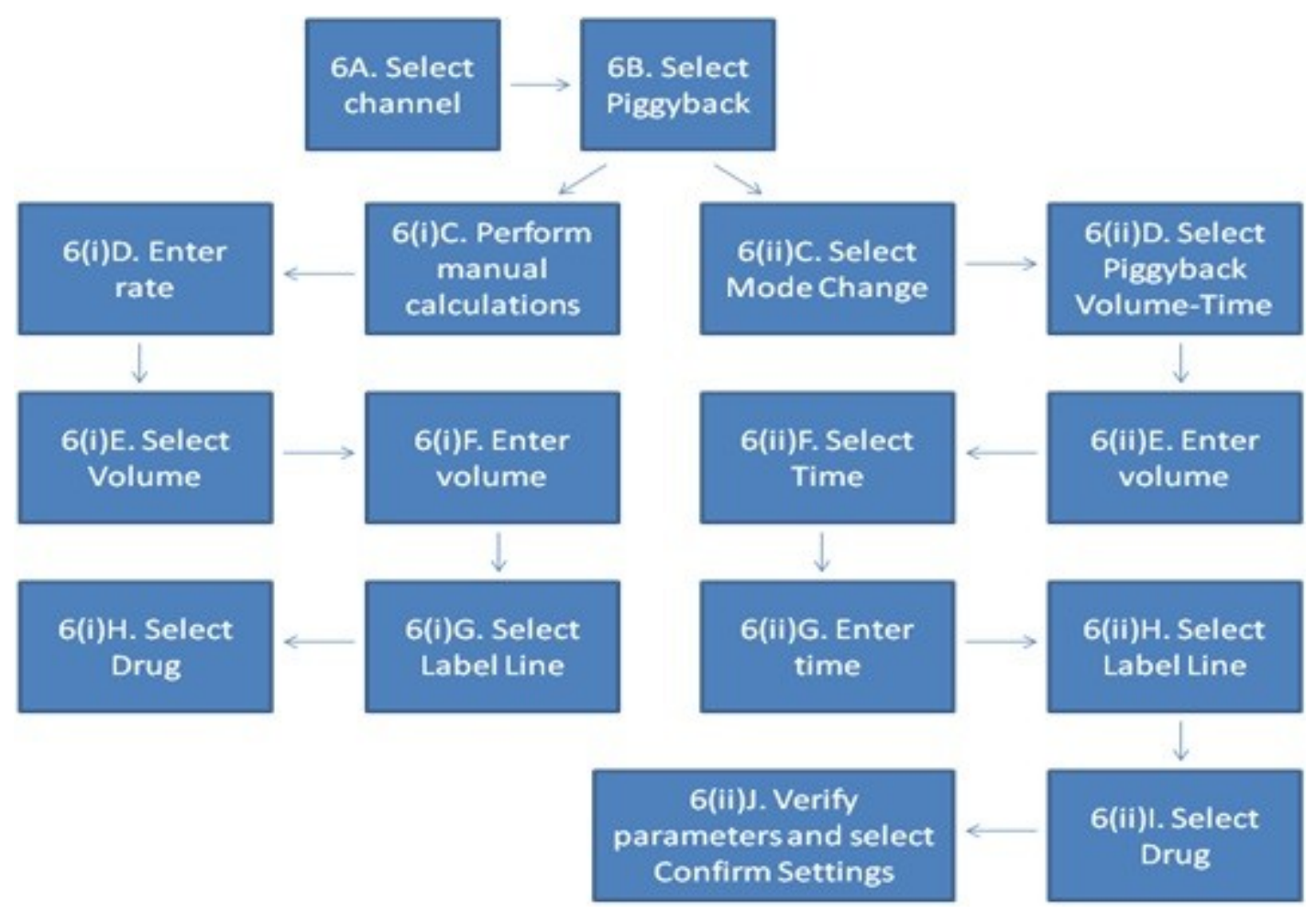

Figure 9: Workflow diagram for programming a secondary infusion on the Baxter Colleague CXE

\subsection{B. Braun Infusomat Space}

Figure 10 shows the workflow process of programming a secondary infusion on the B. Braun Infusomat Space. When inputting infusion parameters on this infusion pump, the pump requires nurses to enter the volume of the infusion. They can then choose to enter time, volumetric rate, or dose rate as a second infusion parameter for drug calculations. As a result, based on the scenario described in this study, nurses would be able to program the infusion pump by entering volume and time written on the physician's order in the scenario outlined for this study. If nurses wish to program the infusion using volumetric rate or dose rate, however, they would have to 
perform manual calculation. Although the B. Braun Infusomat Space offers DERS for secondary infusion program, it is the only pump that requires nurses to select the drug library profile in the secondary program compared to other smart infusion pumps examined in this study. As a result, there is a risk for nurses to select the incorrect drug library profile, which may cause incorrect alerts to sound or failure to detect programming errors as incorrect dosing limits are applied to the drug selected.

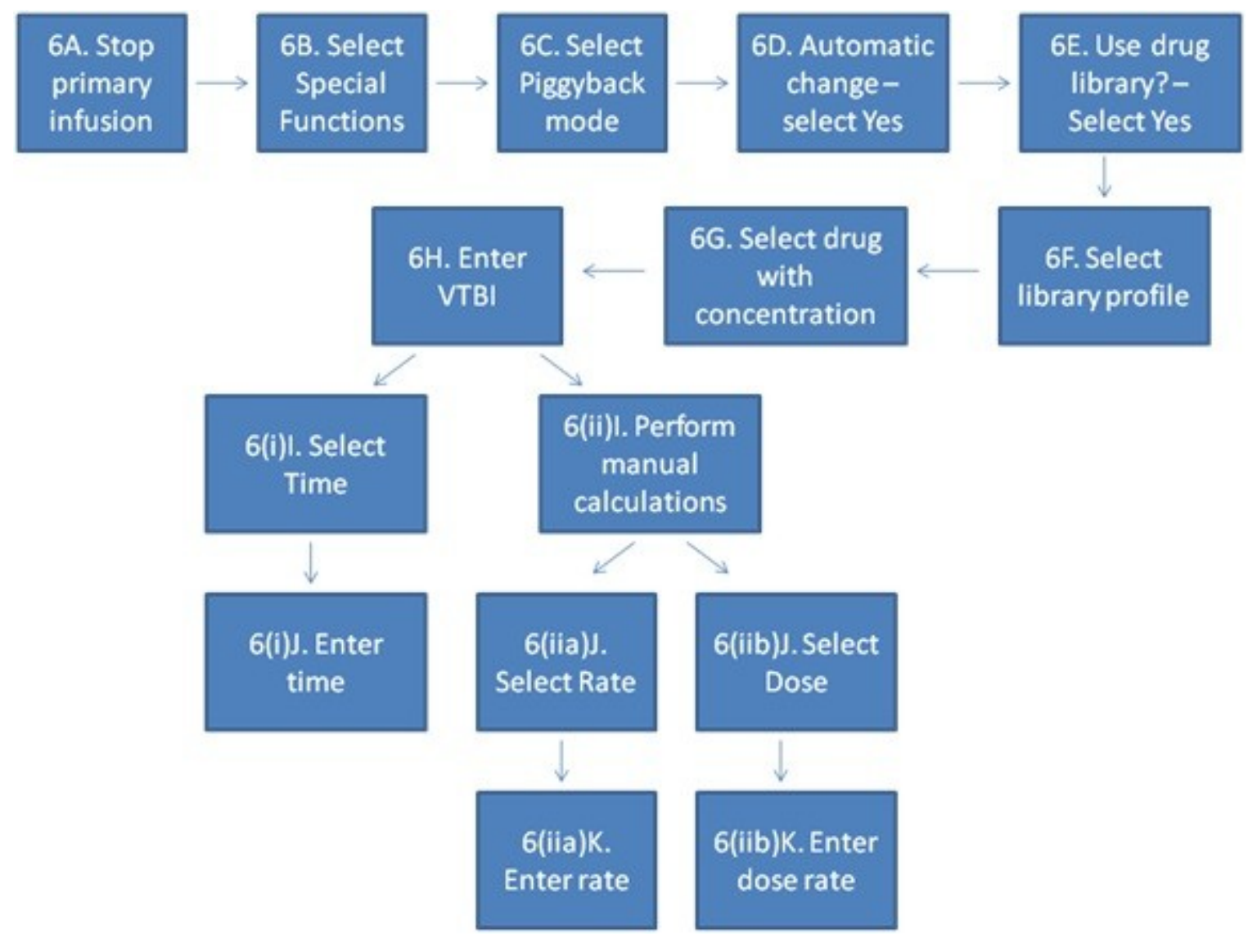

Figure 10: Workflow diagram for programming a secondary infusion on the B. Braun Infusomat Space 


\subsection{Cardinal Health Alaris PC}

Figure 11 shows the workflow process of programming a secondary infusion on the Cardinal Health Alaris PC. This infusion pump offers DERS for secondary infusion program and does not require nurses to select the drug library profile as it assumes the drug library profile for the secondary infusion is the same as the drug library profile selected for the primary infusion on the same infusion pump. As well, the only infusion parameters available for input are volume and duration. Based on the physician's order assumed in the scenario outlined for this study, no manual calculations were required when programming a secondary infusion on this infusion pump. Since this is a linear process, as outlined in Figure 11, there are less variations and potential number of key presses when programming a secondary infusion on this pump. Therefore, there are potentially less areas for programming errors to occur.

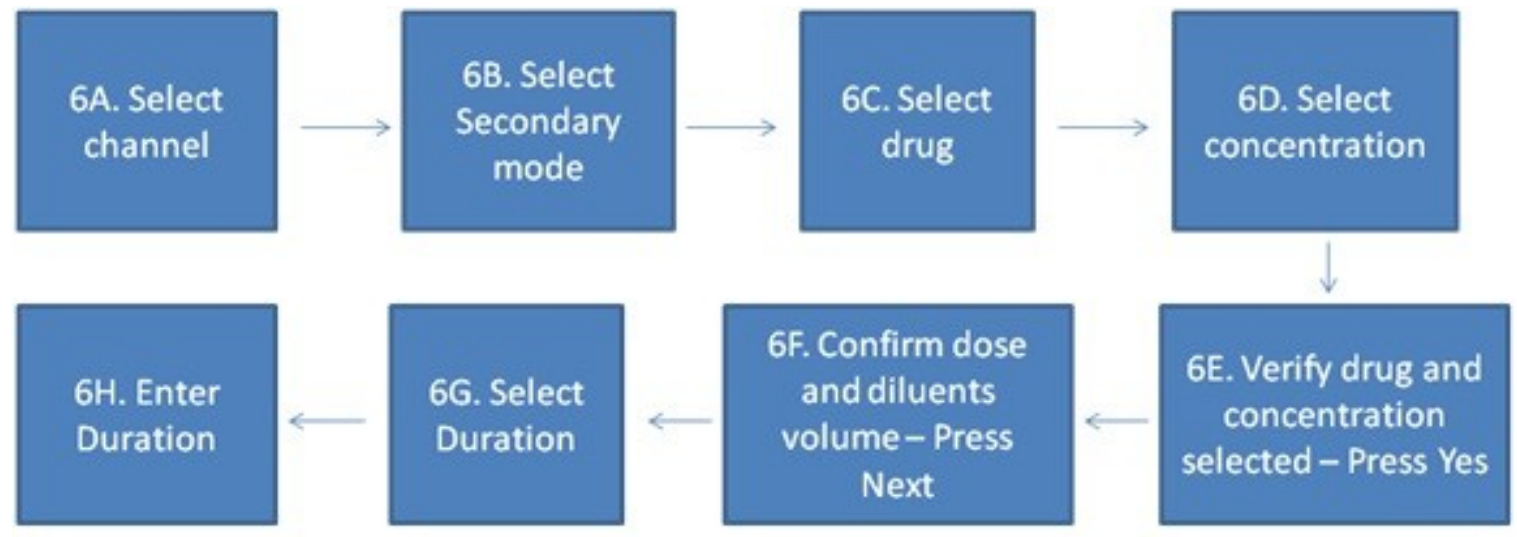

Figure 11: Workflow diagram for programming a secondary infusion on the Cardinal Health Alaris PC 


\subsection{Hospira Symbiq}

Figure 12 shows the workflow process of programming a secondary infusion on the Hospira Symbiq. This infusion pump offers DERS for secondary infusion program and does not require nurses to select the drug library profile as it assumes the drug library profile for the secondary infusion is the same as the drug library profile selected for the primary infusion on the same infusion pump. When inputting infusion parameters on this infusion pump, the pump requires nurses to enter the dose rate or volumetric rate of the infusion. They can then choose to enter either time or volume as a second infusion parameter for drug calculations. Based on the scenario described for this study, the physician's order included drug dose, total volume, and infusion time, but not infusion rate. Therefore, manual calculations would be required when programming secondary infusions using this infusion pump based on the scenario described in this study.

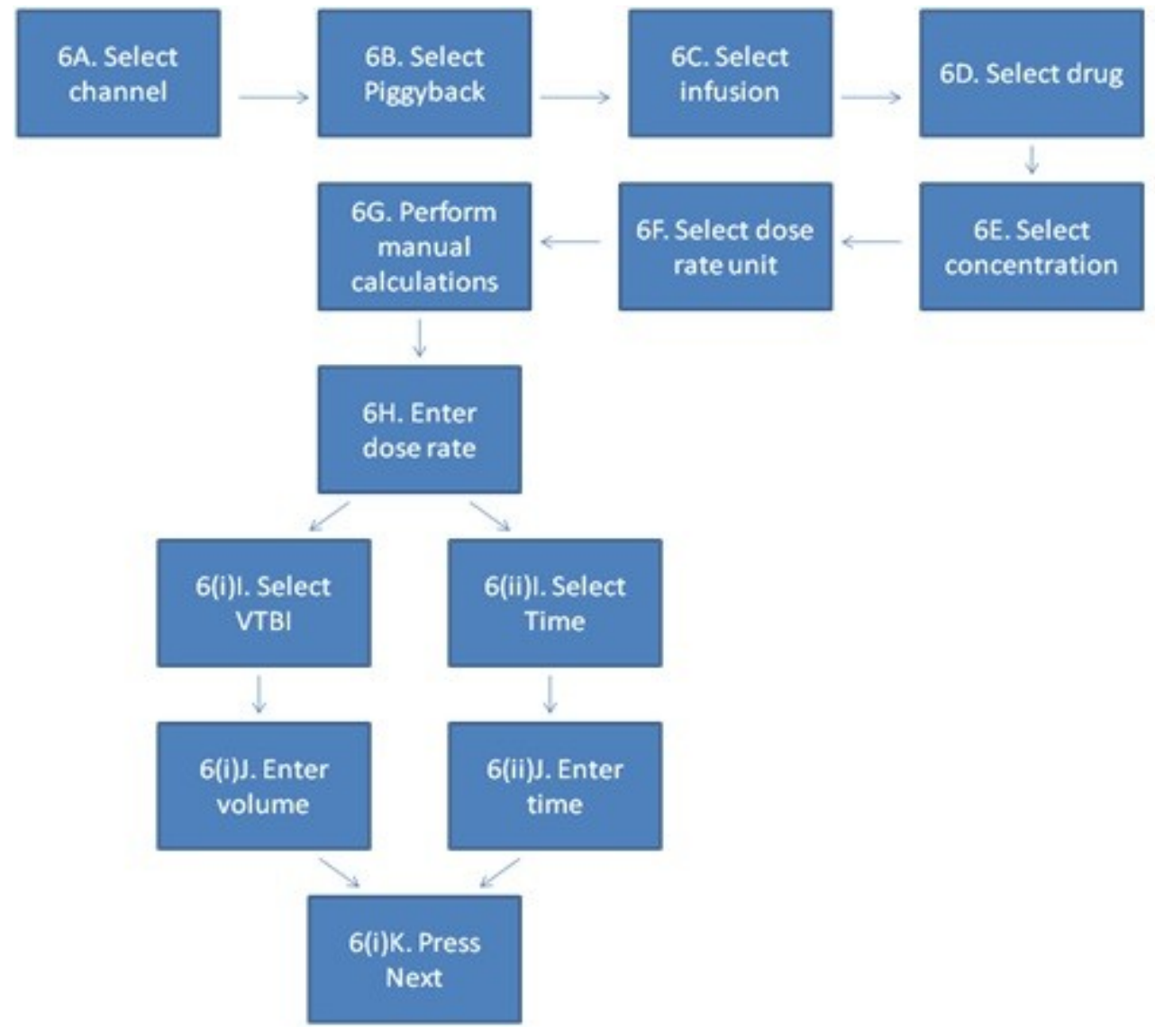

Figure 12: Workflow diagram for programming a secondary infusion on the Hospira Symbiq 


\subsection{Hospira Plum A+}

Figure 13 shows the workflow process of programming a secondary infusion on the Hospira Plum A+. This infusion pump offers DERS for secondary infusion program and does not require nurses to select the drug library profile as it assumes the drug library profile for the secondary infusion is the same as the drug library profile selected for the primary infusion on the same infusion pump. Nurses have the option to input two of the three infusion parameter fields (i.e. rate, volume, and time), none of which are mandatory. As a result, based on the scenario described in this study, they would be able to program the infusion pump by entering volume and time written on the physician's order. If nurses wish to program the infusion using volumetric rate, however, they would have to perform manual calculations.

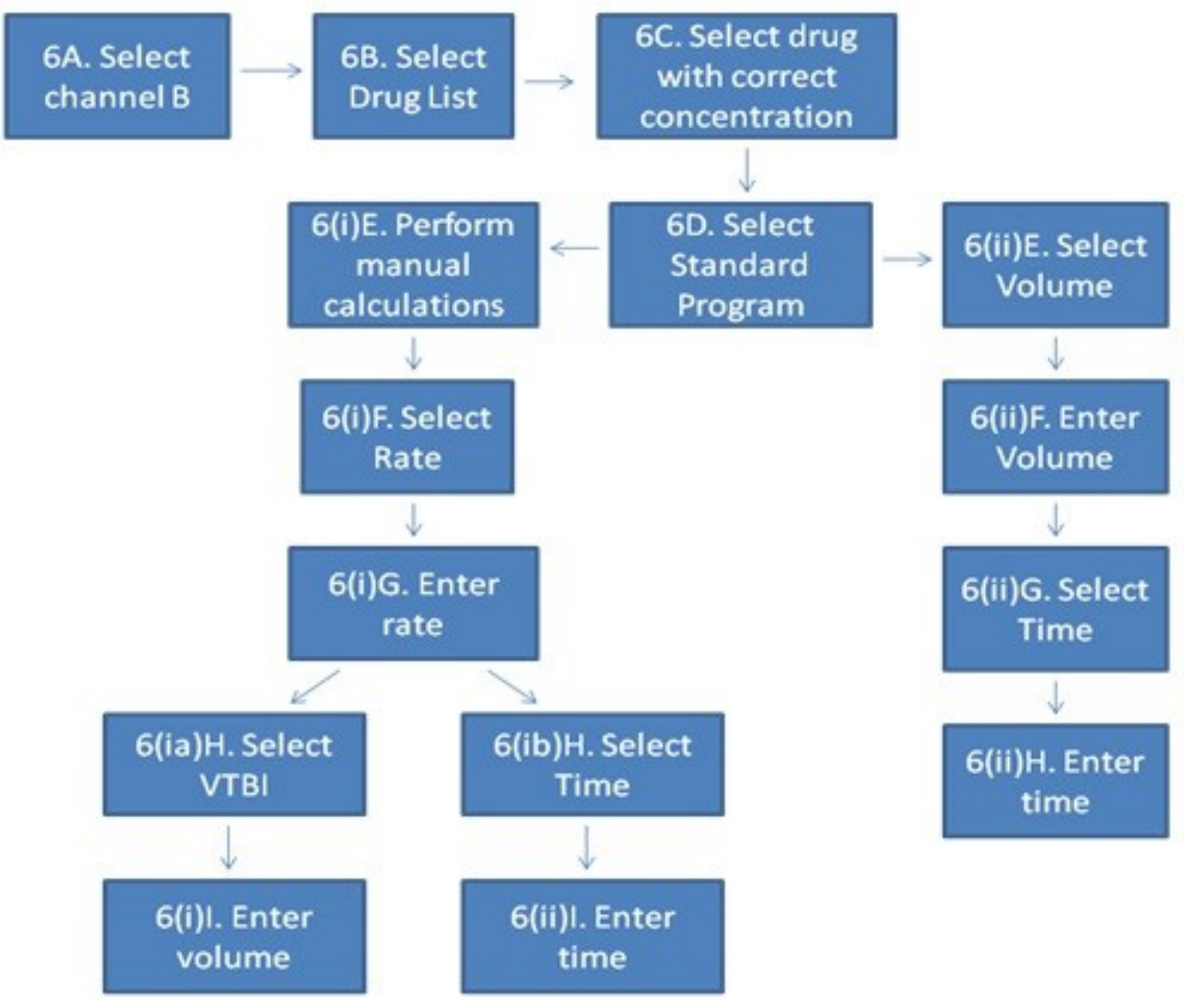

Figure 13: Workflow diagram for programming a secondary infusion on the Hospira Plum A+

The difference between the five smart infusion pumps studied can be summarized in the following table (Table 18). 
Table 18: Comparison of secondary infusion programming between smart infusion pumps

\begin{tabular}{|c|c|c|c|c|c|}
\hline & $\begin{array}{l}\text { Baxter } \\
\text { Colleague } \\
\text { CXE }\end{array}$ & $\begin{array}{l}\text { B. Braun } \\
\text { Infusomat } \\
\text { Space }\end{array}$ & $\begin{array}{l}\text { Cardinal } \\
\text { Health } \\
\text { Alaris PC }\end{array}$ & $\begin{array}{l}\text { Hospira } \\
\text { Symbiq }\end{array}$ & $\begin{array}{l}\text { Hospira } \\
\text { Plum A+ }\end{array}$ \\
\hline Presence of DERS & No & Yes & Yes & Yes & Yes \\
\hline Library profile selection & N/A & Yes & No & No & No \\
\hline $\begin{array}{l}\text { Mandatory Input } \\
\text { parameters }\end{array}$ & Volume & Volume & $\begin{array}{l}\text { Volume } \\
\text { and } \\
\text { Duration }\end{array}$ & $\begin{array}{l}\text { Volumetric } \\
\text { Rate or } \\
\text { dose rate }\end{array}$ & N/A \\
\hline $\begin{array}{l}\text { Optional input } \\
\text { parameters }\end{array}$ & $\begin{array}{l}\text { Volumetric } \\
\text { rate or } \\
\text { duration }\end{array}$ & $\begin{array}{l}\text { Volumetric } \\
\text { rate, dose } \\
\text { rate, or } \\
\text { duration }\end{array}$ & N/A & $\begin{array}{l}\text { Volume or } \\
\text { duration }\end{array}$ & $\begin{array}{l}\text { Volumetric } \\
\text { rate, } \\
\text { volume, or } \\
\text { duration }\end{array}$ \\
\hline Default parameters & $\begin{array}{l}\text { Volume and } \\
\text { volumetric } \\
\text { rate }\end{array}$ & N/A & N/A & N/A & $\mathrm{N} / \mathrm{A}$ \\
\hline $\begin{array}{l}\text { Manual calculations } \\
\text { required based on } \\
\text { scenario }\end{array}$ & Yes & No & No & Yes & No \\
\hline $\begin{array}{l}\text { Number of Possible Steps } \\
\text { to Program Secondary } \\
\text { Infusions }\end{array}$ & 13 & 15 & 8 & 13 & 11 \\
\hline
\end{tabular}

As shown on Table 18, four of the five smart infusion pumps offer DERS for secondary infusion program, of which one of the pumps require nurses to select the appropriate drug library profile. Without the protection of DERS, the Baxter Colleague CXE smart infusion pump would not be able to detect any programming error. As for the B. Braun Infusomat Space, the extra step of selecting the appropriate drug library profile when programming a secondary infusion may introduce a possibility for errors to occur. Default input parameters are also compared in Table 18. Based on the scenario described for this study, manual calculations are required when using two of the five infusion pumps. Lastly, the total number of steps possible to program secondary infusions on each smart infusion pump is compared. The Cardinal Health Alaris PC has the least number of steps possible as there is only one path to programming a secondary infusion on this pump. 


\subsubsection{Step 7: Open Roller Clamp on Secondary Tubing}

Step 7 of the process is to open the roller clamp on the secondary tubing to allow fluid to flow through the secondary tubing once the infusion starts. For most of the infusion pumps (i.e. Baxter Colleague CXE, B. Braun Infusomat Space, Cardinal Health Alaris PC, and Hospira Plum A+), this step only consist of the sub-task "open roller clamp". However, the Hospira Symbiq prompts nurses to check and make sure the roller clamp is opened and the secondary bag is hung higher than the primary bag. They are then required to press "OK" to continue. Table 19 and Table 20 provide a description for each sub-task for all the pumps.

Table 19: Sub-process description for Step 7 - Baxter Colleague CXE, B. Braun Infusomat Space, Cardinal Health Alaris PC, and Hospira Plum A+

\begin{tabular}{|l|l|l|}
\hline $\begin{array}{l}\text { Sub-process } \\
\text { Step Number }\end{array}$ & Sub-process Step Title & Description \\
\hline $7 \mathrm{~A}$ & Open roller clamp & $\begin{array}{l}\text { Open roller clamp to allow for fluid flow and } \\
\text { prepare for drug delivery }\end{array}$ \\
\hline
\end{tabular}

Table 20: Sub-process description for Step 7 - Hospira Symbiq

\begin{tabular}{|l|l|l|}
\hline $\begin{array}{l}\text { Sub-process } \\
\text { Step Number }\end{array}$ & Sub-process Step Title & Description \\
\hline $7 \mathrm{~A}$ & Open roller clamp & $\begin{array}{l}\text { Open roller clamp to allow for fluid flow and } \\
\text { prepare for drug delivery }\end{array}$ \\
\hline 7B & $\begin{array}{l}\text { Check bag height difference } \\
\text { and roller clamp position }- \\
\text { Press OK }\end{array}$ & $\begin{array}{l}\text { Reminder to check and make sure secondary } \\
\text { bag is hung higher than primary bag and roller } \\
\text { clamp is opened }\end{array}$ \\
\hline
\end{tabular}

Although the Hospira Symbiq requires one extra sub-task to complete this step compared to other smart infusion pumps examined (i.e. Baxter Colleague CXE, B. Braun Infusomat Space, Cardinal Health Alaris PC, and Hospira Plum A+), the extra sub-task acts as a reminder for nurses to double-check the secondary infusion set-up and may help reduce the probability of errors to occur when performing this task.

\subsubsection{Step 8: Start Infusion}

The last step of the secondary infusion administration process is to start the infusion on the pump. For three of the five pumps (i.e. Baxter Colleague CXE, B. Braun Infusomat Space, and 
Cardinal Health PC), the infusion starts when nurses press "Start" on the pump (Table 21). For the Hospira Symbiq, nurses are asked to review the parameters before pressing "Start" to start the infusion (Table 22). Lastly, for the Hospira Plum A+, once the nurses press "Start", the pump asks them to review the parameters and confirm by pressing "Yes" before the infusion is started (Table 23).

Table 21: Sub-process description for Step 8 - Baxter Colleague, B. Braun Infusomat Space, Cardinal Health Alaris PC

\begin{tabular}{|l|l|l|}
\hline $\begin{array}{l}\text { Sub-process } \\
\text { Step Number }\end{array}$ & Sub-process Step Title & Description \\
\hline $8 \mathrm{~A}$ & Press Start & Press start to start infusion \\
\hline
\end{tabular}

Table 22: Sub-process description for Step 8 - Hospira Symbiq

\begin{tabular}{|l|l|l|}
\hline $\begin{array}{l}\text { Sub-process } \\
\text { Step Number }\end{array}$ & Sub-process Step Title & Description \\
\hline $8 \mathrm{~A}$ & $\begin{array}{l}\text { Review parameters entered } \\
\text { and Press Start }\end{array}$ & Review parameters then press Start to confirm \\
\hline
\end{tabular}

Table 23: Sub-process description for Step 8 - Hospira Plum A+

\begin{tabular}{|l|l|l|}
\hline $\begin{array}{l}\text { Sub-process } \\
\text { Step Number }\end{array}$ & Sub-process Step Title & Description \\
\hline $8 \mathrm{~A}$ & Press Start & Press start to start infusion \\
\hline $8 \mathrm{~B}$ & $\begin{array}{l}\text { Review and confirm } \\
\text { parameters entered - Press } \\
\text { Yes }\end{array}$ & $\begin{array}{l}\text { Review and confirm the parameters are entered } \\
\text { correctly by pressing Yes }\end{array}$ \\
\hline
\end{tabular}

Thus, two of the five smart infusion pumps by the same manufacturer (i.e. Hospira Symbiq and Hospira Plum $\mathrm{A}+$ ) prompt nurses to review the parameters programmed before starting the infusion, while the other infusion pumps (i.e. Baxter Colleague CXE, B. Braun Infusomat Space, and Cardinal Health Alaris PC) start the infusion as soon as they press "Start". Prompting nurses to double-check the infusion programming is potentially a safer approach since it asks them to stop and check if the parameters entered are correct before the infusion starts. 
In summary, secondary infusion programming varies across all smart infusion pumps examined in terms of the number of steps required to program, the location of the secondary infusion function menu, the use of the DERS, as well as the default parameters needed to program, which dictates whether or not manual calculations are needed in order to enter the parameters the pump requires to program the secondary infusion. For instance, The Cardinal Health Alaris PC requires the least number of steps to program a secondary infusion; therefore, there is potentially less chance for errors to occur when programming a secondary infusion using the Cardinal Health Alaris PC compared to other smart infusion pumps examined (i.e. Baxter Colleague CXE, B. Braun Infusomat Space, Hospira Plum A+, and Hospira Symbiq).

When examining the location of the secondary infusion function menu, the Hospira Symbiq offers a user interface that allows nurses to enter the secondary menu from the main screen, which allows nurses to access the secondary menu easily. When comparing the use of DERS in secondary infusion program on different smart infusion pumps, while the Baxter Colleague CXE does not offer DERS for secondary infusion, nurses have a choice of programming a secondary infusion through the DERS or not on most smart infusion pumps (i.e. B. Braun Infusomat Space, Hospira Symbiq, and Hospira Plum A+). On the other hand, when programming a secondary infusion using the Cardinal Health Alaris PC, the pump enters the DERS by default, which potentially increases the compliance rate of DERS usage and decreases the number of programming steps, or key presses, required for nurses to program a secondary infusion through the DERS.

The usual parameters used to program secondary infusions are: volume, duration, volumetric rate, and dose rate. Both the B. Braun Infusomat Space and the Hospira Plum A+ allow nurses to enter any of the four parameters to program the secondary infusion; therefore, nurses can program the infusion pump using the parameters outlined on the physician's order and avoid the need to perform manual calculations. When programming a secondary infusion using the Hospira Symbiq, nurses are required to enter a volumetric rate or dose rate, and the volume or duration. Therefore, if the physician's order does not specify a volumetric rate or dose rate for the secondary infusion, they would be forced to perform manual calculations in order to program the secondary infusion on the Hospira Symbiq pump. Similarly, the default parameters required to program a secondary infusion on the Baxter Colleague CXE are volumetric rate and volume to be infused. Since most secondary infusions are ordered with only the dose, total volume, and 
duration specified, nurses would likely have to perform manual calculations when programming a secondary infusion using the Baxter Colleague CXE. Lastly, the Cardinal Health Alaris PC requires nurses to enter the total volume and the duration when programming a secondary infusion. Since most physicians' orders specify the volume and duration when prescribing a secondary infusion, it is less likely that they would need to perform manual calculations when programming a secondary infusion using the Cardinal Health Alaris PC.

Additionally, the task of opening the roller clamp is required for all smart infusion pumps examined. However, the Hospira Symbiq provides a prompt at the end of the programming sequence to remind nurses to open the roller clamp and double-check that the primary and secondary bags are hung at the appropriate height. Therefore, the probability of errors made when performing these tasks is potentially reduced. Lastly, two of the five smart infusion pumps examined (i.e. Hospira Symbiq and Hospira Plum A+ prompt nurses to review parameters before starting the infusion, whereas the other smart infusion pumps (i.e. Baxter Colleague CXE, B. Braun Infusomat Space, and Cardinal Health Alaris PC) start the infusion as soon as the nurses press "Start". It is potentially safer to allow nurses to stop and review the parameters programmed before starting the infusion so that nurses have a chance to make sure the patient receives the infusion at the correct rate.

On the whole, most smart infusion pumps examined (i.e. Baxter Colleague CXE, B. Braun Infusomat Space, Cardinal Health Alaris PC, and Hospira Symbiq) are similar in the tasks required for the "Set-up" part of the secondary infusion administration process. The Hospira Plum A+ differs because its pumping mechanism allows the pump to draw secondary fluid directly from the secondary container, eliminating the need of a back-check valve to control the fluid flow. As a result, the secondary infusion no longer relies on the difference in hydrostatic pressure to determine the sequence of fluid flow, eliminating a number of tasks required to set up the secondary infusion and potentially making the process safer. For the "Activation" part of the secondary infusion administration process, more variations are observed between the smart infusion pumps examined as the user interface design for each of the infusion pump is different. Therefore, the steps and parameters required to program a secondary infusion varied between smart infusion pumps. 


\subsection{Failure Modes Identified}

Potential failure modes of the secondary infusion administration process are identified using four different methods: literature search, incident reports analysis, clinical observations, and brainstorming. The results for each method are presented below.

\subsubsection{Literature Search}

A total of ten articles are included from the literature search. Types of secondary infusion errors described in each article are recorded and separated into set-up errors and activation errors. A total of ten different failure modes are identified from the literature, two of which are considered as set-up errors and eight are considered as activation errors. Table 24 and Table 25 list the failure modes identified as well as the corresponding source of reference.

Table 24: Failure modes identified from the literature - Set-up

\begin{tabular}{|l|l|}
\hline Failure Mode & Reference \\
\hline $\begin{array}{l}\text { Fail to establish appropriate bag } \\
\text { height difference }\end{array}$ & Nunnally \& Bitan, 2006; Trbovich et al. 2010 \\
\hline $\begin{array}{l}\text { Connect secondary line to the } \\
\text { incorrect port }\end{array}$ & $\begin{array}{l}\text { Nunnally \& Bitan, 2006; Trbovich et al., 2010; } \\
\text { Wetterneck et al., 2006 }\end{array}$ \\
\hline
\end{tabular}


Table 25: Failure modes identified from the literature - Activation

\begin{tabular}{|l|l|}
\hline Failure Mode & Reference \\
\hline Select incorrect channel & Wetterneck et al., 2006 \\
\hline Fail to access Secondary mode & M. Nunnally \& Bitan, 2006; Rothwell, 2009 \\
\hline $\begin{array}{l}\text { Select incorrect drug or drug } \\
\text { concentration from drug library }\end{array}$ & Rothwell, 2009; Wetterneck et al., 2006 \\
\hline Select incorrect drug library profile & Wetterneck et al., 2006 \\
\hline $\begin{array}{l}\text { Programming primary infusion as } \\
\text { a secondary infusion }\end{array}$ & $\begin{array}{l}\text { ISMP Canada, 2003; M. Nunnally \& Bitan, 2006; Trbovich } \\
\text { et al., 2010 }\end{array}$ \\
\hline $\begin{array}{l}\text { Enter incorrect infusion parameters } \\
\text { Flynn et al., 2003; ISMP Canada, 2003; M. Nunnally \& } \\
\text { Bitan, 2006; Rothwell, 2009; Squires et al., 2005; Trbovich } \\
\text { et al., 2010; Wetterneck et al., 2006 }\end{array}$ \\
\hline $\begin{array}{l}\text { Incorrect calculation } \\
\text { clamp before starting infusion }\end{array}$ & $\begin{array}{l}\text { Hicks \& Becker, 2006; ISMP Canada, 2003; Keay \& } \\
\text { Callander, 2004; M. Nunnally \& Bitan, 2006; Rothwell, } \\
\text { 2009 }\end{array}$ \\
\hline
\end{tabular}

In summary, there appears to be more literature and research efforts around the failure modes and issues related to the "Activation" part of the secondary infusion administration process than the "Set-up" part of the process. For the "Set-up" part of the process, the types of errors reported include error in establishing the appropriate height difference between the primary and secondary containers, as well as errors that occur when connecting the secondary tubing to the y-site port on the primary tubing. For the "Activation" part of the process, most of the errors discussed are related to programming the smart infusion pump incorrectly, which include: difficulty in accessing the secondary infusion function menu, programming incorrect pump channels, selecting incorrect drug or drug concentration from the drug library, and entering incorrect infusion parameters. As well, failure to open the secondary roller clamp prior the start of secondary infusion is also reported as an error that occurs in the "Activation" part of the process. 


\subsubsection{Incident Reports Analysis}

Out of the 211 incident reports analyzed, a total of 156 incidents that are coded either as "piggyback" or "both concurrent and piggyback" were extracted for further review and 45 incidents were found to be relevant to the study. Incident reports were considered as relevant if the incidents occurred in the presence of secondary infusions. Table 26 and Table 27 outline the categories of failures found from the relevant reports as well as the number of incident reports that are associated with each category. The patient outcomes reported as a result of each issue is also listed. 
Table 26: Issues identified from relevant incident reports and numbers of incidents associated with each issue - Set-up

\begin{tabular}{|c|c|c|c|}
\hline Issue & Description & $\begin{array}{l}\text { Number of } \\
\text { Incidents }\end{array}$ & $\begin{array}{l}\text { Patient } \\
\text { Outcome }\end{array}$ \\
\hline $\begin{array}{l}\text { Secondary fluid } \\
\text { back-flow into } \\
\text { primary container }\end{array}$ & $\begin{array}{l}\text { Secondary fluid back-flowed into } \\
\text { primary container }\end{array}$ & 8 & $\begin{array}{l}\text { no medication } \\
\text { intervention } \\
\text { needed ( } 8)\end{array}$ \\
\hline $\begin{array}{l}\text { Concurrent delivery } \\
\text { of primary and } \\
\text { secondary fluids }\end{array}$ & $\begin{array}{l}\text { Concurrent delivery of primary and } \\
\text { secondary fluids observed after } \\
\text { some time even when secondary } \\
\text { bag was hung higher than primary } \\
\text { bag }\end{array}$ & 8 & $\begin{array}{l}\text { no medication } \\
\text { intervention } \\
\text { needed (5) } \\
\text { unknown (3) }\end{array}$ \\
\hline $\begin{array}{l}\text { Tubing } \\
\text { disconnection/leaks }\end{array}$ & $\begin{array}{l}\text { Tubing disconnected at connection } \\
\text { point or fluid leaked at connection } \\
\text { point }\end{array}$ & 4 & $\begin{array}{l}\text { no medication } \\
\text { intervention } \\
\text { needed (4) }\end{array}$ \\
\hline $\begin{array}{l}\text { Primary running at } \\
\text { secondary rate }\end{array}$ & $\begin{array}{l}\text { Primary infusion being delivered at } \\
\text { the secondary infusion rate }\end{array}$ & 3 & $\begin{array}{l}\text { medical } \\
\text { intervention (1) } \\
\text { no medical } \\
\text { intervention } \\
\text { needed (1) } \\
\text { unknown (1) }\end{array}$ \\
\hline Compatibility & $\begin{array}{l}\text { Multiple secondary medications } \\
\text { that were not compatible were } \\
\text { delivered through the same IV } \\
\text { tubing. As a result, they reacted in } \\
\text { the IV tubing }\end{array}$ & 1 & unknown (1) \\
\hline Air in tubing & $\begin{array}{l}\text { Nurse had to manipulate tubing and } \\
\text { fluid containers while caring for the } \\
\text { patient (e.g. changing patient's } \\
\text { clothes) which caused air to pull } \\
\text { into tubing }\end{array}$ & 1 & $\begin{array}{l}\text { no medical } \\
\text { intervention } \\
\text { needed (1) }\end{array}$ \\
\hline
\end{tabular}


Table 27: Issues identified from relevant incident reports and numbers of incidents associated with each issue - Activation

\begin{tabular}{|c|c|c|c|}
\hline Issue & Description & $\begin{array}{l}\text { Number of } \\
\text { Incidents }\end{array}$ & $\begin{array}{l}\text { Patient } \\
\text { Outcome }\end{array}$ \\
\hline Over-infusion & $\begin{array}{l}\text { Medication delivered too quickly; } \\
\text { too much medication delivered in a } \\
\text { short period of time }\end{array}$ & 9 & $\begin{array}{l}\text { death (1) } \\
\text { medical } \\
\text { intervention (5) } \\
\text { no medication } \\
\text { intervention } \\
\text { needed (2) } \\
\text { unknown (1) }\end{array}$ \\
\hline Under-infusion & $\begin{array}{l}\text { Medication delivered slower than } \\
\text { intended; patient not receiving full } \\
\text { dose of medication }\end{array}$ & 6 & $\begin{array}{l}\text { no medication } \\
\text { intervention } \\
\text { needed (5) } \\
\text { unknown (1) }\end{array}$ \\
\hline Programming error & $\begin{array}{l}\text { Error made when programming the } \\
\text { infusion pump }\end{array}$ & 1 & $\begin{array}{l}\text { no medical } \\
\text { intervention } \\
\text { needed (1) }\end{array}$ \\
\hline $\begin{array}{l}\text { Programming wrong } \\
\text { primary channel }\end{array}$ & $\begin{array}{l}\text { The nurse mistakenly programmed } \\
\text { the wrong primary channel for the } \\
\text { delivery of a secondary infusion in } \\
\text { the presence of multiple concurrent } \\
\text { infusions }\end{array}$ & 1 & death (1) \\
\hline $\begin{array}{l}\text { Roller clamp not } \\
\text { completely opened }\end{array}$ & $\begin{array}{l}\text { Roller clamp on secondary tubing } \\
\text { not opened completely }\end{array}$ & 1 & unknown (1) \\
\hline $\begin{array}{l}\text { Primary tubing cut } \\
\text { off by secondary } \\
\text { clamp }\end{array}$ & $\begin{array}{l}\text { Nurse used the on-off tube clamp } \\
\text { provided on secondary set to clamp } \\
\text { off primary tubing and cut tubing } \\
\text { completely }\end{array}$ & 1 & $\begin{array}{l}\text { no medical } \\
\text { intervention } \\
\text { needed (1) }\end{array}$ \\
\hline $\begin{array}{l}\text { High-risk secondary } \\
\text { drugs }\end{array}$ & $\begin{array}{l}\text { A high-risk medication was } \\
\text { delivered as secondary medication } \\
\text { and a bolus of a high-risk } \\
\text { medication was given when } \\
\text { addressing an alarm during the } \\
\text { secondary infusion }\end{array}$ & 1 & death (1) \\
\hline
\end{tabular}

In summary, of the 45 incident reports that met the inclusion criteria, 26 reports are found to be related to the "Set-up" part of the secondary infusion administration process, and 19 are related to the "Activation" part of the process. As well, seven issues, or themes, are identified in the 
"Set-up" part of the process, which include: secondary fluid back-flowing into primary container, concurrent infusion of primary and secondary fluids, tubing disconnection or leaks, primary fluid being delivered at the secondary infusion rate, compatibility issues, introducing air bubbles into secondary tubing, and delivering a high-risk drug as a secondary infusion. The six issues, or themes, identified for the "Activation" part of the process include: over-infusion or overdose, under-infusion or under-dose, programming errors, programming incorrect pump channel, failure to open roller clamp on secondary tubing, and damaging tubing with tubing clamp.

\subsubsection{Clinical Observations}

Eight different failure modes are identified from the clinical observation data. Table 28 describes the eight different failure modes observed as well as the number of institutes where these failure modes were observed. 
Table 28: Potential failure modes identified through clinical observations - Set-up

\begin{tabular}{|l|l|l|}
\hline Potential Failure Mode & Potential Effects & $\begin{array}{l}\text { Number of } \\
\text { hospitals } \\
\text { with issue }\end{array}$ \\
\hline $\begin{array}{l}\text { Failure to establish } \\
\text { appropriate bag height } \\
\text { difference between primary } \\
\text { and secondary bag }\end{array}$ & $\begin{array}{l}\text { Concurrent delivery of primary and secondary } \\
\text { drugs; Or delay therapy and primary fluid running } \\
\text { at secondary rate }\end{array}$ & 3 \\
\hline $\begin{array}{l}\text { Secondary tubing } \\
\text { connected to incorrect port } \\
\text { on the primary tubing }\end{array}$ & $\begin{array}{l}\text { Secondary drug free-flow into patient or not flow at } \\
\text { all depending on the infusion rate of the primary } \\
\text { infusion }\end{array}$ & 2 \\
\hline $\begin{array}{l}\text { Secondary tubing } \\
\text { connected to incorrect } \\
\text { primary line }\end{array}$ & $\begin{array}{l}\text { Primary fluid running at secondary rate; delay } \\
\text { therapy of the wrong primary line; potential } \\
\text { compatibility issues between secondary and wrong } \\
\text { primary; secondary would run at wrong primary } \\
\text { rate }\end{array}$ & 2 \\
\hline $\begin{array}{l}\text { Failure to use primary } \\
\text { tubing with back-check } \\
\text { valve }\end{array}$ & $\begin{array}{l}\text { Primary and secondary drugs deliver concurrently } \\
- \text { under-dose of secondary drug }\end{array}$ & 1 \\
\hline
\end{tabular}

Table 29: Potential failure modes and potential effects identified through clinical observations - Activation

\begin{tabular}{|l|l|c|}
\hline Potential Failure Mode & Potential Effects & $\begin{array}{l}\text { Number of } \\
\text { hospitals with } \\
\text { issue }\end{array}$ \\
\hline Drug library not always used & $\begin{array}{l}\text { Programming errors are less likely to be } \\
\text { detected by the smart infusion pump }\end{array}$ & 4 \\
\hline Failure to open roller clamp & $\begin{array}{l}\text { Delay therapy; Primary fluid delivered at } \\
\text { secondary rate }\end{array}$ & 4 \\
\hline $\begin{array}{l}\text { Programming values switched } \\
\text { between primary and } \\
\text { secondary channels }\end{array}$ & $\begin{array}{l}\text { Secondary drug delivered at primary rate } \\
\text { and vice versa }\end{array}$ & 2 \\
\hline $\begin{array}{l}\text { Confusion between piggyback } \\
\text { versus concurrent mode }\end{array}$ & $\begin{array}{l}\text { Primary fluid and secondary drug delivered } \\
\text { concurrently rather than sequentially }\end{array}$ \\
\hline
\end{tabular}

In summary, eight potential failure modes are identified from field observations. Half of the potential failure modes are related to the "Set-up" part of the secondary infusion administration 
process and the other half are related to the "Activation" part of the process. The failure modes identified for the "Set-up" part of the process include: failure to establish appropriate bag height difference between primary and secondary containers, failure to connect the secondary tubing to the appropriate $y$-site port on the primary tubing, failure to connect the secondary tubing to the correct primary line, and failure to use primary tubing with a back-check valve. Lastly, the failure modes identified for the "Activation" part of the process include: failure to use drug library when programming a secondary infusion, failure to open roller clamp prior to the start of secondary infusion, secondary infusion parameters entered as primary infusion program, and confusion between piggyback and concurrent infusion modes.

\subsubsection{Brainstorming with HFMEA Team}

A total number of 34 additional failure modes are identified by the HFMEA Team as the team brainstormed potential failure modes for each step of the secondary infusion administration process for each of the five smart infusion pumps. As shown in Table 30, 18 potential failure modes are identified for the "Set-up" part of the secondary infusion process, which are grouped into nine different failure mode types. Set-up failure mode types identified include: failure to sterilize connection site, failure to fill secondary drip chamber to appropriate level, failure to select appropriate secondary tubing, failure to closer roller clamp of secondary tubing prior to spiking the secondary container, failure to spike the secondary container properly, failure to prime secondary infusion tubing properly, failure to connect the secondary tubing to the primary line, primary fluid over-flow into secondary container while back-priming, and failure to find the "Back-prime" button when back-priming secondary tubing with the Hospira Plum A+. Similarly, shown in Table 31 are 16 potential failure modes that were identified for the "Activation" part of the process, which are grouped into six different failure mode types. The types of failure modes identified include: failure to select the correct parameter when programming, failure to select the correct command or menu item when programming, failure to stop infusion prior to programming the secondary infusion (only applies to the B. Braun Infusomat), exit secondary infusion menu unintentionally, and failure to start infusion. 
Table 30: Potential failure modes and potential effects identified through brainstorming Set-up

\begin{tabular}{|c|c|}
\hline Failure Mode Type & Failure Mode Identified \\
\hline \multirow[t]{3}{*}{ Failure to sterilize connection site } & Fail to swab y-site port \\
\hline & Fail to "scrub the hub" \\
\hline & Fail to allow antiseptic to dry \\
\hline \multirow{3}{*}{$\begin{array}{l}\text { Failure to fill drip chamber to appropriate } \\
\text { level }\end{array}$} & Drip chamber too full \\
\hline & Drip chamber not filled enough \\
\hline & Drip chamber not filled at all \\
\hline \multirow[t]{2}{*}{ Failure to select appropriate secondary tubing } & Select incorrect material \\
\hline & Select primary tubing with secondary port \\
\hline \multirow{2}{*}{$\begin{array}{l}\text { Failure to close roller clamp of secondary } \\
\text { tubing prior to spiking secondary container }\end{array}$} & Roller clamp left open \\
\hline & Roller clamp not closed all the way \\
\hline \multirow[t]{2}{*}{ Failure to spike secondary container properly } & Nurse pokes a hole in the bag with spike \\
\hline & Bag not spiked all the way \\
\hline \multirow[t]{3}{*}{ Failure to prime secondary tubing properly } & Fail to open roller clamp to begin priming \\
\hline & Fail to fill fluid to end of tubing \\
\hline & Fail to close roller clamp once tubing is primed \\
\hline $\begin{array}{l}\text { Failure to connect secondary line to primary } \\
\text { line }\end{array}$ & Fail to connect secondary line to primary line \\
\hline $\begin{array}{l}\text { Primary fluid overflow into secondary } \\
\text { container while back-priming }\end{array}$ & Fluid backflow into secondary bag \\
\hline $\begin{array}{l}\text { Failure to find back-prime button when back- } \\
\text { priming on Hospira Plum A+ }\end{array}$ & Fail to find Back-prime button \\
\hline
\end{tabular}


Table 31: Potential failure modes and potential effects identified through brainstorming Activation

\begin{tabular}{|c|c|}
\hline Failure Mode Type & Failure Mode Identified \\
\hline \multirow{4}{*}{$\begin{array}{l}\text { Failure to select the correct parameter } \\
\text { when programming }\end{array}$} & Fail to select Duration \\
\hline & Fail to select Volume \\
\hline & Fail to select Rate \\
\hline & Fail to select Dose \\
\hline \multirow{4}{*}{$\begin{array}{l}\text { Failure to select correct command or } \\
\text { menu when programming }\end{array}$} & Fail to select Label Line \\
\hline & Fail to find Select \\
\hline & Fail to select Mode Change \\
\hline & Select incorrect mode \\
\hline Failure to stop infusion & Fail to find Stop \\
\hline \multirow{3}{*}{$\begin{array}{l}\text { Exit secondary infusion menu } \\
\text { unintentionally }\end{array}$} & Thinking Piggyback mode is selected by pressing $\mathrm{C}$ \\
\hline & Fail to select Yes \\
\hline & $\begin{array}{l}\text { Fail to confirm settings (unintentionally exit } \\
\text { confirmation screen) }\end{array}$ \\
\hline \multirow[t]{3}{*}{ Failure to use DERS } & Fail to select Drug List \\
\hline & Select No to use of drug library unintentionally \\
\hline & Select basic infusion instead \\
\hline Failure to start infusion & Fail to start infusion \\
\hline
\end{tabular}

In summary, potential failure modes for the secondary infusion administration process are identified using four different methods for both the "Set-up" and "Activation" parts of the process. The four methods used were: literature review, incident reports analysis, clinical observations, and brainstorming. Eight different failure modes are identified from the literature. Two of which are related to the "Set-up" part of the secondary infusion process and six of the failure modes identified are related to the "Activation" part of the process. The incident report analysis revealed seven types of issues related to the "Set-up" part of the process and six types of 
issues related to the "Activation" part of the process. From the clinical observations data, eight potential failure modes were identified. Four of which are related to the "Set-up" part of the secondary infusion process, and four of which are related to the "Activation" part of the process. Lastly, an additional 34 potential failure modes are identified using the brainstorming method with the HFMEA team. Eighteen of the failure modes are related to the "Set-up" part of the process and 16 of the failure modes are related to the "Activation" part of the process. The failure modes are also grouped into nine different failure mode types for the "Set-up" part of the process and six failure mode types for the "Activation" part of the process.

\subsection{Hazard Scoring Matrix}

Once potential failure modes are identified, hazard scores are assigned to each failure mode in preparation for the Decision Tree Analysis. The hazard scoring matrix part of the HFMEA is done by two raters to determine the severity and probability for each of the failure modes identified. The following section presents the inter-rater reliability results to examine the degree in which the raters agree with each other.

\subsubsection{Inter-rater Reliability}

The inter-rater reliability for the severity and probability ratings for each smart infusion pump were calculated and summarized in 
Table 32. Since there are two raters involved in the rating process, Cohen's kappa is used and the kappa values are calculated for each of the pumps. All kappa values are above 0.81, which meant that the degree of agreement between the raters were "almost perfect" (Landis \& Koch, 1977). 
Table 32: Kappa values for severity and probability ratings for each smart infusion pump examined

\begin{tabular}{|l|l|c|}
\hline \multirow{4}{*}{ Baxter Colleague CXE } & \multicolumn{1}{|c|}{$\begin{array}{c}\text { Inter-rater } \\
\text { Category }\end{array}$} & $\begin{array}{c}\text { Cohen's } \\
\text { Kappa }\end{array}$ \\
\hline \multirow{4}{*}{ B. Braun Infusomat Space } & Severity & 0.95 \\
\cline { 2 - 3 } & Probability & 0.93 \\
\cline { 2 - 3 } Cardinal Health Alaris PC & Probability & 0.87 \\
\cline { 2 - 3 } & Severity & 0.89 \\
\hline \multirow{2}{*}{ Hospira Symbiq } & Probability & 0.97 \\
\hline \multirow{2}{*}{ Hospira Plum A+ } & Severity & 0.95 \\
\cline { 2 - 3 } & Probability & 0.93 \\
\hline
\end{tabular}

\subsection{Decision Tree Analysis}

High-risk failure modes were identified for each infusion pump using the Decision Tree Analysis and the number of high-risk failure modes identified for each smart infusion pumps are compared in the following sections. The completed HFMEA for each smart infusion pump can be found in the Appendices.

\subsubsection{Comparison of Smart Infusion Pumps: Set-up Errors}

Once potential failure modes are identified, the number of failure modes are totaled as well as the number of high-risk failure modes, as shown in Table 33. It is of interest to compare the number of high-risk failure modes identified for each infusion pump as these numbers reflect the number of ways a user can make a mistake on a particular infusion pump which can potentially cause adverse events. 
Table 33: Comparison of total number of failure modes and total number of high-risk failure modes across smart pumps - Set-up

\begin{tabular}{|c|c|c|c|c|c|c|c|c|c|c|}
\hline & \multicolumn{2}{|c|}{$\begin{array}{c}\text { Baxter Colleague } \\
\text { CXE }\end{array}$} & \multicolumn{2}{|c|}{$\begin{array}{c}\text { B. Braun Infusomat } \\
\text { Space }\end{array}$} & \multicolumn{2}{|c|}{$\begin{array}{c}\text { Cardinal Health } \\
\text { Alaris PC }\end{array}$} & \multicolumn{2}{|c|}{ Hospira Symbiq } & \multicolumn{2}{|c|}{$\begin{array}{c}\text { Hospira Plum } \\
\mathrm{A}^{+}\end{array}$} \\
\hline Steps & 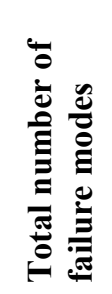 & 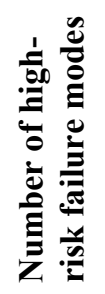 & 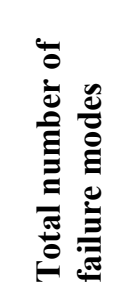 & 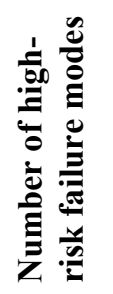 & 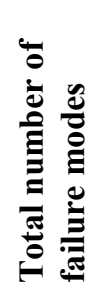 & 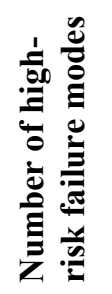 & 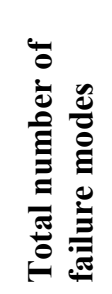 & 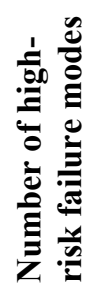 & 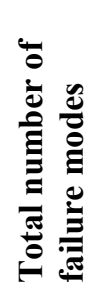 & 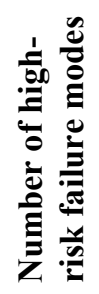 \\
\hline 1 & 6 & 2 & 6 & 1 & 6 & 1 & 6 & 1 & 6 & 1 \\
\hline $\mathrm{a} 2$ & 6 & 0 & 6 & 0 & 6 & 0 & 6 & 0 & 6 & 0 \\
\hline $\mathrm{a} 3 / \mathrm{b} 2$ & 8 & 6 & 8 & 6 & 8 & 6 & 8 & 6 & 0 & 0 \\
\hline $\mathrm{a} 4 / \mathrm{b} 3$ & 7 & 7 & 7 & 7 & 7 & 7 & 7 & 7 & 7 & 3 \\
\hline b4 & 8 & 1 & 8 & 1 & 8 & 1 & 8 & 1 & 6 & 0 \\
\hline 5 & 1 & 1 & 1 & 1 & 1 & 1 & 1 & 1 & 1 & 0 \\
\hline Total & 37 & 17 & 37 & 16 & 37 & 16 & 37 & 16 & 27 & 4 \\
\hline
\end{tabular}

The number of high-risk failure modes identified for each infusion pump is summarized into graphical form for the Set-up part of the secondary infusion process in Figure 14. As shown on the graph, the numbers of high-risk failure modes are similar across all pumps except for the Hospira Plum A+. This is because four of the five pumps require the traditional secondary infusion set-up while the Hospira Plum A + can mitigate most of the set-up issues by using a different set-up model. 


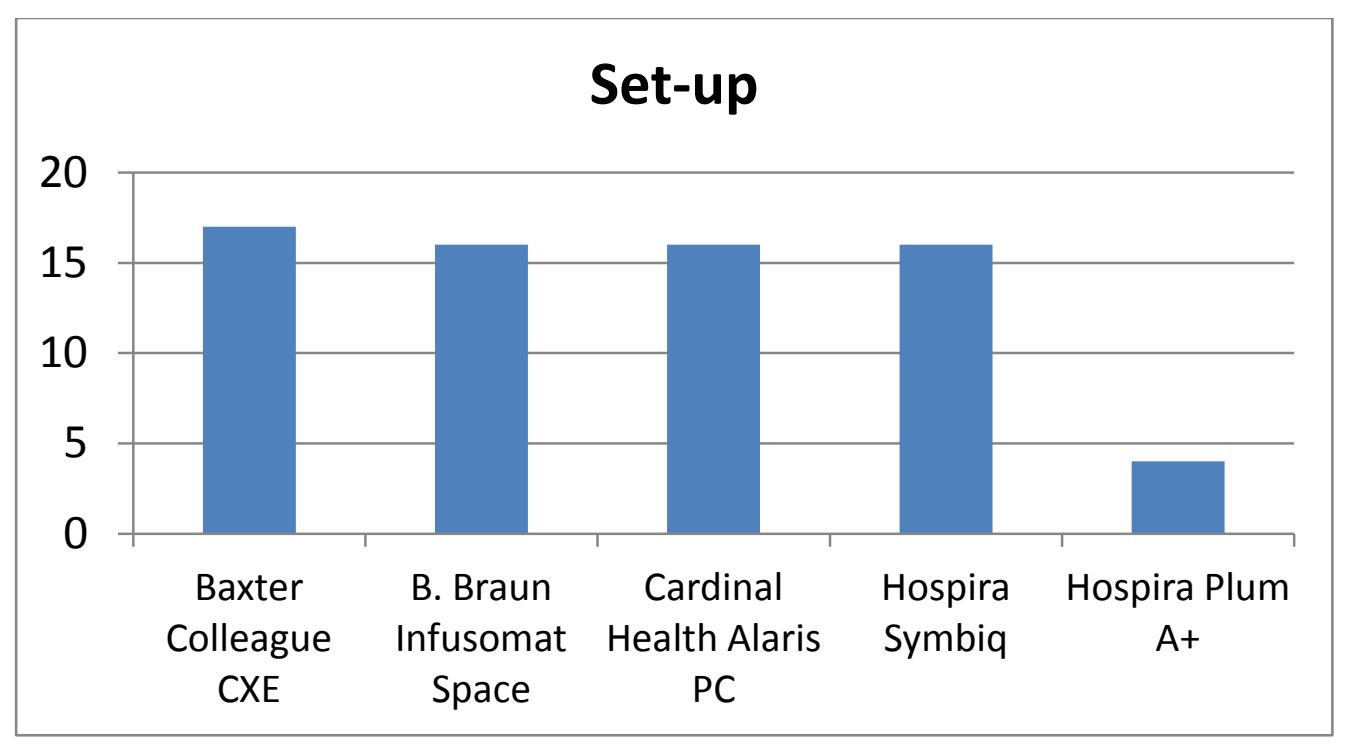

Figure 14: Comparison of total number of high-risk failure modes associated with each smart pump - Set-up

The list of high-risk failure modes for the "Set-up" part of the process are summarized in Table 34. Each high-risk failure mode is matched with the corresponding smart infusion pump with an "X". As shown, most failure modes are common to multiple infusion pumps and one failure mode (i.e. selecting primary tubing as secondary tubing) is unique to the Baxter Colleague CXE. All the high-risk failure modes identified are grouped into one of six types of set-up errors: selecting incorrect secondary infusion set, failure to use back-check valve, failure to establish appropriate hydrostatic pressure differential between primary and secondary containers, failure to sterilize connection site properly, misconnection of secondary line, and failure to open vent on glass or semi-rigid secondary containers. The five smart infusion pumps examined are marked with an " $\mathrm{X}$ " indicating that the particular failure mode is considered high-risk for the corresponding smart infusion pump. 
Table 34: List of high-risk failure modes and failure mode types - Set-up

\begin{tabular}{|c|c|c|c|c|c|c|}
\hline $\begin{array}{l}\text { Failure } \\
\text { Mode } \\
\text { Type }\end{array}$ & Failure Mode & $\begin{array}{l}\text { Baxter } \\
\text { Colleague } \\
\text { CXE }\end{array}$ & $\begin{array}{l}\text { B. Braun } \\
\text { Infusomat } \\
\text { Space }\end{array}$ & $\begin{array}{l}\text { Cardinal } \\
\text { Health } \\
\text { Alaris PC }\end{array}$ & $\begin{array}{l}\text { Hospira } \\
\text { Symbiq }\end{array}$ & $\begin{array}{l}\text { Hospira } \\
\text { Plum } \\
\text { A }+\end{array}$ \\
\hline \multirow{2}{*}{$\begin{array}{l}\text { Select } \\
\text { incorrect } \\
\text { secondary } \\
\text { infusion set }\end{array}$} & $\begin{array}{l}\text { Select primary } \\
\text { tubing as secondary }\end{array}$ & & & & & \\
\hline & $\begin{array}{l}\text { Select incorrect } \\
\text { material }\end{array}$ & & & & & \\
\hline $\begin{array}{l}\text { Fail to use } \\
\text { back-check } \\
\text { valve }\end{array}$ & $\begin{array}{l}\text { Connect secondary } \\
\text { line to primary set } \\
\text { with no back-check } \\
\text { valve }\end{array}$ & & & & & \\
\hline \multirow{4}{*}{$\begin{array}{l}\text { Fail to } \\
\text { establish } \\
\text { appropriate } \\
\text { hydrostatic } \\
\text { pressure } \\
\text { differential } \\
\text { between } \\
\text { primary } \\
\text { and } \\
\text { secondary } \\
\text { containers }\end{array}$} & $\begin{array}{l}\text { Primary and } \\
\text { secondary } \\
\text { containers hung at } \\
\text { the same height }\end{array}$ & & & & & \\
\hline & $\begin{array}{l}\text { Lower secondary } \\
\text { container instead of } \\
\text { primary container }\end{array}$ & & & & & \\
\hline & $\begin{array}{l}\text { Fail to establish } \\
\text { appropriate bag } \\
\text { height differential }\end{array}$ & & & & & \\
\hline & $\begin{array}{l}\text { Lower incorrect } \\
\text { primary bag }\end{array}$ & & & & & \\
\hline \multirow{3}{*}{$\begin{array}{l}\text { Fail to } \\
\text { sterilize } \\
\text { connection } \\
\text { site } \\
\text { properly } \\
\text { prior to } \\
\text { secondary } \\
\text { connection }\end{array}$} & $\begin{array}{l}\text { Fail to swab y-site } \\
\text { port }\end{array}$ & & & & & \\
\hline & $\begin{array}{l}\text { Fail to "scrub the } \\
\text { hub" }\end{array}$ & & & & & \\
\hline & $\begin{array}{l}\text { Fail to allow } \\
\text { antiseptic to dry }\end{array}$ & & & & & \\
\hline \multirow[t]{4}{*}{$\begin{array}{l}\text { Misconnect } \\
\text { secondary } \\
\text { line }\end{array}$} & $\begin{array}{l}\text { Connect secondary } \\
\text { line to y-site ports } \\
\text { downstream of } \\
\text { infusion pump }\end{array}$ & & & & & \\
\hline & $\begin{array}{l}\text { Connect secondary } \\
\text { line to the incorrect } \\
\text { primary line }\end{array}$ & & & & & \\
\hline & $\begin{array}{l}\text { Fail to securely } \\
\text { connect secondary } \\
\text { line to primary line }\end{array}$ & & & & & \\
\hline & $\begin{array}{l}\text { Fail to connect } \\
\text { secondary line }\end{array}$ & & & & & \\
\hline $\begin{array}{l}\text { Fail to open } \\
\text { vent }\end{array}$ & Fail to open vent & & & & & \\
\hline
\end{tabular}




\subsubsection{Comparison of Smart Infusion Pumps: Activation Errors}

Similar to the set-up part of the process, the number of failure modes and the number of high-risk failure modes are totaled for the activation part of the process, as shown in Table 35.

Table 35: Comparison of total number of failure modes and total number of high-risk failure modes across smart pumps - Activation

\begin{tabular}{|c|c|c|c|c|c|c|c|c|c|c|}
\hline & \multicolumn{2}{|c|}{$\begin{array}{c}\text { Baxter Colleague } \\
\text { CXE }\end{array}$} & \multicolumn{2}{|c|}{$\begin{array}{c}\text { B. Braun Infusomat } \\
\text { Space }\end{array}$} & \multicolumn{2}{|c|}{$\begin{array}{l}\text { Cardinal Health } \\
\text { Alaris PC }\end{array}$} & \multicolumn{2}{|c|}{$\begin{array}{l}\text { Hospira } \\
\text { Symbiq }\end{array}$} & \multicolumn{2}{|c|}{$\begin{array}{c}\text { Hospira Plum } \\
\mathrm{A}+\end{array}$} \\
\hline Steps & 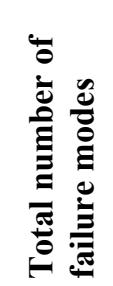 & 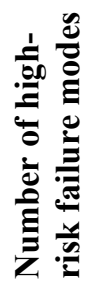 & 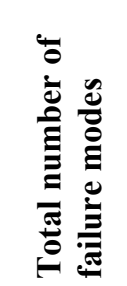 & 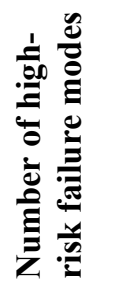 & 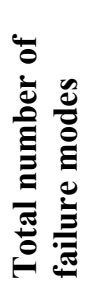 & 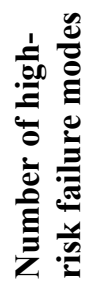 & 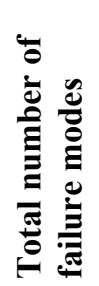 & 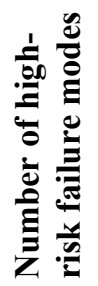 & 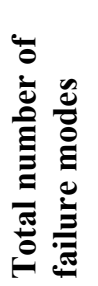 & 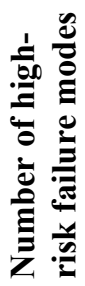 \\
\hline 6 & 13 & 7 & 18 & 10 & 9 & 4 & 12 & 6 & 14 & 7 \\
\hline 7 & 2 & 2 & 2 & 2 & 2 & 2 & 3 & 2 & 2 & 0 \\
\hline 8 & 1 & 1 & 1 & 1 & 1 & 1 & 1 & 1 & 2 & 2 \\
\hline Total & 16 & 11 & 21 & 13 & 12 & 7 & 16 & 9 & 18 & 9 \\
\hline
\end{tabular}

The number of high-risk failure modes for each pump were compared (Table 35) and it is observed to have a higher variability than the Set-up part of the process due to the difference in user interface design between infusion pumps. 


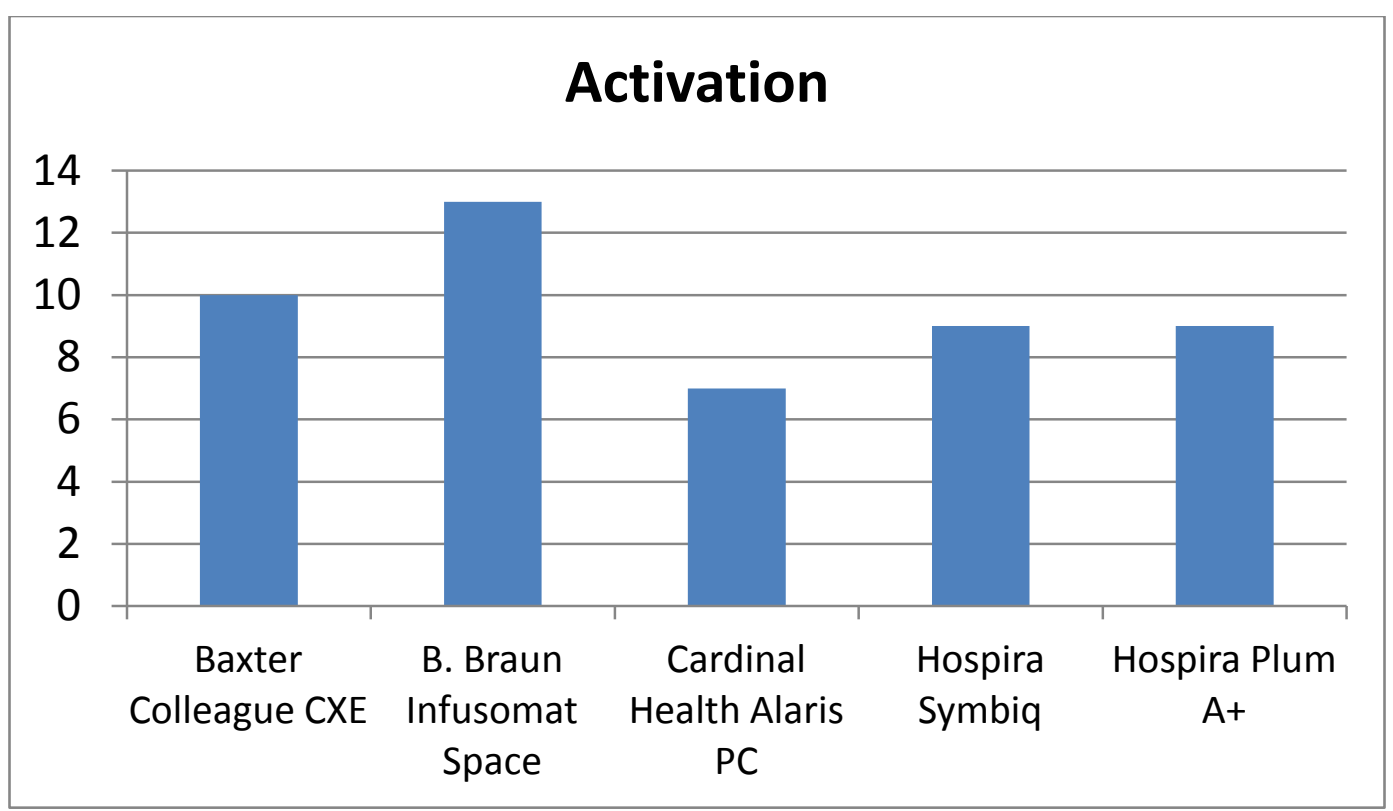

Figure 15: Comparison of total number of high-risk failure modes associated with each smart pump - Activation

The list of high-risk failure modes for the "Set-up" part of the process are summarized in Table 36. Each high-risk failure mode is matched with the corresponding smart infusion pump with a red "X". As shown, some failure modes are common to multiple infusion pumps while some failure modes are unique to a particular infusion pump. All the high-risk failure modes identified are grouped into one of eight types of set-up errors: programming the incorrect infusion pump channel, entering incorrect infusion parameters, error in manual calculations, failure to locate secondary infusion menu, selecting incorrect drug concentration, selecting incorrect drug library profile, failure to open roller clamp, failure to start infusion. 
Table 36: List of high-risk failure modes and failure mode types - Activation

\begin{tabular}{|c|c|c|c|c|c|c|}
\hline $\begin{array}{l}\text { Failure Mode } \\
\text { Type }\end{array}$ & Failure Mode & $\begin{array}{l}\text { Baxter } \\
\text { Colleague } \\
\text { CXE }\end{array}$ & $\begin{array}{l}\text { B. Braun } \\
\text { Infusomat } \\
\text { Space }\end{array}$ & $\begin{array}{l}\text { Alaris } \\
\text { PC }\end{array}$ & $\begin{array}{l}\text { Hospira } \\
\text { Symbiq }\end{array}$ & $\begin{array}{l}\text { Hospira } \\
\text { Plum } \\
\text { A+ }\end{array}$ \\
\hline \multirow{2}{*}{$\begin{array}{l}\text { Program } \\
\text { incorrect } \\
\text { pump channel }\end{array}$} & $\begin{array}{l}\text { Select incorrect } \\
\text { channel }\end{array}$ & & & & & \\
\hline & Stop incorrect channel & & & & & \\
\hline \multirow{5}{*}{$\begin{array}{l}\text { Enter } \\
\text { incorrect } \\
\text { infusion } \\
\text { parameters }\end{array}$} & $\begin{array}{l}\text { Enter incorrect } \\
\text { duration }\end{array}$ & & & & & \\
\hline & $\begin{array}{l}\text { Enter incorrect } \\
\text { volumetric rate }\end{array}$ & & & & & \\
\hline & $\begin{array}{l}\text { Enter incorrect } \\
\text { volume }\end{array}$ & & & & & \\
\hline & $\begin{array}{l}\text { Enter incorrect dose } \\
\text { rate }\end{array}$ & & & & & \\
\hline & $\begin{array}{l}\text { Select incorrect dose } \\
\text { rate unit }\end{array}$ & & & & & \\
\hline $\begin{array}{l}\text { Error in } \\
\text { manual } \\
\text { calculations }\end{array}$ & Inaccurate calculation & & & & & \\
\hline \multirow{4}{*}{$\begin{array}{l}\text { Fail to locate } \\
\text { secondary } \\
\text { infusion menu }\end{array}$} & Select incorrect mode & & & & & \\
\hline & $\begin{array}{l}\text { Fail to select } \\
\text { secondary mode }\end{array}$ & & & & & \\
\hline & $\begin{array}{l}\text { Select channel A } \\
\text { rather than Channel B }\end{array}$ & & & & & \\
\hline & $\begin{array}{l}\text { Unintentionally exit to } \\
\text { main menu }\end{array}$ & & & & & \\
\hline $\begin{array}{l}\text { Select } \\
\text { incorrect drug } \\
\text { concentration }\end{array}$ & $\begin{array}{l}\text { Select incorrect } \\
\text { concentration }\end{array}$ & & & & & \\
\hline $\begin{array}{l}\text { Select } \\
\text { incorrect drug } \\
\text { library profile }\end{array}$ & $\begin{array}{l}\text { Select incorrect drug } \\
\text { library profile }\end{array}$ & & & & & \\
\hline \multirow[t]{2}{*}{$\begin{array}{l}\text { Fail to open } \\
\text { roller clamp }\end{array}$} & $\begin{array}{l}\text { Fail to open roller } \\
\text { clamp }\end{array}$ & & & & & \\
\hline & $\begin{array}{l}\text { Roller clamp not } \\
\text { opened fully }\end{array}$ & & & & & \\
\hline \multirow{2}{*}{$\begin{array}{l}\text { Fail to start } \\
\text { infusion }\end{array}$} & Fail to start infusion & & & & & \\
\hline & $\begin{array}{l}\text { Fail to confirm } \\
\text { settings (thinking that } \\
\text { infusion has started } \\
\text { once "Start" was } \\
\text { pressed) }\end{array}$ & & & & & \\
\hline
\end{tabular}


In summary, the secondary infusion administration process is mapped, including all the major steps as well as all the sub-tasks associated with those steps. The first half of the process is named the "Set-up" while the second half of the process is named "Activation". The detailed process map provided an outline of opportunities where errors may occur and cause the system to fail. When comparing the "Set-up" part of the process between the five smart infusion pumps examined in this study, four of the five infusion pumps (i.e. Baxter Colleague CXE, B. Braun Infusomat Space, Cardinal Health Alaris PC, and Hospira Symbiq) have similar sub-tasks involved when setting up a secondary infusion since they require the conventional secondary infusion set-up (Figure 1) when delivering secondary infusions. The Hospira Plum $\mathrm{A}+$, on the other hand, requires fewer sub-tasks to set-up as the pump can draw fluid the primary or secondary containers directly, eliminating the need to set-up the secondary and primary containers and tubing in the conventional way. When comparing the "Activation" part of the process between the five smart infusion pumps, more variations were observed than in the "Setup" part of the process since the secondary programming sequence is different between the pumps. The programming characteristics for the smart infusion pumps are compared in terms of the presence of DERS, library profile selection, mandatory input parameters, as well as the total number of possible programming steps when programming a secondary infusion.

Once the process is mapped, failure modes are identified using four different methods: literature review, incident reports analysis, clinical observations, and brainstorming with the HFMEA team. The majority of the failure modes found from the literature review focused on the "Activation" part of the secondary infusion process, particularly errors related to programming the smart infusion pump incorrectly. On the other hand, the results from the incident reports analysis reveal that similar numbers of incident reports are found for incidents related to both the "Set-up" and the "Activation" parts of the secondary infusion process, with a slightly higher number of "Set-up" related reports. As well, eight potential failure modes are identified from clinical observations. Four of which are related to the "Set-up" part of the secondary infusion process, and four of which are related to the "Activation" part of the process. Lastly, an additional 34 potential failure modes are identified using the brainstorming method with the HFMEA team. The failure modes are grouped into failure mode types. Nine types of failure modes are identified for the "Set-up" part of the process and six types of failure modes are identified for the "Activation" part of the process. 
Finally, high-risk failure modes are identified using the Hazard Scoring Matrix as well as the Decision Tree Analysis. High-risk failure modes are compared between the five smart infusion pumps examined in this study (i.e. Baxter Colleague, B. Braun Infusomat Space, Cardinal Health Alaris PC, Hospira Symbiq, and Hospira Plum A+). For the "Set-up" part of the secondary infusion process, the results show that the number of high-risk failure modes are consistent among four of the five smart infusion pumps (i.e. Baxter Colleague, B. Braun Infusomat Space, Cardinal Health Alaris PC, and Hospira Symbiq) while the Hospira Plum A+ has the least number high-risk failure modes. On the other hand, the results for the "Activation" part of the process show higher variability between the five smart infusion pumps, where the B. Braun Infusomat Space has the highest number of high-risk failure modes and the Cardinal Health Alaris PC has the lowest number of high-risk failure modes. 


\section{Chapter 5 \\ Discussion}

\section{Discussion}

The discussion section will begin by comparing the different failure modes across smart infusion pumps in terms of Set-up and Activation parts of the process. With those failure modes in mind, desired infusion pump features will be described to highlight infusion pump features that help ensure the safety of secondary infusion administration. Interventions will then be discussed to offer strategies to mitigate risks in the Set-up and Activation parts of the secondary infusion process. After examining the safety of secondary infusion practice in general, the author will take a step back and comment on the methods used in the present work. For instance, the author will compare HFMEA to the traditional FMEA, as well as consider the relevance of the four methods (literature review, incident reports analysis, clinical observations, and brainstorming with the HFMEA team) in identifying failure modes for the HFMEA. Lastly, this chapter will end by outlining the challenges and limitations of the present work.

\subsection{Comparison of Smart Infusion Pumps}

Results from the HFMEA revealed high-risk failure modes in the secondary infusion administration process. The following sections highlight and describe each of those failure modes for both the "Set-up" and "Activation" phases of the process.

\subsubsection{Set-up Errors}

\subsubsection{Select incorrect secondary infusion set}

When setting up the secondary infusion, the appropriate tubing (i.e. secondary infusion set) must be selected to prepare for secondary infusion administration. Since all the physical components of infusion therapy are often stored in a supplies area in the clinical unit, one potential high-risk failure mode when setting up a secondary infusion is selecting the incorrect infusion set. For example, a nurse can select a primary infusion set rather than a secondary infusion set. Primary infusion sets are usually longer than secondary infusion sets, which may allow nurses to attach the infusion set into the lower injection port on the primary fluid. As well, due to the length of 
the primary infusion set, the patient may lose a significant amount of drug from the priming volume of the primary infusion set.

Comparing between the five smart infusion pumps evaluated in this study, this failure mode is considered high-risk for the Baxter Colleague CXE but not for the other smart infusion pumps. The reason being, the Baxter Colleague CXE (Figure 16) uses a standard primary infusion set. Therefore, the only obvious difference between the primary and secondary infusion set (Figure 17 ) is the length of the tubing. However, for the B. Braun Infusomat (Space Figure 18) and the Cardinal Health Alaris PC (Figure 19) smart infusion pumps, the primary infusion set can be distinguished by the pumping segment located below the back-check valve. The pumping segment is the portion of the tubing that is designed to be placed inside the pump. For the Hospira Symbiq and Hospira Plum A+, the primary infusion set can be distinguished by the cassette located below the back-check valve for the Hospira Symbiq (Figure 20), and below the drip chamber for the Hospira Plum A+ (Figure 21) as the Hospira Plum A+ infusion sets are not equipped with back-check valves. Similar to the pumping segment, the cassette is placed inside the infusion pump so that the pump can draw fluid along the infusion tubing.

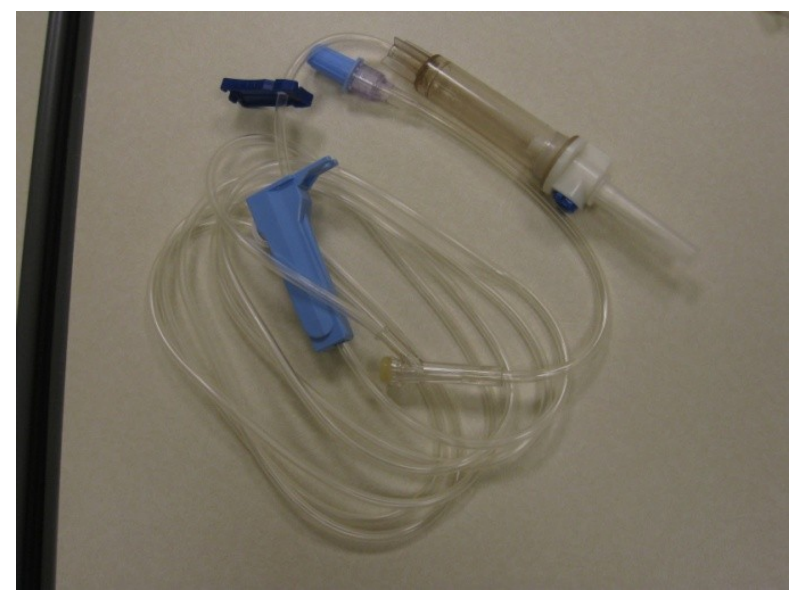

Figure 16: Baxter primary infusion set 


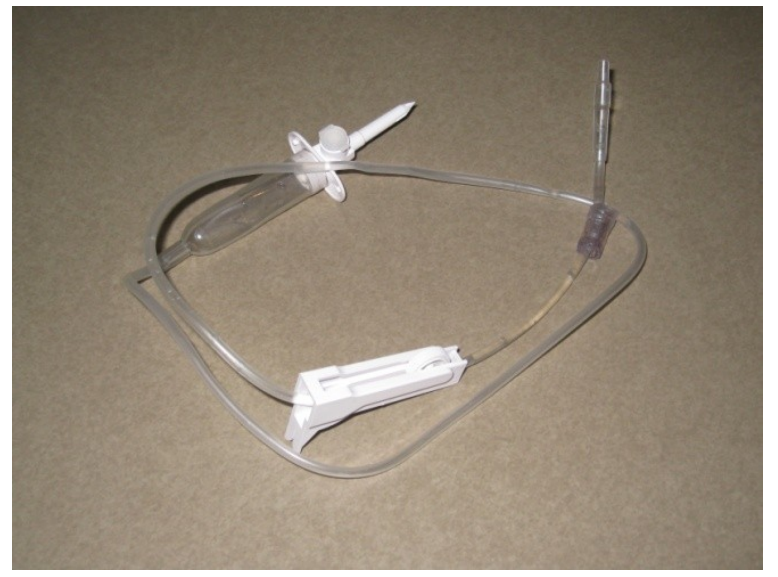

Figure 17: Example of secondary infusion set from Hospira

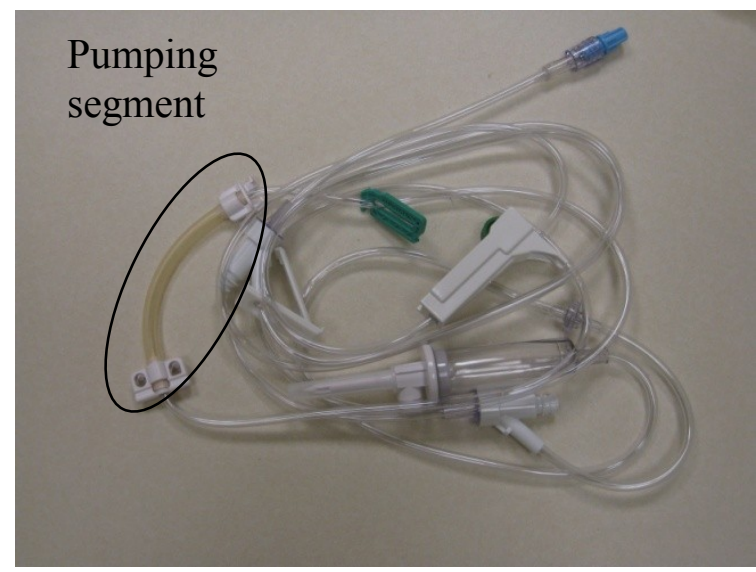

Figure 18: B. Braun Infusomat Space primary infusion set

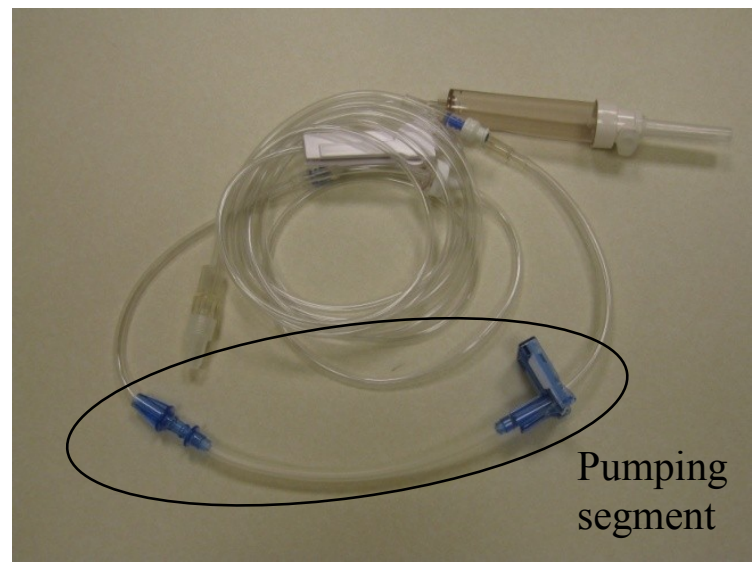

Figure 19: Cardinal Health Alaris PC primary infusion set 


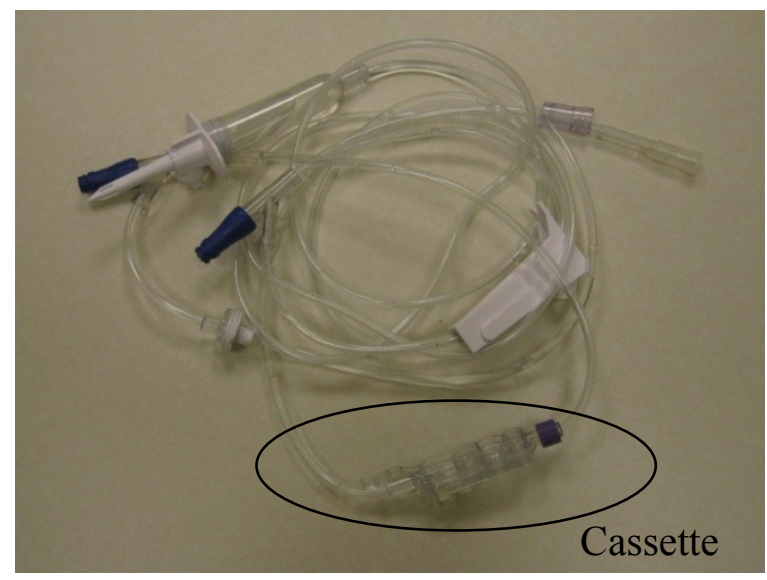

Figure 20: Hospira Symbiq primary infusion set

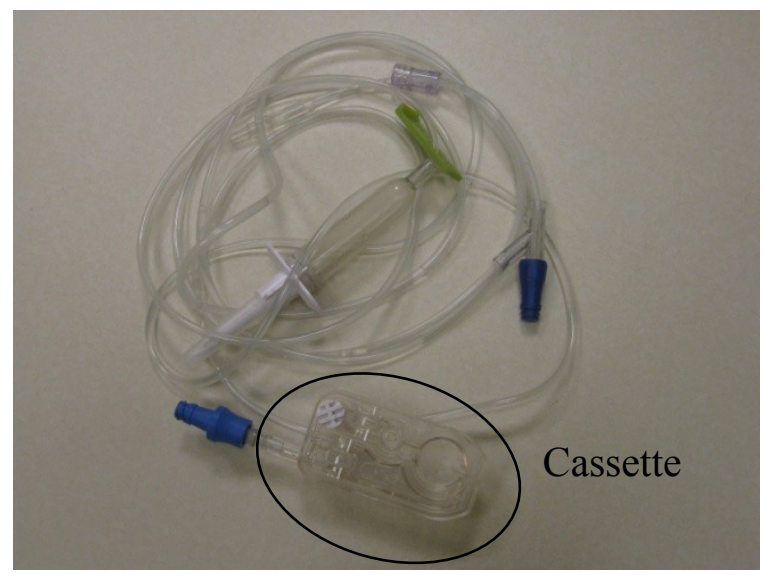

Figure 21: Hospira Plum A+ primary infusion set

\subsubsection{Connect secondary line to a primary infusion set that has no back-check valve}

Back-check valve is essential to the secondary infusion set-up as it allows for sequential infusion by stopping the primary infusion temporarily and allowing only the secondary fluid to be delivered. A potential high-risk failure mode when setting up the secondary infusion is delivering a secondary infusion through a primary infusion set that is not equipped with a back-check valve. Without the back-check valve present, both primary and secondary fluids would be delivered concurrently at an unknown ratio. As a result, the patient would receive a smaller dose of drug than desired.

This failure mode is considered high-risk for all smart infusion pumps evaluated except for the Hospira Plum $\mathrm{A}+$. The reason being, all smart infusion pumps that require the conventional 
secondary infusion set-up require the use of a back-check valve. At the same time, these infusion pumps do not monitor the source of the fluid (i.e. from primary container or secondary container). Therefore, this failure mode does not have a controlled measure in place and is not readily detectable. On the other hand, the Hospira Plum A+ does not require the use of a backcheck valve as the cassette draws fluid directly from the secondary bag through the secondary channel. As a result, the pump ensures only the secondary fluid is being delivered during secondary infusion mode.

\subsubsection{Fail to establish appropriate hydrostatic pressure differential between primary and secondary infusion containers}

As mentioned above, the back-check valve is used to temporarily stop the flow of the primary fluid to allow for delivery of the secondary infusion. The back-check valve opens or closes based on the difference in hydrostatic pressure between the primary and secondary fluids. The correct set-up requires the primary container to be hung lower than the secondary container using a secondary hanger. Any deviations from this arrangement (e.g. primary and secondary containers hung at the same height, primary container hung higher than the secondary container, etc.) were considered as high-risk failure modes from the HFMEA.

This failure mode is considered high-risk for all smart infusion pumps evaluated except for the Hospira Plum A+. The reason being, all smart infusion pumps that require the use of a backcheck valve require the infusion containers to be hung at different heights to establish the hydrostatic pressure differential. As well, these infusion pumps cannot detect the height or pressure differential between infusion bags. Therefore, this failure mode does not have a controlled measure in place and is not readily detectable. On the other hand, the Hospira Plum $\mathrm{A}+$ does not require nurses to establish a hydrostatic pressure differential since the back-check valve is not necessary when using this pump. As a result, this failure mode is not considered high-risk when using the Plum A+.

\subsubsection{Fail to sterilize connection site properly prior to secondary connection}

Before connecting the secondary line to the upper $y$-site port on the primary line, it is important to sterilize the connection site to prevent infections. However, sometimes nurses may forget to sterilize the connection site or fail to sterilize properly, which are considered to be high-risk 
failure modes from the HFMEA. As a result, patients may develop infections from microorganisms on the y-site (O'Grady et al., 2011). This is a serious consequence, especially for critically ill patients as their immune system may not be strong enough to fight off the infection (Ylipalosaari et al., 2006). As well, since microorganisms cannot be seen with the naked eye, it is hard to know if the connection site is indeed sterile. This failure mode was considered high-risk for all smart infusion pumps since infusion pumps do not have a mechanism to check for sterility of connection sites.

\subsubsection{Misconnection of secondary line}

When connecting the secondary line to the primary line, the secondary line should be connected to the upper y-site port (the port above the infusion pump, just under the back-check valve) of the primary tubing so that the flow of the secondary fluid is controlled by the infusion pump. Highrisk failure modes related to this step of the process include connecting the secondary tubing to the wrong primary line and failing to connect the secondary tubing. Although both failure modes result in delay in secondary infusion therapy, connecting the secondary tubing to the wrong primary line may also result in compatibility issues.

This failure mode is considered high-risk for all smart infusion pumps evaluated except for the Hospira Plum $\mathrm{A}^{+}$. This is because the secondary infusion channel on the Hospira Plum $\mathrm{A}+$ is equipped with upstream occlusion detection. Therefore, if the secondary tubing is misconnected, the pump being programmed would alarm since it can detect the lack of fluid flow on the secondary channel. On the other hand, all other smart pumps examined would not be able to detect the error since the pumps would continue to deliver fluid at the programmed rate as long as the primary bag is still connected. As a result, the primary fluid would be delivered at the secondary rate that is programmed. Since secondary infusion rates are usually delivered at a high rate than primary infusions, as observed in clinical observations, the patient would potentially be overloaded with fluids, which may result in respiratory or heart failure (Hilton, Pellegrino, \& Scheinkestel, 2008).

\subsubsection{Fail to open vent for glass or semi-rigid containers}

If the secondary container is glass or semi-rigid, the secondary tubing system must be vented so that air can displace the fluid in the container, allowing fluid to flow. If nurses fail to open the 
vent, fluid would not flow. As a result, the back-check valve would not close and the primary fluid would be running instead of the secondary fluid.

This failure mode is considered high-risk for all smart infusion pumps examined except for the Hospira Plum A+. As mentioned previously, most smart infusion pumps require the conventional secondary infusion set-up, which rely on the back-check valve to control the flow sequence of the primary and secondary fluid. Thus, these infusion pumps cannot monitor the source of the fluid (i.e. from the primary container or secondary container). They would continue to pump as long as there is fluid to be pumped. Therefore, if the secondary tubing system isn't vented when it needs to be, the back-check valve would open and allow the primary fluid to flow in place of the secondary fluid. On the other hand, the Hospira Plum A+ provides a separate port on the cassette for secondary infusions, which is equipped with an occlusion detector. Therefore, when the secondary fluid fails to flow, the pump would alarm nurses when there is a lack of fluid flow above the infusion pump.

In summary, six types of set-up errors were discussed in this section. "Selecting incorrect secondary infusion tubing" error is considered high-risk for the Baxter Colleague CXE only when compared to the other infusion pumps examined in this study (i.e. B. Braun Infusomat Space, Cardinal Health Alaris PC, Hospira Symbiq, and Hospira Plum A+). The reason being, it is the only infusion pump that uses generic primary IV infusion sets for the primary infusion, where other infusion pumps use primary IV infusion sets that have a cassette unique to the pump. Since secondary infusion tubing are generic and do not have cassettes attached, generic primary infusion sets can potentially be mistaken as secondary infusion sets. Set-up errors such as "Connect secondary line to a primary infusion set that has no back-check valve", "Fail to establish appropriate hydrostatic pressure differential between primary and secondary infusion containers", and "misconnection of secondary line" are considered high-risk for all smart infusion pumps examined except for the Hospira Plum A+ (i.e. Baxter Colleague, B. Braun Infusomat Space, Hospira Symbiq, and Hospira Plum A+). The Hospira Plum A+ was able to mitigate these errors by providing a separate port for the secondary infusion at the cassette, which allows the pump to draw fluid from the primary or secondary containers directly as well as monitor the presence of secondary fluid flow. As a result, no back-check valves are needed; therefore, the need for establishing a difference in hydrostatic pressure is eliminated. Lastly, both "fail to sterilize connection site properly prior to secondary connection" and "fail to open vent 
for glass and semi-rigid containers" were considered as high-risk failure modes across all smart infusion pumps examined as these were general infusion practice failure modes that none of the smart infusion pumps can address.

\subsubsection{Activation Errors}

\subsubsection{Programming incorrect pump channel}

To begin programming a secondary infusion, nurses are required to select the pump channel to be programmed. If the wrong channel is selected, they would be programming the incorrect channel. As a result, the incorrect drug would be infused at the programmed secondary rate. As well, the secondary medication would be infused at the primary rate from the correct pump channel.

This potential failure mode is considered high-risk for all the smart infusion pumps examined from the HFMEA. For all the smart pumps that require the conventional secondary infusion setup (i.e. Alaris PC, B. Braun Infusomat Space, Baxter Colleague CXE, Hospira Symbiq), this failure mode is considered high-risk because the pump does not have a mechanism to check if a secondary line is connected to the primary tubing that is currently running in the selected pump channel. Therefore, there is no mechanism of control measure or detection for the failure mode. The Hospira Plum A+ has a slight advantage compared to the other smart infusion pumps examined because when programming the secondary channel nurses are required to select "Channel B", which refers to the secondary port provided on the cassette. If they program "Channel B" on the incorrect pump, the occlusion alarm would sound because the incorrect pump would be able to detect that the secondary channel is empty. However, if the nurses select "Channel A" on the correct or incorrect infusion pump, the primary fluid would be running at the programmed secondary rate and the secondary fluid would not be delivered to the patient. As a result, the primary fluid would be running at an incorrect rate and the patient would not be getting the therapy they need, which may cause harm to the patient.

\subsubsection{Programming incorrect infusion parameters}

Programming incorrect infusion parameters refer to entering incorrect values into one or more infusion flow parameters such as volumetric rate, dose rate, infusion time, and volume to be 
infused. As a result, the infusion would be given at an incorrect rate, which could potentially infuse an overdose, or an under-dose, of the medication to the patient.

The present work agrees with the literature (Flynn et al., 2003; ISMP Canada, 2003; Nunnally \& Bitan, 2006; Rothwell, 2009; Squires et al., 2005; Trbovich et al., 2010; Tosha B Wetterneck et al., 2006) in that this type of failure mode is a common risk when using infusion pump technology to deliver intravenous therapy. Programming incorrect infusion parameters is considered high-risk from the HFMEA for all infusion pumps examined since all pumps require manual programming. However, the number of ways nurses can commit this error reduces as less infusion parameters are offered when programming a secondary infusion, as observed on the Cardinal Health Alaris PC from the HFMEA. As well, infusion pump programming interface and keypads could be better designed to minimize decimal point errors (keying in the infusion rate at 10 times the intended rate) and confusion between parameters (e.g. keying in volume to be infused as infusion rate), as suggested in the literature (ISMP Canada, 2003; Rothwell, 2009). But before these design changes are implemented, checking the programmed parameters against the physician's order as well as independent double-checks with another nurse may help reduce the likelihood of programming incorrect infusion parameters (Flynn et al., 2003).

\subsubsection{Error in manual calculations}

When programming secondary infusions, nurses may need to perform manual calculations in order to enter the parameters required to program the infusion pump. For example, if the physician's order specifies the total volume and the duration of the infusion, but the infusion pump requires nurses to enter the volumetric rate of the infusion when programming a secondary infusion, they would be forced to perform manual calculations to program the infusion pump. If they make a mistake in manual calculations when programming the infusion pump, the incorrect infusion rate would result in an overdose, or under-dose, of the medication to the patient.

The scenario used in the study assumed that the physician's orders specified the total volume to be infused and time for the secondary infusion. Based on the scenario used in the study, the Baxter Colleague CXE and Hospira Symbiq would require nurses to perform manual calculations as the default parameters that the infusion pump requires them to enter are volumetric rate and total volume rather than total volume and time. When using the $\mathrm{B}$. Braun Infusomat Space and the Hospira Plum A+, manual calculations may or may not be required 
depending if nurses choose to program using volumetric rate since the volumetric rate parameter is not a mandatory field. If the nurses choose to program using volume and duration, manual calculations would not be required based on the physician's order described for the study because both the volume and duration are specified on the order. Lastly, based on the scenario used in this study, no manual calculations were needed when programming a secondary infusion using the Cardinal Health Alaris PC.

The results from the present work agree with the literature as errors in manual calculation are common when programming the infusion pump with infusion parameters on physician's orders not matching programmable infusion parameters on the infusion pump (Hicks \& Becker, 2006; ISMP Canada, 2003; Keay \& Callander, 2004; Nunnally \& Bitan, 2006; Rothwell, 2009; Trbovich et al., 2010). As suggested by one study, the design of the DERS interface may influence how calculation errors are made (Rothwell, 2009). Therefore, there is an opportunity for manufacturers to improve patient safety by improving the design parameter programming screens. As well, double-checking calculations independently with another nurse may help reduce the likelihood of calculation errors when programming a secondary infusion (Keay \& Callander, 2004).

\subsubsection{Fail to select secondary mode}

When programming secondary infusions on smart infusion pumps, users are required to select secondary mode from the programming menu as it is not the default mode and it is considered a special function. Therefore, secondary modes are usually listed in the sub-menu, which require nurses to navigate the main menu in order to locate the secondary mode and can lead to confusion for them. Also, the terminology between smart infusion pumps varies; some pumps refer to it as secondary mode and some pumps refer to it as piggyback. Nonetheless, nurses usually need to go through a number of buttons before arriving at the secondary infusion menu. If they fail to find the secondary menu and start programming the parameters into the pump anyway, chances are, they would be altering the primary infusion program.

Out of the five smart infusion pumps examined, the Hospira Symbiq is the only pump that provided the secondary infusion option in the main menu, allowing nurses to find the secondary infusion program menu without difficulty. As well, all infusion functions are separated into tabs near the top of the programming screen, which makes programming in the wrong infusion menu 
(e.g. programming the secondary infusion as a primary infusion) highly detectable. For example, Figure 22 shows the secondary infusion programming menu for both the Hospira Symbiq (left) and the B. Braun Infusomat Space (right). Comparing the two programming screens, the Hospira Symbiq clearly shows that it is in the secondary infusion programming menu and not in any other infusion modes (i.e. bolus or basic). On the contrary, it is hard to identify on the B. Braun Infusomat Space programming screen which infusion mode nurses are programming in.
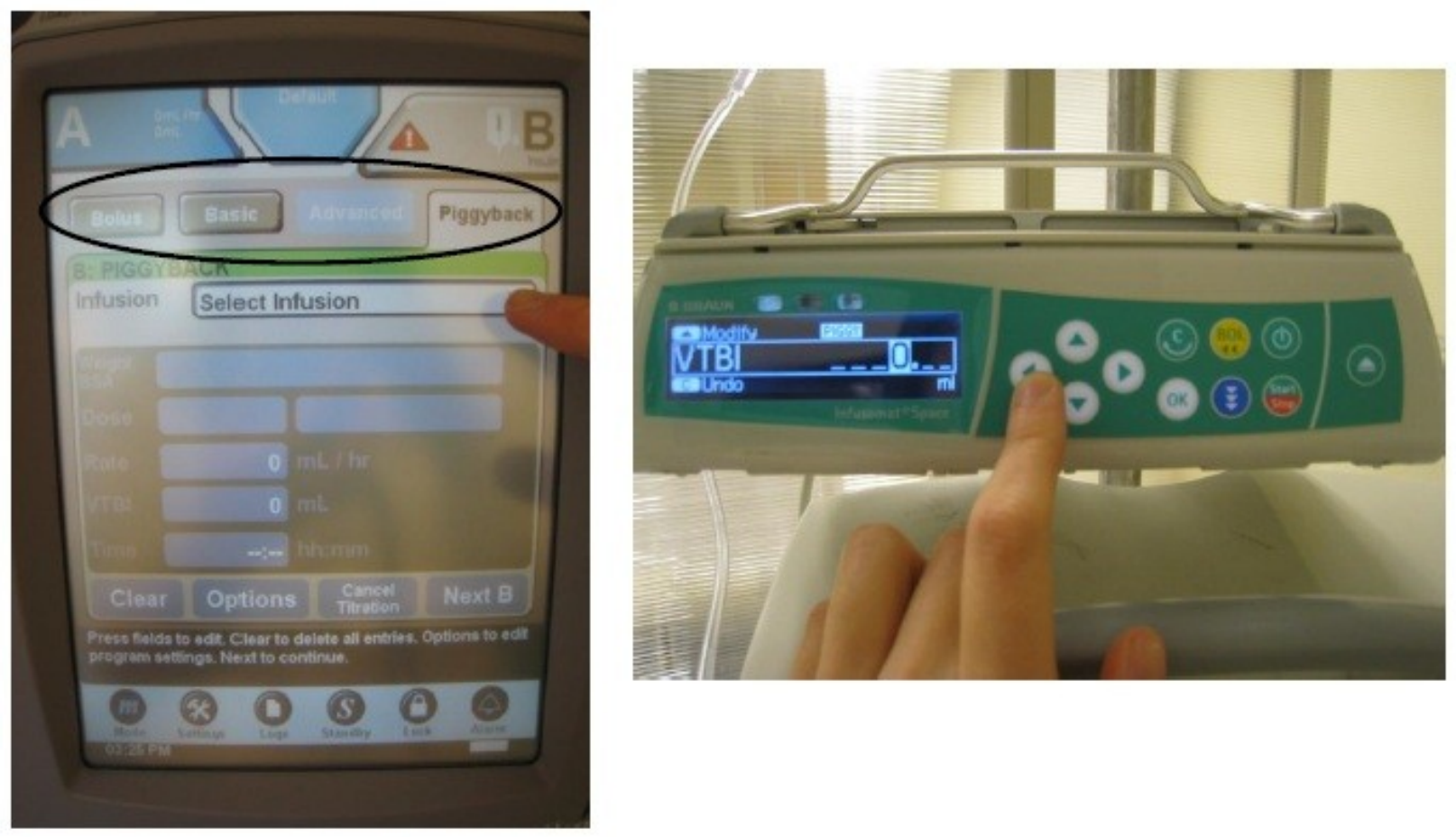

Figure 22: Comparing secondary infusion screens between Hospira Symbiq (left) and B. Braun Infusomat Space (right)

\subsubsection{Select incorrect drug concentration}

When programming the infusion pump through the drug library, nurses are usually prompted to select the drug concentration so that the pump can use that infusion to calculate the dose received by the patient. One of the failure modes is selecting the wrong drug concentration on the pump. As a result of this failure mode, the drug calculations would be incorrect and therefore, deliver the infusion at an incorrect rate.

This failure mode has been discussed in other studies (Rothwell, 2009; Tosha B Wetterneck et al., 2006) where the use of smart infusion pumps were examined. In one of the studies, three 
smart infusion pumps were compared and no significant difference was found between the different interface designs of DERS between the three smart infusion pumps. Results from the literature agree with the present work as error in drug concentration selection is considered highrisk from the HFMEA for all smart infusion pumps that use DERS when programming secondary infusions. From the HFMEA, this failure mode is considered high-risk for the Alaris PC, B. Braun Infusomat Space, Hospira Plum A+ and Hospira Symbiq as all the infusion pumps listed require nurses to select the concentration manually from a list of concentrations or drug names with concentration information, which is susceptible to key punch errors. This failure mode does not apply to the Baxter Colleague CXE because DERS is not present for secondary infusions on the Baxter Colleague CXE. Therefore, when using the Baxter Colleague CXE, nurses do not have to select concentration for the drug being infused.

\subsubsection{Fail to Open Roller Clamp}

The roller clamp on the secondary tubing should be opened, before starting the infusion, so that fluid can be drawn from the secondary bag. If the secondary roller clamp remains closed at the start of the infusion, secondary fluid would not be able to flow through the tubing. As a result, the back-check valve on the primary tubing would not close and primary fluid would be flowing at the secondary rate.

Failure to open secondary roller clamp has been documented in the literature as a common error when administering secondary infusions using the traditional secondary set-up (ISMP Canada, 2005; Trbovich et al., 2010). Similar to the findings from the literature, this failure mode is considered high-risk for all smart infusion pumps evaluated except for the Hospira Plum A+ as all other smart infusion pumps (i.e. Baxter Colleague CXE, B. Braun Infusomat Space, Cardinal Health Alaris PC, and Hospira Symbiq) require the traditional secondary set-up (refer to Figure 1). This failure mode, however, is not considered high-risk for the Hospira Plum A+ because the secondary infusion channel on the Hospira Plum A+ is equipped with upstream occlusion detection. Therefore, if the secondary clamp remains closed, the pump being programmed would alarm since it can detect the lack of fluid flow on the secondary channel. On the other hand, all other smart pumps examined would not be able to detect this error since the back-check valve on the primary tubing would not close and primary fluid would be flowing through the tubing. As long as there is fluid to be pumped in the primary bag, the infusion pumps would deliver fluid at 
the programmed rate. As a result, the primary fluid would be delivered at the secondary rate that is programmed.

\subsubsection{Fail to Start Infusion}

All infusion pumps require nurses to press "Start" in order to start the programmed infusion. For smart infusion pumps that require nurses to stop the primary infusion when programming a secondary infusion (i.e. B. Braun Infusomat Space), if they fail to start the secondary infusion on the pump, the secondary fluid would not flow which leads to a delay in therapy. For smart infusion pumps that do not require nurses to stop the primary infusion when programming a secondary infusion (i.e. Alaris PC, Baxter Colleague CXE, and Hospira Symbiq), if they fail to start the secondary infusion on the pump, the secondary fluid would be delivered in the primary rate. For the Hospira Plum A+, even though it does not require the nurses to stop the primary infusion when programming a secondary infusion, failure to start the secondary infusion would only lead to delay in therapy since the secondary infusion is programmed on a separate channel.

\subsection{Desired Infusion Pump Features}

The comparison between smart infusion pumps revealed infusion pump features that smart infusion pumps have, or could potentially have, to help mitigate some of the high-risk failure modes described in the previous sections. These desired infusion pump features are highlighted in the next sections for both the "set-up" and "activation" phases of the secondary infusion administration process.

\subsubsection{Set-up}

\subsubsection{Fluid Drawn Directly from Secondary Line}

The conventional way of setting up a secondary infusion requires the clinician to hang the secondary bag higher than the primary bag, use an integral back-check valve with the primary tubing, connect the secondary tubing to the $y$-site port above the infusion pump, and remember to open the secondary clamp when the infusion starts. Most high-risk secondary infusion set-up failure modes were a result of errors when performing any of these four steps. The reason being, the conventional secondary infusion set-up relies on hydrostatic pressure and manual tubing manipulation for the system to work, without any system in place to constantly monitor if the system is working properly. And since at the end of a secondary infusion the infusion pump 
automatically switches back to primary infusion, nurses tend to attend to other responsibilities when delivering secondary infusion. Therefore, if the system wasn't working properly, nurses may not know until sometime later.

From the HFMEA, the Hospira Plum A+ offers a different model of delivering secondary infusion that does not require nurses to set up the infusion bags at different heights, use the backcheck valve, and connect the secondary port to the upper port. The purpose of setting up the bags at different heights is to use the difference in hydrostatic pressure produce to cause the backcheck valve to close and allow only the secondary fluid to flow through. However, with the conventional set-up, it is difficult to know if the back-check valve closed properly so that the secondary infusion is being delivered at the intended rate and concentration. The only way to check is to actively monitor the drip chambers of the primary and secondary lines to make sure only the secondary fluid is being delivered and not the primary. To eliminate this issue, the Hospira Plum $\mathrm{A}+$ is equipped with a separate port for secondary infusions right on the cassette. The cassette is then able to monitor and draw fluid directly from the infusion bags individually. Therefore, the pump is able to control which bag to draw the fluid from. So the clinician can know for sure only secondary medication is being delivered when nurses program the pump to deliver in piggyback mode.

\subsubsection{Secondary Line Occlusion Detector}

Another problem with the conventional set-up is that the secondary tubing has to be connected to the $y$-site port that is upstream of the infusion pump so that the pump can control the rate of fluid flow of the secondary infusion. However, nurses were observed to mistakenly connect the secondary tubing to the y-site ports just below the pump during clinical observation. As a result, the secondary medication could be free-flowing into the patient or it may not be delivered at all, depending on the rate the primary fluid is being delivered. This could potentially cause an overdose to the patient. The Hospira Plum A+ solves this issue by providing a second port at the cassette, which is equipped with a line occlusion detector. As a result, the pump can detect the lack of fluid flow from the secondary port and would alarm nurses if the secondary tubing is mistakenly connected to the y-site ports downstream of the infusion pump or if it is not connected at all. 


\subsubsection{Activation}

\subsubsection{Clearly Display the Infusion Mode that the User is Currently Programming in}

The secondary infusion function is usually found under a sub-menu on the smart infusion pumps rather than on the main screen. Therefore, users can potentially get lost in the programming sequence and fail to find the secondary mode. As well, it might not be intuitive as to which mode the nurses are currently programming in. For example, nurses could go into secondary mode but accidently exit the secondary programming screen and go back into the primary screen without knowing. They may then continue to program the primary infusion thinking that they are programming a secondary infusion. One infusion pump feature that helped prevent this was the tabs menu design by Hospira Symbiq where nurses can easily identify the infusion mode that they are currently programming in, which makes programming in the wrong mode easily detectable.

\subsubsection{Auto-Programming}

One of the main failure modes when programming an infusion pump is committing key punch errors or calculation errors, both of which result in delivering the medication at the wrong rate. As a result, the patient may get an overdose or under-dose of the medication, which can be detrimental to the patient. Also, by having to manual program, nurses may select the wrong drug or wrong concentration of the drug in the drug library. This may also cause mistakes in calculations and deliver the drug to the patient at the wrong infusion rate. Lastly, On pumps where nurses have to select the drug library profile to deliver secondary infusions, they could select the wrong profile which would apply different soft or hard dose limits to the drug and may fail to alarm the nurses if the rate is not within the normal range of delivery for that particular care area or type of patient. Therefore, infusion pumps that allow auto-programming would be desirable as it would eliminate transcription errors, as well as calculation errors.

\subsubsection{Clamp Detector}

During the activation phase, the clinician has to make sure the roller clamp on the secondary line is opened before starting the infusion so that secondary fluid can flow through the tubing. However, it is often a step that is missed because it is more natural for nurses to enter all the infusion parameters and press start rather than opening the roller clamp between programming 
and starting the infusion. If the roller clamp is not opened at the start of the infusion, the backcheck valve on the primary line would not close and the secondary fluid cannot flow. As a result, the primary fluid would be delivered at a secondary rate. Since secondary rates are often higher than primary infusion rates, the primary fluid would be delivered to the patient at a higher rate. While this is not detrimental to most patients, provided that the primary fluid is a fluid rather than medication, it can be especially harmful to fluid restricted patients. One potential solution is to have a clamp detector on the secondary line to detect whether the clamp is open at the start of the secondary infusion. By alarming the nurses when the clamp is closed at the start of the infusion, they can easily detect if a mistake was made.

\subsection{Interventions}

Since not all infusion pumps have all the features listed above, there are some potential solutions that would allow hospitals or infusion pump users to mitigate some of the high-risk failure modes that were identified in this study. The following sections describe the different potential interventions to address high-risk set-up and activation failure modes.

\subsubsection{Set-up}

\subsubsection{Set-up using Separate Infusion Pump or Pump Channel}

The conventional secondary infusion set-up requires clinicians to manipulate infusion bags and tubing in a non-intuitive way with extra components (i.e. back-check valve) in order for secondary infusion to be delivered successfully. There are a number of failure modes that were identified for this part of the process. A lot of these failure modes were considered high-risk due to the lack of detection mechanism in most smart infusion pumps. This is because current infusion pumps do not monitor the source of the infusion fluid but only monitor whether or not there is flow above the infusion pump (i.e. occlusion detector). As a result, for example, if the back-check valve on the primary tubing fails, it is not obvious that both secondary and primary fluid would be flowing concurrently into the patient, which ultimately changes the rate of the drug infused to the patient. To eliminate this risk, one potential intervention is to eliminate secondary infusions and set up the secondary infusion as a separate infusion on a separate infusion pump or pump channel and connect the tubing to the primary tubing below the infusion pump to share the IV access with the primary infusion. By doing this, the infusion pump can monitor and control the rate of the secondary drug directly rather than relying on the back-check 
valve to control which fluid is running in the infusion line at any given time. Therefore, the clinician would not have to hang the bags at different heights and would not have to remember to connect the secondary tubing upstream of the infusion pump rather than downstream. As well, hospitals would not have to purchase tubing with the back-check valve and the upstream port, which can potentially save money on tubing cost.

One disadvantage of this proposed intervention is that once the secondary infusion is done, the pump will not automatically revert back to the primary infusion but rather alarm the nurses with the end-of-infusion alarm. As a result, nurses would have to come back to the pump and manually change the secondary infusion back to the primary fluid. Although this may seem like an inconvenience, the current nursing practice is to come back to the end of the secondary infusion and reprogram the pump to flush the secondary line with the primary fluid just to make sure all the medication from the secondary bag is delivered to the patient. Therefore, having nurses come back to the bedside at the end of the secondary infusion does not deviate too much from current nursing practice.

As well, setting up secondary infusions this way, more infusion pump channels may be needed at the bedside. However, patients usually only have one secondary infusion running at one time; therefore, each patient would only need one extra pump channel. In critical care areas, where infusion pumps are mostly used, there is usually extra pump channels available at the patient's bedside since most high-risk drugs have to be delivered as a primary infusion.

As mentioned in the previous section, the Hospira Plum A+ was able to mitigate most of the setup issues by monitoring the flow of secondary fluid directly at the cassette level by providing a separate port and occlusion detection for the secondary line. One way to achieve the same outcome without having to redesign the infusion pump is to deliver secondary medication as a second primary medication where the secondary medication would be set up on a separate infusion pump or infusion pump channel. That way, the infusion pump would be able to control the flow of the medication directly and offer occlusion detection. 


\subsubsection{Activation}

\subsubsection{Barcode Infusion Pumps}

Barcode infusion pumps can potentially mitigate programming errors by automating the programming task. As mentioned in the previous section, having the ability to auto-program would help reduce most of the programming errors associated with manual programming. Using barcode infusion pumps would provide a means of auto-data-entry with the use of a barcode. Currently, the B. Braun technology allows the pharmacy to print drug labels with infusion parameters on barcodes so that nurses can scan the barcodes to program the infusion pump. The Alaris PC and the Hospira Symbiq also have barcode and wireless capabilities to allow for integrated systems eventually. In the long run, it would be best when the Electronic Health Records (EHR) and the Computerized Physician Order Entry (CPOE) systems are linked with the infusion pumps. This way, the infusion pump can verify in real-time the drug and drug dose prescribed to the patient, and make sure it is given at the right rate, at the right dose, and by the right route. As well, the infusion parameters would be loaded to the pump automatically through the CPOE and nurses would just have to verify the parameters (Cerner Corporation, 2011). This eliminates all the potential wrong drug and wrong dose errors that were considered high-risk from the HFMEA through manual programming and calculations. Although desirable, very few healthcare organizations have attained this goal at the moment because it is difficult to interconnect and operate these systems to get full functionality.

\subsubsection{Check Drip Chamber for Fluid Flow}

Another main error during the activation part of the process is forgetting to open the secondary clamp and fail to start the infusion pump. Both of these errors lead to lack of fluid flow in the secondary line, which cause the primary fluid to be delivered at the secondary rate. One way to double check if the secondary infusion is flowing properly is to check the drip chamber. Fluid should be dripping in the secondary drip chamber but not the primary when the secondary infusion is set up and programmed correctly.

\subsection{Comparison of HFMEA and FMEA}

FMEA was originally used in the aviation, manufacturing, and nuclear industry to evaluate the risk of products. The healthcare sector recently adopted FMEA as both Accreditation Canada in 
Canada and The Joint Commission in the United States require all accredited healthcare organizations to perform a proactive risk analysis on a high-risk technology or process periodically. To help health care organizations meet the accreditation standards, the Department of Veterans' affairs developed HFMEA by combining concepts from other risk analysis tools to make the FMEA process more applicable to the healthcare setting. The difference between FMEA and HFMEA lies in the way that the potential failure modes are prioritized. In FMEA, the RPN is calculated by taking the product of the severity, probability, and detectability scores. Failure modes that have the highest RPN would be considered as hazard of highest priority. As a result, failure modes with a high probability but low severity could be prioritized the same as a failure mode with high severity but low probability. Although this may work for other industries, a failure mode with a high severity but low probability is not acceptable in the healthcare field because it may lead to patient morbidity or even mortality. On the other hand, when using the HFMEA, although severity and probability are scored, the prioritization comes from the decision tree analysis that helps determine if there were any measures of preventing or obviously detecting these failure modes.

As mentioned above, when conducting an FMEA, the prioritization of the failure modes rely on the RPN where severity, probability, and detectability scores are multiplied. Because the numbers are multiplied, any small change in the rating may cause a dramatic change to the overall score. For example, changing one of the scores by one point may result in a change in the overall score by a maximum of 16, assuming a four-point scale is used. A difference in 16 would easily move a failure mode from low priority to high priority. Therefore, the prioritization of failure modes when using FMEA is not robust and may not always reflect the relative priority of the failure modes accurately. On the other hand, the decision tree analysis component of the HFMEA offers "yes" or "no" decisions when considering the criticality, presence of control measures, and detectability when prioritizing the failure modes. As a result, it is more robust compared to the traditional FMEA. To demonstrate this observation, an analysis was done for the smart infusion pump that had the least number of high-risk failure modes, Hospira Plum A+. Assuming the HFMEA team underestimated the severity of the failure modes by one point, the analysis aimed to test if by increasing the severity scores by one would significantly increase the number of high-risk failure modes. All severity scores were increased by one point, to a maximum score of four, since the HFMEA uses a four-point scale. New hazard scores were then 
calculated and the decision tree analysis was performed to determine if the failure modes were considered high-risk. The complete HFMEA with the adjusted severity ratings can be found in Appendix F. Compared to the original HFMEA conducted, only one additional high-risk failure modes was identified based on the new hazard scores. Therefore, the decision tree analysis observed to increase the robustness of the HFMEA hazard scoring by prioritizing the failure modes using object measures.

\subsection{Relevancy of Methods Used to Identify Failure Modes}

Several methods were used in this study to help identify failure modes for the HFMEA in an attempt to capture most, if not all, high-risk failure modes associated with secondary infusions. The same methods were also used as references for severity and probability ratings.

Failure modes found in the literature often provided prevalence information, which helped with the probability rating. As well, potential patient outcome was sometimes described, providing information for severity ratings for the HFMEA. However, the amount of literature related to the topic of secondary infusion is limited. Therefore, the number of failure modes extracted from the literature was limited.

During clinical observations, nurses communicated common failure modes when delivering secondary infusions. The nurses often provide description of the failure modes, and the prevalence of these failure modes. Therefore, this method was useful as a reference for probability ratings. However, nurses did not usually describe patient outcomes; therefore, not enough data were available to inform the potential severity of failure modes from clinical observations.

Incident reports often contained information such as the event that happened and the patient outcome. Since patient outcome is often reported, the author was able to use incident reports to match severity to potential effects as result of different failure modes. However, incident reports were not a good source for potential failure modes as an event is usually reported without providing information on the failure mode that caused the event. 


\subsection{Challenges and Limitations}

\subsubsection{HFMEA Team Size}

The HFMEA team consisted of three people: the author and two human factors engineers. Since human factors engineers are trained to analyze the system as a whole, the HFMEA team had the expertise to identify and evaluate the potential failure modes that may be present in the secondary infusion administration process. As well, although the HFMEA team did not consist of a subject matter expert (i.e. clinician), the team spent a number of hours observing how nurses manage secondary infusions in a multiple infusion setting; therefore, the HFMEA team has a good understanding of the clinical practice for secondary infusions. As a result, the HFMEA team is confident that most high-risk failure modes were identified for the study.

\subsubsection{Secondary Infusion Scenario and Assumptions}

A secondary infusion scenario was developed to provide context for possible failures as well as potential effects when the system failed. However, this approach has some limitations. One limitation is the level of complexity of the system in the scenario. The secondary scenario assumed only two primary infusions running at the same time with one secondary infusion added onto the fluids line. In reality, depending on the clinical environment and the condition of the patient, a patient may have more than two infusions running at the same time. But because the aim of this study was to evaluate secondary infusions as a stand-alone task, the number of variables involved in the process was restricted. As a result, the simplified process allowed the HFMEA team to focus on identifying failure modes for only the secondary infusion task. It should be noted that a simplified scenario was assumed when conducting the HFMEA, and any errors that were identified in this study are likely to compound in a real clinical environment that is more complex and dynamic. Therefore, the failure modes that were identified in the present work may only be a subset of all the failure modes that are associated with secondary infusions.

\subsubsection{Limitations of the Study}

There were two aspects of HFMEA that were not included in the study, which are identifying potential causes and identifying actions and outcomes. Potential causes for the failure modes were not identified because the HFMEA team consists of only human factors experts and not subject matter experts. Subject matter experts are necessary when identifying potential causes for 
failure modes because they have an understanding of the typical environment and how these errors are committed. Actions and outcomes were also not identified since the process described in this study was generic and did not take into account practices and policies within a specific institute. Therefore, it was not feasible to assign specific action items for specific failure modes. Nonetheless, interventions and desirable infusion pump features discussed in the present work aim to provide possible ways to address failure modes that were considered high-risk and need further attention.

\subsubsection{Limitations on Probability Ratings and Severity Ratings of HFMEA}

Although the literature, incident reports, and clinical observations were able to inform the probability of the failure modes identified, the probability of programming errors depends on the user interface design for the different infusion pumps. The probability ratings were mostly based on subjective judgment from the raters when comparing the user interface designs between the five smart infusion pumps. Therefore, further research is required to validate the probability of various programming mistakes.

Severity ratings were mostly based on patient outcomes described in incident reports. The worst case scenario was used as a reference for the severity ratings for various effects described as a result of the failure modes. However, because there were no clinicians on the HFMEA team, it was hard to know for sure if those ratings were valid. 


\section{Chapter 6 Conclusion}

\section{Conclusion}

Secondary infusions are a common practice for clinicians to deliver intermittent medications to patients as they allow the clinician to deliver intravenous medications through an already established access, limiting the number of needle insertions for patients. The conventional way of delivering secondary infusions requires a unique set-up and requires programming in a submenu when using a smart infusion pump. As a result, clinicians often commit operation errors while administering secondary infusions, which have led to adverse events (ISMP Canada, 2003, 2005; Nunnally \& Bitan, 2006; Trbovich et al., 2010). In order to gain a better understanding of the types of failure modes present and evaluate the safety of the secondary infusion administration process, HFMEA was performed on five different smart infusion pumps.

The secondary infusion administration process was mapped and evaluated using HFMEA methodology. The first half of the process was considered as the "set-up" part of the process and the second half of the process was referred to as the "activation" part. The results of the HFMEA revealed that there are a number of failure modes that are considered high-risk when administering secondary infusion. For the set-up part of the process, the Baxter Colleague had 22 high-risk failure modes, which was the highest number of high-risk failure modes identified out of the five infusion pumps. In contrast, the Hospira Plum A+ only had 6 high-risk failure modes identified in the "set-up" phase, which was the lowest number between the five smart infusion pumps studied. All other pumps (i.e. B. Braun Infusomat Space, Cardinal Health Alaris PC, and Hospira Symbiq) had 20 high-risk failure modes associated with the "set-up" part of the process. The Hospira Plum A+ was able to eliminate most of the "set-up" errors due to the feature of secondary infusion flow monitoring and occlusions detection. On the other hand, the number of high-risk failure modes identified for the "activation" phase of the process varied between infusion pumps with the number ranging from 7 (Cardinal Health Alaris PC) to 13 (B. Braun Infusomat Space). Since pump programming was a major part of the "activation" phase, the variation in the number of high-risk failure modes can be attributed to the difference in interface design between smart infusion pumps. The different factors contributed to the risk of these 
failure modes include the number of parameters needed to program, the need to perform manual calculations when programming, and the location of the secondary infusion menu.

To mitigate potential failure modes for the "set-up" part of the process, manufacturers should consider designing infusion pumps that have a similar pumping mechanism to the Hospira Plum $\mathrm{A}+$ where the flow of secondary fluid is directly monitored by the pump. It is recommended that the optimal infusion pump can draw fluid directly from the secondary bag, eliminating the need to hang the secondary bag higher than the primary bag and the need to use a back-check valve. As well, equipping the infusion pump with a line occlusion detector for the secondary line would allow the pump to notify nurses when there is a lack of flow above the infusion pump due to a misconnection or a closed roller clamp. To mitigate potential failure modes for the "activation" part of the process, it is recommended that the infusion pump should display clearly the infusion mode that nurses are currently programming in at all times to prevent nurses from accidently programming the secondary infusion as a primary infusion, for example. As well, the secondary infusion function should be readily available on the main screen as it is sometimes hard for nurses to find, which causes delay in therapy. Lastly, roller clamp detectors may be useful in alarming nurses if the secondary roller clamp is mistakenly left closed at the start of the infusion.

Current smart infusion pump users can potentially reduce "set-up" errors by delivering secondary infusions using separate pump channels as primary intermittent infusions. Thus, the infusion pump can monitor the flow of the infusion directly and thus eliminate the need to hang the secondary bag higher and to use a back-check valve. However, at the end of the intermittent infusion, the end-of-infusion alarm would sound on the infusion pump instead of automatically reverting back to the primary infusion. As a result, nurses would have to come back to the infusion pump and manually start the primary infusion again to prevent the IV access from collapsing.

On the other hand, barcode-enabled smart infusion pumps interconnected with the EHR and CPOE (i.e. closed-loop system) could potentially reduce "activation" errors by automating the pump programming task. This would eliminate the need to perform manual calculations and reduce the risk of transcription errors. However, it is currently difficult to interconnect and operate these systems with full functionality. As well, while automation seems to be able to eliminate most of the human errors associated with intravenous infusion administration (e.g. 
wrong patient, wrong drug, wrong dose, etc.), this intervention still cannot alleviate any set-up errors associated with secondary infusion administration. Therefore, even with the use of barcode infusion pumps that are integrated with the EHR and CPOE, any hospitals that are using infusion pumps that require the conventional set-up for secondary infusions have a great potential for secondary infusion errors to occur.

Based on the HFMEA results, the secondary infusion practice is error prone. It may be beneficial to eliminate this practice altogether and deliver intermittent infusions through syringes or primary intermittent infusions in the long run. However, there may be resistance to the change of practice from nurses because of the comfort level nurses have with this common practice and may not see the need for change. As well, changing the way that intermittent infusions are delivered may mean changing the way that intravenous drugs are compounded (e.g. concentrate what is usually given in a $100 \mathrm{~mL}$ bag to a $25 \mathrm{~mL}$ syringe), which may cause pharmacists to resist as well. Thus, even though eliminating secondary infusion practice may improve the safety of IV infusion therapy, the change in practice may be difficult to achieve in the near future due to resistance from clinicians. Therefore, in the short term, it is important to raise awareness on the issues of secondary infusions so that clinicians understand the risks that are associated with the secondary infusion practice. By doing so, clinicians are more likely to accept proposed interventions that make the secondary infusion practice safer and ultimately work towards eliminating the secondary infusion practice altogether.

Despite best efforts in improving the safety features on smart infusion pumps, there are still many vulnerabilities in the secondary infusion administration process that are not currently address by smart infusion pumps, as shown in the results of the HFMEA. It should be noted that this study was not endorsed by any manufacturers and so the purpose of the HFMEA was not to endorse one pump over another. As well, the present work only focused on evaluating infusion pump features based on the secondary infusion practice. However, smart infusion pumps are used for infusion therapy including primary infusions, secondary infusions, and boluses. Therefore, the evaluation of smart infusion pump performance would need to consider other infusion therapy practices as well. 


\subsection{Future Work}

Healthcare Failure Mode and Effect Analysis (HFMEA) was useful in identifying potential failure modes in the secondary infusion administration process, as well as evaluating the risks associated with the failure modes. HFMEA also allowed the analyst to develop recommendations based on areas that need further attention (i.e. high-risk failure modes identified). However, since this study did not include an experimental study, the effectiveness of the design recommendations and proposed interventions cannot be certain. For example, further research is required to explore the efficacy of the proposed practice of setting up secondary infusions on separate infusion pump channels in eliminating "set-up" errors, as well as to test if this intervention introduces additional failure modes to the system. To study the efficacy of this proposed practice, a high-fidelity simulation study could be done where one group of nurses are asked to perform secondary infusion tasks using the conventional secondary infusion set-up, while another group of nurses are asked to set-up each infusion on a separate pump channel. The nurses would be observed through a one-way mirror and data such as time to complete secondary task, number of errors made, types of errors made, as well as any comments or concerns would be recorded. The data can then be compared between the two groups to determine if there was a significant improvement in the number of errors made in the group of nurses who were asked to set-up each infusion on a separate pump channel. As well, the types of errors made and comments from nurses may help reveal additional failure modes that this practice introduces to the system.

Also, further research is needed to determine the value of closed-loop systems in mitigating infusion errors as this solution is thought to allow health practitioners to achieve the five-rights of medication safety. Although, in theory, the closed-loop systems approach seems promising, it would be useful to learn how automation may change nursing behaviour when delivering secondary infusions. For example, by relying too much on the closed-loop system to perform infusion tasks without understanding how this automation is achieved, nurses may eventually become complacent on the system. As a result, if at some point the closed-loop system breaks down and automation can no longer be achieved, nurses may not know how to troubleshoot the system or may no longer have the confidence to program secondary infusions manually, which can compromise the patient's safety. 
Lastly, the HFMEA is largely based on a simplified scenario of the secondary infusion system and does not represent the real clinical environment, where multiple secondary infusions may be given at the same time and nurses may be constantly interrupted by other people or other responsibilities. Therefore, further research is needed to explore additional failure modes that may be present in a realistic representation of the clinical environment. 


\section{Bibliography}

Accreditation Canada. (2012). Required Organizational Practices 2012 (pp. 1-65). Retrieved from http://www.accreditation.ca/uploadedFiles/ROP Handbook EN.pdf

Adachi, W., \& Lodolce, A. (2005). Use of failure mode and effects analysis in improving the safety of iv drug administration. American Journal of Health-System Pharmacy, 62(Mc 886), 917-920. Retrieved from http://ajhp.org/content/62/9/917.short

Ahluwalia, J., \& Marriott, L. (2005). Critical incident reporting systems. Seminars in fetal \& neonatal medicine, 10(1), 31-7. doi:10.1016/j.siny.2004.09.012

Ashley, L., \& Armitage, G. (2010). Failure mode and effects analysis: an empirical comparison of failure mode scoring procedures. Journal of patient safety, 6(4), 210-5. Retrieved from http://www.ncbi.nlm.nih.gov/pubmed/21500607

Bates, D., Cullen, D., \& Laird, N. (1995). Incidence of adverse drug events and potential adverse drug events. JAMA: the journal of the American Medical Association, 274(1), 29-34.

Retrieved from http://jama.ama-assn.org/content/274/1/29.short

Braun, V., \& Clarke, V. (2006). Using thematic analysis in psychology. Qualitative Research in Psychology, 3(2), 77-101. doi:10.1191/1478088706qp063oa

Burdeu, G., Crawford, R., van de Vreede, M., \& McCann, J. (2006). Taking aim at infusion confusion. Journal of Nursing Care Quality, 21(2), 151. Retrieved from http://journals.lww.com/jncqjournal/Abstract/2006/04000/Taking_Aim_at_Infusion_Confus ion.11.aspx

Burgmeier, J. (2002). Failure mode and effect analysis: an application in reducing risk in blood transfusion. The Joint Commission journal on quality improvement, 28(6), 331-9. Retrieved from http://www.ncbi.nlm.nih.gov/pubmed/12066625

Carayon, P., Wetterneck, T. B., Schoofs, A., Ozkaynak, M., \& Ram, P. (2004). Assessing Nurse Interaction with Medication Administration Technologies : The Development of Observation Methodologies. Work with Computing Systems, 319-324. 
Carefusion Corporation. (2011). Secondary infusions : Backpriming technique. San Diego: Carefusion Corporation. Retrieved from http://www.carefusion.com/pdf/Infusion/clinical_documentation/faq_tip_sheets/Secondary_ Infusions_TipSheet.pdf

Centre for Quality and Productivity Improvement. (2004). IV Medication Process - Adult Inpatient Care Units. Retrieved February 19, 2012, from http://cqpi.engr.wisc.edu/system/files/IV_FMEA_RptOct03_flow.pdf

Cerner Corporation. (2011). CareAware Infusion Management and Smart Pump Auto Programming. Kansas City: Cerner Corporation. Retrieved from http://www.cerner.com/uploadedFiles/Wellspan_Whitepaper_Cerner.pdf

Codex_Alimentarius_Commission. (1997). Hazard Analysis and Critical Control Points (HACCP) System Principles and Guidelines for its Application. Annex II CAC/RCP-1 1969.

Colvin, C. (2011). An Exploratory Study of the Fundamental Characteristics Influencing the Analysis and Communication Activities of Health Care Incident Reporting Systems by An Exploratory Study of the Fundamental Characteristics Care Incident Reporting Systems. Biomedical Engineering. University of Toronto. Retrieved from https://tspace.library.utoronto.ca/bitstream/1807/30557/3/Colvin_Christopher_A_201111_ MHSc_thesis.pdf

Crane, J. (2006). Preventing medication errors in hospitals through a systems approach and technological innovation: a prescription for 2010. Hospital Topics, 84(4), 3-8. Retrieved from http://heldref-publications.metapress.com/index/h863ul27452m51w5.pdf

Day, S., Dalto, J., Fox, J., Allen, A., \& Ilstrup, S. (2007). Utilization of failure mode effects analysis in trauma patient registration. Quality management in health care, 16(4), 342-8. doi:10.1097/01.QMH.0000296296.29310.be

DeRosier, J., \& Stalhandske, E. (2002). Using health care Failure Mode and Effect Analysis: the VA National Center for Patient Safety's prospective risk analysis system. Journal on Quality Improvement, 28(5), 248-267. Retrieved from http://www.ingentaconnect.com/content/jcaho/jcjqs/2002/00000028/00000005/art00006 
Dougherty, L., \& Elliott, T. (2008). Intravenous Therapy in Nursing Practice (2nd ed., pp. 125127). Blackwell Publishing Ltd.

ECRI Institute. (2007). Evaluation: General-Purpose Infusion Pumps (pp. 309-337).

Elias, B. L., \& Moss, J. a. (2011). Smart pump technology: what we have learned. Computers, informatics, nursing : CIN, 29(3), 184-90. doi:10.1097/NCN.0b013e3181fcbe6d

Esmail, R., Cummings, C., Dersch, D., Duchscherer, G., Glowa, J., Liggett, G., \& Hulme, T. (2005). Using Healthcare Failure Mode and Effect Analysis tool to review the process of ordering and administrating potassium chloride and potassium phosphate. Healthcare quarterly (Toronto, Ont.), 8 Spec No(February), 73-80. Retrieved from http://www.ncbi.nlm.nih.gov/pubmed/16334076

Flynn, F., Mohr, L., \& Lawlor-Klean, P. (2003). Case Study in Brief: Right Programming of Pumps to Prevent Errors in the Infusion Process. Joint Commission journal on quality and patient safety / Joint Commission Resources, 29(1), 37-40.

Habraken, M. M. P., Van der Schaaf, T. W., Leistikow, I. P., \& Reijnders-Thijssen, P. M. J. (2009). Prospective risk analysis of health care processes: a systematic evaluation of the use of HFMEA in Dutch health care. Ergonomics, 52(7), 809-19. doi:10.1080/00140130802578563

Health Technology Safety Research Team. (2010). Multiple Intravenous Infusions Phase 1a : Situation Scan Summary Report. Methods (pp. 1-26). Toronto. Retrieved from http://www.ehealthinnovation.org/files/Multiple IV Infusions_Phase1a_SummaryReport.pdf

Hicks, R. W., \& Becker, S. C. (2006). An Overview of Intravenous-related Medication Administration Errors as Reported to MEDMARX ${ }^{\circledR}$, a national Medication Error-reporting Program. Journal of Infusion Nursing, 29(1), 20-27.

Hilton, A., Pellegrino, V., \& Scheinkestel, C. (2008). Avoiding common problems associated with intravenous fluid therapy. Med J Aust, 189(9). Retrieved from http://onlinelibrary.wiley.com/doi/10.1002/bjs.6466/full 
Husch, M., Sullivan, C., Rooney, D., Barnard, C., Fotis, M., Clarke, J., \& Noskin, G. (2005). Insights from the sharp end of intravenous medication errors: implications for infusion pump technology. Quality \& safety in health care, 14(2), 80-6.

doi:10.1136/qshc.2004.011957

ISMP Canada. (2003). Infusion Pump - Opportunities for Improvement. ISMP Canada Safety Bulletin, 3(7), 1-2. Retrieved from http://www.ismpcanada.org/download/safetyBulletins/ISMPCSB2003-07InfusionPumps.pdf

ISMP Canada. (2005). Secondary Infusions Require "Primary" Attention. ISMP Canada Safety Bulletin, 5(2), 1-2. Retrieved from http://ismpcanada.org/download/safetyBulletins/ISMPCSB2005-02SecondaryInfusions.pdf

Institute of Medicine. (1999). To Err is Human: Building a Safer Health System. (L. Kohn, J. Corrigan, \& M. Donaldson, Eds.) (pp. 1-34). Washington, D.C.: National Academy Press.

Institute of Medicine. (2007). Preventing Medication Errors. (P. Aspden, J. Wolcott, J. Bootman, \& L. Cronenwett, Eds.)Quality. Washington, D.C.: National Academy Press. Retrieved from http://books.google.com/books?hl=en\&amp;lr=\&amp;id=DFbQ6D61t5MC\&amp;oi=fnd\&a mp;pg=PA1\&amp;dq=Preventing+medication+errors\&amp;ots=TzIQqeujwB\&amp;sig=c Ma1ZOr1UeHeImtlpk7FO5OhpjQ

Jensen, E. B. (2004). Root Cause Analysis: Compendium for use by Patient Safety Officers and others responsible for conducting root cause analysis of adverse events. Danish Society for Patient Safety. Retrieved from http://patientsikkerhed.dk/fileadmin/user_upload/documents/Publikationer/Danske/RCA_T ool_Kit/Compendia_Root_Cause_Analysis_English.pdf

Keay, S., \& Callander, C. (2004). The safe use of infusion devices. Continuing Education in Anaesthesia, Critical Care \& Pain, 4(3), 81-85.

La Pietra, L., Calligaris, L., Molendini, L., Quattrin, R., \& Brusaferro, S. (2005). Medical errors and clinical risk management: state of the art. Acta otorhinolaryngologica Italica : organo ufficiale della Società italiana di otorinolaringologia e chirurgia cervico-facciale, 25(6), 
339-46. Retrieved from

http://www.pubmedcentral.nih.gov/articlerender.fcgi?artid=2639900\&tool=pmcentrez\&ren dertype $=$ abstract

Landis, J., \& Koch, G. (1977). The measurement of observer agreement for categorical data. Biometrics, 33(1), 159-174. Retrieved from http://www.jstor.org/stable/10.2307/2529310

Leape, L., Bates, D., Cullen, D., Cooper, J., Demonaco, H., Gallivan, T., Hallisey, R., et al. (1995). Systems Analysis of Adverse Drug Events. JAMA : the journal of the American Medical Association, 274, 35-43.

Lyons, M. (2009). Towards a framework to select techniques for error prediction: Supporting novice users in the healthcare sector. Applied Ergonomics, 40, 379-395. Retrieved from http://journals2.scholarsportal.info.myaccess.library.utoronto.ca/tmp/181588281589125943 51.pdf

McDonough, J. (2002). Proactive Hazard Analysis and Health Care Policy. Retrieved from http://www.milbank.org/reports/Proactive/020925Proactive.html

Mills, P., Neily, J., \& Luan, D. (2005). Using aggregate root cause analysis to reduce falls and related injuries. Journal on Quality and Patient Safety, 31(1), 21-31. Retrieved from http://www.ingentaconnect.com/content/jcaho/jcjqs/2005/00000031/00000001/art00004

Mulhall, A. (2003). In the field: notes on observation in qualitative research. Journal of advanced nursing, 41(3), 306-13. Retrieved from http://www.ncbi.nlm.nih.gov/pubmed/12581118

Nagamine, J., \& Williams, M. (2005). Quality Tools: Root Cause Analysis (RCA) and Failure Modes and Effects Analysis (FMEA). The Hospitalist. Retrieved from http://www.thehospitalist.org/details/article/257825/Quality_Tools_Root_Cause_Analysis_RCA_and_Fail ure_Modes_and_Effects_Analysis_FME.html

Nagpal, K., Vats, A., Ahmed, K., Smith, A. B., Sevdalis, N., Jonannsson, H., Vincent, C., et al. (2010). A systematic quantitative assessment of risks associated with poor communication 
in surgical care. Archives of surgery (Chicago, Ill. : 1960), 145(6), 582-8. doi:10.1001/archsurg.2010.105

National Patient Safety Agency. (2008). Root Cause Analysis Investigation Tools Guide to investigation report writing following Root Cause Analysis of patient safety incidents (pp. 1-16). Retrieved from http://www.google.ca/url?sa=t\&rct=j\&q=\&esrc=s\&source=web\&cd=3\&ved=0CFcQFjAC \&url=http\%3A\%2F\%2Fwww.nrls.npsa.nhs.uk\%2FEasySiteWeb\%2Fgetresource.axd\%3FA ssetID\%3D60180\%26type\%3Dfull\%26servicetype\%3DAttachment\&ei=FekvUNPxGeTby $\mathrm{AHesYCwCw \& usg=AFQjCNEtHz7Ss7KeOslrCWwbsOs0jeeJkg \& sig2=DiszU04o-}$ 1 iqRXs7kGLF1w\&cad=rja

Nettina, S. M. (2009). The Lippincott manual of nursing practice 9th edition (9th ed., pp. 92-93). Wolters Kluwer Health, Lippincott Williams \& Wilkins. Retrieved from http://scholar.google.com/scholar?hl=en\&btnG=Search\&q=intitle:Lippincott+Manual+of + Nursing+Practice $\# 2$

Nickerson, T., Jenkins, M., \& Greenall, J. (2008). Using ISMP Canada's framework for failure mode and effects analysis: a tale of two FMEAs. Healthcare Quarterly, 11, 40-46. Retrieved from http://scholar.google.com/scholar?hl=en\&btnG=Search\&q=intitle:Using+ISMP+Canada's+ Framwork+for+Failure+Mode+and+Effects+Analysis $+:+$ A+Tale+of+Two+FMEAs $\# 0$

Noble, D. J., \& Pronovost, P. J. (2010). Underreporting of patient safety incidents reduces health care's ability to quantify and accurately measure harm reduction. Journal Of Patient Safety, 6(4), 247-250. Retrieved from http://content.wkhealth.com/linkback/openurl?sid=WKPTLP:landingpage\&an=01209203201012000-00010

Nunnally, M. E., \& Bitan, Y. (2006). Time to Get Off this Pig's Back? The Human Factors Aspects of the Mismatch Between Device and Real-world Knowledge in the Health Care Environment. Journal of Patient Safety, 2(3), 124-131. Retrieved from http://journals.lww.com/journalpatientsafety/Abstract/2006/09000/Time_to_Get_Off_this_P ig_s_Back__The_Human.3.aspx 
O’Grady, N., Alexander, M., Burns, L., Dellinger, E., Garland, J., Heard, S., Lipsette, P., et al. (2011). Guidelines for the prevention of intravascular catheter-related infections. Clinical Infectious .... Retrieved from http://aappolicyaappublications.awaith.info/cgi/content/abstract/pediatrics;110/5/e51

Paparella, S. (2007). Failure mode and effects analysis: a useful tool for risk identification and injury prevention. Journal of emergency nursing: JEN : official publication of the Emergency Department Nurses Association, 33(4), 367-71. doi:10.1016/j.jen.2007.03.009

Parsons, H. (1974). What happened at Hawthorne? Science, 183(4128), 922-932. Retrieved from http://www.sciencemag.org/content/183/4128/922.short

Posner, K. L., Sampson, P. D., Caplan, R. a, Ward, R. J., \& Cheney, F. W. (1990). Measuring interrater reliability among multiple raters: an example of methods for nominal data. Statistics in medicine, 9(9), 1103-15. Retrieved from http://www.ncbi.nlm.nih.gov/pubmed/2244082

Reid, R. (2005). FMEA — Something Old, Something New. Quality Progress, (May), 90-93. Retrieved from http://www.fmeainfocentre.com/updates/dec08/FMEA\%97Something Old Something New.PDF

Reiling, J., \& Knutzen, B. (2003). FMEA-The cure for medical Errors. Quality Progress, (April 2002), 67-71. Retrieved from http://nassar2000.tripod.com/services2007/6.pdf

Roth, E. M., Christian, C. K., Gustafson, M., Sheridan, T. B., Dwyer, K., Gandhi, T. K., Zinner, M. J., et al. (2004). Using field observations as a tool for discovery: analys ing cognitive and collaborative demands in the operating room. Cognition, Technology \& Work, 6(3), 148-157. doi:10.1007/s10111-004-0156-0

Rothwell, S. (2009). Effect of Dose Error Reduction Software on the Ability of Nurses to Safely and Efficiently Administer Intravenous Medications by Nurses to Safely and Efficiently Administer Intravenous Medications. Human Factors. University of Toronto. Retrieved from http://hdl.handle.net/1807/18263 
Shojania, K. G., Duncan, B. W., McDonald, K. M., Wachter, R. M., \& Markowitz, a J. (2001). Making health care safer: a critical analysis of patient safety practices. Evidence report/technology assessment (Summary), (43), i-x, 1-668. Retrieved from http://www.ncbi.nlm.nih.gov/pubmed/11510252

Spath, P. (2003). Using failure mode and effects analysis to improve patient safety. Association of periOperative Registered Nurses (AORN) Journal, 78(1), 15-37. Retrieved from http:/www.sciencedirect.com/science/article/pii/S0001209206613434

Squires, B. M., Biesiada, B. D., Fanizza, R., Stationwala, A., MacLean, J., \& Strapp, A.-M. (2005). New Approaches to Improving Patient Safety: Strategy, Technology and Funding. Healthcare Quarterly, 8(3), 2-10. Retrieved from http://scholar.google.com/scholar?hl=en\&btnG=Search\&q=intitle:Strategy,+Technology+a nd+Funding\#0

Trbovich, P. L., Jeon, J., \& Easty, A. C. (2009). Smart Medication Delivery Systems : Infusion Pumps (pp. 1-98). Toronto. Retrieved from http://www.ehealthinnovation.org/files/SmartMedicationDeliverySystems_FullReport.pdf

Trbovich, P. L., Pinkney, S., Cafazzo, J. A., \& Easty, A. C. (2010). The impact of traditional and smart pump infusion technology on nurse medication administration performance in a simulated inpatient unit. Quality \& safety in health care, 19(5), 430-4.

doi:10.1136/qshc.2009.032839

Vanderveen, T. (2006). IVs First: A New Barcode Implementation Strategy. Patient Safety \& Quality Healthcare. Retrieved March 15, 2012, from http://www.psqh.com/mayjun06/ivs.html

Wetterneck, T B, Skibinski, K. A., Roberts, T. L., Kleppin, S. M., Schroeder, M. E., Enloe, M., Rough, S. S., et al. (2006). Using Failure Mode and Effects Analysis to Plan Implementation of I.V. Pump Technology. American Journal of Health-System Pharmacy, $63,1528-1538$.

Wetterneck, T., Skibinski, K., \& Schroeder, M. (2004). Challenges with the performance of failure mode and effects analysis in healthcare organizations: an iv medication 
administration HFMEA. Proceedings of the Human Factors and Ergonomics Society annual meeting: Medical systems and rehabilitation. Retrieved from http://pro.sagepub.com/content/48/15/1708.short

Wetterneck, Tosha B, Skibinski, K. a, Roberts, T. L., Kleppin, S. M., Schroeder, M. E., Enloe, M., Rough, S. S., et al. (2006). Using failure mode and effects analysis to plan implementation of smart i.v. pump technology. American journal of health-system pharmacy: AJHP : official journal of the American Society of Health-System Pharmacists, 63(16), 1528-38. doi:10.2146/ajhp050515

Ylipalosaari, P., Ala-Kokko, T. I., Laurila, J., Ohtonen, P., \& Syrjälä, H. (2006). Intensive care acquired infection is an independent risk factor for hospital mortality: a prospective cohort study. Critical care (London, England), 10(2), R66. doi:10.1186/cc4902

van Tilburg, C. M., Leistikow, I. P., Rademaker, C. M. a, Bierings, M. B., \& van Dijk, a T. H. (2006). Health Care Failure Mode and Effect Analysis: a useful proactive risk analysis in a pediatric oncology ward. Quality \& safety in health care, 15(1), 58-63. doi:10.1136/qshc.2005.014902 


\section{Appendix A: HFMEA for Baxter Colleague CXE}

\begin{tabular}{|c|c|c|c|c|c|c|c|c|c|c|c|}
\hline \multicolumn{2}{|c|}{$\begin{array}{c}\text { Subprocess Step Title and } \\
\text { Number }\end{array}$} & \multicolumn{2}{|c|}{$\begin{array}{l}\text { Failure Mode: First Evaluate } \\
\text { failure mode before determining } \\
\text { potential causes }\end{array}$} & Potential Effects & 空 & 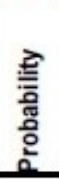 & $\begin{array}{l}\text { \& } \\
0 \\
0 \\
\text { 또 } \\
\end{array}$ & 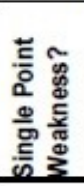 & 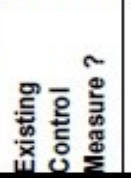 & 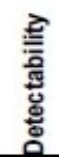 & \\
\hline \multirow[t]{2}{*}{${ }^{1 \mathrm{~A}}$} & \multirow[t]{2}{*}{$\begin{array}{l}\text { Select appropriate } \\
\text { secondary tubing }\end{array}$} & & Select primary tubing & $\begin{array}{l}\text { Patient may lose a significant percentage of drug } \\
\text { to priming volume - underdose } \\
\text { And } \\
\text { Tubing may be able to reach lower injection port - } \\
\text { secondlary drug could free flow into patient }\end{array}$ & $\sigma$ & m & 12 & & $\mathrm{~N}$ & $\mathrm{~N}$ & $Y$ \\
\hline & & $1 \mathrm{AA2}$ & Select incorrect material & Compatibility issues & n & $\sim$ & 4 & $\mathrm{Y}$ & $\mathrm{N}$ & $\mathrm{N}$ & $\mathrm{Y}$ \\
\hline \multirow[t]{2}{*}{ 1B } & \multirow[t]{2}{*}{$\begin{array}{l}\text { Open secondary } \\
\text { tubing package and } \\
\text { close roller clamp on } \\
\text { secondary tubing }\end{array}$} & & Roller clamp left open & $\begin{array}{l}\text { Drug leak to floor when bag is spiked } \\
\text { And } \\
\text { Potential cytotoxic drug exposure }\end{array}$ & N & - & 2 & $\mathrm{Y}$ & $\mathrm{N}$ & $\mathrm{Y}$ & Stop \\
\hline & & & $\begin{array}{l}\text { Roller clamp not closed } \\
\text { all the way }\end{array}$ & $\begin{array}{l}\text { Drug drip to floor when bag is spiked } \\
\text { And } \\
\text { Potential cytotoxic drug exposure }\end{array}$ & - & N & 2 & $\mathrm{Y}$ & $\mathrm{N}$ & $\mathrm{Y}$ & Stop \\
\hline \multirow[t]{2}{*}{$1 \mathrm{C}$} & \multirow[t]{2}{*}{$\begin{array}{l}\text { Spike secondary } \\
\text { container }\end{array}$} & & $\begin{array}{l}\text { Nurse pokes a hole in } \\
\text { the bag with spike }\end{array}$ & \begin{tabular}{|l|} 
Drug leak \\
And \\
Potential cytotoxic drug exposure \\
\end{tabular} & $\sim$ & - & 2 & $\mathrm{Y}$ & $\mathrm{N}$ & $\mathrm{Y}$ & Stop \\
\hline & & $1 \mathrm{C} 2$ & $\begin{array}{l}\text { Bag not spiked all the } \\
\text { way }\end{array}$ & \begin{tabular}{|l} 
Drug leak \\
Or \\
Spike may come off and cause drug spill \\
And \\
Potential cytotoxic drugexposure \\
\end{tabular} & $\sim$ & - & 2 & Y & $\mathrm{N}$ & $\mathrm{Y}$ & Stop \\
\hline
\end{tabular}




\begin{tabular}{|c|c|c|c|c|c|c|c|c|c|c|}
\hline \multicolumn{11}{|c|}{$\begin{array}{l}\text { Step a2: Prime Secondary Line } \\
\text { HFMEA Step } 4 \text { - Hazard Analysis }\end{array}$} \\
\hline \multicolumn{2}{|c|}{$\begin{array}{c}\text { Subprocess Step Title and } \\
\text { Number }\end{array}$} & $\begin{array}{l}\text { Failure Mode: First Evaluate } \\
\text { failure mode before determining } \\
\text { potential causes }\end{array}$ & Potential Effects & 空 & 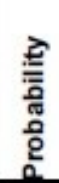 & $\begin{array}{l}8 \\
0 \\
\infty \\
N \\
\text { T्x }\end{array}$ & 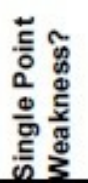 & 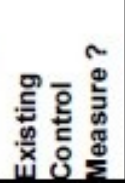 & 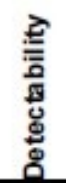 & 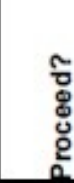 \\
\hline \multirow[t]{3}{*}{$2 \mathrm{a}$} & \multirow[t]{3}{*}{$\begin{array}{l}\text { Fill drip chamber to } \\
2 / 3 \text { full }\end{array}$} & a2A1 Drip chamber too full & Not able to see or check if drug is being delivered & - & a & 4 & $\mathrm{~N}$ & & & Stop \\
\hline & & $\begin{array}{ll}2 \mathrm{~A} 2 & \begin{array}{l}\text { Drip chamber not filled } \\
\text { enough }\end{array} \\
\end{array}$ & Air may get into IV tubing & - & N & 2 & $\mathrm{~N}$ & & & Stop \\
\hline & & $\begin{array}{ll}\text { a2A3 } & \begin{array}{l}\text { Drip chamber not filled } \\
\text { at all }\end{array}\end{array}$ & Air may get into IV tubing & - & $\sim$ & 2 & Y & $\mathrm{N}$ & Y & Stop \\
\hline $\mathrm{a} 2 \mathrm{~B}$ & $\begin{array}{l}\text { Open roller clamp on } \\
\text { secondary tubing }\end{array}$ & a2B1 Fail to open roller clamp & Delay therapy & - & - & 1 & $Y$ & $\mathrm{~N}$ & Y & Stop \\
\hline $\mathrm{a} 2 \mathrm{C}$ & $\begin{array}{l}\text { Allow fluid to flow } \\
\text { until tubing is primed }\end{array}$ & $\begin{array}{ll}2 \mathrm{C} 1 & \text { Fail to fill fluid to end of } \\
\text { tubing }\end{array}$ & Air bubble in tubing & - & - & 1 & Y & $\mathrm{N}$ & Y & Stop \\
\hline & $\begin{array}{l}\text { Close roller clamp on } \\
\text { secondary tubing }\end{array}$ & a2D1 Fail to close roller clamp & $\begin{array}{l}\text { Drug waste } \\
\text { And } \\
\text { Potential cytotoxic drug exposure }\end{array}$ & $N$ & - & 2 & Y & $\mathrm{N}$ & Y & Stop \\
\hline
\end{tabular}




\begin{tabular}{|c|c|c|c|c|c|c|c|c|c|c|c|}
\hline \multirow{2}{*}{\multicolumn{2}{|c|}{$\begin{array}{c}\text { Subprocess Step Title and } \\
\text { Number }\end{array}$}} & \multirow{2}{*}{\multicolumn{2}{|c|}{$\begin{array}{c}\text { Failure Mode: First Evaluate } \\
\text { tallure mode before determining } \\
\text { potental causes }\end{array}$}} & \multirow[b]{2}{*}{ Potential Effects } & \multicolumn{3}{|c|}{ Scoring } & \multicolumn{4}{|c|}{ Decision Iree Analys } \\
\hline & & & & & 空 & 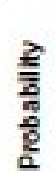 & 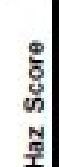 & 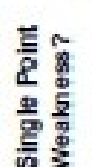 & 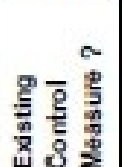 & 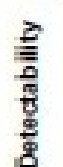 & \\
\hline $33 \mathrm{~A} / \mathrm{b} 2 \mathrm{~A}$ & $\begin{array}{l}\text { Hang secondary } \\
\text { contai ner on IV pole }\end{array}$ & $\begin{array}{l}\text { a3A-15 } \\
2 \mathrm{~B} 1\end{array}$ & $\begin{array}{l}\text { Hang secondary bag on } \\
\text { secondary hanger }\end{array}$ & $\begin{array}{l}\text { Delay therapy and primary fluidd will run at } \\
\text { secondary rate } \\
\text { Or } \\
\text { Concurrent infusion of primary and secondary } \\
\text { drug }\end{array}$ & N & $\sim$ & 4 & $Y$ & $\mathrm{~N}$ & N & $Y$ \\
\hline \multirow[t]{3}{*}{ ब3З $162 \mathrm{~B}$} & \multirow[t]{3}{*}{$\begin{array}{l}\text { Confirm primary set } \\
\text { has backcheck valve }\end{array}$} & $\begin{array}{l}338716 \\
2 B 1\end{array}$ & Fail to perform check & $\begin{array}{l}\text { If backcheck valve not present, primary and } \\
\text { secondary drug will deliver concurrently } \\
\text { Or } \\
\text { Backflow occurs }\end{array}$ & - & $\nabla$ & 4 & $\mathrm{~N}$ & & & Stop \\
\hline & & $\begin{array}{l}\mathrm{a3} 8 \mathrm{~B} 2 \mathrm{~b} \\
2 \mathrm{~B} 2\end{array}$ & $\begin{array}{l}\text { Fail to locate backcheck } \\
\text { valve on tubing }\end{array}$ & $\begin{array}{l}\text { Delay therapy and if backcheck valve not present, } \\
\text { primary and secondary drugs will deliver } \\
\text { concurrently } \\
\text { Or } \\
\text { Backflow occurs }\end{array}$ & N & - & 2 & $\mathrm{~N}$ & & & Stop \\
\hline & & $\begin{array}{l}338356 \\
2 B 3\end{array}$ & $\begin{array}{l}\text { Connect secondary line } \\
\text { to primary set that has } \\
\text { no backcheck. valve }\end{array}$ & $\begin{array}{l}\text { Delay therapy and if backcheck valve not present, } \\
\text { primary and secondary drugs will deliver } \\
\text { concurrently } \\
\text { Or } \\
\text { Backflow occurs }\end{array}$ & ev & + & 8 & & $\mathrm{~N}$ & $\mathrm{~N}$ & $\mathrm{Y}$ \\
\hline \multirow[t]{4}{*}{$33 \mathrm{C} / 62 \mathrm{C}$} & \multirow[t]{4}{*}{$\begin{array}{l}\text { Hang primary } \\
\text { contai ner lower using } \\
\text { hanger }\end{array}$} & $2 \mathrm{Cl}$ & \begin{tabular}{l|} 
Fail to lower primary \\
container; primary and \\
secondary containers \\
hung at the same height
\end{tabular} & $\begin{array}{l}\text { Concurrent delivery of primary and secondary } \\
\text { drugs } \\
\text { And } \\
\text { Backflow into secondary bag is possible }\end{array}$ & - & $\nabla$ & 4 & $Y$ & $\mathrm{~N}$ & $\mathrm{~N}$ & $\mathrm{Y}$ \\
\hline & & $\begin{array}{l}33 \mathrm{C} 2 / \mathrm{b} \\
2 \mathrm{C} 2\end{array}$ & $\begin{array}{l}\text { Lowered secondary } \\
\text { container instead of } \\
\text { primary container }\end{array}$ & $\begin{array}{l}\text { Delay therapy and primary fluid will run at } \\
\text { secondary rate } \\
\text { And } \\
\text { Secondary will run at incorrect rate } \\
\text { And } \\
\text { Backflow into secondary bag imay occur }\end{array}$ & N & $\infty$ & 6 & $Y$ & $\mathrm{~N}$ & N & $\mathrm{Y}$ \\
\hline & & $\begin{array}{l}33 \mathrm{CB} 36 \mathrm{6} \\
2 \mathrm{CB}\end{array}$ & $\begin{array}{l}\text { Fail to create appropriate } \\
\text { head height differential }\end{array}$ & $\begin{array}{l}\text { Concurrent delivery of primary and secondary } \\
\text { drugs } \\
\text { And } \\
\text { Backflow into secondary bag is possible }\end{array}$ & - & + & 4 & Y & N & $\mathrm{N}$ & $Y$ \\
\hline & & $\begin{array}{l}3304 / 6 \\
2 C 4\end{array}$ & $\begin{array}{l}\text { Lower incorrect primary } \\
\text { bag }\end{array}$ & $\begin{array}{l}\text { Concurrent delivery of primary and secondary } \\
\text { drugs } \\
\text { And } \\
\text { Backflow into secondary bag is possible }\end{array}$ & - & $\infty$ & 2 & Y & N & N & $\mathrm{Y}$ \\
\hline
\end{tabular}


Step a4 \& b3: Connect Secondary Line to Primary Tubing

\begin{tabular}{|c|c|c|c|c|c|c|c|c|c|c|}
\hline \multicolumn{11}{|c|}{$\begin{array}{r}\text { Step a4 \& b3: Connect Secondary Line to Primary Tubing } \\
\text { HFMEA Step } 4 \text {-Hazard Analysis }\end{array}$} \\
\hline \multicolumn{2}{|c|}{$\begin{array}{l}\text { Subprocess Step Title and } \\
\text { Number }\end{array}$} & $\begin{array}{l}\text { Failure Mode: First Evaluate } \\
\text { failure mode before determining } \\
\text { potential causes }\end{array}$ & Potential Effects & 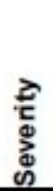 & 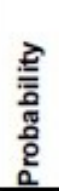 & 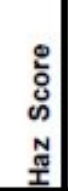 & 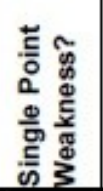 & 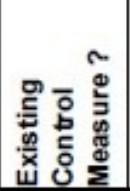 & 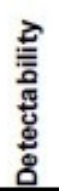 & 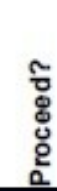 \\
\hline \multirow[t]{3}{*}{$\mathrm{a} 4 \mathrm{~A} / \mathrm{b} 3 \mathrm{~A}$} & $\begin{array}{l}\text { Swab upper y-site } \\
\text { port on primary tubing } \\
\text { with appropriate } \\
\text { antiseptic }\end{array}$ & $\begin{array}{l}\text { a4A1/b Fail to swab y-site port } \\
3 A 1\end{array}$ & Infection & $\nabla$ & $\forall$ & 16 & & $\mathrm{~N}$ & $\mathrm{~N}$ & Y \\
\hline & & $\begin{array}{ll}\text { a4A2/b } & \text { Fail to "scrub the hub" } \\
3 \mathrm{~A} 2 & \text { thoroughly }\end{array}$ & Infection & 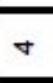 & $\forall$ & 16 & & $\mathrm{~N}$ & $\mathrm{~N}$ & $\mathrm{Y}$ \\
\hline & & $\begin{array}{ll}24 A 3 / b & \text { Fail to allow antiseptic to } \\
3 \mathrm{~A} 3 & \text { dry }\end{array}$ & Infection & $\nabla$ & $\forall$ & 16 & & $\mathrm{~N}$ & $\mathrm{~N}$ & Y \\
\hline \multirow[t]{4}{*}{$\mathrm{a} 4 \mathrm{~B} / \mathrm{b} 3 \mathrm{~B}$} & $\begin{array}{l}\text { Connect secondary } \\
\text { line to upper y-site } \\
\text { port on primary tubing } \\
\text { (upstream of infusion }\end{array}$ & \begin{tabular}{|ll} 
24B1/b & Connect secondary line \\
3B1 & to $y$-site ports located \\
& downstream of infusion \\
& pump
\end{tabular} & Secondary drug freeflow into patient & $\nabla$ & $\nabla$ & 16 & & $\mathrm{~N}$ & $\mathrm{~N}$ & $\mathrm{Y}$ \\
\hline & & $\begin{array}{l}\text { a4B2/b Connect secondary line } \\
3 \mathrm{~B} 2 \quad \text { to the wrong primary line }\end{array}$ & $\begin{array}{l}\text { Primary fluid running at secondary rate } \\
\text { And } \\
\text { Delay therapy of the wrong primary line } \\
\text { And } \\
\text { Potential compatibility issues between secondary } \\
\text { and wrong primary } \\
\text { And } \\
\text { Secondary would run at wrong primary rate }\end{array}$ & $\nabla$ & $m$ & 12 & & $\mathrm{~N}$ & $\mathrm{~N}$ & $\mathrm{Y}$ \\
\hline & & \begin{tabular}{|ll} 
a4B3/b & Fail to securely connect \\
$3 \mathrm{~B} 3$ & secondary line to \\
& primary line
\end{tabular} & Luer connect may come off and cause drug leak & $N$ & N & 4 & $\mathrm{Y}$ & $\mathrm{N}$ & $\mathrm{N}$ & $\mathrm{Y}$ \\
\hline & & $\begin{array}{ll}\text { a4B4/b } & \text { Fail to connect } \\
3 \mathrm{~B} 4 & \text { secondary line }\end{array}$ & $\begin{array}{l}\text { Delay therapy and primary fluid running at } \\
\text { secondary rate }\end{array}$ & $N$ & $\sim$ & 4 & Y & $\mathrm{N}$ & $\mathrm{N}$ & $Y$ \\
\hline
\end{tabular}




\begin{tabular}{|c|c|c|c|c|c|c|c|c|c|c|}
\hline \multicolumn{11}{|c|}{$\begin{array}{c}\text { Step b4: Backprime Secondary Tubing } \\
\text { HFin=A step 4-Hazard Anabyals }\end{array}$} \\
\hline \multicolumn{2}{|c|}{$\begin{array}{l}\text { Subprocess Step Title and } \\
\text { Number }\end{array}$} & $\begin{array}{l}\text { Failure M ode: Firat Evaluate: } \\
\text { fallure mode before determining } \\
\text { potentlal causes }\end{array}$ & Potential Effects & 密 & $\begin{array}{l}\frac{2}{10} \\
\frac{10}{0} \\
\frac{10}{0}\end{array}$ & 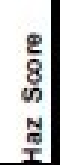 & 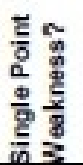 & 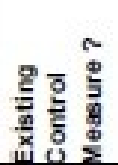 & 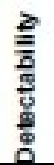 & \\
\hline$\overline{B A A}$ & $\begin{array}{l}\text { Open secondary } \\
\text { clamp }\end{array}$ & b4A1 Fail to open roller clamp & $\begin{array}{l}\text { Delay therapy } \\
\text { And } \\
\text { Secondary line does not get backprimed leading to } \\
\text { air in line }\end{array}$ & $\infty$ & - & 2 & 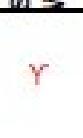 & $N$ & $\mathrm{Y}$ & Stop \\
\hline 1548 & $\begin{array}{l}\text { Lower secondary bag } \\
\text { below primary } \\
\text { container }\end{array}$ & $\begin{array}{l}\text { D481 Lower primary container } \\
\text { rather than secondary }\end{array}$ & Delay therapy & $\infty$ & - & 2 & Y & $\mathrm{N}$ & $\mathrm{Y}$ & Stop \\
\hline \multirow[t]{4}{*}{$\mathrm{b} 4 \mathrm{C}$} & $\begin{array}{l}\text { Allow primary fluid to } \\
\text { flow into secondary } \\
\text { tubing until drip } \\
\text { chamber } 2 / 3 \text { full }\end{array}$ & $\begin{array}{ll}\text { b4C1 } & \text { Fluid backfow into } \\
& \text { secondary bag }\end{array}$ & Underdose & - & $N$ & 2 & $\Upsilon$ & $\mathrm{N}$ & $\mathrm{Y}$ & Stop \\
\hline & & D4C2 $\quad$ Drip chamber too full & Not able to see or check if drug is being delivered & - & $m$ & 3 & $\mathrm{~N}$ & & & Stop \\
\hline & & \begin{tabular}{|l}
$4 C_{3}$ Drip chamber not filled \\
enough
\end{tabular} & Air may get into $I V$ tubing & - & $\sim$ & 2 & $\mathrm{~N}$ & & & Stop \\
\hline & & $\begin{array}{l}\text { BACA Drip chamber not filled } \\
\text { at all }\end{array}$ & Air may get into IV tubing & - & $N$ & 2 & $Y$ & $N$ & $\mathrm{Y}$ & Stop \\
\hline BAD & $\begin{array}{l}\text { Close secondary } \\
\text { clamp }\end{array}$ & D4D1 Fail to close roller clamp & $\begin{array}{l}\text { Secondary drug imay be delivered at primary rate } \\
\text { once the priming volume of the primary fluid had } \\
\text { been delivered }\end{array}$ & - & $m$ & 3 & $\Upsilon$ & $\mathrm{N}$ & $\mathrm{Y}$ & Stop \\
\hline & Hang secondary bag & $\begin{array}{l}\text { b4E1 Hang secondary bag on } \\
\text { secondary hanger }\end{array}$ & $\begin{array}{l}\text { Concurrent infusion of primary and secondary } \\
\text { drug } \\
\text { And } \\
\text { Backflow into secondlary bag is possible }\end{array}$ & - & $N$ & 2 & $\Upsilon$ & $\mathrm{N}$ & $\mathrm{N}$ & Y \\
\hline
\end{tabular}

\begin{tabular}{|c|c|c|c|c|c|c|c|c|c|}
\hline \multirow[b]{2}{*}{$\begin{array}{l}\text { Subprocess Step Title and } \\
\text { Number }\end{array}$} & \multirow[b]{2}{*}{$\begin{array}{l}\text { Failure M ode: Firat Evaluate: } \\
\text { fallure mode before determining } \\
\text { potentlal causes }\end{array}$} & \multicolumn{8}{|l|}{ HFi=A step 4 - Hazard Anabyalla } \\
\hline & & Potential Effects & 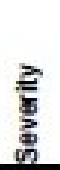 & 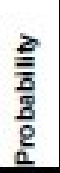 & 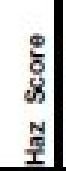 & 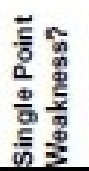 & 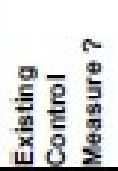 & 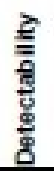 & 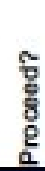 \\
\hline Open vent & 5A1 Fail to open vent & $\begin{array}{l}\text { Delay therapy } \\
\text { Or } \\
\text { Administration of primary fluid at secondary rate }\end{array}$ & $\infty$ & $m$ & 6 & $Y$ & $\mathrm{~N}$ & $\mathrm{~N}$ & Y \\
\hline
\end{tabular}




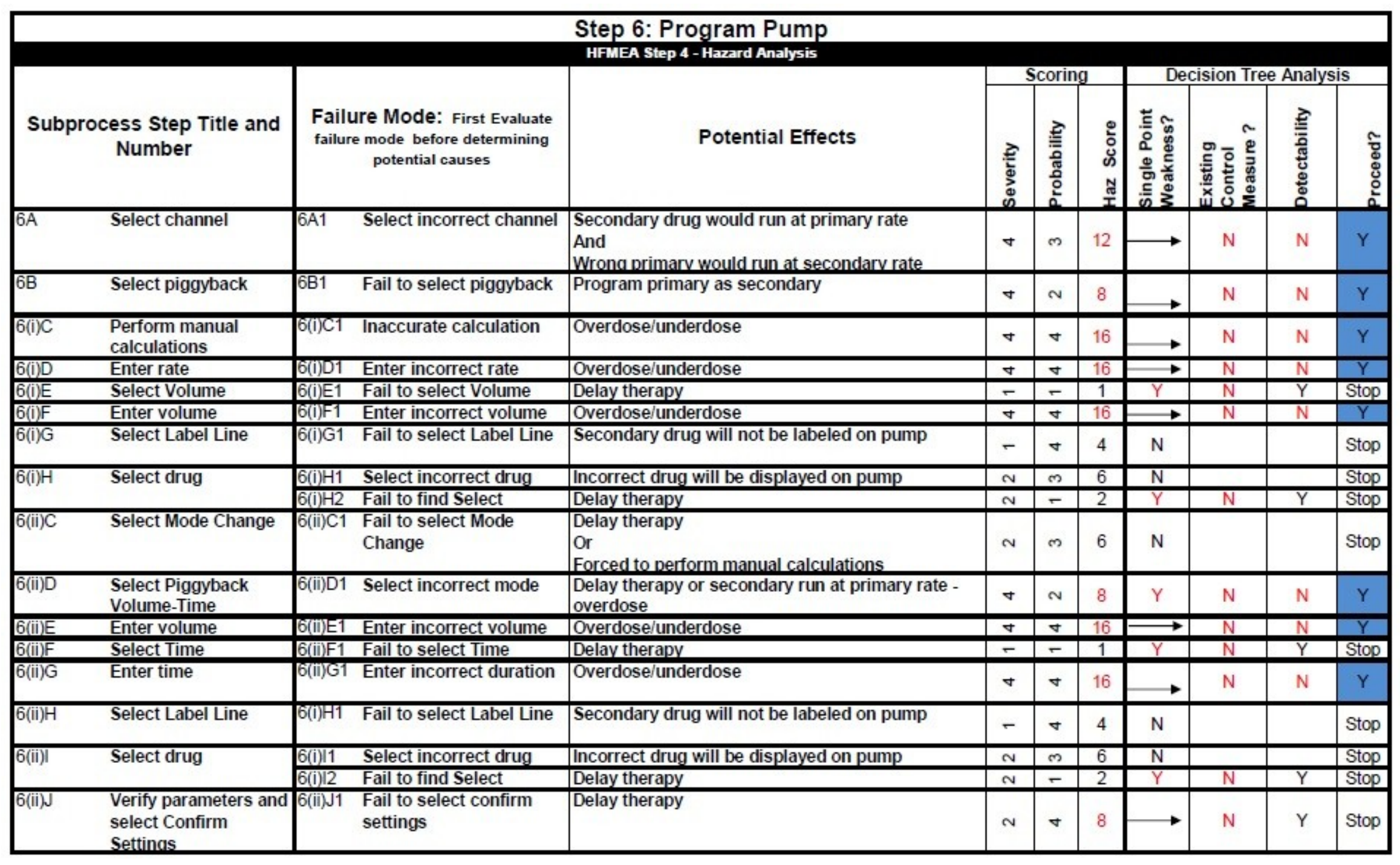




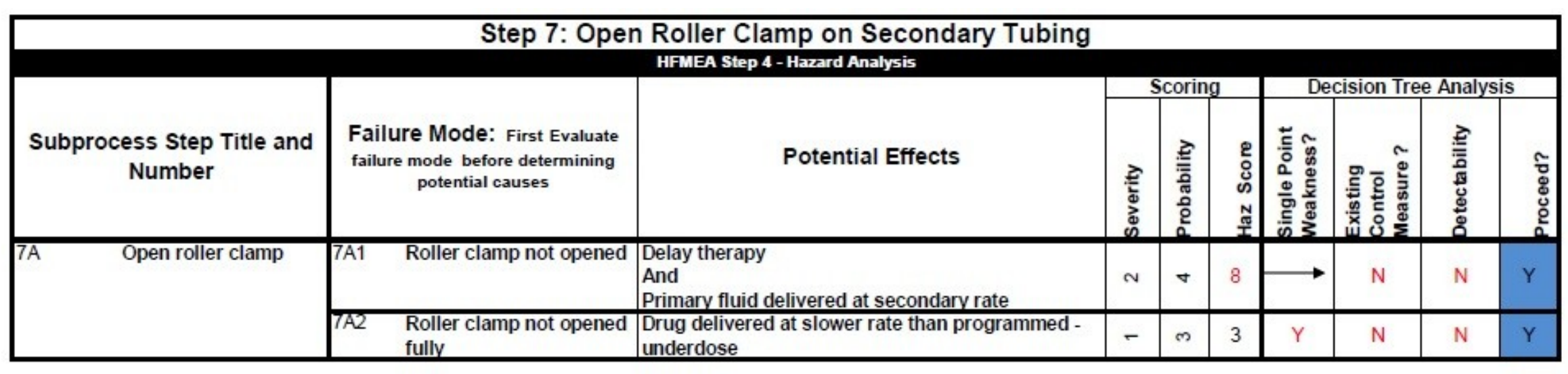

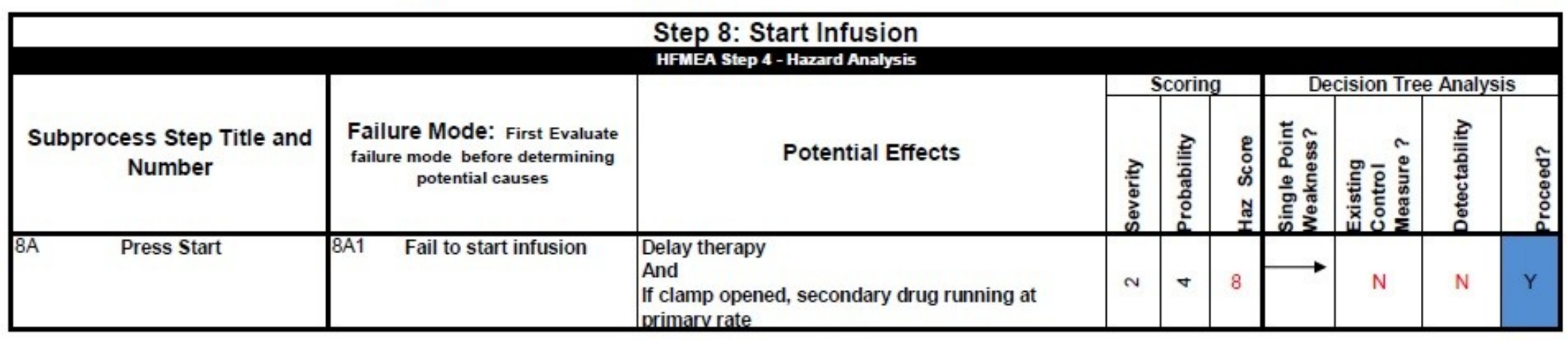




\section{Appendix B: HFMEA for B. Braun Infusomat Space}

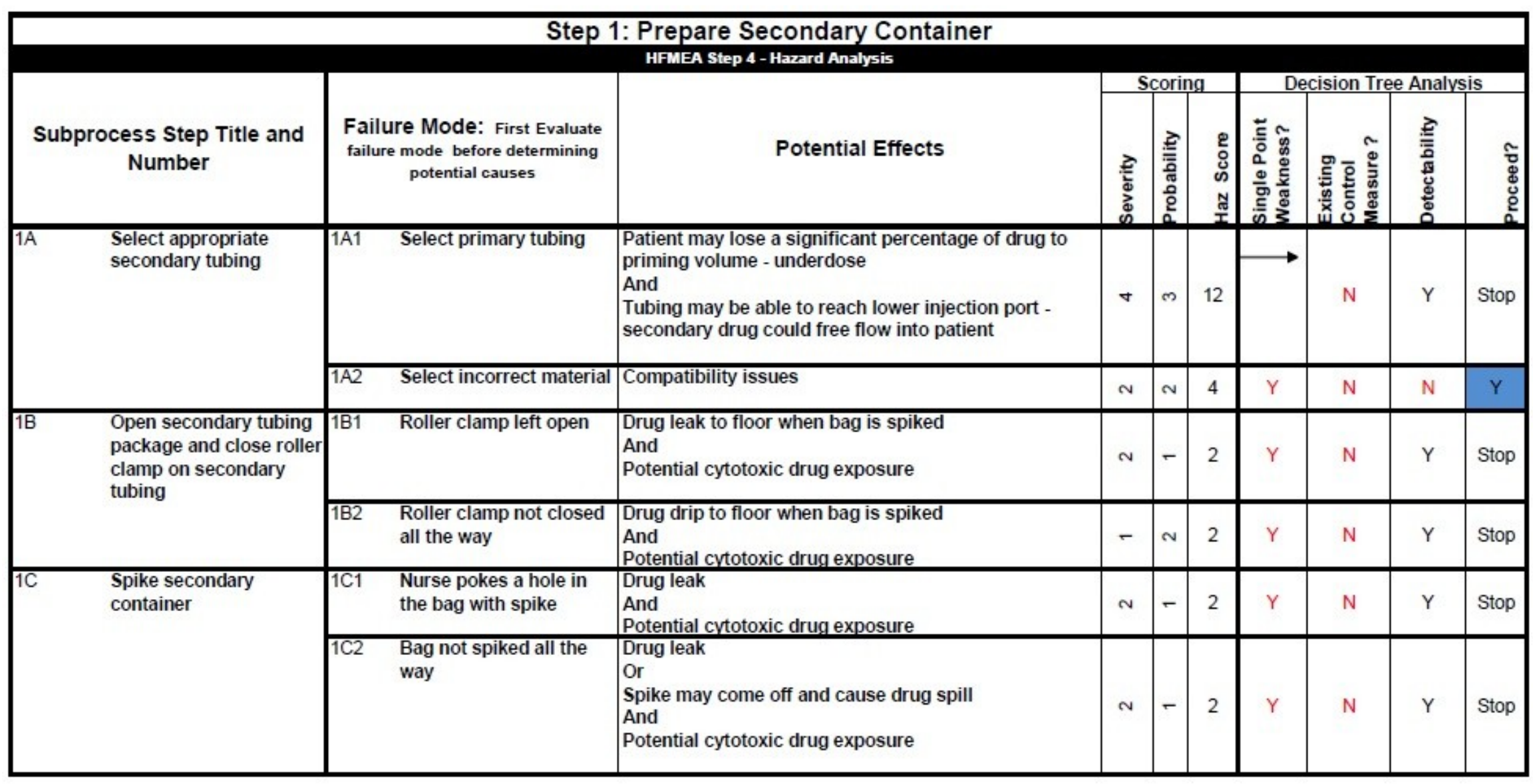




\begin{tabular}{|c|c|c|c|c|c|c|c|c|c|c|}
\hline \multicolumn{11}{|c|}{$\begin{array}{r}\text { Step a2: Prime Secondary Line } \\
\text { HFMEA Step 4 - Hazard Analysis }\end{array}$} \\
\hline & & \multirow[b]{2}{*}{$\begin{array}{l}\text { Failure Mode: First Evaluate } \\
\text { failure mode before determining } \\
\text { potential causes }\end{array}$} & \multirow[b]{2}{*}{ Potential Effects } & \multirow[b]{2}{*}{ 部 } & \multirow[b]{2}{*}{ 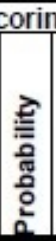 } & \multirow[b]{2}{*}{ 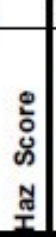 } & \multirow[b]{2}{*}{ 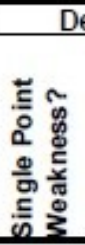 } & \multirow[b]{2}{*}{ 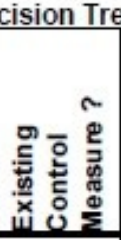 } & \multirow[b]{2}{*}{ 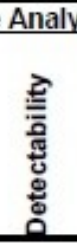 } & \multirow[b]{2}{*}{ 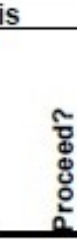 } \\
\hline & $\begin{array}{l}\text { cess Step Title and } \\
\text { Number }\end{array}$ & & & & & & & & & \\
\hline \multirow[t]{3}{*}{$\overline{\mathrm{a} 2 \mathrm{~A}}$} & \multirow{3}{*}{$\begin{array}{l}\text { Fill drip chamber to } 2 / 3 \\
\text { full }\end{array}$} & a2A1 Drip chamber too full & Not able to see or check if drug is being delivered & - & 8 & 4 & $\mathrm{~N}$ & & & Stop \\
\hline & & \begin{tabular}{|ll}
$2 \mathrm{~A} 2$ & $\begin{array}{l}\text { Drip chamber not filled } \\
\text { enough }\end{array}$ \\
\end{tabular} & Air may get into IV tubing & - & N & 2 & $\mathrm{~N}$ & & & Stop \\
\hline & & $\begin{array}{ll}\text { a2A3 } & \begin{array}{l}\text { Drip chamber not filled } \\
\text { at all }\end{array} \\
\end{array}$ & Air may get into IV tubing & - & $\sim$ & 2 & Y & N & Y & Stop \\
\hline$\overline{\mathrm{a} 2 \mathrm{~B}}$ & $\begin{array}{l}\text { Open roller clamp on } \\
\text { secondary tubing }\end{array}$ & 22B1 Fail to open roller clamp & Delay therapy & - & - & 1 & Y & $\mathrm{N}$ & Y & Stop \\
\hline $\mathrm{a} 2 \mathrm{C}$ & $\begin{array}{l}\text { Allow fluid to flow until } \\
\text { tubing is primed }\end{array}$ & $\begin{array}{ll}\text { a2C1 Fail to fill fluid to end of } \\
\text { tubing }\end{array}$ & Air bubble in tubing & - & - & 1 & $Y$ & $\mathrm{~N}$ & Y & Stop \\
\hline & $\begin{array}{l}\text { Close roller clamp on } \\
\text { secondary tubing }\end{array}$ & 22D1 Fail to close roller clamp & $\begin{array}{l}\text { Drug waste } \\
\text { And } \\
\text { Potential cytotoxic drua exposure }\end{array}$ & N & - & 2 & $\mathrm{Y}$ & $\mathrm{N}$ & $\mathrm{Y}$ & Stop \\
\hline
\end{tabular}


Step a3 \& b2: Hang Secondary Container and Adjust Primary Container

\begin{tabular}{|c|c|c|c|c|c|c|c|c|c|c|c|}
\hline & & & & HFil EA Step 4 - Hazard Analyallo & & & & & & & \\
\hline Subpr & $\begin{array}{l}\text { Neess Step Title and } \\
\text { Number }\end{array}$ & $\begin{array}{l}\text { Failur } \\
\text { fallure }\end{array}$ & $\begin{array}{l}\text { ure Mode: First Evaluate } \\
\text { e mode before determining } \\
\text { potentlal causes }\end{array}$ & Potential Effects & 尝 & 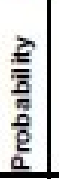 & 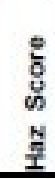 & 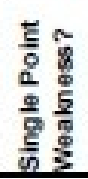 & 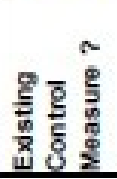 & 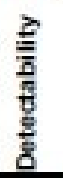 & 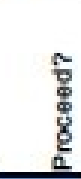 \\
\hline $23 \mathrm{~A} / \mathrm{b} 2 \mathrm{~A}$ & $\begin{array}{l}\text { Hang secondary } \\
\text { container on IV pole }\end{array}$ & $\begin{array}{l}33 \mathrm{~A} A 1 / \mathrm{b} \\
2 \mathrm{~B} 1\end{array}$ & $\begin{array}{l}\text { Hang secondary bag on } \\
\text { secondary hanger }\end{array}$ & $\begin{array}{l}\text { Delay therapy and primary fluid will run at secondary } \\
\text { rate } \\
\text { Or } \\
\text { Concurrent infusion of primary and secondary drug }\end{array}$ & $\sim$ & $\approx$ & 4 & $\mathrm{Y}$ & $\mathrm{N}$ & $\mathrm{N}$ & $\mathrm{Y}$ \\
\hline $338 / 628$ & $\begin{array}{l}\text { Confirm primary set has } \\
\text { backcheck valve }\end{array}$ & $\begin{array}{l}\mathrm{a} 3 \mathrm{~B} 1 / \mathrm{b} \\
2 \mathrm{~B} 1\end{array}$ & Fail to perform check & $\begin{array}{l}\text { If backcheck valve not present, primary and secondary } \\
\text { drug will deliver concurrently } \\
\text { Or } \\
\text { Backflow occurs }\end{array}$ & - & 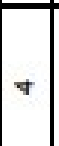 & 4 & $\mathrm{~N}$ & & & Stop \\
\hline & & $\begin{array}{l}23 B 22 / b \\
2 B 2\end{array}$ & $\begin{array}{l}\text { Fail to locate backcheck } \\
\text { valve on tubing }\end{array}$ & $\begin{array}{l}\text { Delay therapy and if backcheck valve not present, } \\
\text { primary and secondary drugs will deliver concurrently } \\
\text { Or } \\
\text { Backflow occurs }\end{array}$ & $\sim$ & - & 2 & $\mathrm{~N}$ & & & Stop \\
\hline & & $2 \mathrm{~B} B 3 \mathrm{~B} / \mathrm{b}$ & $\begin{array}{l}\text { Connect secondary line } \\
\text { to primary set that has } \\
\text { no backcheck valve }\end{array}$ & $\begin{array}{l}\text { Delay therapy and if backcheck valve not present, } \\
\text { primary and secondary drugs will deliver concurrently } \\
\text { Or } \\
\text { Backflow occurs }\end{array}$ & N & $\nabla$ & 8 & & $\mathrm{~N}$ & $\mathrm{~N}$ & $\mathrm{Y}$ \\
\hline $\mathrm{a} 3 \mathrm{C} / \mathrm{b} 2 \mathrm{C}$ & $\begin{array}{l}\text { Hang primary container } \\
\text { lower using hanger }\end{array}$ & $2 \mathrm{C} 1$ & $\begin{array}{l}\text { Fail to lower primary } \\
\text { container, primary and } \\
\text { secondary containers } \\
\text { hung at the same height }\end{array}$ & $\begin{array}{l}\text { Concurrent delivery of primary and secondary drugs } \\
\text { And } \\
\text { Backflow into secondary bag is possible }\end{array}$ & - & 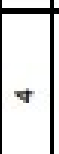 & 4 & Y & $\mathrm{N}$ & $\mathrm{N}$ & $\mathrm{Y}$ \\
\hline & & $\begin{array}{l}3 \mathrm{a} C 2 \mathrm{~b} \\
2 \mathrm{C} 2\end{array}$ & $\begin{array}{l}\text { Lowered secondary } \\
\text { container instead of } \\
\text { primary container }\end{array}$ & $\begin{array}{l}\text { Delay therapy and primary fluid will run at secondary } \\
\text { rate } \\
\text { And } \\
\text { Secondary will run at incorrect rate } \\
\text { And } \\
\text { Rarkflowinto }\end{array}$ & N & $m$ & 6 & $\mathrm{Y}$ & $\mathrm{N}$ & $\mathrm{N}$ & Y \\
\hline & & $2 \mathrm{a} C 3 \mathrm{C} / \mathrm{b}$ & $\begin{array}{l}\text { Fail to create } \\
\text { appropriate head height } \\
\text { differential }\end{array}$ & $\begin{array}{l}\text { Concurrent delivery of primary and secondary drugs } \\
\text { And } \\
\text { Backflow into secondary bag is possible }\end{array}$ & - & $\nabla$ & 4 & $\mathrm{Y}$ & $\mathrm{N}$ & $\mathrm{N}$ & $\mathrm{Y}$ \\
\hline & & $2 \mathrm{a3C4/b}$ & $\begin{array}{l}\text { Lower incorrect primary } \\
\text { bag }\end{array}$ & $\begin{array}{l}\text { Concurrent delivery of primary and secondary drugs } \\
\text { And } \\
\text { Backflow into secondary bag is possible }\end{array}$ & - & $\sim$ & 2 & Y & $\mathrm{N}$ & $\mathrm{N}$ & $\mathrm{Y}$ \\
\hline
\end{tabular}




\begin{tabular}{|c|c|c|c|c|c|c|c|c|c|c|c|}
\hline \multirow{2}{*}{\multicolumn{2}{|c|}{$\begin{array}{c}\text { Subprocess Step Title and } \\
\text { Number }\end{array}$}} & \multirow{2}{*}{\multicolumn{2}{|c|}{$\begin{array}{l}\text { Failure Mode: First Evaluate } \\
\text { failure mode before determining } \\
\text { potential causes }\end{array}$}} & \multirow[b]{2}{*}{ Potential Effects } & \multicolumn{3}{|c|}{ Scoring } & \multicolumn{4}{|c|}{ Decision Tree Analysis } \\
\hline & & & & & 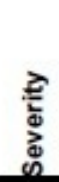 & 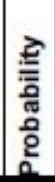 & $\begin{array}{l}8 \\
\stackrel{8}{0} \\
\text { N } \\
\text { 푸 }\end{array}$ & 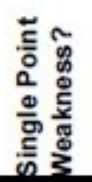 & 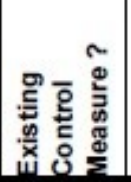 & 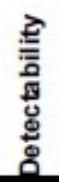 & \\
\hline \multirow[t]{3}{*}{ a4AVb3A } & \multirow{3}{*}{$\begin{array}{l}\text { Swab upper y-site port } \\
\text { on primary tubing with } \\
\text { appropriate antiseptic }\end{array}$} & $\begin{array}{l}24 \mathrm{~A} 1 / \mathrm{b} \\
3 \mathrm{~A} 1\end{array}$ & Fail to swab y-site port & Infection & $\sigma$ & 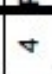 & 16 & $\rightarrow$ & $\mathrm{N}$ & $\mathrm{N}$ & $Y$ \\
\hline & & $\begin{array}{l}24 \mathrm{~A} 2 \mathrm{~b} \\
3 \mathrm{~A} 2\end{array}$ & $\begin{array}{l}\text { Fail to "scrub the hub" } \\
\text { thoroughly }\end{array}$ & Infection & $\nabla$ & $\theta$ & 16 & $\rightarrow$ & $\mathrm{N}$ & $\mathrm{N}$ & Y \\
\hline & & $\begin{array}{ll}44 \mathrm{~A} 3 / \mathrm{b} \\
3 \mathrm{~A} 3\end{array}$ & $\begin{array}{l}\text { Fail to allow antiseptic } \\
\text { to dry }\end{array}$ & Infection & $\nabla$ & $\nabla$ & 16 & & $\mathrm{~N}$ & $\mathrm{~N}$ & $\mathrm{Y}$ \\
\hline \multirow[t]{4}{*}{$\mathrm{a} 4 \mathrm{~B} / \mathrm{b} 3 \mathrm{~B}$} & \multirow{4}{*}{$\begin{array}{l}\text { Connect secondary line } \\
\text { to upper y-site port on } \\
\text { primary tubing } \\
\text { (upstream of infusion } \\
\text { pump) }\end{array}$} & $\begin{array}{l}24 \mathrm{~B} 1 / \mathrm{b} \\
3 \mathrm{~B} 1 \\
\end{array}$ & $\begin{array}{l}\text { Connect secondary line } \\
\text { to y-site ports located } \\
\text { downstream of infusion } \\
\text { pump }\end{array}$ & Secondary drug freeflow into patient & 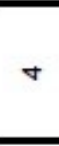 & 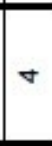 & 16 & & $\mathrm{~N}$ & $\mathrm{~N}$ & Y \\
\hline & & $3 \mathrm{~B} 2$ & $\begin{array}{l}\text { Connect secondary line } \\
\text { to the wrong primary } \\
\text { line }\end{array}$ & $\begin{array}{l}\text { Primary fluid running at secondary rate } \\
\text { And } \\
\text { Delay therapy of the wrong primary line } \\
\text { And } \\
\text { Potential compatibility issues between secondary and } \\
\text { wrong primary } \\
\text { And }\end{array}$ & $\nabla$ & $m$ & 12 & & $\mathrm{~N}$ & $\mathrm{~N}$ & Y \\
\hline & & $\begin{array}{l}24 \mathrm{~B} 3 / \mathrm{b} \\
3 \mathrm{~B} 3\end{array}$ & $\begin{array}{l}\text { Fail to securely connect } \\
\text { secondary line to } \\
\text { primary line }\end{array}$ & \begin{tabular}{|l} 
Luer connect may come off and cause drug leak \\
\end{tabular} & N & $\sim$ & 4 & $\mathrm{Y}$ & $\mathrm{N}$ & $\mathrm{N}$ & Y \\
\hline & & $\begin{array}{l}24 \mathrm{~B} 4 / \mathrm{b} \\
3 \mathrm{~B} 4\end{array}$ & $\begin{array}{l}\text { Fail to connect } \\
\text { secondary line }\end{array}$ & $\begin{array}{l}\text { Delay therapy and primary fluid running at secondary } \\
\text { rate }\end{array}$ & N & N & 4 & $\mathrm{Y}$ & $\mathrm{N}$ & $\mathrm{N}$ & Y \\
\hline
\end{tabular}




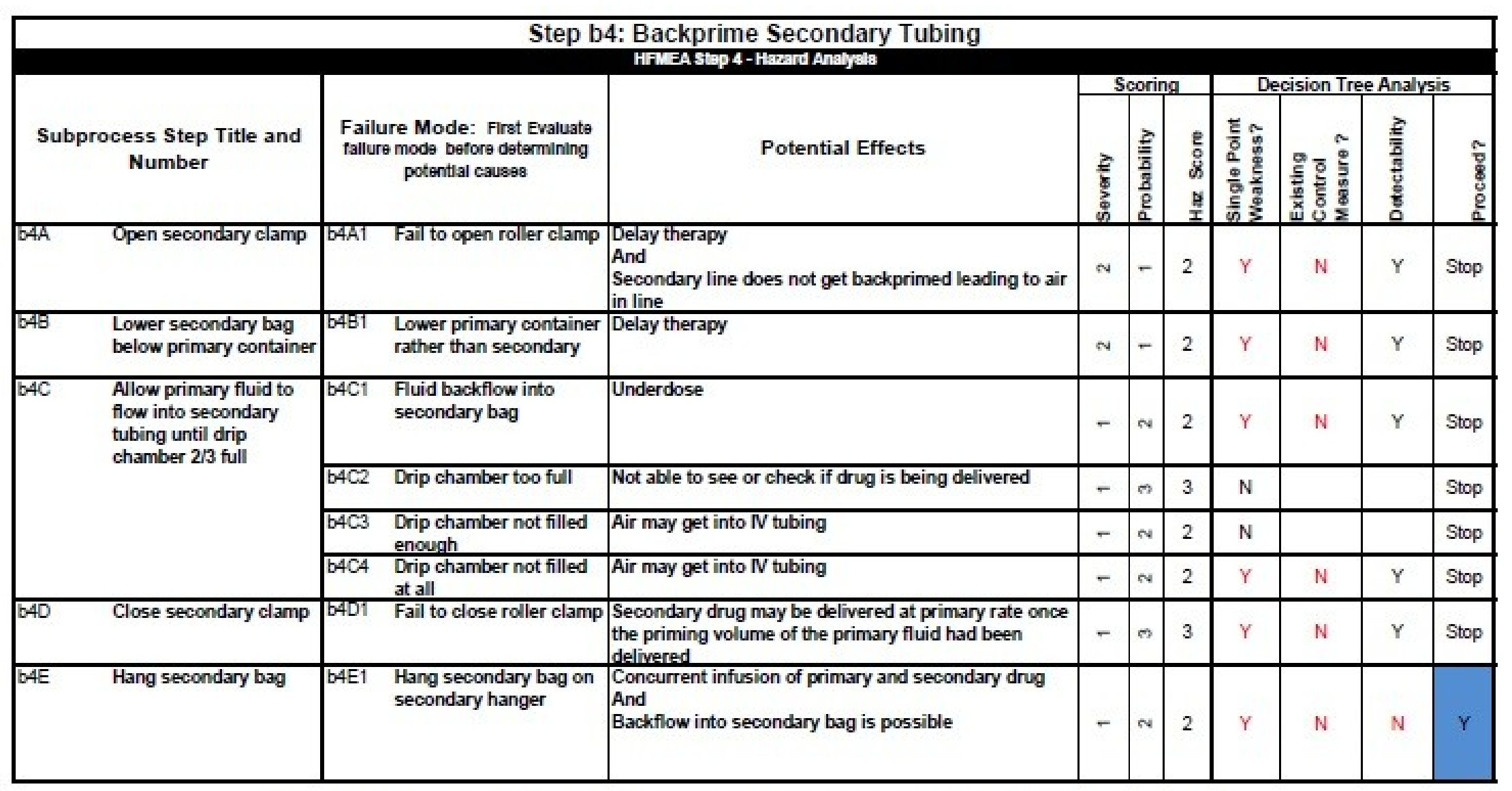

\begin{tabular}{|c|c|c|c|c|c|c|c|c|c|}
\hline \multirow[b]{2}{*}{$\begin{array}{c}\text { Subprocess Step Title and } \\
\text { Number }\end{array}$} & \multirow[b]{2}{*}{$\begin{array}{l}\text { Failure Mode: First Evaluate } \\
\text { fallure mode before determining } \\
\text { potentlal causes }\end{array}$} & \multirow[t]{2}{*}{ HFil ZA Stiep 4 - Hazard Analyalis } & \multicolumn{3}{|c|}{ Scoring } & \multicolumn{4}{|c|}{ cision Tree Analys } \\
\hline & & & 衰 & 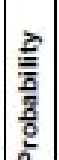 & 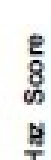 & 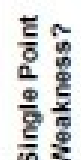 & हृ & 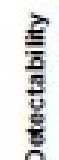 & 策 \\
\hline Open vent & 5A1 Fail to open vent & $\begin{array}{l}\text { Delay therapy } \\
\text { Or } \\
\text { Administration of primary fluid at secondary rate }\end{array}$ & $\sim$ & $m$ & 6 & $\mathrm{Y}$ & $\mathrm{N}$ & $\mathrm{N}$ & $Y$ \\
\hline
\end{tabular}




\begin{tabular}{|c|c|c|c|c|c|c|c|c|c|c|}
\hline & & & Step 6: Program Pump & & & & & & & \\
\hline & & & HFil zA Step 4 - Hanard Analyalis & & & & & & & \\
\hline & & & & & & & & cision 1 & Anal & is \\
\hline Sut & $\begin{array}{l}\text { ocess Step Title and } \\
\text { Number }\end{array}$ & $\begin{array}{l}\text { Failure Mode: First Evaluate } \\
\text { fallure mode before determining } \\
\text { potentlal causes }\end{array}$ & Potential Effects & 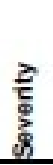 & 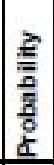 & $\begin{array}{l}\text { 음 } \\
\text { फ } \\
\text { 룰 } \\
\end{array}$ & 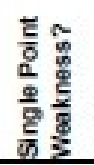 & 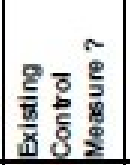 & $\frac{\sqrt{2}}{\frac{1}{8}}$ & \\
\hline$\overline{6 A}$ & Stop primary infusion & Fail to find Stop & Delay therapy & $\frac{1}{n}$ & $m$ & $\frac{1}{6}$ & $\mathrm{Y}$ & $\mathrm{N}$ & $\mathrm{Y}$ & Stop \\
\hline & & 6A2 Stop incorrect channel & $\begin{array}{l}\text { Secondary drug would run at primary rate } \\
\text { And } \\
\text { Wrong primary would run at secondary rate }\end{array}$ & $\nabla$ & $m$ & 12 & $\longrightarrow$ & $\mathrm{N}$ & $\mathrm{N}$ & $\mathrm{Y}$ \\
\hline $6 \mathrm{~B}$ & $\begin{array}{l}\text { Select Special } \\
\text { Functions }\end{array}$ & 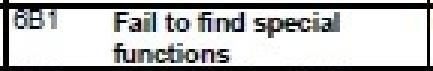 & Delay therapy & N & $m$ & 6 & $\mathrm{Y}$ & $\mathrm{N}$ & $\mathrm{Y}$ & Stop \\
\hline & Select Piggyback mode & $\begin{array}{l}\text { Thinking Piggyback } \\
\text { mode is selected by } \\
\text { pressing C }\end{array}$ & $\begin{array}{l}\text { Return to main menu } \\
\text { And } \\
\text { Delay therapy } \\
\text { And/or } \\
\text { Program primary as secondary }\end{array}$ & $\nabla$ & $m$ & 12 & & $\mathrm{~N}$ & $\mathrm{~N}$ & $Y$ \\
\hline $6 \mathrm{D}$ & $\begin{array}{l}\text { Automatic change - } \\
\text { select Yes }\end{array}$ & \begin{tabular}{|ll} 
6D1 & Select No \\
& unintentionally
\end{tabular} & End of infusion alarm at the end of secondary infusion & - & - & 1 & $\mathrm{~N}$ & & & Stop \\
\hline & & $\begin{array}{l}\text { UD2 Unintentionally exit to } \\
\text { main menu }\end{array}$ & $\begin{array}{l}\text { Delay therapy } \\
\text { And/or } \\
\text { Program primary as secondary }\end{array}$ & $\nabla$ & $m$ & 12 & $\longrightarrow$ & $\mathrm{N}$ & $\mathrm{N}$ & $Y$ \\
\hline $6 \mathrm{E}$ & $\begin{array}{l}\text { Use drug library? - } \\
\text { Select Yes }\end{array}$ & 6E1 Fail to select Yes & Dose limits will not apply to program & - & q & 4 & $\mathrm{~N}$ & & & Stop \\
\hline $6 \mathrm{~F}$ & Select library profile & $\begin{array}{ll}\text { 6iF1 } & \begin{array}{l}\text { Select incorrect library } \\
\text { profile }\end{array}\end{array}$ & $\begin{array}{l}\text { Drug and/or concentration may not be available and } \\
\text { delay therapy }\end{array}$ & - & $\sim$ & 2 & $\mathrm{Y}$ & N & $\mathrm{N}$ & Y \\
\hline $8 G$ & $\begin{array}{l}\text { Select drug with } \\
\text { concentration }\end{array}$ & 6G1 Select incorrect drug & $\begin{array}{l}\text { Incorrect drug label on pump } \\
\text { And } \\
\text { Incorrect dose limits applied to program }\end{array}$ & $N$ & $m$ & 6 & $\mathrm{~N}$ & & & Stop \\
\hline & & $\begin{array}{ll}\text { 6G2 } & \begin{array}{l}\text { Select incorrect } \\
\text { concentration }\end{array}\end{array}$ & Incorrect dose calculations - overdose/underdose & $\nabla$ & $\sim$ & 8 & & $\mathrm{~N}$ & $\mathrm{~N}$ & $Y$ \\
\hline $\mathrm{BH}$ & Enter VIB! & 6H1 Enter incorrect volume & Overdose/underdose & $\nabla$ & 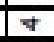 & 16 & $\Rightarrow$ & $\bar{N}$ & $\bar{N}$ & $\bar{Y}$ \\
\hline 6(i)I & Select Time & 6(i) 1 Fail to find Time & $\begin{array}{l}\text { Delay therapy } \\
\text { And } \\
\text { Forced to perform manual calculations }\end{array}$ & N & $m$ & 6 & $\mathrm{~N}$ & & & Stop \\
\hline (1) & Enter Time & (6)J1 Enter incorrect duration & Overdose/Underdose & $\nabla$ & q & 16 & & $\mathrm{~N}$ & $\mathrm{~N}$ & Y \\
\hline 8(iii) & $\begin{array}{l}\text { Perform manual } \\
\text { calculations }\end{array}$ & 6(ii)/ Inaccurate calculation & Overdose/Underdose & $\nabla$ & v & 16 & - & $\mathrm{N}$ & $\mathrm{N}$ & $Y$ \\
\hline 6(ii) J & Select Rate & 6(ii) 1 Fail to select Rate & Delay therapy & $\bar{N}$ & - & 2 & $\mathrm{~N}$ & & & Stop \\
\hline 6(ii)K & Enter rate & bin)K1 Enter incorrect rate & Overdose/underdose & 8 & 8 & 16 & & $\mathrm{~T}$ & $\mathbb{N}$ & $\mathrm{Y}$ \\
\hline 8 (iii)! & $\begin{array}{l}\text { Perform manual } \\
\text { calculations }\end{array}$ & 6(iii) If Inaccurate calculation & Overdose/Underdose & $\nabla$ & v & 16 & & $\mathrm{~N}$ & $\mathrm{~N}$ & $Y$ \\
\hline $8(1 i i)$ & Select Dose & D(ii) J1 Fail to select Dose & Delay theragy & iv & - & 2 & $\mathrm{~N}$ & & & Stop \\
\hline 6(iii)K & Enter dose rate & 6(iii)K1 Enter incorrect dose rate & Overdose/underdose & $\nabla$ & 8 & 16 & & $\mathrm{~N}$ & $\mathrm{~N}$ & $\mathrm{Y}$ \\
\hline
\end{tabular}


Step 7: Open Roller Clamp on Secondary Tubing

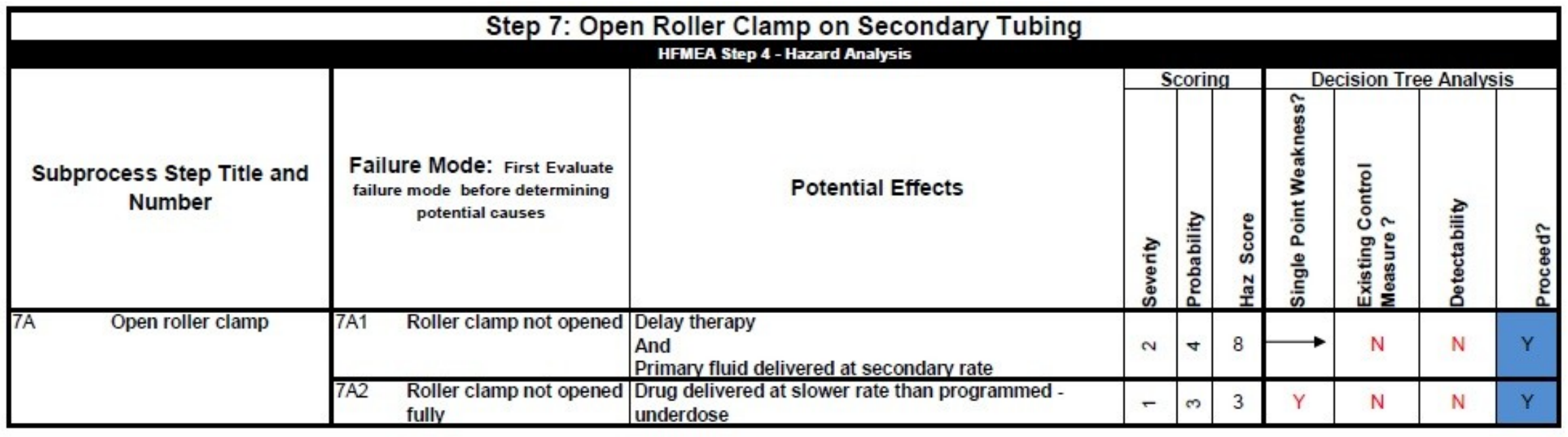

\begin{tabular}{|c|c|c|c|c|c|c|c|c|c|}
\hline \multicolumn{10}{|c|}{$\begin{array}{l}\text { Step 8: Start Infusion } \\
\text { HFMEA Step } 4 \text { - Hazard Analysis }\end{array}$} \\
\hline \multirow[b]{2}{*}{$\begin{array}{c}\text { Subprocess Step Title and } \\
\text { Number }\end{array}$} & \multirow[b]{2}{*}{$\begin{array}{l}\text { Failure Mode: First Evaluate } \\
\text { failure mode before determining } \\
\text { potential causes }\end{array}$} & \multirow[b]{2}{*}{ Potential Effects } & \multicolumn{3}{|c|}{ Scoring } & \multicolumn{4}{|c|}{ Decision Tree Analysis } \\
\hline & & & 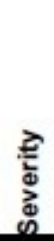 & 胥 & $\begin{array}{l}\text { ¿ } \\
\text { फ } \\
\text { त् }\end{array}$ & 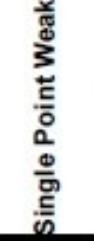 & 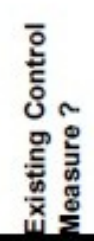 & 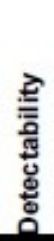 & ? \\
\hline 8A $\quad$ Press Start & 8A1 Fail to start infusion & Delay therapy & N & $\nabla$ & 8 & & $\mathrm{~N}$ & $\mathrm{~N}$ & $Y$ \\
\hline
\end{tabular}




\section{Appendix C: HFMEA for Cardinal Health Alaris PC}

\begin{tabular}{|c|c|c|c|c|c|c|c|c|c|c|c|}
\hline \multicolumn{12}{|c|}{ Step 1: Prepare Secondary Container } \\
\hline \multicolumn{2}{|c|}{$\begin{array}{c}\text { Subprocess Step Title and } \\
\text { Number }\end{array}$} & \multicolumn{2}{|c|}{$\begin{array}{l}\text { Failure Mode: First Evaluate } \\
\text { failure mode before determining } \\
\text { potential causes }\end{array}$} & Potential Effects & 离 & $\frac{\sqrt{2}}{\frac{\pi}{2}}$ & 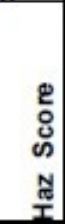 & 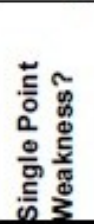 & 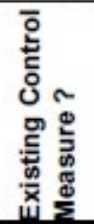 & 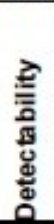 & 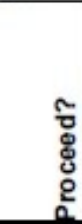 \\
\hline \multirow[t]{2}{*}{$1 \mathrm{~A}$} & \multirow[t]{2}{*}{$\begin{array}{l}\text { Select appropriate } \\
\text { secondary tubing }\end{array}$} & $1 \mathrm{~A} 1$ & Select primary tubing & $\begin{array}{l}\text { Patient may lose a significant percentage of drug to } \\
\text { priming volume - underdose } \\
\text { And } \\
\text { Tubing may be able to reach lower injection port - } \\
\text { secondary drug could free flow into patient }\end{array}$ & $\nabla$ & $m$ & 12 & & $\mathrm{~N}$ & $\mathrm{Y}$ & Stop \\
\hline & & & $\begin{array}{l}\text { Select incorrect } \\
\text { material }\end{array}$ & Compatibility issues & N & N & 4 & $\mathrm{Y}$ & $\mathrm{N}$ & $\mathrm{N}$ & $\mathrm{Y}$ \\
\hline \multirow[t]{2}{*}{18} & \multirow{2}{*}{$\begin{array}{l}\text { Open secondary } \\
\text { tubing package and } \\
\text { close roller clamp on } \\
\text { secondary tubing }\end{array}$} & 181 & Roller clamp left open & $\begin{array}{l}\text { Drug leak to floor when bag is spiked } \\
\text { And } \\
\text { Potential cytotoxic drug exposure }\end{array}$ & $N$ & - & 2 & $\mathrm{Y}$ & $\mathrm{N}$ & $\mathrm{Y}$ & Stop \\
\hline & & & $\begin{array}{l}\text { Roller clamp not } \\
\text { closed all the way }\end{array}$ & $\begin{array}{l}\text { Drug drip to floor when bag is spiked } \\
\text { And } \\
\text { Potential cytotoxic drug exposure }\end{array}$ & - & N & 2 & $Y$ & $\mathrm{~N}$ & $\mathrm{Y}$ & Stop \\
\hline & \multirow[t]{2}{*}{$\begin{array}{l}\text { Spike secondary } \\
\text { container }\end{array}$} & & $\begin{array}{l}\text { Nurse pokes a hole in } \\
\text { the bag with spike }\end{array}$ & $\begin{array}{l}\text { Drug leak } \\
\text { And } \\
\text { Potential cytotoxic drua exposure }\end{array}$ & N & - & 2 & $Y$ & $\mathrm{~N}$ & $\mathrm{Y}$ & Stop \\
\hline & & & $\begin{array}{l}\text { Bag not spiked all the } \\
\text { way }\end{array}$ & $\begin{array}{l}\text { Drug leak } \\
\text { Or } \\
\text { Spike may come off and cause drug spill } \\
\text { And } \\
\text { Potential cutotoxic drua exnosure }\end{array}$ & N & - & 2 & $\mathrm{Y}$ & $\mathrm{N}$ & $\mathrm{Y}$ & Stop \\
\hline
\end{tabular}




\begin{tabular}{|c|c|c|c|c|c|c|c|c|c|c|c|}
\hline & & & & $\begin{array}{l}\text { tep a2: Prime Secondary Line } \\
\text { HFMEA Step 4-Hazard Analysis }\end{array}$ & & & & & & & \\
\hline & & & & & & corit & & & cision Tre & Anals & \\
\hline & $\begin{array}{l}\text { cess Step Title and } \\
\text { Number }\end{array}$ & $\begin{array}{l}\text { Failu } \\
\text { failure }\end{array}$ & $\begin{array}{l}\text { Mode: First Evaluate } \\
\text { mode before determining } \\
\text { potential causes }\end{array}$ & Potential Effects & 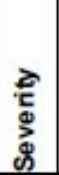 & 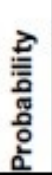 & 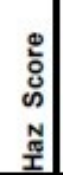 & 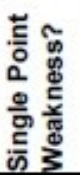 & 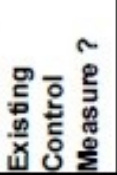 & 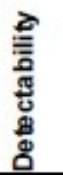 & 蒗 \\
\hline $\mathrm{a} 2 \mathrm{~A}$ & $\begin{array}{l}\text { Fill drip chamber to } \\
2 / 3 \text { full }\end{array}$ & $22 A 1$ & Drip chamber too full & Not able to see or check if drug is being delivered & - & + & 4 & $\mathrm{~N}$ & & & Stop \\
\hline & & & $\begin{array}{l}\text { Drip chamber not filled } \\
\text { enough }\end{array}$ & Air may get into IV tubing & - & N & 2 & $\mathrm{~N}$ & & & Stop \\
\hline & & 2 & $\begin{array}{l}\text { Drip chamber not filled } \\
\text { at all }\end{array}$ & Air may get into IV tubing & - & N & 2 & $\mathrm{Y}$ & $\mathrm{N}$ & $\mathrm{Y}$ & Stop \\
\hline a2B & $\begin{array}{l}\text { Open roller clamp on } \\
\text { secondary tubing }\end{array}$ & 22B1 & $\begin{array}{l}\text { Fail to open roller } \\
\text { clamp }\end{array}$ & Delay therapy & - & - & 1 & $\mathrm{Y}$ & $\mathrm{N}$ & $\mathrm{Y}$ & Stop \\
\hline & $\begin{array}{l}\text { Allow fluid to flow } \\
\text { until tubing is primed }\end{array}$ & $\mathrm{a} 2 \mathrm{C1}$ & $\begin{array}{l}\text { Fail to fill fluid to end } \\
\text { of tubing }\end{array}$ & Air bubble in tubing & - & - & 1 & $\mathrm{Y}$ & $\mathrm{N}$ & $\mathrm{Y}$ & Stop \\
\hline & $\begin{array}{l}\text { Close roller clamp on } \\
\text { secondary tubing }\end{array}$ & Q201 & $\begin{array}{l}\text { Fail to close roller } \\
\text { clamp }\end{array}$ & $\begin{array}{l}\text { Drug waste } \\
\text { And } \\
\text { Potential cytotoxic drug exposure }\end{array}$ & N & - & 2 & $\mathrm{Y}$ & $\mathrm{N}$ & $\mathrm{Y}$ & Stop \\
\hline
\end{tabular}


Step a3 \& b2: Hang Secondary Container and Adjust Primary Container

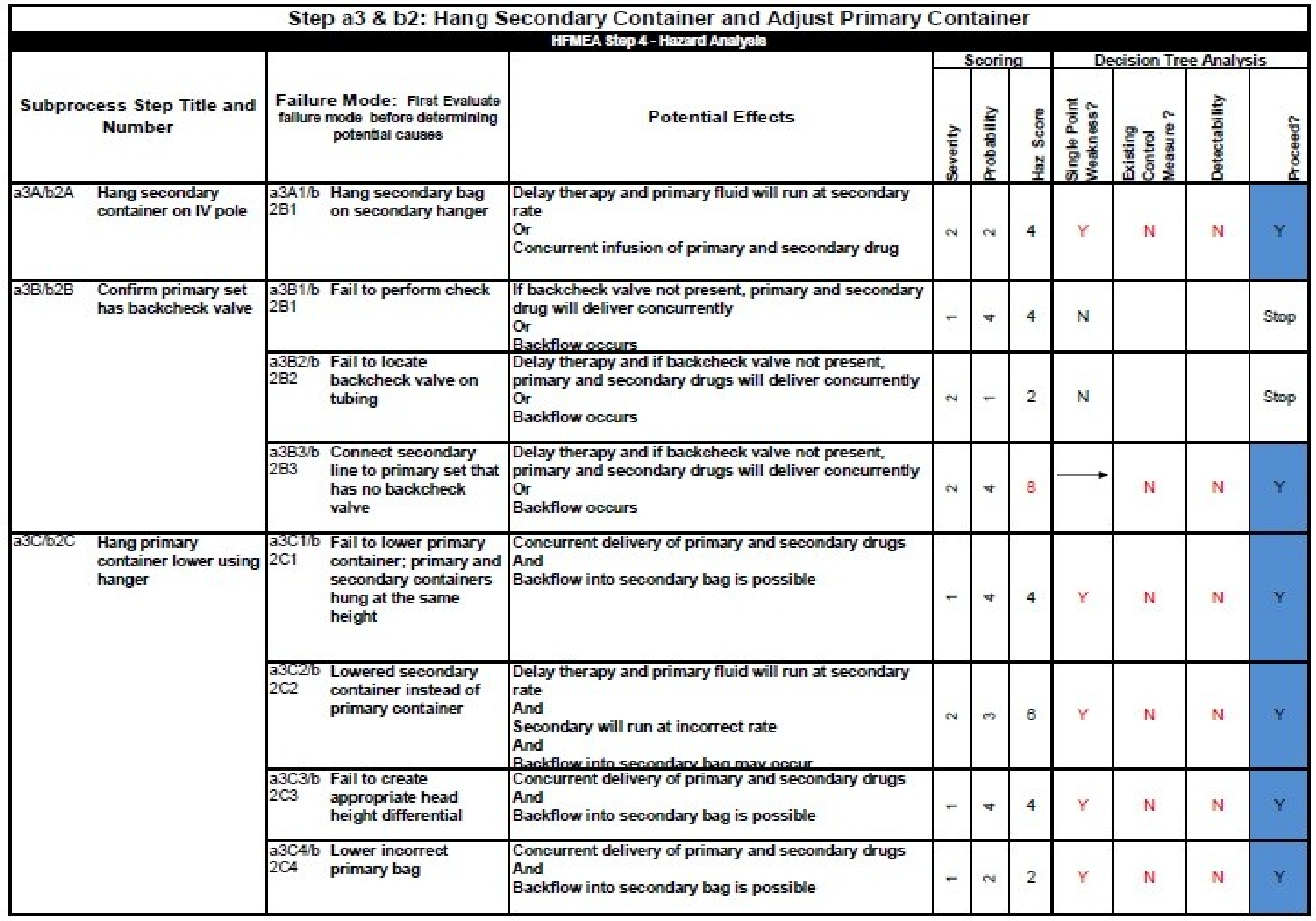




\begin{tabular}{|c|c|c|c|c|c|c|c|c|c|c|c|}
\hline & & & & HFMEA Step 4 - Hazard Analysis & & & & & & & \\
\hline Subpro & $\begin{array}{l}\text { cess Step Title and } \\
\text { Number }\end{array}$ & $\begin{array}{l}\text { Failur } \\
\text { failure }\end{array}$ & $\begin{array}{l}\text { re Mode: First Evaluate } \\
\text { mode before determining } \\
\text { potential causes }\end{array}$ & Potential Effects & 竝 & 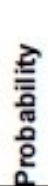 & 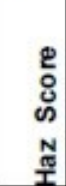 & 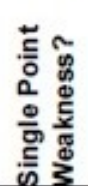 & 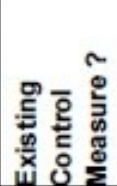 & 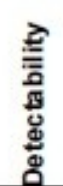 & \\
\hline a4AVb3А & $\begin{array}{l}\text { Swab upper y-site } \\
\text { port on primary }\end{array}$ & $\begin{array}{l}24 A 1 / b \\
3 A 1\end{array}$ & Fail to swab y-site port & Infection & + & + & 16 & $\rightarrow$ & $\mathrm{N}$ & $\mathrm{N}$ & $Y$ \\
\hline & $\begin{array}{l}\text { tubing with } \\
\text { appropriate antiseptic }\end{array}$ & $\begin{array}{l}24 A 2 / 6 \\
3 A 2\end{array}$ & $\begin{array}{l}\text { Fail to "scrub the hub" } \\
\text { thoroughly }\end{array}$ & Infection & a & $\sigma$ & 16 & $\rightarrow$ & $\mathrm{N}$ & $\mathrm{N}$ & Y \\
\hline & & $\begin{array}{l}a 4 A 3 / b \\
3 A 3\end{array}$ & $\begin{array}{l}\text { Fail to allow antiseptic } \\
\text { to dry }\end{array}$ & Infection & A & $\theta$ & 16 & & $\mathrm{~N}$ & $\mathrm{~N}$ & $Y$ \\
\hline a4B/b3B & $\begin{array}{l}\text { Connect secondary } \\
\text { line to upper y-site } \\
\text { port on primary } \\
\text { tubing (upstream of } \\
\text { infusion pump) }\end{array}$ & $\begin{array}{l}\mathrm{a} 4 \mathrm{~B} 1 / \mathrm{b} \\
3 \mathrm{~B} 1\end{array}$ & $\begin{array}{l}\text { Connect secondary } \\
\text { line to y-site ports } \\
\text { located downstream of } \\
\text { infusion pump }\end{array}$ & Secondary drug freeflow into patient & t & $\nabla$ & 16 & & $\mathrm{~N}$ & $\mathrm{~N}$ & $\mathrm{Y}$ \\
\hline & & $\begin{array}{l}\mathrm{a} 4 \mathrm{~B} 2 / \mathrm{b} \\
3 \mathrm{~B} 2\end{array}$ & $\begin{array}{l}\text { Connect secondary } \\
\text { line to the wrong } \\
\text { primary line }\end{array}$ & $\begin{array}{l}\text { Primary fluid running at secondary rate } \\
\text { And } \\
\text { Delay therapy of the wrong primary line } \\
\text { And } \\
\text { Potential compatibility issues between secondary and } \\
\text { wrong primary } \\
\text { And } \\
\text { Secondarumould run at wrong nrimanurate }\end{array}$ & $\theta$ & $m$ & 12 & & $\mathrm{~N}$ & $\mathrm{~N}$ & $\mathrm{Y}$ \\
\hline & & $3 \mathrm{~B} 33 / \mathrm{b}$ & $\begin{array}{l}\text { Fail to securely } \\
\text { connect secondary line } \\
\text { to primary line }\end{array}$ & Luer connect may come off and cause drug leak & $N$ & N & 4 & $\mathrm{Y}$ & $\mathrm{N}$ & $\mathrm{N}$ & $\mathrm{Y}$ \\
\hline & & $\begin{array}{l}\mathrm{a} 4 \mathrm{~B} 4 / \mathrm{b} \\
3 \mathrm{~B} 4\end{array}$ & $\begin{array}{l}\text { Fail to connect } \\
\text { secondary line }\end{array}$ & $\begin{array}{l}\text { Delay therapy and primary fluid running at secondary } \\
\text { rate }\end{array}$ & $N$ & N & 4 & $\mathrm{Y}$ & $\mathrm{N}$ & $\mathrm{N}$ & $\mathrm{Y}$ \\
\hline
\end{tabular}




\begin{tabular}{|c|c|c|c|c|c|c|c|c|c|c|c|}
\hline \multirow{2}{*}{\multicolumn{12}{|c|}{$\begin{array}{c}\text { Step b4: Backprime Secondary Tubing } \\
\text { nFMEA step 4-Hazerd Analyals }\end{array}$}} \\
\hline & & & & & & & & & & & \\
\hline \multicolumn{2}{|c|}{$\begin{array}{l}\text { Subprocess Step Title and } \\
\text { Number }\end{array}$} & \multicolumn{2}{|c|}{$\begin{array}{c}\text { Failure Mode: Firat Evaluate } \\
\text { fallure mode before determining } \\
\text { potentlal causes }\end{array}$} & Potential Effects & 帘 & $\begin{array}{l}\frac{\gtrsim}{2} \\
\frac{\bar{n}}{0} \\
\frac{0}{2} \\
\frac{2}{2} \\
\end{array}$ & 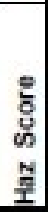 & 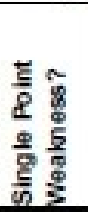 & 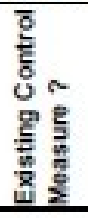 & 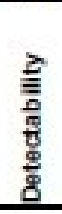 & 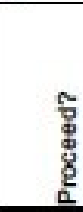 \\
\hline BAA & $\begin{array}{l}\text { Open secondary } \\
\text { clamp }\end{array}$ & BAA1 & $\begin{array}{l}\text { Fail to open roller } \\
\text { clamp }\end{array}$ & $\begin{array}{l}\text { Delay therapy } \\
\text { And } \\
\text { Secondary line does not get backprimed leading to air } \\
\text { in line }\end{array}$ & $\sim$ & - & 2 & $Y$ & $\mathrm{~N}$ & $\mathrm{Y}$ & Stop \\
\hline $\mathrm{b} 4 \mathrm{~B}$ & $\begin{array}{l}\text { Lower secondary bag } \\
\text { below primary } \\
\text { container }\end{array}$ & b4B1 & $\begin{array}{l}\text { Lower primary } \\
\text { container rather than } \\
\text { secondary }\end{array}$ & Delay therapy & $N$ & - & 2 & $Y$ & $\mathrm{~N}$ & $\mathrm{Y}$ & Stop \\
\hline \multirow[t]{4}{*}{$\mathrm{b4C}$} & \multirow{4}{*}{$\begin{array}{l}\text { Allow primary fiuid to } \\
\text { flow into secondary } \\
\text { tubing until drip } \\
\text { chamber } 2 / 3 \text { full }\end{array}$} & b4CT & $\begin{array}{l}\text { Fluid backfilow into } \\
\text { secondary bag }\end{array}$ & Underdose & - & N & 2 & $Y$ & $\mathrm{~N}$ & $\mathrm{Y}$ & Stop \\
\hline & & $\overline{\mathrm{BAC} 2}$ & Drip chamber too full & Not able to see or check if drug is being delivered & - & $m$ & 3 & $\mathrm{~N}$ & & & Stop \\
\hline & & $\mathrm{B} 4 \mathrm{C} 3$ & $\begin{array}{l}\text { Drip chamber not filled } \\
\text { enough }\end{array}$ & Air may get into IV tubing & - & * & 2 & $\mathrm{~N}$ & & & Stop \\
\hline & & $\overline{b 4 C 4}$ & $\begin{array}{l}\text { Drip chamber not filled } \\
\text { at all }\end{array}$ & Air may get into IV tubing & - & $\sim$ & 2 & $Y$ & $\mathrm{~N}$ & $\mathrm{Y}$ & Stop \\
\hline $\mathrm{b} 4 \mathrm{D}$ & $\begin{array}{l}\text { Close secondary } \\
\text { clamp }\end{array}$ & $\sqrt{\mathrm{b} 4 \mathrm{D} 1}$ & $\begin{array}{l}\text { Fail to close roller } \\
\text { clamp }\end{array}$ & $\begin{array}{l}\text { Secondary drug may be delivered at primary rate once } \\
\text { the priming volume of the primary fluid had been } \\
\text { delivered }\end{array}$ & - & $m$ & 3 & $Y$ & $\mathrm{~N}$ & $\mathrm{Y}$ & Stop \\
\hline & Hang secondary bag & BAET & $\begin{array}{l}\text { Hang secondary bag } \\
\text { on secondary hanger }\end{array}$ & $\begin{array}{l}\text { Concurrent infusion of primary and secondary drug } \\
\text { And } \\
\text { Backflow into secondary bag is possible }\end{array}$ & - & N & 2 & $Y$ & $\mathrm{~N}$ & $N$ & Y \\
\hline
\end{tabular}

\begin{tabular}{|c|c|c|c|c|c|c|c|c|c|}
\hline \multirow[b]{2}{*}{$\begin{array}{l}\text { Subprocess Step Title and } \\
\text { Number }\end{array}$} & \multirow[b]{2}{*}{$\begin{array}{l}\text { Failure Mode: First Evaluate } \\
\text { fallure mode before determining } \\
\text { potentdal causes }\end{array}$} & \multirow[b]{2}{*}{ Potential Effects } & \multicolumn{3}{|c|}{ Scoring } & \multicolumn{4}{|c|}{ Decision Tree Analysis } \\
\hline & & & 站 & $\begin{array}{l}\frac{\lambda}{E} \\
\overline{\bar{a}} \\
\frac{0}{0} \\
\frac{0}{2} \\
0\end{array}$ & 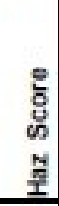 & 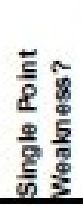 & 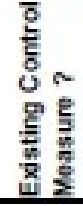 & 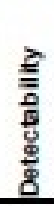 & 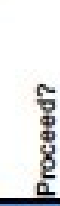 \\
\hline Open vent & 5A1 Fail to open vent & $\begin{array}{l}\text { Delay therapy } \\
\text { Or } \\
\text { Administration of primary fluid at secondary rate }\end{array}$ & N & $\infty$ & 6 & $Y$ & $\mathrm{~N}$ & $\mathrm{~N}$ & $\mathbf{Y}$ \\
\hline
\end{tabular}




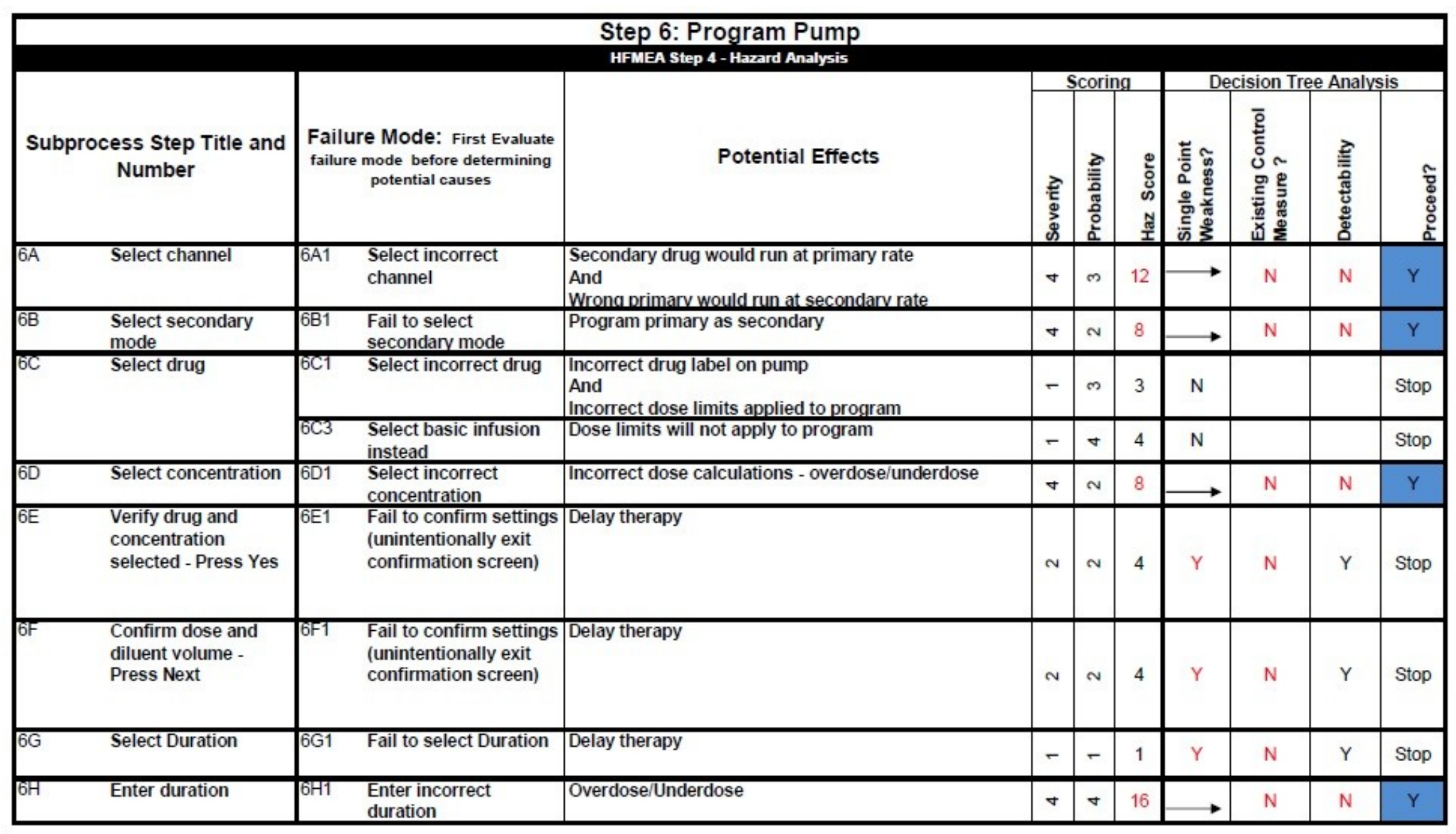




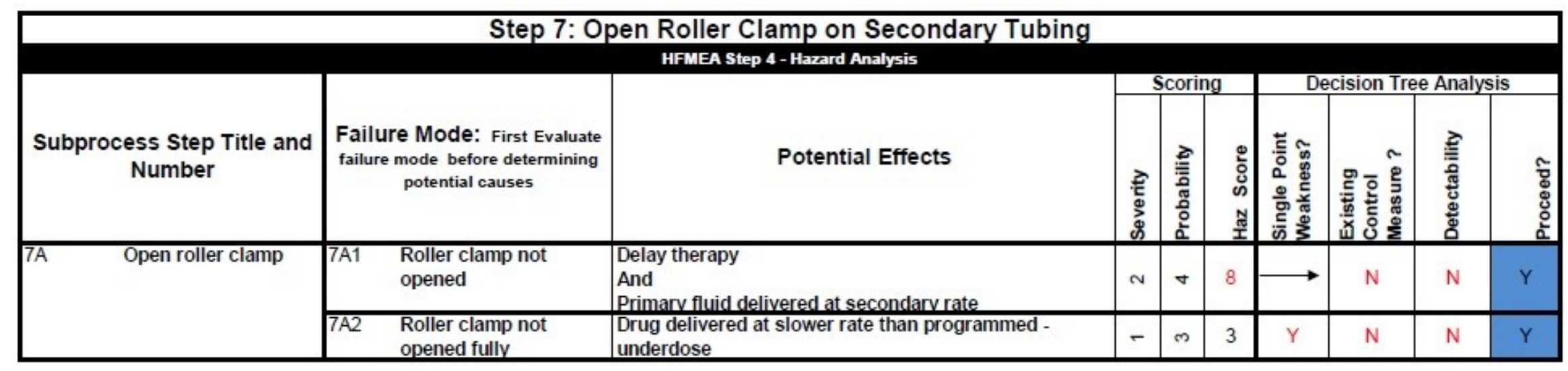

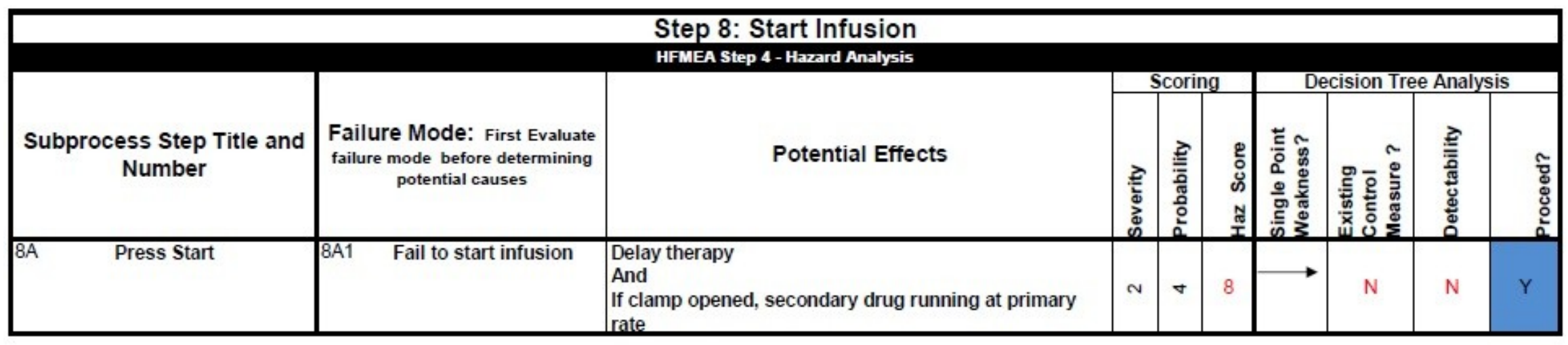




\section{Appendix D: HFMEA for Hospira Symbiq}

\begin{tabular}{|c|c|c|c|c|c|c|c|c|c|c|c|}
\hline \multicolumn{12}{|c|}{ Step 1: Prepare Secondary Container } \\
\hline & & & & \multicolumn{8}{|l|}{ HFMEA Step 4 - Hazard Analysis } \\
\hline & $\begin{array}{l}\text { ocess Step Title and } \\
\text { Number }\end{array}$ & \multicolumn{2}{|c|}{$\begin{array}{l}\text { Failure Mode: First Evaluate failure } \\
\text { mode before determining potential causes }\end{array}$} & Potential Effects & 蛋 & 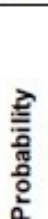 & 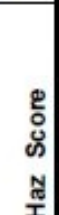 & 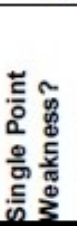 & 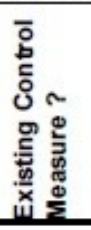 & 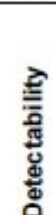 & ๆ.ّ. \\
\hline \multirow[t]{2}{*}{$\overline{1 A}$} & $\begin{array}{l}\text { Select appropriate } \\
\text { secondary tubing }\end{array}$ & & Select primary tubing & $\begin{array}{l}\text { Patient may lose a significant percentage of drug to } \\
\text { priming volume - underdose } \\
\text { And } \\
\text { Tubing may be able to reach lower injection port - } \\
\text { secondary drug could free flow into patient }\end{array}$ & $\theta$ & $m$ & 12 & & $\mathrm{~N}$ & Y & Stop \\
\hline & & $1 \mathrm{A2}$ & Select incorrect material & Compatibility issues & n & n & 4 & $Y$ & $\mathrm{~N}$ & $\mathrm{~N}$ & $\mathrm{Y}$ \\
\hline \multirow[t]{2}{*}{ 18 } & $\begin{array}{l}\text { Open secondary tubing } \\
\text { package and close roller } \\
\text { clamp on secondary }\end{array}$ & & Roller clamp left open & $\begin{array}{l}\text { Drug leak to floor when bag is spiked } \\
\text { And } \\
\text { Potential cytotoxic drug exposure }\end{array}$ & N & - & 2 & $\mathrm{Y}$ & $\mathrm{N}$ & Y & Stop \\
\hline & & & $\begin{array}{l}\text { Roller clamp not closed all the } \\
\text { way }\end{array}$ & $\begin{array}{l}\text { Drug drip to floor when bag is spiked } \\
\text { And } \\
\text { Potential cytotoxic drug exposure }\end{array}$ & - & n & 2 & $\mathrm{Y}$ & $\mathrm{N}$ & Y & Stop \\
\hline \multirow[t]{2}{*}{$\overline{1 C}$} & $\begin{array}{l}\text { Spike secondary } \\
\text { container }\end{array}$ & & $\begin{array}{l}\text { Nurse pokes a hole in the bag } \\
\text { with spike }\end{array}$ & $\begin{array}{l}\text { Drug leak } \\
\text { And } \\
\text { Potential cytotoxic drug exposure }\end{array}$ & N & - & 2 & $\mathrm{Y}$ & $\mathrm{N}$ & Y & Stop \\
\hline & & & Bag not spiked all the way & $\begin{array}{l}\text { Drug leak } \\
\text { Or } \\
\text { Spike may come off and cause drug spill } \\
\text { And } \\
\text { Potential cytotoxic drug exposure }\end{array}$ & N & - & 2 & Y & $\mathrm{N}$ & Y & Stop \\
\hline
\end{tabular}




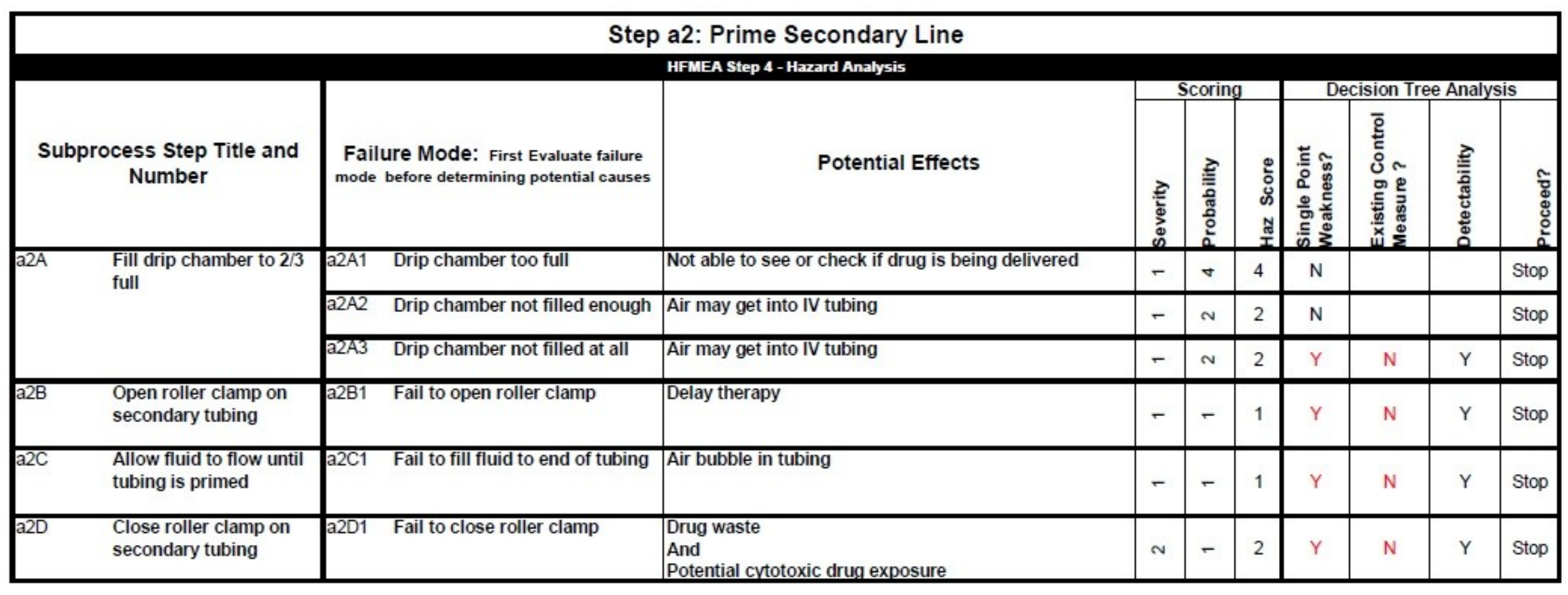


Step a3 \& b2: Hang Secondary Container and Adjust Primary Container

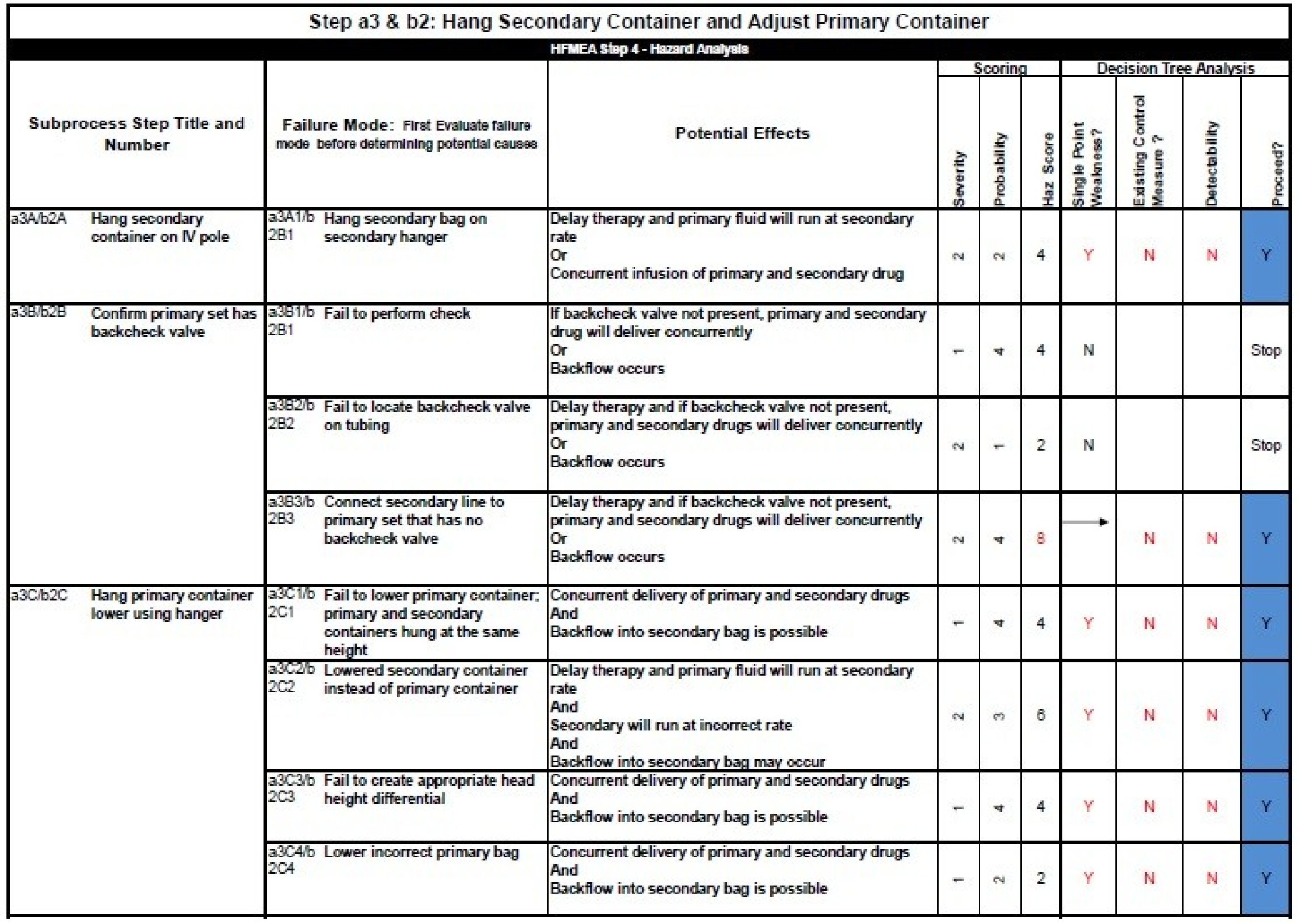




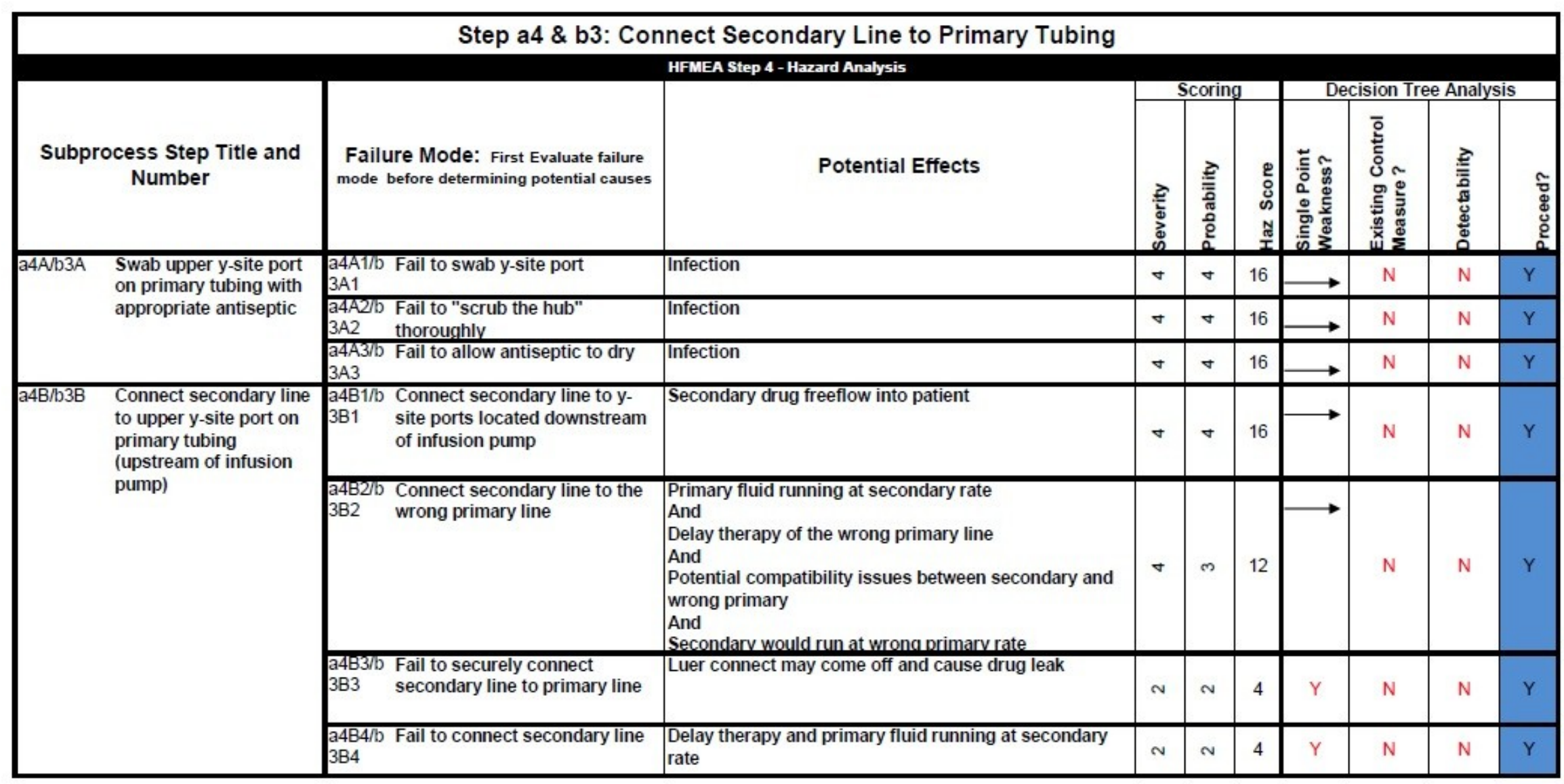


Step b4: Backprime Secondary Tubing

\begin{tabular}{|c|c|c|c|c|c|c|c|c|c|c|}
\hline \multicolumn{11}{|c|}{ HFMEA Stap 4 - Hazard Aneyvals } \\
\hline \multirow{2}{*}{\multicolumn{2}{|c|}{$\begin{array}{l}\text { Subprocess Step Title and } \\
\text { Number }\end{array}$}} & \multirow[b]{2}{*}{$\begin{array}{l}\text { Failure Mode: First Evaluate fallure } \\
\text { mode before determining potential causes }\end{array}$} & \multirow[b]{2}{*}{ Potential Effects } & \multirow[b]{2}{*}{ 空 } & \multirow[b]{2}{*}{ 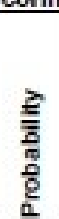 } & \multirow[b]{2}{*}{ 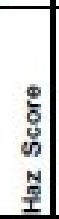 } & \multirow[b]{2}{*}{ 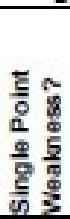 } & \multirow[b]{2}{*}{ 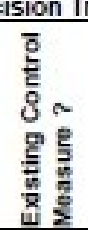 } & \multirow[b]{2}{*}{ 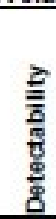 } & \\
\hline & & & & & & & & & & \\
\hline $\mathrm{b4A}$ & Open secondary clamp & b4A1 Fail to open roller clamp & $\begin{array}{l}\text { Delay therapy } \\
\text { And } \\
\text { Secondary line does not get backprimed leading to air } \\
\text { in line }\end{array}$ & $\sim$ & - & 2 & $\mathrm{Y}$ & $\mathrm{N}$ & $\mathrm{Y}$ & Stop \\
\hline B48 & $\begin{array}{l}\text { Lower secondary bag } \\
\text { below primary container }\end{array}$ & $\begin{array}{l}\text { B481 Lower primary container rather } \\
\text { than secondary }\end{array}$ & Delay therapy & N & - & 2 & $\mathrm{Y}$ & $\mathrm{N}$ & $\mathrm{Y}$ & Stop \\
\hline \multirow[t]{4}{*}{$\mathrm{b} 4 \mathrm{C}$} & \multirow{4}{*}{$\begin{array}{l}\text { Allow primary fluid to } \\
\text { flow into secondary } \\
\text { tubing until drip } \\
\text { chamber } 2 / 3 \text { full }\end{array}$} & $\begin{array}{ll}\mathrm{b} 4 \mathrm{Cl} 1 & \begin{array}{l}\text { Fluid backflow into secondary } \\
\text { bag }\end{array} \\
\end{array}$ & Underdose & - & $\sim$ & 2 & Y & $\mathrm{N}$ & $\mathrm{Y}$ & Stop \\
\hline & & B4C2 Drip chamber too full & Not able to see or check if drug is being delivered & $=$ & $m$ & 3 & $\mathrm{~N}$ & & & Stop \\
\hline & & b4C3 Drip chamber not filled enough & Air may get into IV tubing & - & $\sim$ & 2 & $\mathrm{~N}$ & & & Stop \\
\hline & & b4C4 Drip chamber not filled at all & Air may get into IV tubing & - & $\sim$ & 2 & $Y$ & $\mathrm{~N}$ & $\mathrm{Y}$ & Stop \\
\hline b4D & Close secondary clamp & b4D1 Fail to close roller clamp & $\begin{array}{l}\text { Secondary drug may be delivered at primary rate once } \\
\text { the priming volume of the primary fluid had been } \\
\text { delivered }\end{array}$ & - & $m$ & 3 & $\mathrm{Y}$ & $\mathrm{N}$ & $\mathrm{Y}$ & Stop \\
\hline $\mathrm{b} 4 \mathrm{E}$ & Hang secondary bag & $\begin{array}{ll}\text { b4E1 Hang secondary bag on } \\
\text { secondary hanger }\end{array}$ & $\begin{array}{l}\text { Concurrent infusion of primary and secondary drug } \\
\text { And } \\
\text { Backflow into secondary bag is possible }\end{array}$ & - & $\omega$ & 2 & $\mathrm{r}$ & $\mathrm{N}$ & $\mathrm{N}$ & $\mathrm{Y}$ \\
\hline
\end{tabular}

\begin{tabular}{|c|c|c|c|c|c|c|c|c|c|}
\hline \multicolumn{10}{|c|}{$\begin{array}{l}\text { Step 5: Open Vent on Drip Chamber if Secondary Container is Glass or Semi-Rigid } \\
\text { HFMEA step 4-Harard Aneysals }\end{array}$} \\
\hline $\begin{array}{c}\text { Subprocess Step Title and } \\
\text { Number }\end{array}$ & $\begin{array}{l}\text { Failure Mode: First Evaluate fallure } \\
\text { mode before determining potential causes }\end{array}$ & Potential Effects & 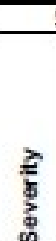 & 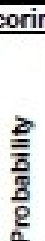 & 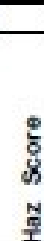 & 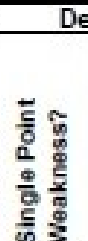 & 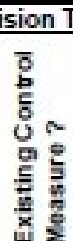 & 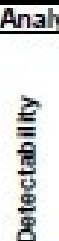 & \\
\hline 5A $\quad$ Open vent & 5A1 Fail to open vent & \begin{tabular}{|l|} 
Delay therapy \\
Or \\
Administration of primary fluid at secondary rate
\end{tabular} & N & $\infty$ & 6 & $Y$ & $\mathrm{~N}$ & $\mathrm{~N}$ & $\mathrm{Y}$ \\
\hline
\end{tabular}




\begin{tabular}{|c|c|c|c|c|c|c|c|c|c|}
\hline & & Step 6: Program Pump & & & & & & & \\
\hline & & HFMEA Step 4 - Hazard Analysis & & & & & & & \\
\hline $\begin{array}{c}\text { Subprocess Step Title and } \\
\text { Number }\end{array}$ & $\begin{array}{l}\text { Failure Mode: First Evaluate failure } \\
\text { mode before determining potential causes }\end{array}$ & Potential Effects & 言 & 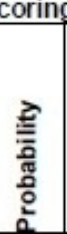 & 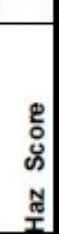 & 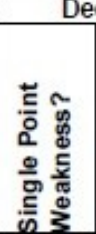 & 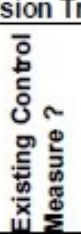 & 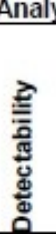 & 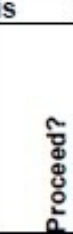 \\
\hline Select channel & $\begin{array}{ll}\text { 6A1 } & \text { Select incorrect channel }\end{array}$ & $\begin{array}{l}\text { Secondary drug would run at primary rate } \\
\text { And } \\
\text { Wrong primary would run at secondary rate } \\
\end{array}$ & $\sigma$ & m & 12 & $\longrightarrow$ & $\mathrm{N}$ & $\mathrm{N}$ & $\mathrm{Y}$ \\
\hline Select piggyback & 6B1 Select incorrect mode & $\begin{array}{l}\text { Program piggyback as bolus or basic infusion } \\
\text { Or } \\
\text { Program primary as secondary }\end{array}$ & 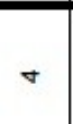 & - & 4 & & $\mathrm{~N}$ & $\mathrm{Y}$ & Stop \\
\hline Select infusion & 6C1 $\quad$ Fail to select Infusion & Delay therapy & - & - & 1 & $\mathrm{Y}$ & $\mathrm{N}$ & $\mathrm{Y}$ & Stop \\
\hline Select drug & $\begin{array}{ll}\text { 6D1 } & \text { Select incorrect drug }\end{array}$ & $\begin{array}{l}\text { Incorrect drug label on pump } \\
\text { And } \\
\text { Incorrect dose limits applied to program } \\
\end{array}$ & - & m & 3 & $\mathrm{~N}$ & & & Stop \\
\hline Select concentration & 6E1 Select incorrect concentration & Incorrect dose calculations - overdose/underdose & $\Delta$ & n & 8 & $\rightarrow$ & $\mathrm{N}$ & N & Y \\
\hline Select dose rate unit & $\begin{array}{ll}6 \mathrm{~F} 1 & \text { Select incorrect dose rate unit }\end{array}$ & Incorrect dose calculations - overdose/underdose & $\nabla$ & $\theta$ & 16 & $\rightarrow$ & N & $\mathrm{N}$ & $\mathrm{Y}$ \\
\hline Enter dose rate & 6G1 Enter incorrect dose rate & Incorrect dose calculations - overdose/underdose & $\forall$ & $\sigma$ & 16 & $\rightarrow$ & N & N & Y \\
\hline Select VTBI & 6(i)H1 Fail to select VTBI & Delay therapy & $\overline{-}$ & $\overline{-}$ & 1 & $\bar{Y}$ & $\mathrm{~N}$ & $\bar{Y}$ & Stop \\
\hline Enter VTBI & 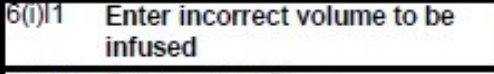 & Overdose/underdose & $\Delta$ & + & 16 & $\longrightarrow$ & $\mathrm{N}$ & $\mathrm{N}$ & Y \\
\hline Select Time & 6(ii)H1 Fail to select Time & Delay therapy & $\bar{F}$ & $\bar{T}$ & 1 & $\begin{array}{c}\mathrm{Y} \\
\end{array}$ & $\overline{\mathrm{N}}$ & $\bar{Y}$ & Stop \\
\hline Enter Time & E(ii)l1 Enter incorrect Time & Overdose/underdose & $\nabla$ & $\nabla$ & 16 & $\longrightarrow$ & $\mathrm{N}$ & $\mathrm{N}$ & $\mathrm{Y}$ \\
\hline Press Next & 61 $\quad$ Fail to press Next & Delay therapy & - & - & 1 & $\mathrm{Y}$ & $\mathrm{N}$ & $\mathrm{Y}$ & Stop \\
\hline
\end{tabular}




\begin{tabular}{|c|c|c|c|c|c|c|c|c|c|}
\hline \multicolumn{10}{|c|}{ Step 7: Open Roller Clamp on Secondary Tubing } \\
\hline \multicolumn{10}{|c|}{ HFMEA Step 4 - Hazard Analysis } \\
\hline $\begin{array}{c}\text { Subprocess Step Title and } \\
\text { Number }\end{array}$ & $\begin{array}{l}\text { Failure Mode: First Evaluate failure } \\
\text { mode before determining potential causes }\end{array}$ & Potential Effects & 蛋 & 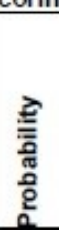 & 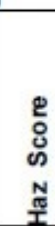 & 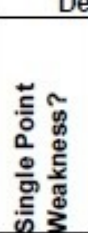 & 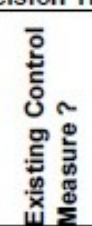 & 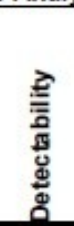 & ๕ั้ \\
\hline Open roller clamp & 7A1 Roller clamp not opened & $\begin{array}{l}\text { Delay therapy } \\
\text { And } \\
\text { Primary fluid delivered at secondary rate }\end{array}$ & $N$ & $\sigma$ & 8 & & $\mathrm{~N}$ & $\mathrm{~N}$ & Y \\
\hline & 7A2 $\quad$ Roller clamp not opened fully & $\begin{array}{l}\text { Drug delivered at slower rate than programmed - } \\
\text { underdose }\end{array}$ & - & m & 3 & $\mathrm{Y}$ & $\mathrm{N}$ & $\mathrm{N}$ & $\mathrm{Y}$ \\
\hline $\begin{array}{l}\text { Check bag height } \\
\text { difference and roller } \\
\text { clamp position - Press } \\
\text { OK }\end{array}$ & $\begin{array}{ll}7 \mathrm{BB} 1 & \begin{array}{l}\text { Fail to proceed (unintentionally } \\
\text { exit confirmation screen) }\end{array}\end{array}$ & Delay therapy & N & N & 4 & $\mathrm{Y}$ & $\mathrm{N}$ & $Y$ & Stop \\
\hline
\end{tabular}

\begin{tabular}{|c|c|c|c|c|c|c|c|c|c|}
\hline \multicolumn{10}{|c|}{ Step 8: Start Infusion } \\
\hline \multirow[b]{3}{*}{$\begin{array}{c}\text { Subprocess Step Title and } \\
\text { Number }\end{array}$} & \multirow[b]{3}{*}{$\begin{array}{l}\text { Failure Mode: First Evaluate failure } \\
\text { mode before determining potential causes }\end{array}$} & \multirow[b]{3}{*}{ Potential Effects } & \multirow{2}{*}{\multicolumn{3}{|c|}{ scoring }} & \multirow{2}{*}{\multicolumn{4}{|c|}{ Decision Tree Analys }} \\
\hline & & & & & & & & & \\
\hline & & & 空 & 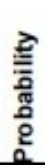 & 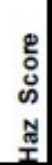 & 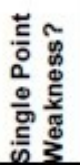 & 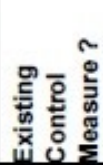 & 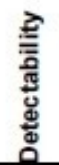 & \\
\hline $\begin{array}{l}\text { Review parameters } \\
\text { entered and start } \\
\text { secondary infusion on } \\
\text { pump }\end{array}$ & BA1 Fail to start infusion & $\begin{array}{l}\text { Delay therapy } \\
\text { And } \\
\text { If clamp opened, secondary drug running at primary } \\
\text { rate }\end{array}$ & $\sim$ & a & 8 & & $\mathrm{~N}$ & $\mathrm{~N}$ & $\mathrm{Y}$ \\
\hline
\end{tabular}




\section{Appendix E: HFMEA for Hospira Plum A+}

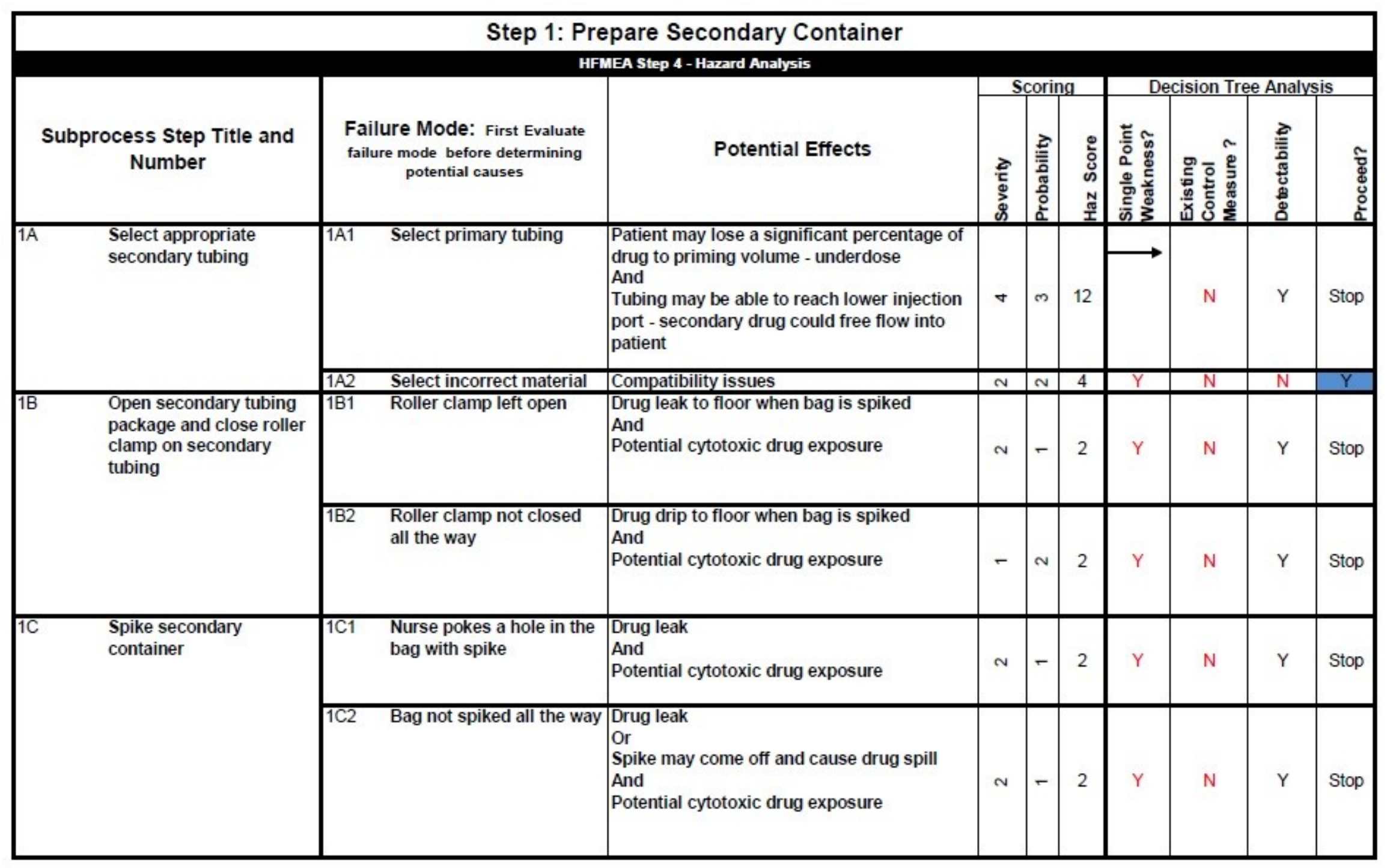




\begin{tabular}{|c|c|c|c|c|c|c|c|c|c|c|}
\hline \multicolumn{11}{|c|}{ Step a2: Prime Secondary Line } \\
\hline \multicolumn{11}{|c|}{ HFMEA Step 4 - Hazard Analysis } \\
\hline \multicolumn{2}{|c|}{$\begin{array}{l}\text { Subprocess Step Title and } \\
\text { Number }\end{array}$} & $\begin{array}{l}\text { Failure Mode: First Evaluate } \\
\text { failure mode before determining } \\
\text { potential causes }\end{array}$ & Potential Effects & \begin{tabular}{l}
2 \\
\multirow{2}{*}{} \\
$\sum_{\infty}^{2}$ \\
\end{tabular} & 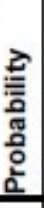 & 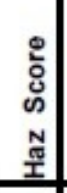 & 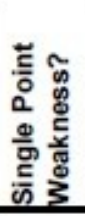 & 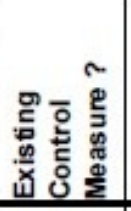 & 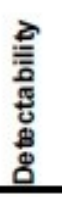 & 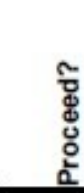 \\
\hline \multirow[t]{3}{*}{$\mathrm{a} 2 \mathrm{~A}$} & \multirow[t]{3}{*}{$\begin{array}{l}\text { Fill drip chamber to } 2 / 3 \\
\text { full }\end{array}$} & 22A1 Drip chamber too full & $\begin{array}{l}\text { Not able to see or check if drug is being } \\
\text { delivered }\end{array}$ & - & $\nabla$ & 4 & $\mathrm{~N}$ & & & Stop \\
\hline & & \begin{tabular}{|ll}
$2 \mathrm{~A} 2$ & $\begin{array}{l}\text { Drip chamber not filled } \\
\text { enough }\end{array}$ \\
\end{tabular} & Air may get into IV tubing & - & n & 2 & $\mathrm{~N}$ & & & Stop \\
\hline & & $\begin{array}{ll}2 \text { A3 } & \begin{array}{l}\text { Drip chamber not filled at } \\
\text { all }\end{array}\end{array}$ & Air may get into IV tubing & - & $N$ & 2 & $\mathrm{Y}$ & $\mathrm{N}$ & $Y$ & Stop \\
\hline $\mathrm{a} 2 \mathrm{~B}$ & $\begin{array}{l}\text { Open roller clamp on } \\
\text { secondary tubing }\end{array}$ & a2B1 Fail to open roller clamp & Delay therapy & - & - & 1 & Y & N & $Y$ & Stop \\
\hline $\mathrm{a} 2 \mathrm{C}$ & $\begin{array}{l}\text { Allow fluid to flow until } \\
\text { tubing is primed }\end{array}$ & \begin{tabular}{|ll}
$22 \mathrm{C} 1$ & $\begin{array}{l}\text { Fail to fill fluid to end of } \\
\text { tubing }\end{array}$ \\
\end{tabular} & Air bubble in tubing & - & - & 1 & $\mathrm{Y}$ & $\mathrm{N}$ & Y & Stop \\
\hline & $\begin{array}{l}\text { Close roller clamp on } \\
\text { secondary tubing }\end{array}$ & a2D1 Fail to close roller clamp & $\begin{array}{l}\text { Drug waste } \\
\text { And } \\
\text { Potential cytotoxic drug exposure }\end{array}$ & $\sim$ & - & 2 & $Y$ & $\mathrm{~N}$ & Y & Stop \\
\hline
\end{tabular}

\begin{tabular}{|c|c|c|c|c|c|c|c|c|c|}
\hline \multicolumn{10}{|c|}{ Step a3 \& b2: Hang Secondary Container and Adjust Primary Container } \\
\hline \multirow[b]{3}{*}{$\begin{array}{c}\text { Subprocess Step Title and } \\
\text { Number }\end{array}$} & \multirow{2}{*}{\multicolumn{5}{|c|}{ HFMEA Step 4 - Hazard Analysis }} & \multirow{2}{*}{\multicolumn{4}{|c|}{ Decision Tree Analysis }} \\
\hline & & & & & & & & & \\
\hline & $\begin{array}{l}\text { Failure Mode: First Evaluate } \\
\text { failure mode before determining } \\
\text { potential causes }\end{array}$ & Potential Effects & 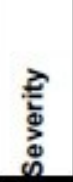 & 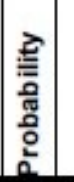 & 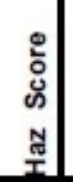 & 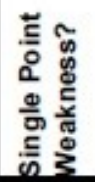 & 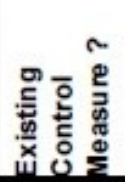 & 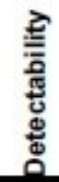 & 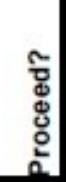 \\
\hline $\begin{array}{ll}\mathrm{a} 3 \mathrm{~A} / \mathrm{b} 2 \mathrm{~A} & \begin{array}{l}\text { Hang secondary } \\
\text { container on IV pole }\end{array}\end{array}$ & & & & & & & & & \\
\hline
\end{tabular}




\begin{tabular}{|c|c|c|c|c|c|c|c|c|c|c|}
\hline & & HFN & MEA Step 4 - Hazard Analysis & & & & & & & \\
\hline & & & & & & & & 11 & & \\
\hline Subp & $\begin{array}{l}\text { ocess Step Title and } \\
\text { Number }\end{array}$ & $\begin{array}{l}\text { Failure Mode: First Evaluate } \\
\text { failure mode before determining } \\
\text { potential causes }\end{array}$ & Potential Effects & 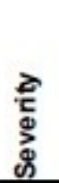 & 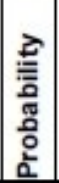 & 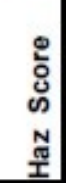 & 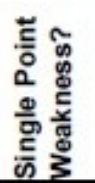 & 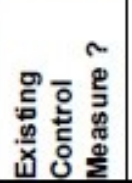 & 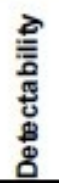 & 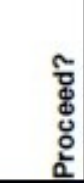 \\
\hline $\mathrm{a} 4 \mathrm{~A} / \mathrm{b} 3 \mathrm{~A}$ & $\begin{array}{l}\text { Swab upper y-site port on } \\
\text { primary tubing with } \\
\text { appropriate antiseptic }\end{array}$ & $\begin{array}{l}24 \mathrm{~A} 1 / \mathrm{b} \text { Fail to swab y-site port } \\
3 \mathrm{~A} 1\end{array}$ & Infection & t & $\theta$ & 16 & & $\mathrm{~N}$ & $\mathrm{~N}$ & $\mathrm{Y}$ \\
\hline & & $\begin{array}{ll}\text { a4A2/b } & \text { Fail to "scrub the hub" } \\
3 \mathrm{~A} 2 & \text { thoroughly }\end{array}$ & Infection & 寸 & $\theta$ & 16 & & N & $\mathrm{N}$ & $\mathrm{Y}$ \\
\hline & & $\begin{array}{ll}24 A 3 / b & \text { Fail to allow antiseptic to } \\
3 A_{3} & \text { dry }\end{array}$ & Infection & 寸 & $\theta$ & 16 & & $\mathrm{~N}$ & $\mathrm{~N}$ & $\mathrm{Y}$ \\
\hline $\mathrm{a} 4 \mathrm{~B} / \mathrm{b} 3 \mathrm{~B}$ & $\begin{array}{l}\text { Connect secondary line to } \\
\text { secondary port on } \\
\text { cassette }\end{array}$ & 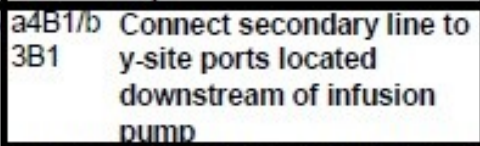 & Secondary drug freeflow into patient & $\theta$ & $\nabla$ & 16 & & $\mathrm{~N}$ & Y & Stop \\
\hline & & $\begin{array}{l}\text { a4B2/b Connect secondary line to } \\
3 \mathrm{~B} 2 \text { the wrong primary line }\end{array}$ & Delay therapy & $\sigma$ & $m$ & 12 & & $\mathrm{~N}$ & $Y$ & Stop \\
\hline & & $\begin{array}{ll}\mathrm{a} 4 \mathrm{~B} 3 / \mathrm{b} & \text { Fail to securely connect } \\
3 \mathrm{~B} 3 & \text { secondary line to cassette }\end{array}$ & $\begin{array}{l}\text { Luer connect may come off and cause drug } \\
\text { leak }\end{array}$ & N & N & 4 & $Y$ & $\mathrm{~N}$ & $Y$ & Stop \\
\hline & & $\begin{array}{ll}4 \mathrm{~B} 4 / \mathrm{b} & \text { Fail to connect secondary } \\
3 \mathrm{~B} 4 & \text { line }\end{array}$ & Delay therapy & $N$ & N & 4 & $Y$ & $\mathrm{~N}$ & Y & Stop \\
\hline
\end{tabular}




\begin{tabular}{|c|c|c|c|c|c|c|c|c|c|c|}
\hline \multicolumn{11}{|c|}{ Step b4: Backprime Secondary Tubing } \\
\hline \multicolumn{11}{|c|}{ HFMEA Step 4 - Hazard Analysis } \\
\hline \multirow{2}{*}{\multicolumn{2}{|c|}{$\begin{array}{c}\text { Subprocess Step Title and } \\
\text { Number }\end{array}$}} & \multirow[b]{2}{*}{$\begin{array}{l}\text { Failure Mode: First Evaluate } \\
\text { failure mode before determining } \\
\text { potential causes }\end{array}$} & \multirow[b]{2}{*}{ Potential Effects } & \multicolumn{3}{|c|}{ Scoring } & \multirow[b]{2}{*}{ 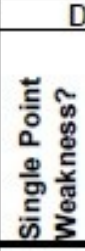 } & \multirow[b]{2}{*}{ 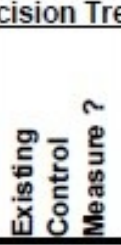 } & \multirow[b]{2}{*}{ 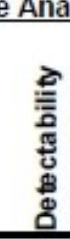 } & \multirow[b]{2}{*}{ 总 } \\
\hline & & & & 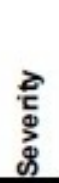 & 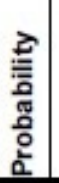 & 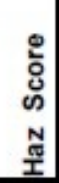 & & & & \\
\hline $\mathrm{b} 4 \mathrm{~A}$ & Open secondary clamp & b4A1 Fail to open roller clamp & Delay therapy & - & - & 1 & $\mathrm{Y}$ & $N$ & Y & Stop \\
\hline $\mathrm{b} 4 \mathrm{~B}$ & Hold Backprime button & $\begin{array}{ll}\text { b4B1 } & \begin{array}{l}\text { Fail to find Backprime } \\
\text { button }\end{array} \\
\end{array}$ & Delay therapy & - & - & 1 & Y & $\mathrm{N}$ & Y & Stop \\
\hline \multirow[t]{4}{*}{$\overline{b 4 C}$} & \multirow{4}{*}{$\begin{array}{l}\text { Allow primary fluid to } \\
\text { flow into secondary } \\
\text { tubing until drip chamber } \\
2 / 3 \text { full }\end{array}$} & 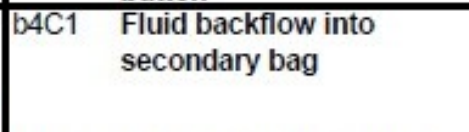 & Underdose & - & m & 3 & Y & $\mathrm{N}$ & Y & Stop \\
\hline & & 134C2 Drip chamber too full & $\begin{array}{l}\text { Not able to see or check if drug is being } \\
\text { delivered }\end{array}$ & - & m & 3 & $\mathrm{~N}$ & & & Stop \\
\hline & & \begin{tabular}{|l} 
b4C3 \\
Drip chamber not filled \\
enough
\end{tabular} & Air may get into IV tubing & - & N & 2 & $\mathrm{~N}$ & & & Stop \\
\hline & & $\begin{array}{ll}\text { D4C4 } & \begin{array}{l}\text { Drip chamber not filled at } \\
\text { all }\end{array}\end{array}$ & Air may get into IV tubing & - & N & 2 & Y & $\mathrm{N}$ & Y & Stop \\
\hline
\end{tabular}

\begin{tabular}{|c|c|c|c|c|c|c|c|c|c|}
\hline \multicolumn{10}{|c|}{ Step 5: Open Vent on Drip Chamber if Secondary Container is Glass or Semi-Rigid } \\
\hline \multirow[b]{2}{*}{$\begin{array}{c}\text { Subprocess Step Title and } \\
\text { Number }\end{array}$} & \multirow[b]{2}{*}{$\begin{array}{l}\text { Failure Mode: First Evaluate } \\
\text { failure mode before determining } \\
\text { potential causes }\end{array}$} & \multirow[b]{2}{*}{ Potential Effects } & \multicolumn{3}{|c|}{ Scoring } & \multicolumn{4}{|c|}{ Decision Tree Analysis } \\
\hline & & & 离 & 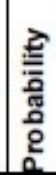 & $\begin{array}{l}8 \\
\text { o } \\
\text { तु } \\
\text { त्र }\end{array}$ & 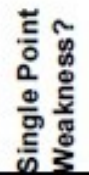 & 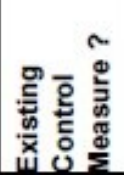 & 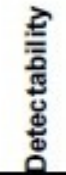 & 葛 \\
\hline DA Open vent & 5A1 Fail to open vent & Delay therapy & N & m & 6 & $Y$ & $\mathrm{Y}$ & & Stop \\
\hline
\end{tabular}




\begin{tabular}{|c|c|c|c|c|c|c|c|c|c|c|}
\hline \multicolumn{11}{|c|}{ Step 6: Program Pump } \\
\hline \multicolumn{11}{|c|}{ HFi EA stop 4 - Hazard Analyale } \\
\hline \multirow{2}{*}{\multicolumn{2}{|c|}{$\begin{array}{c}\text { Subprocess Step Title and } \\
\text { Number }\end{array}$}} & \multirow[b]{2}{*}{$\begin{array}{l}\text { Failure Mode: First Evaluate } \\
\text { fallure mode before determining } \\
\text { potentlal causes }\end{array}$} & \multirow[b]{2}{*}{ Potential Effects } & \multirow{2}{*}{\multicolumn{2}{|c|}{\begin{tabular}{l|}
$\frac{2}{3}$ \\
$\frac{1}{2}$ \\
$\frac{\pi}{2}$ \\
$\frac{2}{0}$ \\
\end{tabular}}} & \multirow[b]{2}{*}{ 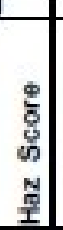 } & \multirow[b]{2}{*}{ 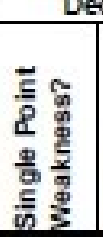 } & \multirow[b]{2}{*}{ 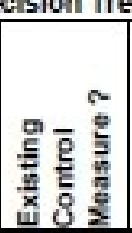 } & \multirow[b]{2}{*}{ 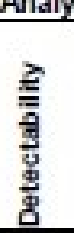 } & \multirow[b]{2}{*}{ 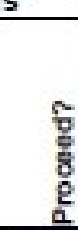 } \\
\hline & & & & & & & & & & \\
\hline \multirow[t]{2}{*}{$6 \mathrm{~A}$} & \multirow[t]{2}{*}{ Select channel B } & $\begin{array}{l}\text { BA1 Select channel A rather } \\
\text { than channel B }\end{array}$ & $\begin{array}{l}\text { Delay therapy } \\
\text { And } \\
\text { Primary would be programmed to run at } \\
\text { secondary rate }\end{array}$ & $m$ & $m$ & 9 & & $\mathrm{~N}$ & $\mathrm{~N}$ & Y \\
\hline & & \begin{tabular}{|ll}
$\mathrm{BA} 2$ & $\begin{array}{l}\text { Select channel B on } \\
\text { incorrect pump }\end{array}$ \\
\end{tabular} & Delay therapy & - & $\sim$ & 2 & Y & $\mathrm{N}$ & Y & Stop \\
\hline $8 \mathrm{~B}$ & Select Drug List & Fail to select Drug List & Dose limits will not apply to program & - & $\nabla$ & 4 & $\mathrm{~N}$ & & & Stop \\
\hline \multirow[t]{2}{*}{$8 \mathrm{C}$} & \multirow[t]{2}{*}{ Select drug } & $\mathrm{BCT}$ Select incorrect Drug & \begin{tabular}{|l|} 
Incorrect drug label on pump \\
And \\
Incorrect dose limits applied to program
\end{tabular} & - & $m$ & 3 & $\mathrm{~N}$ & & & Stop \\
\hline & & $\begin{array}{ll}\mathrm{CC} 3 & \begin{array}{l}\text { Select incorrect } \\
\text { concentration }\end{array} \\
\end{array}$ & $\begin{array}{l}\text { Incorrect dose calculations - } \\
\text { overdose/underdose }\end{array}$ & $\nabla$ & $\sim$ & 8 & & $\mathrm{~N}$ & N & $\mathrm{Y}$ \\
\hline & \multirow[t]{2}{*}{ Select Stancard Program } & $\begin{array}{l}\text { BDT Fail to select Standard } \\
\text { Program (Exit screen } \\
\text { unintentionally) }\end{array}$ & Delay therapy & - & $\sim$ & 2 & $\mathrm{Y}$ & N & Y & Stop \\
\hline & & $\begin{array}{ll}8 D 2 & \begin{array}{l}\text { Select Loading Dose or } \\
\text { Multistep Infusion }\end{array}\end{array}$ & $\begin{array}{l}\text { Delay therapy } \\
\text { Or } \\
\text { Air-in-line alarm rather than switching back } \\
\text { to primary if secondary bag empties before } \\
\text { the multistep program is finished }\end{array}$ & $N$ & $\sim$ & 4 & N & & & Stop \\
\hline 8(i)E & $\begin{array}{l}\text { Perform Manual } \\
\text { Calculations }\end{array}$ & B(i)E1 Inaccurate calculation & Overdose/Underdose & $\nabla$ & v & 16 & $\rightarrow$ & $\mathrm{N}$ & N & Y \\
\hline $\mathrm{E(0) \textrm {F }}$ & Select Rate & B(1)F1 Fail to select Rate & Delay therapy & $\mathrm{N}$ & - & 2 & $\mathbb{N}$ & & & Stop \\
\hline $8(i) G$ & Enter Rate & B(i)G1 Enter incorrect rate & Overdose/underdose & 8 & \pm & 18 & $\longrightarrow$ & $\mathrm{N}$ & $\mathbb{N}$ & $\bar{Y}$ \\
\hline 6E & Select VIBI & BE1 Fail to select VTBI & Delay therapy & - & - & 1 & $\mathrm{Y}$ & $\mathrm{N}$ & $\mathrm{Y}$ & Stop \\
\hline BF & Enter VIBIT & Enter incorrect volume & Overdose/Underdose & 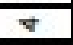 & + & 18 & & $\mathrm{~N}$ & $\mathbb{N}$ & $\mathrm{Y}$ \\
\hline $8 \mathrm{G}$ & Select Duration & Fail to select Duration & Delay therapy & 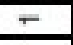 & - & 1 & $\mathrm{Y}$ & $\mathrm{N}$ & $\mathrm{Y}$ & Stoo \\
\hline $\mathrm{BH}$ & Enter duration & Enter incorrect duration & Overdose/Underdose & $\nabla$ & 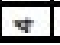 & 18 & & $\mathrm{~N}$ & $\mathbb{N}$ & $\bar{Y}$ \\
\hline
\end{tabular}




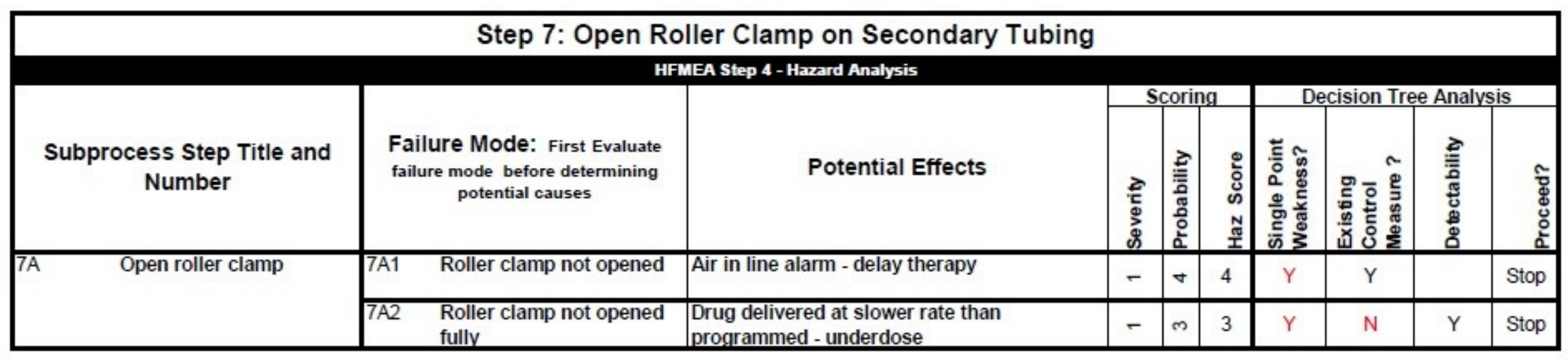

\begin{tabular}{|c|c|c|c|c|c|c|c|c|c|}
\hline \multicolumn{10}{|c|}{ Step 8: Start Infusion } \\
\hline \multicolumn{10}{|c|}{ HFMEA Step 4 - Hazard Analysis } \\
\hline \multirow[b]{2}{*}{$\begin{array}{c}\text { Subprocess Step Title and } \\
\text { Number }\end{array}$} & \multirow[b]{2}{*}{$\begin{array}{l}\text { Failure Mode: First Evaluate } \\
\text { failure mode before determining } \\
\text { potential causes }\end{array}$} & \multirow[b]{2}{*}{ Potential Effects } & \multicolumn{3}{|c|}{ Scoring } & \multicolumn{4}{|c|}{ Decision Tree Analysis } \\
\hline & & & 空 & 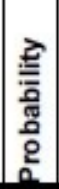 & 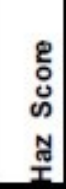 & 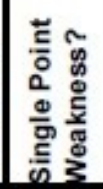 & 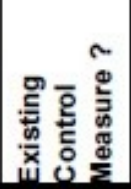 & 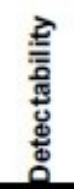 & 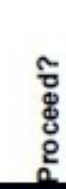 \\
\hline Press Start & Fail to press Start & Delay therapy & $n$ & $\theta$ & 8 & $\longrightarrow$ & $\mathrm{N}$ & $\mathrm{N}$ & $\bar{Y}$ \\
\hline $\begin{array}{l}\text { Review and confirm } \\
\text { parameters entered - } \\
\text { press Yes }\end{array}$ & \begin{tabular}{|l}
$8 \mathrm{~B} 1 \mathrm{Fail}$ to Press Yes (thinking \\
that infusion has already \\
started)
\end{tabular} & Delay therapy & N & a & 8 & & $\mathrm{~N}$ & $\mathrm{~N}$ & Y \\
\hline
\end{tabular}




\section{Appendix F: HFMEA for Hospira Plum A+ (Robustness Analysis)}

\begin{tabular}{|c|c|c|c|c|c|c|c|c|c|c|}
\hline \multirow{2}{*}{\multicolumn{11}{|c|}{$\begin{array}{c}\text { Step 1: Prepare Secondary Container } \\
\text { HFMEA Step 4-Hazard Analysis }\end{array}$}} \\
\hline \multirow{3}{*}{\multicolumn{2}{|c|}{$\begin{array}{c}\text { Subprocess Step Title and } \\
\text { Number }\end{array}$}} & & & & & & & & & \\
\hline & & \multirow[b]{2}{*}{$\begin{array}{l}\text { Failure Mode: First Evaluate } \\
\text { failure mode before determining } \\
\text { potential causes }\end{array}$} & \multirow[b]{2}{*}{ Potential Effects } & \multirow{2}{*}{\multicolumn{2}{|c|}{ 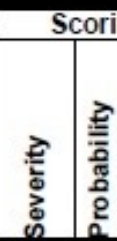 }} & \multirow[b]{2}{*}{$\begin{array}{l}2 \\
0 \\
\infty \\
\text { 또 } \\
\end{array}$} & \multicolumn{4}{|c|}{ Decision Tree Analysi } \\
\hline & & & & & & & 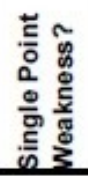 & 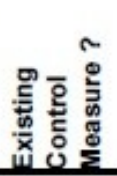 & 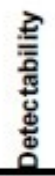 & \\
\hline \multirow[t]{2}{*}{ 18 } & \multirow[t]{2}{*}{$\begin{array}{l}\text { Select appropriate } \\
\text { secondary tubing }\end{array}$} & 1B1 Select primary tubing & $\begin{array}{l}\text { Patient may lose a significant percentage of drug to } \\
\text { priming volume - underdose } \\
\text { And } \\
\text { Tubing may be able to reach lower injection port - } \\
\text { secondary drug could free flow into patient }\end{array}$ & $\theta$ & t & 16 & & $\mathrm{~N}$ & Y & Stop \\
\hline & & Select incorrect material & Compatibility issues & m & $m$ & 9 & & $\bar{N}$ & $\bar{N}$ & $\bar{Y}$ \\
\hline \multirow[t]{2}{*}{$\overline{1 C}$} & \multirow[t]{2}{*}{$\begin{array}{l}\text { Open secondary tubing } \\
\text { package and close roller } \\
\text { clamp on secondary } \\
\text { tubing }\end{array}$} & Roller clamp left open & $\begin{array}{l}\text { Drug leak to floor when bag is spiked } \\
\text { And } \\
\text { Potential cytotoxic drug exposure }\end{array}$ & m & n & 6 & Y & N & Y & Stop \\
\hline & & $\begin{array}{ll}\mathrm{C} 2 & \begin{array}{l}\text { Roller clamp not closed } \\
\text { all the way }\end{array}\end{array}$ & $\begin{array}{l}\text { Drug drip to floor when bag is spiked } \\
\text { And } \\
\text { Potential cytotoxic drug exposure }\end{array}$ & $n$ & m & 6 & $\mathrm{Y}$ & $\mathrm{N}$ & Y & Stop \\
\hline & \multirow[t]{2}{*}{$\begin{array}{l}\text { Spike secondary } \\
\text { container }\end{array}$} & $\begin{array}{l}\text { 1D1 } \begin{array}{l}\text { Nurse pokes a hole in the } \\
\text { bag with spike }\end{array} \\
\text { (a) }\end{array}$ & $\begin{array}{l}\text { Drug leak } \\
\text { And } \\
\text { Potential cytotoxic drug exposure }\end{array}$ & m & n & 6 & $\mathrm{Y}$ & $\mathrm{N}$ & Y & Stop \\
\hline & & 1 1D2 Bag not spiked all the way & $\begin{array}{l}\text { Drug leak } \\
\text { Or } \\
\text { Spike may come off and cause drug spill } \\
\text { And } \\
\text { Potential cytotoxic drug exposure }\end{array}$ & m & N & 6 & Y & $\mathrm{N}$ & Y & Stop \\
\hline
\end{tabular}




\begin{tabular}{|c|c|c|c|c|c|c|c|c|c|c|}
\hline & & Ste & p a2: Prime Secondary Line & & & & & & & \\
\hline \multirow{3}{*}{\multicolumn{2}{|c|}{$\begin{array}{c}\text { Subprocess Step Title and } \\
\text { Number }\end{array}$}} & \multirow[b]{3}{*}{$\begin{array}{c}\text { Failure Mode: First Evaluate } \\
\text { failure mode before determining } \\
\text { potential causes }\end{array}$} & HFMEA Step 4 - Hazard Analysis & & & & & & & \\
\hline & & & \multirow[b]{2}{*}{ Potential Effects } & \multicolumn{3}{|c|}{ Scoring } & \multicolumn{4}{|c|}{ Decision Tree Analysis } \\
\hline & & & & 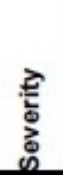 & 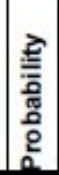 & 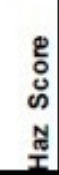 & 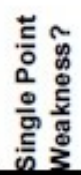 & 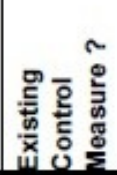 & 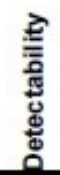 & \\
\hline \multirow[t]{3}{*}{$2 \mathrm{a} A$} & \multirow[t]{3}{*}{$\begin{array}{l}\text { Fill drip chamber to } 2 / 3 \\
\text { full }\end{array}$} & 22A1 Drip chamber too full & Not able to see or check if drug is being delivered & N & + & 8 & $\rightarrow$ & $\mathrm{N}$ & $\mathrm{Y}$ & Stop \\
\hline & & \begin{tabular}{|ll} 
a2A2 & $\begin{array}{l}\text { Drip chamber not filled } \\
\text { enough }\end{array}$
\end{tabular} & Air may get into IV tubing & N & m & 6 & $\mathrm{~N}$ & & & Stop \\
\hline & & \begin{tabular}{|ll} 
a2A33 & $\begin{array}{l}\text { Drip chamber not filled at } \\
\text { all }\end{array}$ \\
\end{tabular} & Air may get into IV tubing & $\sim$ & m & 6 & $\mathrm{Y}$ & $\mathrm{N}$ & $\mathrm{Y}$ & Stop \\
\hline $\mathrm{a} 2 \mathrm{~B}$ & $\begin{array}{l}\text { Open roller clamp on } \\
\text { secondary tubing }\end{array}$ & 22B1 Fail to open roller clamp & Delay therapy & N & N & 4 & Y & $\mathrm{N}$ & $\mathrm{Y}$ & Stop \\
\hline$\overline{\mathrm{a} 2 \mathrm{C}}$ & $\begin{array}{l}\text { Allow fluid to flow until } \\
\text { tubing is primed }\end{array}$ & $\begin{array}{ll}\text { a2C1 Fail to fill fluid to end of } \\
\text { tubing }\end{array}$ & Air bubble in tubing & N & N & 4 & Y & $\mathrm{N}$ & $\mathrm{Y}$ & Stop \\
\hline $\mathrm{a} 2 \mathrm{D}$ & $\begin{array}{l}\text { Close roller clamp on } \\
\text { secondary tubing }\end{array}$ & a2D1 Fail to close roller clamp & $\begin{array}{l}\text { Drug waste } \\
\text { And } \\
\text { Potential cytotoxic drug exposure }\end{array}$ & $m$ & n & 6 & $\mathrm{Y}$ & $\mathrm{N}$ & $\mathrm{Y}$ & Stop \\
\hline
\end{tabular}

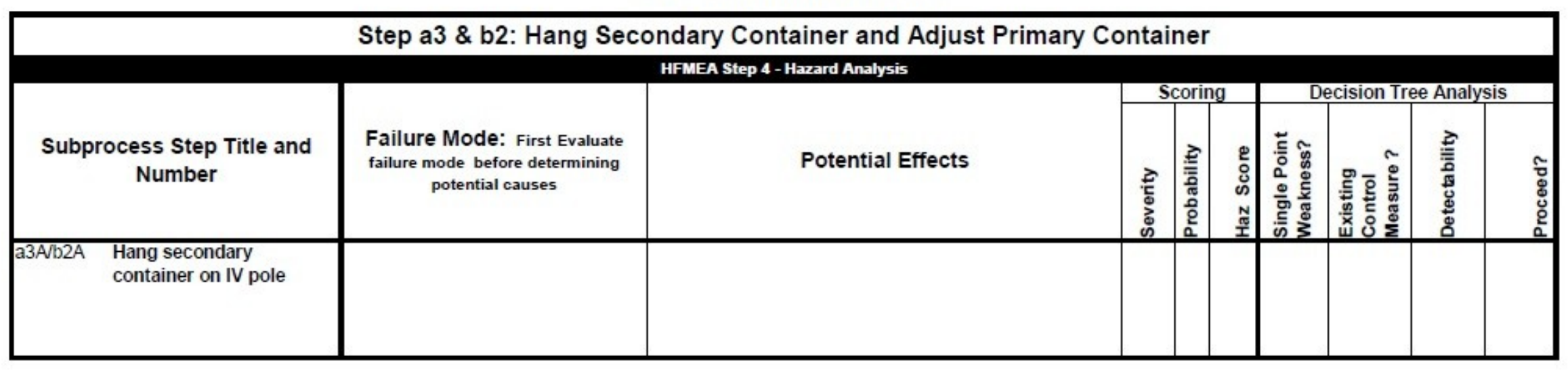




\begin{tabular}{|c|c|c|c|c|c|c|c|c|c|c|}
\hline \multicolumn{11}{|c|}{ Step a4 \& b3: Connect Secondary Line to Primary Tubing } \\
\hline & & & HFMEA Step 4 - Hazard Analysis & & & & & & & \\
\hline \multirow{2}{*}{\multicolumn{2}{|c|}{$\begin{array}{c}\text { Subprocess Step Title and } \\
\text { Number }\end{array}$}} & \multirow[b]{2}{*}{$\begin{array}{c}\text { Failure Mode: First Evaluate } \\
\text { failure mode before determining } \\
\text { potential causes }\end{array}$} & \multirow[b]{2}{*}{ Potential Effects } & \multicolumn{3}{|c|}{ Scoring } & \multicolumn{4}{|c|}{ Decision Tree Analysis } \\
\hline & & & & 胥 & $\frac{2}{\frac{2}{2}}$ & 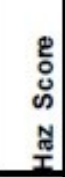 & 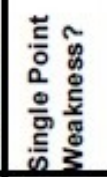 & 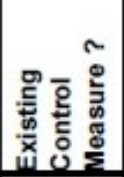 & 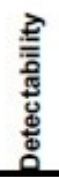 & ₹ \\
\hline \multirow[t]{3}{*}{ a4AVb3A } & $\begin{array}{l}\text { Swab upper y-site port on } \\
\text { primary tubing with } \\
\text { appropriate antiseptic }\end{array}$ & $\begin{array}{l}\text { a4A1/b Fail to swab y-site port } \\
3 A 1\end{array}$ & Infection & $\nabla$ & $\nabla$ & 16 & & $\mathrm{~N}$ & $\mathrm{~N}$ & $\mathrm{Y}$ \\
\hline & & $\begin{array}{ll}\text { a4A2/b } & \text { Fail to "scrub the hub" } \\
3 \mathrm{~A} 2 & \text { thoroughly }\end{array}$ & Infection & $\checkmark$ & 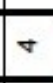 & 16 & & $\mathrm{~N}$ & $\mathrm{~N}$ & $\mathrm{Y}$ \\
\hline & & $\begin{array}{ll}24 A 3 / b & \text { Fail to allow antiseptic to } \\
3 A 3 & \text { dry }\end{array}$ & Infection & $\checkmark$ & $\forall$ & 16 & & $\mathrm{~N}$ & $\mathrm{~N}$ & Y \\
\hline \multirow[t]{4}{*}{ a4B/b3B } & $\begin{array}{l}\text { Connect secondary line to } \\
\text { upper y-site port on } \\
\text { primary tubing (upstream } \\
\text { of infusion pump) }\end{array}$ & $\begin{array}{ll}\text { a4B1/b } & \text { Connect secondary line to } \\
\text { 3B1 } & \text { y-site ports located } \\
& \text { downstream of infusion } \\
& \text { pump }\end{array}$ & Secondary drug freeflow into patient & $\Delta$ & $\nabla$ & 16 & & $\mathrm{~N}$ & $\mathrm{Y}$ & Stop \\
\hline & & $\begin{array}{l}\text { a4B2/b Connect secondary line to } \\
3 \mathrm{~B} 2 \quad \text { the wrong primary line }\end{array}$ & Delay therapy & $\checkmark$ & $\nabla$ & 16 & & $\mathrm{~N}$ & $\mathrm{Y}$ & Stop \\
\hline & & $\begin{array}{ll}\text { a4B3/b } & \text { Fail to securely connect } \\
3 \mathrm{~B} 3 & \text { secondary line to cassette }\end{array}$ & Luer connect may come off and cause drug leak & $m$ & $m$ & 9 & & $\mathrm{~N}$ & $\mathrm{Y}$ & Stop \\
\hline & & $\begin{array}{ll}24 \mathrm{~B} 4 / \mathrm{b} & \text { Fail to connect secondary } \\
3 \mathrm{~B} 4 & \text { line }\end{array}$ & Delay therapy & $m$ & $m$ & 9 & & $\mathrm{~N}$ & $\mathrm{Y}$ & Stop \\
\hline
\end{tabular}




\begin{tabular}{|c|c|c|c|c|c|c|c|c|c|c|}
\hline \multicolumn{11}{|c|}{ Step b4: Backprime Secondary Tubing } \\
\hline \multicolumn{11}{|c|}{ HFMEA Step 4 - Hazard Analysis } \\
\hline \multicolumn{2}{|c|}{$\begin{array}{c}\text { Subprocess Step Title and } \\
\text { Number }\end{array}$} & $\begin{array}{l}\text { Failure Mode: First Evaluate } \\
\text { failure mode before determining } \\
\text { potential causes }\end{array}$ & Potential Effects & 壳 & 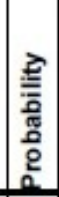 & 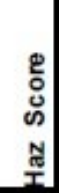 & 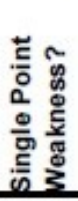 & 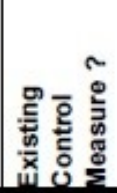 & 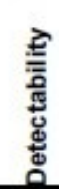 & \\
\hline$\overline{b 4 \mathrm{~A}}$ & Open secondary clamp & b4A1 Fail to open roller clamp & Delay therapy & n & N & 4 & $Y$ & $\mathrm{~N}$ & $\mathrm{Y}$ & Stop \\
\hline b4B & Hold Backprime button & 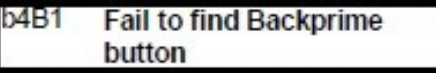 & Delay therapy & N & n & 4 & Y & $\mathrm{N}$ & Y & Stop \\
\hline \multirow[t]{4}{*}{$\mathrm{b4C}$} & \multirow{4}{*}{$\begin{array}{l}\text { Allow primary fluid to } \\
\text { flow into secondary } \\
\text { tubing until drip chamber } \\
2 / 3 \text { full }\end{array}$} & $\begin{array}{ll}\text { b4C1 } & \begin{array}{l}\text { Fluid backflow into } \\
\text { secondary bag }\end{array} \\
\end{array}$ & Underdose & N & + & 8 & & $\mathrm{~N}$ & Y & Stop \\
\hline & & b4C2 Drip chamber too full & Not able to see or check if drug is being delivered & N & a & 8 & $\rightarrow$ & N & Y & Stop \\
\hline & & \begin{tabular}{|ll} 
b4C3 & $\begin{array}{l}\text { Drip chamber not filled } \\
\text { enough }\end{array}$ \\
\end{tabular} & Air may get into IV tubing & N & m & 6 & N & & & Stop \\
\hline & & $\begin{array}{ll}\text { b4C4 } & \text { Drip chamber not filled at } \\
\text { all }\end{array}$ & Air may get into IV tubing & N & $m$ & 6 & Y & $\mathrm{Y}$ & & Stop \\
\hline
\end{tabular}

\begin{tabular}{|c|c|c|c|c|c|c|c|c|c|}
\hline \multirow[b]{2}{*}{$\begin{array}{c}\text { Subprocess Step Title and } \\
\text { Number }\end{array}$} & \multirow[b]{2}{*}{$\begin{array}{c}\text { Failure Mode: First Evaluate } \\
\text { failure mode before determining } \\
\text { potential causes }\end{array}$} & \multicolumn{8}{|l|}{ HFMEA Step 4 - Hazard Analysis } \\
\hline & & Potential Effects & $\stackrel{?}{2}$ & $\begin{array}{l}\frac{2}{2} \\
0 \\
0 \\
0 \\
0 \\
0 \\
0\end{array}$ & 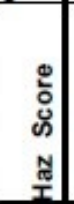 & 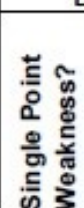 & 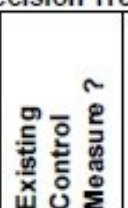 & 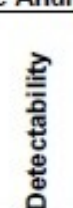 & \\
\hline Open vent & Fail to open vent & Delay therapy & $m$ & $\nabla$ & 12 & & $\mathrm{~N}$ & $\mathrm{Y}$ & Stop \\
\hline
\end{tabular}




\begin{tabular}{|c|c|c|c|c|c|c|c|c|c|}
\hline & & Step 6: Program Pump & & & & & & & \\
\hline & & HFMEA step 4 - Hazard Anelyals & & & & & & & \\
\hline & & & & & & & & & \\
\hline $\begin{array}{c}\text { Subprocess Step Title and } \\
\text { Number }\end{array}$ & $\begin{array}{c}\text { Failure Mode: First Evaluate } \\
\text { fallure mode before determining } \\
\text { potentlal causes }\end{array}$ & Potential Effects & 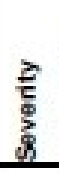 & 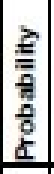 & 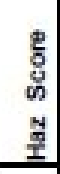 & 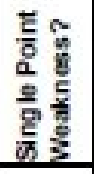 & 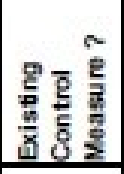 & 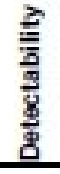 & 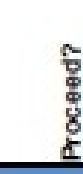 \\
\hline Select channel B & $\begin{array}{ll}\text { 6A1 Select channel A rather } \\
\text { than channel B }\end{array}$ & $\begin{array}{l}\text { Delay therapy } \\
\text { And } \\
\text { Primary would be programmed to run at secondary } \\
\text { rate }\end{array}$ & v & $\nabla$ & 16 & & $\mathrm{~N}$ & $\mathrm{~N}$ & $\mathrm{Y}$ \\
\hline & \begin{tabular}{|ll}
6 A2 & $\begin{array}{l}\text { Select channel B on } \\
\text { incorrect pump }\end{array}$
\end{tabular} & Delay therapy & N & $m$ & 6 & Y & $\mathrm{N}$ & $Y$ & Stop \\
\hline Select Drug List & 6B1 Fail to select Drug List & Dose limits will not apply to program & v & $\nabla$ & 8 & & $\mathrm{~N}$ & Y & Stop \\
\hline Select drug & $8 \mathrm{C1}$ Select incorrect Drug & $\begin{array}{l}\text { Incorrect drug label on pump } \\
\text { And } \\
\text { Incorrect dose limits applied to program }\end{array}$ & v & $\nabla$ & 8 & & $\mathrm{~N}$ & $\mathrm{~N}$ & Y \\
\hline & $\begin{array}{cl}603 & \begin{array}{l}\text { Select incorrect } \\
\text { concentration }\end{array}\end{array}$ & Incorrect dose calculations - overdoselunderdose & v & $m$ & 12 & & $\mathrm{~N}$ & $\mathrm{~N}$ & Y \\
\hline 6elect Standard Program & \begin{tabular}{|l} 
Fin to select Standard \\
Program (Exit screen \\
unintentionally)
\end{tabular} & Delay therapy & N & $m$ & 6 & Y & $\mathrm{N}$ & $Y$ & Stop \\
\hline & \begin{tabular}{|ll}
$6 D 2$ & $\begin{array}{l}\text { Select Loading Dose or } \\
\text { Multistep Infusion }\end{array}$
\end{tabular} & $\begin{array}{l}\text { Delay therapy } \\
\text { Or } \\
\text { Air-in-line alarm rather than switching back to primary } \\
\text { if secondary bag empties before the multistep } \\
\text { program is finished }\end{array}$ & $m$ & $m$ & $\theta$ & & $\mathrm{N}$ & $\mathrm{N}$ & $\mathrm{Y}$ \\
\hline \begin{tabular}{|ll} 
8(i)E & $\begin{array}{l}\text { Perform Manual } \\
\text { Calculations }\end{array}$ \\
\end{tabular} & 8(i)E1 Inaccurate calculation & Overdose/Underdose & v & $\nabla$ & 16 & & $\mathrm{~N}$ & $N$ & $\mathrm{Y}$ \\
\hline 8(i)F $\quad$ Select Rate & 8(i)F1 Fail to select Rate & Delay therapy & $m$ & N & 6 & $\mathrm{~N}$ & & & Stop \\
\hline 8(i)G $\quad$ Enter Rate & 8(i)G1 Enter incorrect rate & Overdose/underdose & 8 & $\nabla$ & 16 & $\longrightarrow$ & $\mathrm{N}$ & $\mathrm{N}$ & $\mathrm{Y}$ \\
\hline $\begin{array}{l}\text { 8(ii)E E(ia) Select VTBI } \\
\mathrm{H}\end{array}$ & $\begin{array}{l}\text { 6(ii)E1/ Fail to select VTBI } \\
6(i a) \mathrm{H} 1\end{array}$ & Delay therapy & v & $N$ & 4 & Y & $\mathrm{N}$ & $Y$ & Stop \\
\hline 8(ii)F/8(ia)| Enter VTBI & 6(ii)F1/ Enter incorrect volume & Overdose/Underdose & $\checkmark$ & $\nabla$ & 16 & & $\mathrm{~N}$ & $\mathrm{~N}$ & Y \\
\hline B(ii)G(Ib)H Select Duration & 6(ii)GI/( Fail to select Duration & Delay therapy & $\sim$ & $N$ & 4 & $\mathrm{Y}$ & $\mathrm{N}$ & Y & Stop \\
\hline B(ii)H(b) I Enter duration & 6(ii) $\mathrm{H} 1 /$ (Enter incorrect duration & Overdose/Underdose & q & $\nabla$ & 16 & & $\mathrm{~N}$ & $\mathrm{~N}$ & $\mathrm{Y}$ \\
\hline
\end{tabular}




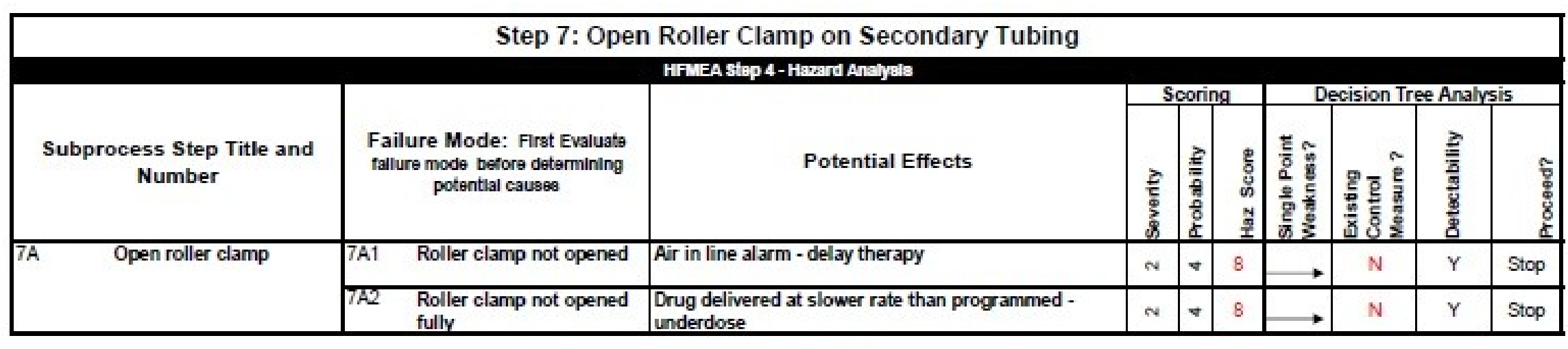

\begin{tabular}{|c|c|c|c|c|c|c|c|c|c|}
\hline \multicolumn{10}{|c|}{ Step 8: Start Infusion } \\
\hline \multirow[b]{3}{*}{$\begin{array}{c}\text { Subprocess Step Title and } \\
\text { Number }\end{array}$} & \multirow[b]{3}{*}{$\begin{array}{l}\text { Failure Mode: First Evaluate } \\
\text { fallure mode before determining } \\
\text { potentlal causes }\end{array}$} & \multirow[t]{3}{*}{ HFMEA Stap 4 - Hazard Anabyals } & & & & & & & \\
\hline & & & \multicolumn{3}{|c|}{ Scoring } & \multirow[b]{2}{*}{ 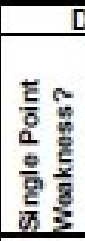 } & \multirow[b]{2}{*}{ 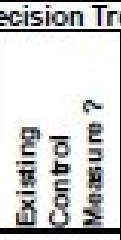 } & \multirow[b]{2}{*}{ 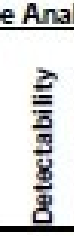 } & \multirow[b]{2}{*}{$\begin{array}{l}\text { \% } \\
\$ \\
8 \\
\&\end{array}$} \\
\hline & & & 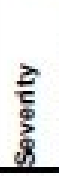 & 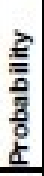 & 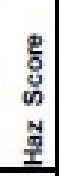 & & & & \\
\hline Press Start & Fail to press Start & Delay therapy & $m$ & $\nabla$ & 12 & $\longrightarrow$ & $N$ & $\mathrm{~N}$ & $\mathrm{Y}$ \\
\hline $\begin{array}{l}\text { Review and confirm } \\
\text { parameters entered - } \\
\text { press Yes }\end{array}$ & $\begin{array}{ll}\text { BB1 } & \text { Fail to confirm settings } \\
\text { (thinking that infusion has } \\
\text { already started) }\end{array}$ & Delay therapy & $m$ & $\nabla$ & 12 & & N & $\mathrm{N}$ & Y \\
\hline
\end{tabular}

